MARCELO HAMAGUCHI

ANÁLISE DO CIRCUITO DE ÁGUA EM PROCESSO DE FABRICAÇÃO DE PAPEL IMPRENSA INTEGRADA COM PRODUUÇÃO DE PASTAS TERMOMECÂNICAS 
MARCELO HAMAGUCHI

\section{ANÁLISE DO CIRCUITO DE ÁGUA EM PROCESSO DE FABRICAÇÃO DE PAPEL IMPRENSA INTEGRADA COM PRODUÇÃO DE PASTAS TERMOMECÂNICAS}

Dissertação apresentada à Escola Politécnica da Universidade de São Paulo para obtenção do Título de Mestre em Engenharia. 
MARCELO HAMAGUCHI

\section{ANÁLISE DO CIRCUITO DE ÁGUA EM PROCESSO DE FABRICAÇÃO DE PAPEL IMPRENSA INTEGRADA COM PRODUÇÃO DE PASTAS TERMOMECÂNICAS}

Dissertação apresentada à Escola Politécnica da Universidade de São Paulo para obtenção do título de Mestre em Engenharia

Área de Concentração:

Engenharia Química

Orientador:

Prof. Dr. Song Won Park 
Este exemplar foi revisado e alterado em relação à versão original, sob responsabilidade única do autor e com a anuência do seu orientador.

São Paulo, 28 de Setembro de 2007

Assinatura do autor:

Assinatura do orientador:

\section{FICHA CATALOGRÁFICA}

Hamaguchi, Marcelo

Análise do circuito de água em processo de fabricação de papel imprensa integrada com produção de pastas termomecânicas / M. Hamaguchi. -- ed.rev. -- São Paulo, 2007.

$162 \mathrm{p}$.

Dissertação (Mestrado) - Escola Politécnica da Universidade de São Paulo. Departamento de Engenharia Química.

1.Água (Uso; Redução) 2.Programação linear 3.Polpação (Fabricação; Simulação) 4.Papel (Fabricação; Simulação) 5.Método Pinch I.Universidade de São Paulo. Escola Politécnica. Departamento de Engenharia Química II.t. 


\section{AGRADECIMENTOS}

Ao professor Song Won Park pela orientação.

Aos amigos do Departamento de Engenharia Química, Laboratório de Controle e Simulação de Processos, pela motivação e amizade.

Ao amigo Lafaety Carneiro, por sua importante colaboração durante as etapas de visitas técnicas, coleta de dados e apresentação do processo produtivo. 


\section{RESUMO}

A indústria de papel e celulose passa por constantes desafios para solucionar problemas relacionados ao alto consumo de água industrial. Uma alternativa é utilizar ferramentas como a Integração de Processos, onde é possível aplicar técnicas gráficas como o "Water Pinch" ou técnicas com programação matemática para otimizar o circuito de água. Para contribuir com o setor, as técnicas foram aplicadas no presente trabalho utilizando-se dados reais coletados em uma unidade produtora de polpa termomecânica e papel imprensa. Com os dados, um caso base em um simulador foi desenvolvido para iniciar a análise por Integração de Processos. A análise é baseada no aproveitamento das correntes de águas residuais em outras etapas do processo sob restrições na concentração limite de contaminantes, especificamente finos e sólidos dissolvidos.

Diferentemente dos trabalhos apresentados na literatura que alegam que a solução encontrada trata-se de valores otimizados, os resultados mostram que os valores encontrados através da programação matemática e do método Pinch são teoricamente corretos, porém, quando novamente simuladas sob estas novas condições obtidas por Integração de Processos, as condições operacionais da unidade industrial mostram-se inadequadas. As concentrações limites de contaminantes previamente estabelecidos pelas técnicas utilizadas são frequentemente ultrapassadas nos resultados de recálculo por simulação, e portanto, as soluções de Integração de Processos devem ser corrigidas antes de implantação. Por isso, os valores previstos, por exemplo, de redução de consumo de até $38 \%$ no projeto realístico atinge o valor de $23 \%$, o que ainda é um bom resultado. O trabalho ainda mostra que a programação matemática é eficaz e rápida para encontrar soluções com múltiplos contaminantes, enquanto o método Pinch é mais voltado para casos com contaminante simples. 


\begin{abstract}
The Pulp and Paper industry has constantly struggled to solve problems related to high water consumption. One alternative is to use tools like Process Integration, where graphical methods and mathematical programming can be applied to optimize the water circuit. To contribute to the Pulp and Paper sector, the methods were applied in the present work using real process data that have been collected in an integrated thermomechanical and newsprint mill. With these data, a base case simulation was developed to initiate the analysis by Process Integration. The analysis is based on residual water reuse in other process stages under propriety constraints like contaminants concentration limits, specifically the dissolved solids and fine fibers.
\end{abstract}

Differently from works presented in the references that claim that solutions found are optimized values, the results of this work show that values found by mathematical programming and pinch method are theoretically correct, however, the operational conditions of the mill become inadequate when simulated under new conditions achieved by Process Integration. The concentration limits of contaminants previously established for the methods have their values frequently exceed after recalculation by simulation, and thus, the solutions by Process Integration must be corrected before using them. So, if the predicted value for reduction of fresh water consumption is, for example, $38 \%$, in the realistic project this value will reach only $23 \%$, which is still a good result. The work also shows that mathematical programming is efficient to find solutions when there are multiple contaminants, while pinch method is more adequate for those cases with single contaminant. 


\section{LISTA DE FIGURAS}

Figura 1.1 Diminuição no consumo de água na indústria de papel. Fonte: 14 Mutjé et al. (2002)

Figura 2.1 Representação de transferência de massa entre correntes de $\mathbf{1 9}$ água e de processo

Figura 3.1 Diagrama geral simplificado da fabricação de pasta 27 termomecânica

Figura 3.2 Cavacos refinados em um estreito espaço entre dois discos rotativos de metal.

Figura 3.3 Diagrama simplificado do sistema de fabricação de papel.

Figura 3.4 Refinação de cavacos do Cadsim

Figura 3.5 Depuração e Lavagem do Cadsim

Figura 3.6 Tanques do Cadsim

Figura 3.7 Filtros Save-all do Cadsim

Figura 3.8 Simulação do processo de refinação de cavaco, lavagem, filtração e preparação de massa em Cadsim

Figura 3.9 Simulação do processo de fabricação de papel em Cadsim

Figura 3.10 Comparação gráfica de dados coletados e simulados

Figura 4.1 Estrutura da Integração de Processos

Figura 4.2 (a) Variação da concentração do contaminante e, (b) curva composta de concentração. Fonte: Wang; Smith (1994).

Figura 4.3 Obtenção do ponto de mínimo consumo de água. Fonte: Wang; Smith (1994).

Figura 4.4 Representação esquemática do exemplo 2. Fonte: Mann; Liu 76 (1999). 
Figura 4.5 Representação gráfica do exemplo 2 (passo 1). Fonte: Mann; 77 Liu (1999).

Figura 4.6 Representação gráfica do exemplo 2 (passo 2). Fonte: Mann; 78 Liu (1999).

Figura 4.7 Representação gráfica do exemplo 2 (passo 3). Fonte: Mann; 79 Liu (1999).

Figura 4.8 Curva composta dupla após alteração no processo 3. Fonte: $\mathbf{8 0}$ Mann; Liu (1999).

Figura 4.9 Representação esquemática do exemplo 2 após a alteração no 80 processo 3. Fonte: Mann; Liu (1999).

Figura 4.10 Representação esquemática do exemplo 3. Fonte: Jacob et al. (2002)

Figura 4.11 Construção da curva composta dupla para o exemplo 3. Fonte: Jacob et al. (2002)

Figura 4.12 Ponto Pinch da curva composta dupla para o exemplo 3. Fonte: Jacob et al. (2002)

Figura 4.13 Mistura de fontes para atingir limites do exemplo 3. Fonte: Jacob et al. (2002)

Figura 4.14 Extração de contaminantes para atingir limites. Fonte: Jacob et al. (2002)

Figura 4.15 Representação gráfica para programação linear. Fonte: Man; Liu (1999)

Figura 4.16 Representação do exemplo 4 para circuito aberto. Fonte: Jacob et al.(2002)

Figura 4.17 Representação esquemática do exemplo para circuito fechado

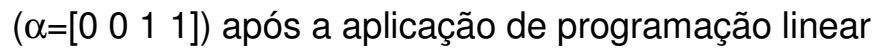


Figura 5.1 Esquema ilustrando as principais correntes de água do 99 processo.

Figura 5.2 Curva composta dupla para sólidos dissolvidos em máquina de papel

Figura 5.3 Curva composta dupla para fibras em máquina de papel (passo 1)

Figura 5.4 Curva composta dupla para fibras em máquina de papel 103 (passo 2)

Figura 5.5 Mistura de fontes para atingir limite de concentração de fibras (passo 3)

Figura 5.6 Curvas de concentração de sólidos dissolvidos em processo integrado. Caso para um contaminante.

Figura 5.7 Curvas de concentração de fibras em processo integrado

Figura 5.8 Curva para atingir limite de concentração de fibras em processo integrado

Figura 5.9 Curvas de concentração de sólidos dissolvidos em processo integrado. Caso para múltiplo contaminante.

Figura 5.10 Modificações no caso 3 para atingir limites permitidos para concentração de sólidos dissolvidos 


\section{LISTA DE TABELAS}

Tabela 1 Dados coletados durante visita técnica no setor de TMP

Tabela 2 Dados coletados durante visita técnica na máquina de papel

42

Tabela 3 Resultados da simulação do processo produtivo para caso-

56 base

Tabela 4 Demanda de água para os processos desenvolvidos no

72 exemplo.

Tabela 5 Carga de contaminante para todos os intervalos de 73 concentração.

Tabela 6 Dados limites para o exemplo. Fonte: Mann; Liu (1999).

Tabela 7 Novos dados limites para 0 exemplo, modificando $0 \quad 79$ processo 3

Tabela 8 Dados para exemplificar programação matemática 91

Tabela 9 Resultados obtidos após aplicar programação linear no 93 exemplo 4

Tabela 10 Tabela com as correntes de água 97

Tabela 11 Fontes de água ordenadas para fibras em de produção de 100 papel

Tabela 12 Demandas ordenadas para fibras em produção de papel 100

Tabela 13 Subdivisão da fonte 2 após a aplicação do método Pinch 104

Tabela 14 Distribuição das fontes para as demandas com método Pinch

Tabela 15 Fontes de água consideradas em processo integrado 106

Tabela 16 Demandas ordenadas para fibras e SD em processo integrado 
Tabela 17 Subdivisão da fonte 4 após a aplicação do método Pinch

Tabela 18 Distribuição das fontes para as demandas com método Pinch em processo integrado (valores de vazão de água em $\mathrm{kg} / \mathrm{min}$ )

Tabela 19 Distribuição das fontes para as demandas com programação 112 matemática

Tabela 20 Distribuição das fontes utilizando programação matemática em processo integrado (valores de vazão de água em $\mathrm{kg} / \mathrm{min}$ )

Tabela 21 Alterações observadas nas vazões das fontes pós otimizadas $\mathbf{1 1 5}$ (em L/min)

Tabela 22 Alterações observadas nas consistências das fontes (em \%) 116

Tabela 23 Alterações observadas nas concentrações de SD das fontes $\mathbf{1 1 7}$ (em ppm)

Tabela 24 Alterações observadas nas vazões das demandas pós 118 otimizadas (em L/min)

Tabela 25 Alterações observadas nas concentrações de SD das 119 demandas (em ppm)

Tabela 26 Alterações observadas nas consistências das demandas 121 (em \%)

Tabela 27 Demandas do caso 3: corrigido para atingir limite estabelecido 123

Tabela 28 Fontes do caso 3: corrigido para atingir limite estabelecido

Tabela 29 Vazão total de água nos elfuentes para cada caso (em $\mathrm{kg} / \mathrm{min}$ ) 125

Tabela 30 Vazão total de fibras nos elfuentes para cada caso 126 (em $\mathrm{kg} / \mathrm{min})$ 


\section{LISTA DE ABREVIATURAS E SIGLAS}

$\begin{array}{ll}\text { TMP } & \text { Thermo Mechanical Pulping } \\ \text { CMP } & \text { Chemi-Mechanical Pulping } \\ \text { CTMP } & \text { Chemi-Thermo-Mechanical Pulping } \\ \text { PI } & \text { Process Integration } \\ \text { SDCD } & \text { Sistema Digital de Controle Distribuído } \\ \text { LP } & \text { Linear Programming } \\ \text { NLP } & \text { Non-Linear Programming } \\ \text { SD } & \text { Sólidos Dissolvidos } \\ \text { F } & \text { Fonte } \\ \text { D } & \text { Demanda }\end{array}$




\section{SUMÁRIO}

1 INTRODUÇÃO............................................................................. 14

1.1 Desafios no uso de água na indústria de celulose e papel .........................14

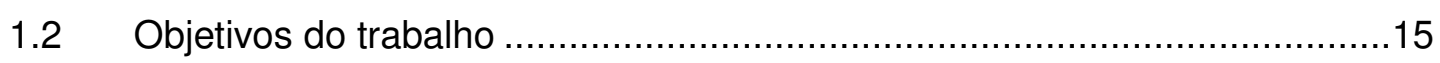

$1.3 \quad$ Estrutura da dissertação ............................................................... 16

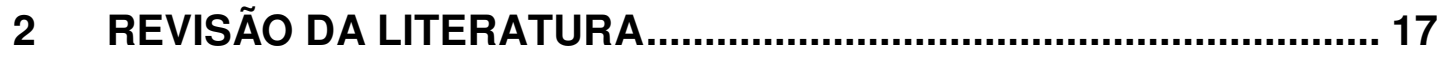

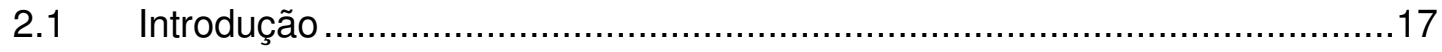

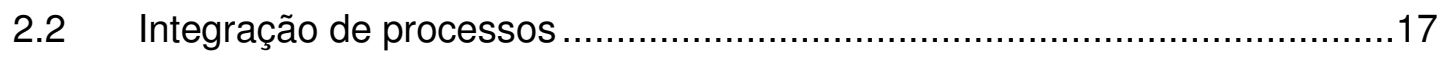

2.3 Método Pinch ............................................................................. 18

2.4 Técnicas de Programação Linear e Não-linear..........................................21

2.5 Simulação na indústria de Celulose e Papel .............................................23

3 DESCRIÇÃO DO PROCESSO INDUSTRIAL E A SUA SIMULAÇÃO25

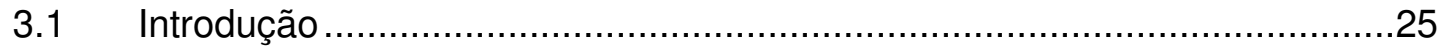

3.2 Pastas Termomecânicas e Máquina de Papel Imprensa............................26

3.2.1 Fabricação de Pasta Termomecânica ................................................................... 26

3.2.2 Preparação de Massa para a Fabricação do Papel ................................................. 31

3.2.3 Circuito de Baixa Consistência na Fabricação do Papel ......................................... 32

3.2.4 Fabricação de Papel .......................................................................................... 33

3.2.5 Sistema de Recuperação de Fibras da Fabricação do Papel .................................. 33

3.2.6 Caixa de Entrada da Máquina de Papel .............................................................. 34

3.2.7 Seção de Formação da Máquina de Papel........................................................... 35

3.2.8 Seção de Prensas da Máquina de Papel............................................................... 36

3.2.9 Seção de Secagem da Máquina de Papel......................................................... 36

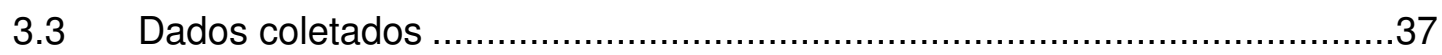

3.3.1 Dados da produção de pasta termomecânica …………………………............... 39

3.3.2 Dados da produção de Papel Imprensa ............................................................ 42

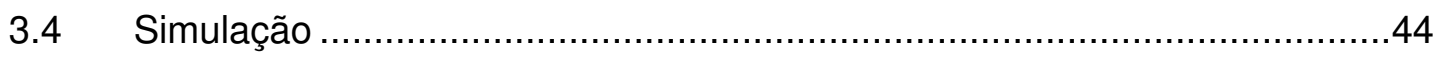

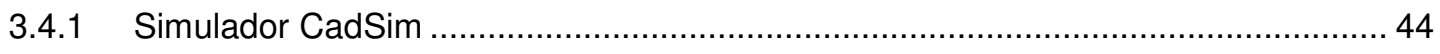

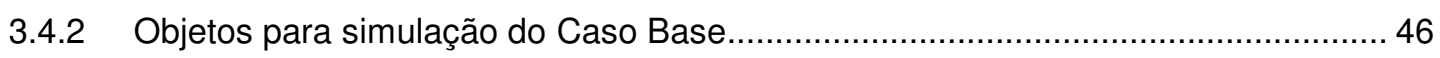

3.4.3 Estruturação do processo produtivo em CadSim ................................................ 51

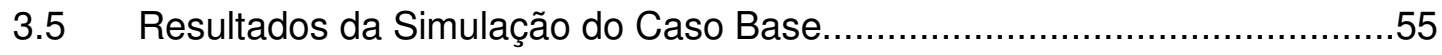

3.5.1 Comparação de dados simulados com dados reais .............................................. 60

4 ANÁLISE DO CIRCUITO DE ÁGUA .............................................. 63

4.1 Generalidades sobre o circuito de água ...............................................63 


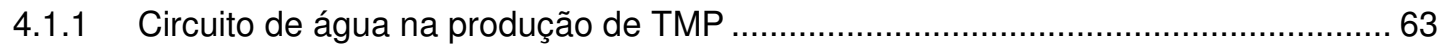

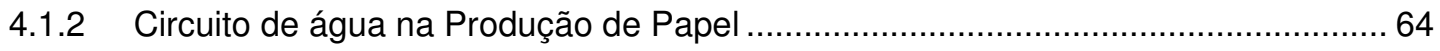

4.2 Integração de Processos....................................................................66

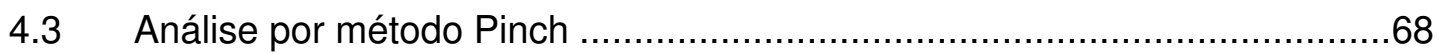

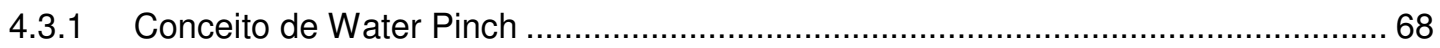

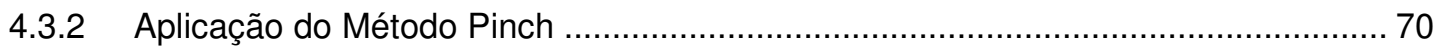

4.4 Análise com programação matemática ................................................. 85

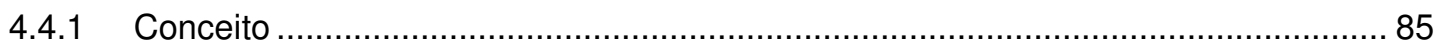

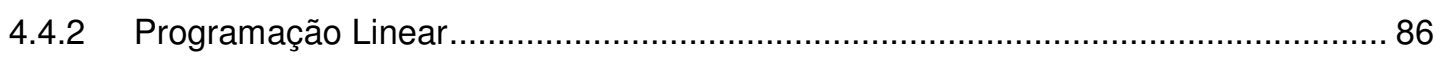

4.4.3 Aplicação do método de programação linear ..................................................... 88

5 ANÁLISE DAS ALTERNATIVAS PARA O CIRCUITO DE ÁGUAS DA FÁBRICA DE TMP E PAPEL IMPRENSA ....................................... 95

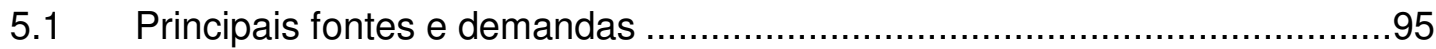

5.2 Resultados do método Pinch........................................................100

5.2.1 Análise somente para a máquina de papel aplicando pinch ................................. 100

5.2.2 Análise para processo TMP integrada à máquina de papel aplicando pinch.......... 105

5.3 Resultados do método por programação linear ......................................112

5.3.1 Análise somente para máquina de papel aplicando programação linear............... 112

5.3.2 Análise para processo TMP integrado à máquina de papel aplicando programação linear.

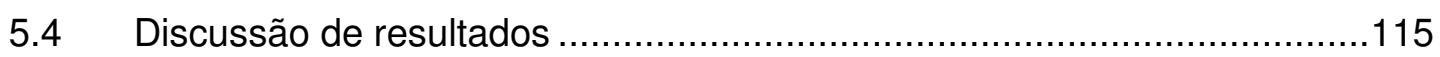

6 CONCLUSÃO .......................................................................... 127

$7 \quad$ REFERÊNCIAS BIBLIOGRÁFICAS ............................................ 132 


\subsection{Desafios no uso de água na indústria de celulose e papel}

Estudos ambientais indicam que já é notável a redução de algumas fontes naturais de água, um recurso imprescindível para o desenvolvimento econômico e social de uma nação. E a indústria de papel e celulose, por possuir um consumo específico de água relativamente alto, deve iniciar uma movimentação importante em busca de novas tecnologias, ou até mesmo, de métodos convencionais que possibilitem uma aplicação abrangente sobre a minimização na captação de água. Paralelamente, engenheiros e cientistas devem constantemente impulsionar as pesquisas na área de reutilização de água em processos industriais para acompanhar a tendência demonstrada na figura 1.1.

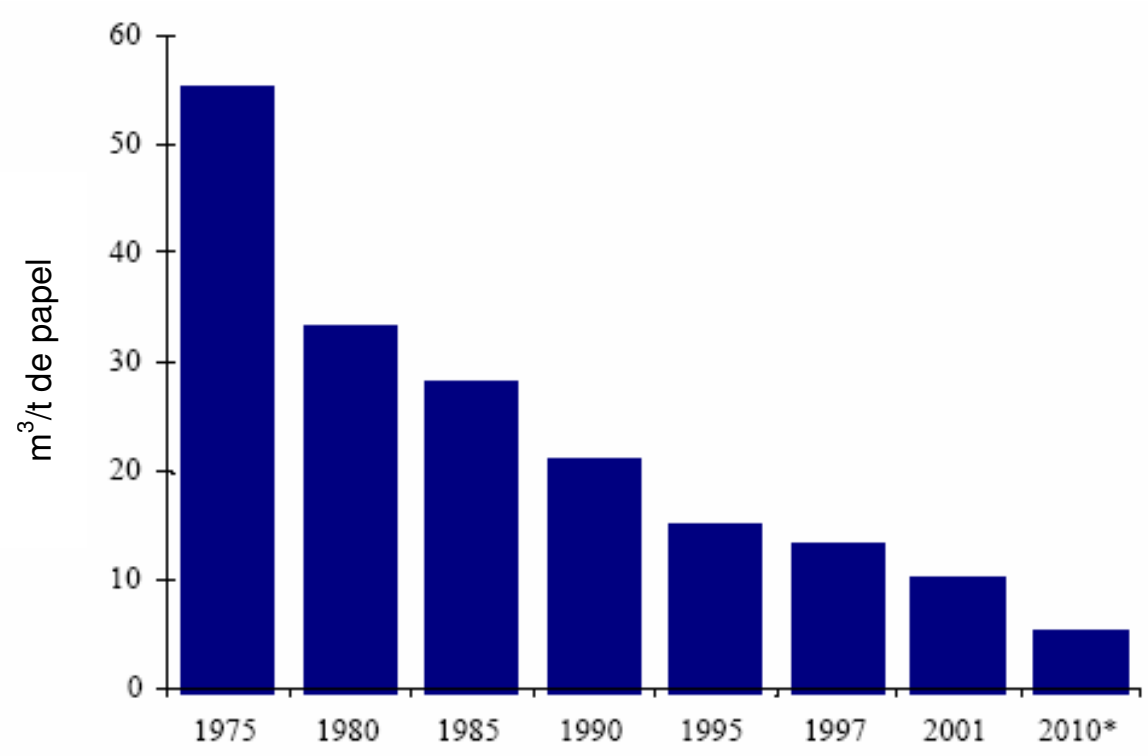

Figura 1.1. Consumo de água na indústria de papel. Fonte: Mutjé et al. (2002)

Ao mesmo tempo, a legislação ambiental é rigorosa, preocupando-se cada vez mais com o crescimento incontrolado da população mundial, ou seja, são desafios que merecem atenção dos profissionais da área. Explorar ferramentas que hoje estão mais difundidas entre os profissionais do meio 
acadêmico é um importante passo para caminhar rumo aos desafios do uso de água na indústria.

Há soluções para a indústria de papel reduzir o consumo de água limpa captada dos rios. $E$ tendo isso em vista, o presente trabalho enfoca uma aplicação de ferramentas de otimização em uma indústria de papel imprensa. Mas é bom enfatizar que nenhuma técnica, por mais inovadora que seja, obterá resultados sem a conscientização de profissionais sobre a importância na redução do consumo de água.

\subsection{Objetivos do trabalho}

O presente trabalho tem como principal finalidade estudar o circuito de água do processo produtivo de TMP (Thermo-Mechanical-Pulping) integrada a máquina de papel imprensa, utilizada principalmente para a produção de jornais e revistas. A produção desse tipo de papel no Brasil é feita por uma indústria que produz anualmente 185 mil toneladas de papel imprensa.

Através de alguns dados coletados, seu processo produtivo será analisado utilizando-se um simulador dinâmico dedicado ao setor de celulose e papel. Com os resultados da simulação, ferramentas de otimização serão implementadas com o objetivo de encontrar alternativas para minimizar o consumo de água fresca e a geração de efluente. 


\subsection{Estrutura da dissertação}

A dissertação foi desenvolvida de acordo com a estrutura indicada a seguir:

Capítulo 2: Apresenta uma revisão de trabalhos relevantes já publicados sobre as técnicas de Integração de Processos, que abordam a questão do reuso de água em unidades industriais através de métodos de otimização e gráficos. Na seção Water Pinch, será feita uma revisão abrangente da ferramenta, pois se trata de uma tecnologia convencional bastante estudada no mundo acadêmico.

Capítulo 3: Descreve o processo produtivo de pastas termomecânicas e papel imprensa da unidade fabril adotada para o estudo de caso. Em seguida, sua simulação foi realizada e descrita com enfoque no circuito de água. Informações sobre o software utilizado, assim como os dados coletados e simulados, estão descritos nesse capítulo.

Capítulo 4: Apresenta uma descrição do circuito de água da unidade fabril juntamente com a metodologia a ser aplicada sobre os métodos water pinch e programação linear.

Capítulo 5: Capítulo dedicado a conclusões e discussões sobre os diferentes métodos por integração de processo. Serão relatadas as dificuldades e vantagens observadas durante a aplicação dos métodos.

Capítulo 6: Consolida as conclusões do trabalho e sugestões para futuros trabalhos.

Capítulo 7: Reúne as referências bibliográficas consultadas e utilizadas para o desenvolvimento do trabalho.

Apêndices: Reúnem informações importantes porém não necessárias ao contexto principal da dissertação. 


\section{REVISÃO DA LITERATURA}

\subsection{Introdução}

As técnicas utilizadas para minimizar o consumo de água em um complexo industrial incluem o reaproveitamento desta água no circuito de fabricação da indústria. Segundo Wang; Smith $(1994,1995)$, existem três casos: o reuso direto da água decorrente de uma operação em outra área, reuso através de recuperação por um tratamento parcial para remover contaminantes, e reciclo das correntes de água junto com esta recuperação para remoção de contaminantes.

A análise de circuito de águas por integração de processos é uma abordagem recorrente nos processos químicos industriais, que pode ser desenvolvida através de métodos gráficos ou por otimização matemática. Porém, é necessário aplicar algumas ferramentas de simulação, preferivelmente de modelos dinâmicos, junto com técnicas de otimização ou de aproximação de melhores soluções, para obter resultados de minimização de uso de água utilizando métodos de integração de processos.

\subsection{Integração de processos}

O projeto de um sistema industrial de águas, para utilizar de modo eficiente os recursos disponíveis, é um problema complexo que envolve balanceamentos de diferentes compromissos, e por isso, é necessário estudar a integração de processos sob o enfoque mais matemático, com a modificação de diferentes combinações de uso de água. El-Halwagi; Manousiouthakis (1989) introduziram a noção de "Mass Exchanger Network Synthesis" (MEN) para uma transferência preferencial de um contaminante chave de um sistema com correntes ricas para um sistema com correntes pobres em contaminante.

Alva-Argaéz et al. (1998) discutem de um modo genérico a minimização de geração de efluentes usando uma abordagem integrada com programação 
inteira-mista. Assumindo que alterações drásticas no processo não podem ser feitas por questões de custo, é preciso combinar técnicas que aumentem a eficiência do sistema de água através de práticas de reuso e recuperação de águas residuais. Utilizando o conceito de integração de processos, os autores descrevem uma combinação de técnicas gráficas chamada "water pinch" com ferramentas de programação matemática. A técnica consiste no desenvolvimento de um modelo superestruturado do sistema a ser analisado, englobando as características do processo de forma detalhada. Mas, para avaliar sua eficiência, deve-se levar em consideração o grau de fechamento do circuito de água em uma fábrica existente. Proporcionar reduções significativas é uma tarefa simples se uma unidade fabril possui um circuito praticamente aberto. Porém grandes desafios podem ser encontrados, por exemplo, em uma máquina de papel, onde minuciosas análises de restrições de contaminantes devem ser impostas para garantir um eficiente resultado.

Smith (2000) em seu artigo sobre o estado da arte em integração de processos, enfatiza que no passado, meados dos anos 80 , a técnica de integração de processo era mais utilizada na área de conservação de energia. Ultimamente, a técnica tem se estendido bastante para aumentar eficiências em troca de massa. Bagajewicz; Savelski (2001) discorrem sobre projetos de sistema de utilização de água onde apenas um simples contaminante está presente no processo. Em sua publicação são ilustradas metodologias propostas para encontrar alternativas de melhorias em projetos industriais onde o uso de água é intenso, sendo possível otimizá-los através de técnicas de programação linear.

\subsection{Método Pinch}

O método Pinch para análise de redução de consumo de água tem encontrado algumas críticas e restrições, principalmente por tratar a troca de massa de modo muito similar à troca de energia. Entretanto, periodicamente têm surgido aplicações com Pinch associado à troca de massa, o que torna 
obrigatório a revisão deste método e também a literatura pertinente ao método.

A ferramenta Pinch por troca de massa segue os mesmos princípios do Thermal Pinch, desenvolvido para troca de energia. Os primeiros estudos nessa direção foram introduzidos em 1989 por El-Hawagi e Manousiouthakis na Universidade da Califórnia, onde foram tratados os problemas relacionados à troca de massa entre correntes de processo, rica e pobre de contaminantes.

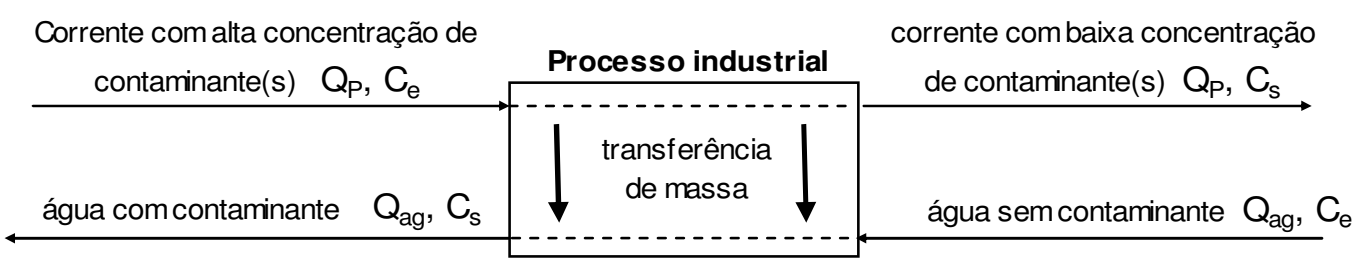

Figura 2.1 - Representação de transferência de massa entre correntes de água e de processo.

Wang; Smith (1994), consideraram o problema de transferência de contaminantes de uma corrente de processo para uma corrente de água através de métodos gráficos. O método poderia ser aplicado na área de minimização do consumo de água, considerando que contaminantes são transferidos, conforme figura 2.1, de uma de corrente de processo $\left(Q_{p}\right)$ para uma corrente de água $\left(Q_{a g}\right)$. Observa-se na figura 2.1, que a concentração de contaminantes na entrada $\left(\mathrm{C}_{\mathrm{e}}\right)$ do processo industrial é maior para a corrente $Q_{p}$ do que para a corrente $Q_{a g}$, que por sua vez, possui a concentração de contaminantes maior na saída $\left(\mathrm{C}_{\mathrm{s}}\right)$ do processo industrial. As técnicas são baseadas em modelos de uma unidade de processo como sendo uma unidade de transferência de massa. Porém a aplicabilidade do método de Wang e Smith é dificultada quando circuitos miscíveis de águaágua são frequentes, como ocorre na indústria de celulose e papel. Além disso, a técnica não impõe restrições práticas como a distância geográfica de uma tubulação ou outras restrições de processo que proíbam o reuso de 
água de uma unidade para outra. Essa preocupação foi citada por Jödicke et al. (2001), que publicaram uma técnica de programação linear envolvendo custos operacionais e de investimento.

Com o intuito de desenvolver novos métodos gráficos, Dhole et al. (1996) denominaram de "curva composta dupla" o método no qual o gráfico é construído através de curvas de demanda e de fontes, ou seja, consumidores e geradores de água de determinados processos respectivamente. Suas vazões são introduzidas na abcissa da curva enquanto na ordenada são colocadas as respectivas purezas de cada corrente. Tanto o método apresentado por Wang e Smith, quanto o apresentado por Dhole e colaboradores, serão revistos no presente trabalho.

Savulescu et al. (2005) aplicam método Pinch para minimização do consumo de água e energia em fabricação de cartão com celulose Kraft de uma unidade industrial.

O método utilizado por Wang; Smith $(1994,1995)$ e por Kuo (1996), fornece importantes critérios sobre os problemas em sistemas de água. A ferramenta gráfica também foi citada por Hallale (2002), que apresenta um novo método para minimizar o uso de água fresca e a geração de efluentes. O autor considera o método desenvolvido por Dhole como atrativo, porém deficiente por não representar o sistema em estudo de forma clara. Hallale aponta corretamente que a mistura de diferentes fontes pode afetar o resultado final, ou seja, o resultado da técnica não pode ser considerado correto por que depende do modelo de mistura das fontes, que é na verdade parte do projeto do circuito de água.

Jacob et al. (2002) analisam, como uma parte do trabalho, a rede de água em processos de papel e celulose por método Pinch, mais especificamente relacionada com processos de destintamento de papel e de TMP com papel imprensa. Foi mostrado que a análise pelo método gráfico não foi muito eficiente na unidade de destintamento, pois o processo já operava em 
circuito bastante fechado e o sistema proposto para mudanças assemelhava-se com o existente. No caso da fabricação de TMP e papel imprensa, o método Pinch não foi capaz de atingir um objetivo: a concentração em excesso de sólidos dissolvidos deve ser evitada durante o processo, mas ao mesmo tempo, fibras residuais devem ser recuperadas por fazerem parte da composição do papel, ou seja, o método deveria ser aplicado para múltiplos componentes com objetivos opostos. Porém, o método Pinch não se mostrou uma ferramenta adequada para esse propósito, sendo necessário, a aplicação de programação matemática linear para superar os obstáculos.

Dunn; Wenzel (2001a, 2001b, 2002), em uma série de trabalhos divididos em três partes, discutem métodos de projeto com integração de processos para conservação de água e redução de efluentes em indústria. Manan et al. (2004) aplicam método Pinch modificado e seus procedimentos de cálculos, com exemplos de ilustração.

\subsection{Técnicas de Programação Linear e Não-linear}

A programação linear surge como uma forte ferramenta, pois pode ser aplicada para levar simultaneamente em conta vários contaminantes no circuito de água. Papalexandri et al (1994) apresentam uma técnica para síntese de MEN (Mass Exchanger Network) baseada em programação matemática não linear inteira mista (MINLP). Alva-Argaez et al. (1998) basearam-se nessa técnica de otimização para reduzir a vazão de efluentes em uma refinaria. Na função objetivo, os autores incluiram termos para o custo de operação, de água fresca em uma base anual, e para o custo de capital devido a tubulação e investimentos requeridos para o tratamento.

Jacob et al. (2002) ilustram, além do citado método pinch, a aplicação de programação linear em circuito de água em processos de reciclagem de papel e destintamento, com bons resultados. Em sua conclusão, os autores recomendam a aplicação do método em outras fábricas de celulose e papel. 
Segundo Jödicke et al (2001), muitos circuitos de água otimizados através de ferramentas de integração de processos são rejeitados por engenheiros pelo fato dos resultados não levarem em consideração os custos de bombeamento e comprimento de tubulações. Em sua publicação, um modelo de programação linear inteira mista (MILP) é desenvolvido para superar esses obstáculos. O modelo minimiza os custos totais de um empreendimento, que pode ser dividido em custos operacionais e de investimento. Com os resultados da aplicação do modelo em uma unidade industrial, vários circuitos foram gerados e discutidos levando em consideração os aspectos econômico, ambiental e técnico.

Recentemente, Mariano et al. (2007) descreveram como a ferramenta "water pinch" pode ser utilizada nos dias atuais. Mencionam que a ferramenta é formulada como um problema de programação não linear altamente restrita para se aproximar cada vez mais de um modelo real. Devido a existência de diversos tipos de operações com água, custo e eficiência de seu tratamento e inúmeros tipos de contaminantes, o critério para o uso eficiente da água torna-se essencialmente não linear, multi objetivo e conflitante. Em sua publicação, estendem a análise por método Pinch englobando, além da minimização do consumo de água, o custo de infra-estrutura. Em trabalhos futuros, Mariano e colaboradores pretendem criar restrições para selecionar processos diferentes de forma eficiente, ou seja, se a tecnologia para tratamento de efluentes for selecionada baseado no tipo de contaminantes, a remoção da substância poderia ser feita de forma mais eficiente se o próprio processo for selecionado e otimizado em termos de custo e eficiência.

Cao et al. (2007) afirmam que a programação matemática linear pode ser formulada para problemas com simples contaminante e a programação nãolinear para múltiplos contaminantes. Entretanto, afirmam os autores, esta programação não-linear não é a mais adequada, e propõem o método heurístico baseado em algoritmo genético. 


\subsection{Simulação na indústria de Celulose e Papel}

A simulação de processos na indústria de celulose e papel (Syberg; Wild; Simons, 1992) pode se tornar uma ferramenta útil à medida em que a integração de massa e energia ganha importância quando o assunto é reduzir o consumo específico de água nas indústrias. Porém, segundo Jutila; Leiviska (1981), problemas com a simulação na indústria de celulose e papel estão relacionados com o ajuste do modelo em casos onde há correntes de reciclo no processo, o que pode causar uma limitação nos estudos de caso. E o problema persiste até os dias atuais. Além disso, testes dos modelos podem se tornar deficientes por falta de dados necessários para uma verificação completa do balanço. Como exemplo, o artigo destaca a dificuldade em introduzir dados de média e alta consistência de polpa no modelo, pois a taxa de produção de fibras não é medida com precisão até o produto final. Sendo assim, dados simulados podem ser precisamente calculados somente na teoria, porém não podem ser comparados com dados de produção de períodos curtos.

Desde a década de 80 , as ferramentas de simulação têm-se desenvolvido de forma satisfatória, tanto em relação ao desempenho nos cálculos de iterações quanto em teorias aplicadas a modelos para simular estudos de casos. Para exemplificar simulações de processo em máquinas de papel imprensa, Dabros et al (2005), por exemplo, desenvolvem um modelo a partir da operação de uma unidade fabricante de pasta termomecânica integrada a quatro máquinas de papel imprensa. A simulação é desenvolvida através de simulação modular dinâmico seqüencial, onde as flutuações de variáveis medidas (fluxo, temperatura e consistência da polpa) e não medidas (sólidos dissolvidos e distribuição do comprimento de fibras) na caixa de entrada são quantificadas através de uma função objetivo utilizando o método simplex geométrico Nelder-Mead e o método de algoritmo genético. Com o resultado, foi possível analisar as quebras de folhas que são recirculadas para o processo e desenvolver alternativas para aumentar a estabilidade da máquina de papel. Porém, dificuldades surgem quando o 
modelo é utilizado para outros estudos de caso, pois parâmetros e variáveis que distinguem um processo de outro não são contemplados.

Turon et al. (2005) simulam uma unidade produtora de papel revestido. A coleta de dados foi feita através de medições, análises de amostras e estimativas por balanço de massa. O objetivo principal é otimizar o circuito de água e matérias-primas como a fibra implantando ferramentas matemáticas. No trabalho, os autores reproduzem o estudo de casos com precisão, o que possiblita a predição de parâmetros operacionais. Isso ocorreu principalmente por causa da escolha criteriosa de dados de processo e a utilização eficiente do método escolhido para ajuste de parâmetros.

Lappalainen, Mäkinen (2006) desenvolvem um estudo dos sólidos dissolvidos e colóides com simulação dinâmica da produção de pasta mecânica. Como alguns sólidos são prejudiciais, e outros benéficos, durante a produção, o objetivo do trabalho foi criar balanços dinâmicos destes sólidos dissolvidos e colóides em todo o processo para entender seu comportamento através de sensores virtuais de predição. Mais uma vez, o artigo também enfatiza a questão das oscilações do processo que dificilmente são acompanhados no modelo. O problema pode ser minimizado se a coleta de dados for feita a médio ou longo prazo para analisar parâmetros em situações reais de processo.

No presente trabalho, descreve-se no próximo capítulo, o processo produtivo e a coleta dos dados de produção e, a seguir, no capítulo 4, a integração de processos pelo método Pinch de Dhole et al. (1996) e o método de otimização por programação matemática utilizado por Jacob et al. (2002). Porém, para a aplicação da programação matemática nesta fábrica de TMP e na máquina de papel, a função objetivo será baseada em uma técnica linear que não englobará a análise de redução de custos e sim, a vazão de água em cada ponto de consumo de água fresca, que estará sob restrições de concentração de contaminantes e fibras. 


\section{DESCRIÇÃO DO PROCESSO INDUSTRIAL E A SUA SIMULAÇÃO}

Neste capítulo, uma introdução sobre os diferentes processos de polpação será feita, dando-se em seguida, ênfase à descrição do processo produtivo de pasta termomecânica integrada à máquina de papel imprensa da unidade fabril. A descrição foi baseada no texto de Oliveira (2004) e tecnicamente complementada pelo livro editado por Sundholm (1999) sobre pastas mecânicas. Para finalizar, será descrito o funcionamento do simulador Cadsim com os dados inicialmente coletados.

\subsection{Introdução}

O objetivo de um processo de polpação é separar as fibras da madeira para torná-las adequadas para a fabricação de papel.

Basicamente, a polpa pode ser classificada em pasta química ou pasta de alto rendimento, sendo que essa última pode ou não ser tratada com compostos químicos. Para pasta química, o processo mais utilizado é o "Kraft", que proporciona uma capacidade para recuperação dos compostos químicos de polpação. As pastas de alto rendimento podem ser classificadas em pasta puramente mecânica, quimiomecânica (CMP), termomecânica (TMP), e quimiotermomecânica (CTMP). A TMP será o foco principal do presente trabalho.

Em termos de propriedades tais como a resistência e pureza do papel, a pasta química é a mais recomendada. Além disso, a fabricação de pasta mecânica preserva a lignina por não existir sua degradação química no processo de fabricação; portanto ocasiona, com o decorrer do tempo, um amarelamento no papel. Isso é perceptível nos jornais e revistas, que são produzidos a partir de pastas mecânicas. Outra desvantagem do processo mecânico é o consumo específico elevado de energia elétrica. 
No processo mecânico, as fibras da madeira são processadas para proporcionar um rendimento da estrutura celulósica de aproximadamente 95\%, sendo que em processos químicos essa porcentagem dificilmente chega a 50\% devido ao tratamento térmico e à reação de compostos da madeira com produtos químicos que ocasionam a destruição de parte dos componentes da madeira.

\subsection{Pastas Termomecânicas e Máquina de Papel Imprensa}

$\mathrm{Na}$ unidade fabril em questão, a madeira utilizada para a fabricação de pasta termomecânica é predominantemente o pinus taeda, uma fonte de fibra longa que oferece boa produtividade e qualidade para fabricação de papel imprensa. Além da pasta termomecânica, é necessário o uso de pasta química, para conferir resistência física ao papel.

A fábrica possui duas linhas de produção de TMP, constituídas de diferentes equipamentos e processos. Consequentemente, as propriedades físicas da polpa final variam de acordo com a capacidade utilizada de cada linha. Mas para a fabricação do papel, as polpas se misturam para alcançar a capacidade de produção desejada.

\subsubsection{Fabricação de Pasta Termomecânica}

Como pode ser observado na figura 3.1, o setor de TMP desta fábrica é dividido em duas linhas de produção, sendo que a maior parte está concentrada na linha 2 , ou seja, a mais nova e tecnologicamente mais avançada. 


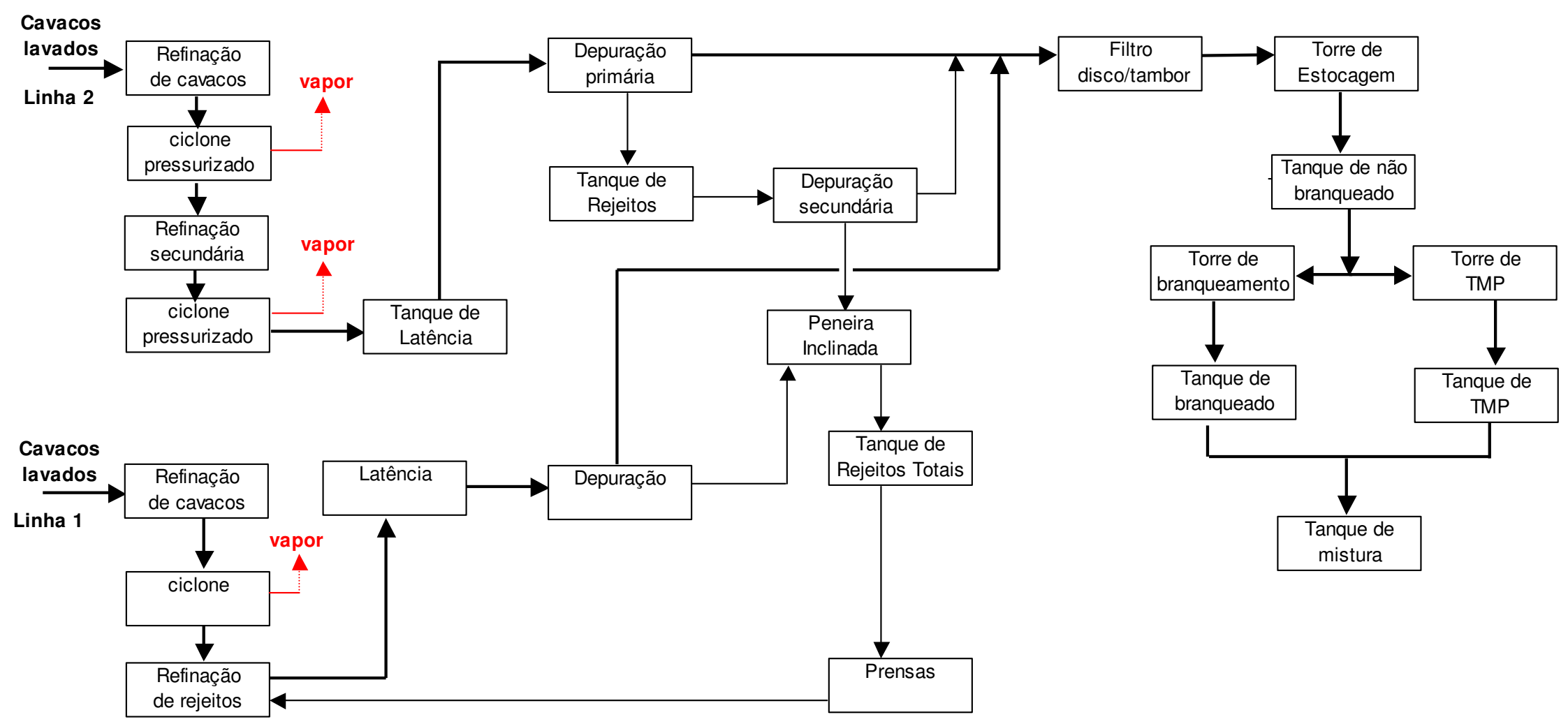

Figura 3.1. Diagrama geral simplificado da fabricação de pasta termomecânica 
O processo se inicia com a lavagem do cavaco, não representado na figura 3.1. A função desta seção de lavagem é separar dos cavacos qualquer material indesejável, tais como areia, pedras ou metal. Isto é necessário para proteger o equipamento contra danos e para remover materiais que possam prejudicar a qualidade da pasta. Após o processo de lavagem, é feito o transporte do cavaco proveniente para o silo de estocagem. Os cavacos são extraídos do silo para alimentar um vaso, ou distribuidor pressurizado, de impregnação a alta pressão de seguinte modo: os cavacos lavados seguem para o silo vibratório, onde são descarregados para uma rosca de alimentação e selagem, que além de servir como tampão de selagem do sistema pressurizado dos refinadores, faz o papel de medidor e de controle de produção. A rosca comprime os cavacos e extrai certa quantidade de água juntamente com alguns constituintes solúveis da madeira, ao mesmo tempo que auxilia a impregnação dos cavacos pelo vapor. Essa etapa de pressurização permite uma impregnação de vapor com um conseqüente amaciamento da lignina, para facilitar o processo de desfibrilação mecânica nos refinadores de cavacos.

O bloco referente a refinação de cavacos, da linha 1 mostrada na figura 3.1, é descrito a seguir. Após a impregnação os cavacos são transferidos para o refinador de cavacos, composta de dois refinadores, onde a estrutura fibrilar é mecanicamente processada para a formação de pasta termomecânica. A consistência de saída do primeiro refinador, esquematizado na figura 3.2, é de aproximadamente $30-35 \%$, levando em consideração que a zona de refinação deve ser determinada pela consistência de entrada e pela quantidade de água adicionada. Alguns fatores como o diâmetro do disco, a velocidade do disco, vibração e temperatura influenciam a qualidade da polpa de saída. 


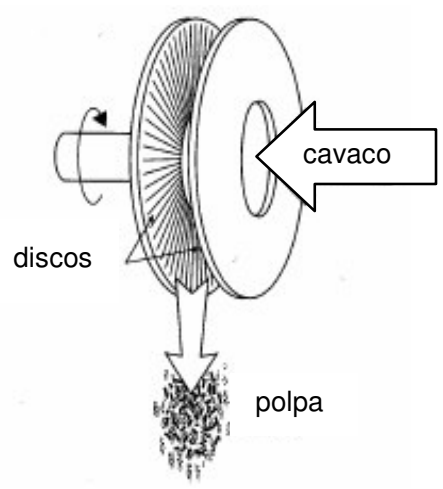

Figura 3.2. Cavacos refinados em um estreito espaço entre dois discos rotativos de metal. Pelo menos um dos discos rotaciona com alta velocidade.

A refinação nesta linha 1 é feita em dois estágios: no refinador primário, que refina os cavacos, e em seguida no refinador secundário, onde é refinada a pasta produzida no primeiro refinador proporcionando um melhor acabamento às fibras. Do refinador primário, a polpa é direcionada para um separador centrífugo denominado ciclone. A polpa entra no ciclone tangencialmente e é direcionada para o fundo, de onde é descarregada para o refinador secundário. O vapor gerado, que poderia ser recuperado e utilizado em etapas como a impregnação de cavacos, é direcionado para a atmosfera através do ciclone.

A pasta celulósica que sai do refinador primário segue para o refinador secundário que também recebe uma parte dos rejeitos da prensa. Um terceiro refinador recebe a maior parte dos rejeitos da prensa. Por isso este terceiro refinador é considerado refino de rejeitos tanto da linha 1 quanto da linha 2, apesar de uma parte dos rejeitos totais também entrar no refinador secundário da linha 1. Da saída do refinador secundário segue-se para um tanque de latência. Quando cavacos são desfibrados a altas temperaturas e alta consistência, como ocorre no refinador, as fibras são deformadas devido ao processo. Durante o processo de refinação, as fibras são comprimidas, torcidas e encurvadas. Esse fenômeno é chamado de latência e deve ser removida, o que pode ser feita através de agitação da polpa a baixa consistência (3 a 5\%) e altas temperaturas. 
Após a remoção de latência, é possível melhorar as condições de drenabilidade, opacidade, formação da folha e obter melhores propriedades físicas de resistência. Portanto, da saída do refinador de rejeitos, a polpa segue para o tanque de latência da linha 1 .

Para aumentar significativamente a produção com qualidade superior, diminuir o custo de produção e reduzir o consumo de fibras de celulose, foi implantada a linha 2 de TMP. O processo é similar à linha 1, com algumas características adicionais, tais como o tipo de refinador em si com o seu ciclone pressurizado.

Na linha 2, uma rosca distribuidora projetada para dividir o fluxo de cavacos em duas partes idênticas, alimenta as duas zonas do mesmo refinador uniformemente. Aqui também existe um refinador primário da qual se segue para um secundário, de onde as fibras celulósicas são descarregadas a uma consistência de $45 \%$ para o tanque de latência.

Após o tanque de latência a pasta segue para os depuradores, onde é feita a remoção das impurezas e das fibras residuais contidas na polpa, o que pode prejudicar a qualidade da folha e causar quebras do papel na máquina. $A$ separação é feita em aceites e rejeitos. Os rejeitos das duas linhas são direcionados para um tanque e em seguida para as prensas de rejeitos. Nessa etapa, a água extraída é reutilizada no processo e o rejeito enviado para um refinador de rejeitos. Os aceites seguem para os filtros, que possuem a função de concentrar a massa a uma consistência entre 7 e 10\%. Posteriormente, a pasta é novamente diluída de forma controlada como parte do processo de lavagem.

Dois tipos de filtros executam a etapa de lavagem em duas linhas em paralelo: o filtro a tambor e o filtro a disco. O primeiro é constituído de um cilindro, com a parte externa revestida com uma tela fina, apoiado sobre uma chapa perfurada sobre as canaletas de drenagem. Cada canaleta está ligada através do eixo tubular até a válvula de vácuo, localizada em uma das 
extremidades do tambor. As fibras da pasta ficam retidas na tela e a água é coletada nas canaletas. O segundo filtro é constituído por discos com telas posicionados paralelamente uns aos outros. Os discos possuem dupla face e funcionam com vácuo. A pasta circula lateralmente às telas sendo succionadas e aderidas na tela dos discos. Os discos giram lentamente e as fibras são coletadas na parte superior do equipamento através de jatos de água com pressão suficiente para descolar as fibras da tela. A pasta diluída é estocada e a água extraída retorna ao processo. A pasta é estocada em um tanque de pasta não branqueada, da qual pode ser enviada para uma torre de branqueamento ou para uma torre de estocagem de TMP.

\subsubsection{Preparação de Massa para a Fabricação do Papel}

A pasta celulósica é estocada a uma consistência de aproximadamente $5 \%$. $\mathrm{Na}$ descarga do tanque, a pasta de celulose é diluída com água branca, isto é, com a água proveniente do desaguamento na máquina de papel, e bombeada para o refinador. A refinação da celulose ocorre entre os discos dos refinadores. A maior ou menor quantidade de fibrilos formados depende do grau de aproximação entre os discos do refinador. Com os discos mais próximos, existe um maior grau de refinação e um consumo de energia maior. O grau de refinação necessário da celulose é determinado a partir das propriedades do produto final, o papel. A partir do monitoramento, principalmente da resistência à tração e ao rasgo, o operador tem uma referência sobre o grau de refinação a ser aplicado à celulose. Uma maior refinação tende a aumentar a resistência à tração e a diminuir a resistência ao rasgo. Fica claro aqui que existem dois processos com o mesmo nome de refinação: o desmembramento de fibras da estrutura da madeira, para produzir pasta celulósica de alto rendimento em TMP, e o tratamento mecânico de pastas celulósicas para melhorar as propriedades do papel produzido na máquina de papel.

A presente unidade fabril tem uma característica diferente, a de submeter à refinação apenas a pasta celulósica Kraft adquirida. A pasta de celulose 
refinada é misturada com as demais matérias-primas constituintes do papel, ou seja: pasta mecânica, pasta termomecânica, celulose, refugo e massa recuperada. O tanque de mistura recebe a proporção desejada de cada um dos componentes. O refugo é bombeado de tanques contendo resíduos de papéis, que são continuamente gerados durante a seção de formação para obter a largura desejada da folha na máquina de papel. Problemas operacionais como falha na formação de bobinas ou quebras de folha na máquina de papel também geram resíduos, porém de forma periódica. Resíduos ainda são gerados durante o início da produção, pois é um período necessário para a estabilização do processo. O refugo é engrossado em um filtro e posteriormente estocado.

\subsubsection{Circuito de Baixa Consistência na Fabricação do Papel}

No setor de preparação de massa, a mistura possui uma consistência ajustada de aproximadamente 3\%. A polpa deve então ser diluída e depurada para que possa seguir para a caixa de entrada da máquina de papel com características desejáveis para uma boa formação do papel. A mistura é alimentada na caixa de nível, onde é garantida uma pressão constante da caixa de nível na alimentação. A alimentação da mistura ocorre na saída do tanque de água branca, sendo em seguida admitida na bomba de mistura, após ter sido diluída com a água branca para uma consistência da ordem de $1 \%$.

A pasta proveniente da bomba de mistura é bombeada para o sistema de tratamento para retirar pequenos resíduos. O último tratamento da pasta antes de ser admitida na máquina de papel é uma depuração e desaeração. Estas duas operações são efetuadas em um sistema de cleaners que consiste essencialmente de um conjunto de depuradores centrífugos arranjados em quatro estágios, dos quais os três primeiros estão ligados a um sistema de vácuo. As frações aceitas do primeiro, segundo e terceiro estágios são alimentadas em um tubulão coletor horizontal, bipartido 
verticalmente. A mistura é bombeada com vazão constante para os depuradores do sistema de cleaners, composto por quatro estágios.

\subsubsection{Fabricação de Papel}

Um diagrama simplificado da fabricação de papel imprensa está mostrado na figura 3.3. Neste item, pelo fato de possuir grande importância no circuito de água, cada etapa do processo de fabricação de papel será explicada.

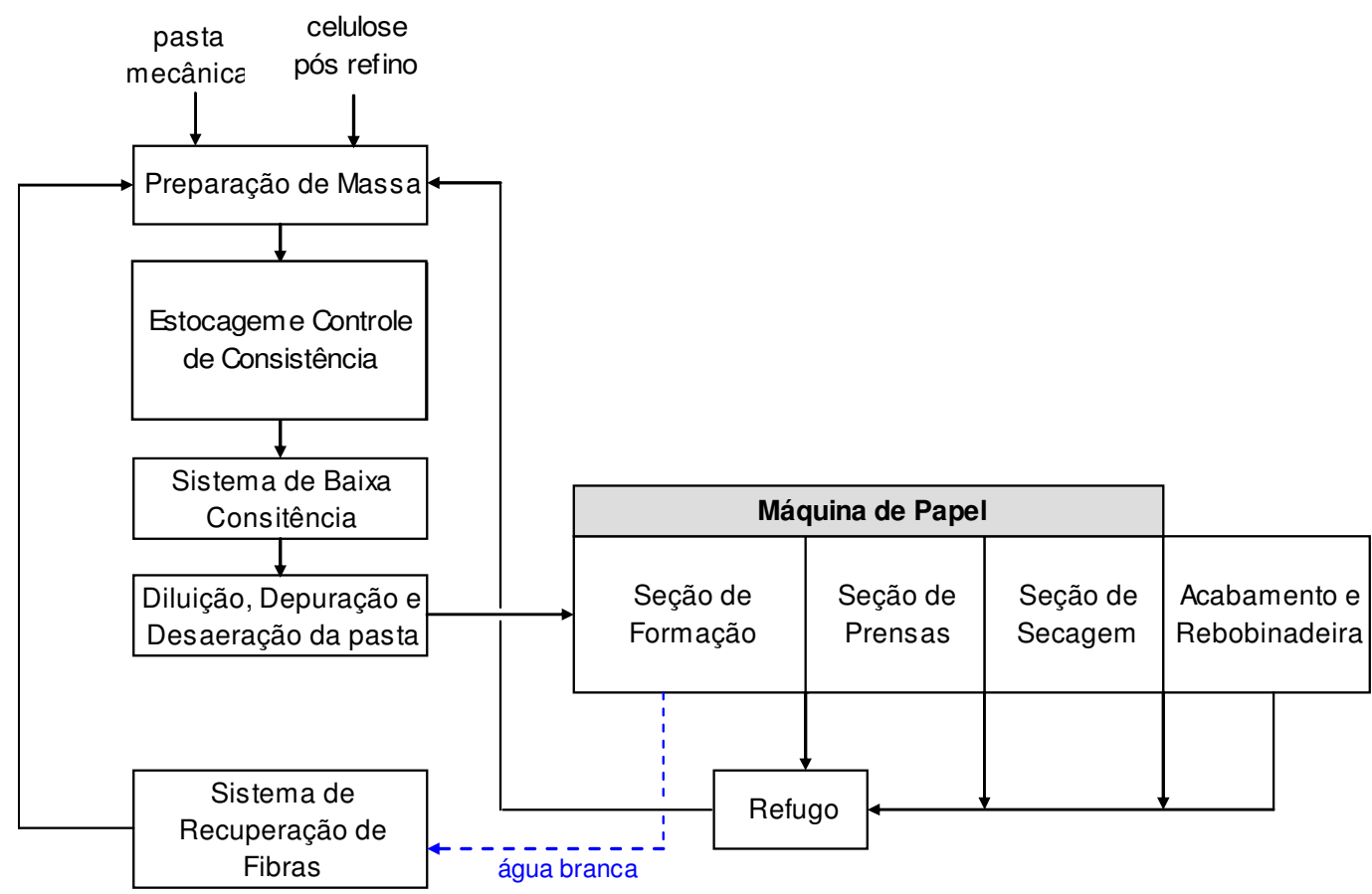

Figura 3.3. Diagrama simplificado do sistema de fabricação de papel.

\subsubsection{Sistema de Recuperação de Fibras da Fabricação do Papel}

A água branca extraída na seção de formação tem um teor considerável de fibras. E com esse objetivo, o sistema de recuperação de fibras é normalmente implantado para a separação de dois componentes: água e fibras.

Para essa finalidade, dois filtros a disco operando em paralelo são utilizados. Porém antes de ser enviada para os equipamentos, é necessário aumentar o 
teor de fibras da água branca para facilitar a formação de uma camada filtrante. Isso é realizado através da adição de pasta termomecânica e/ou celulose para obter uma consistência mais adequada à função dos filtros.

O filtro é constituído por discos com telas de material sintético posicionados paralelamente um ao outro. Os discos possuem dupla face e funcionam sob pressão negativa. Conseqüentemente, a pasta que circula lateralmente às telas são succionadas e a massa aderida às paredes dos discos forma uma manta. Os discos, que estão parcialmente submersos, rotacionam lentamente para que as fibras sejam coletadas na parte superior do equipamento através de jatos de água. A água utilizada para realizar os jatos é proveniente da própria água filtrada no equipamento.

\subsubsection{Caixa de Entrada da Máquina de Papel}

A caixa de entrada ocupa uma posição de extrema importância no processo de fabricação de papel e é responsável pela adição de massa com fibras em suspensão ao longo de toda a largura da máquina. O método de operação da caixa de entrada determina acentuadamente a qualidade da folha de papel, a capacidade produtiva e o grau de eficiência da máquina de papel.

A caixa de entrada recebe a polpa preparada e tem por função distribuir as fibras na tela da mesa de formação da folha. Ela é o elemento posicionador mais importante para o ajuste do perfil transversal do papel, mantendo uma gramatura estável e proporcionando uma orientação adequada das fibras. A caixa de entrada, distribuindo uniformemente as fibras no sentido da máquina de papel durante longo tempo, procura garantir valores constantes das características físicas para o papel em cada ponto da folha fabricada.

A suspensão de fibras deve entrar na tela desaguadora com as seguintes características: jato fechado no sentido transversal da tela, espessura do jato calibrada, mistura homogênea, velocidade constante e com direção e sentidos fixos. Para obtenção de tais características é necessário que a 
polpa alimentada seja distribuída ao longo do bocal de saída com um jato calibrado. A estratificação da folha de papel nestas telas chama-se formação.

\subsubsection{Seção de Formação da Máquina de Papel}

O tipo de formador desta unidade fabril consiste de duas telas, onde o papel formado entre elas apresenta propriedades semelhantes em ambas as superfícies. Conseqüentemente há poucas diferenças entre as absorções de tinta em ambos os lados, proporcionando uma característica requerida pelos clientes, que normalmente processam a impressão nos dois lados. A seção possui um sistema completo de rolos que conduzem o funcionamento adequado das telas inferior e superior

A seção de pré-desaguamento é composta por mesa da tela, sistema de réguas e caixas de sucção úmidas. Nesta área apenas uma das superfícies do papel está em contato com a tela. A mesa da tela tem a função de suportar a tela ao receber o jato de massa vindo da caixa de entrada e constitui o primeiro elemento de desaguamento. O segundo elemento é uma caixa constituída de um sistema de réguas. Os últimos elementos de desaguamento da seção de pré-formação são as caixas de sucção úmidas, acionadas através de bombas de vácuo.

O vácuo é aumentado lentamente de acordo com o avanço da folha, desde a mesa da tela até o rolo formador, situado no início da seção. No rolo formador o desaguamento é feito através do vácuo existente nas câmaras de sucção e também devido à tensão da tela inferior contra a massa. A partir da primeira zona de sucção do rolo formador, o aumento de vácuo passa a ser mais acentuado sem afetar a retenção, pois neste ponto a folha já está praticamente formada.

Depois do rolo formador, tem-se na tela superior um defletor de sucção, que desvia a água expelida por centrifugação da camisa do rolo formador para 
uma calha de saída e que promove um desaguamento da folha pelo lado da tela superior.

As duas telas se separam sobre o rolo de sucção da tela, que conta com três zonas de vácuo, sendo que a folha permanece sobe a tela inferior. Após o rolo de sucção, a folha apresenta teores secos entre 16 e 18\%.

\subsubsection{Seção de Prensas da Máquina de Papel}

A prensagem é uma seção importante para a remoção de água da folha. Além disso, a seção pode proporcionar lisura, aumentar a densidade da folha e aumentar a operacionalidade da folha na área de secagem. A prensagem representa uma economia no custo de remoção de água, pois através do processo de evaporação, energia térmica é requerida. Porém como há dificuldades em extrair toda a água através de prensas, essa seção fica responsável por minimizar o consumo de vapor na seção de secagem.

A remoção de água ocorre quando a folha passa por um ponto de contato entre dois rolos. O feltro utilizado transporta a folha e absorve a água retirada durante a prensa.

\subsubsection{Seção de Secagem da Máquina de Papel}

O objetivo da secagem é a evaporação da água residual na folha de papel, após o processo de prensagem. A folha é conduzida à seção de secagem através de uma passagem que se torna mais fácil quanto mais seca estiver a folha, pois nesse estado a tensão que a folha consegue suportar é maior.

Os cilindros secadores estão dispostos em duas fileiras horizontais, de modo que a folha passa alternadamente pela parte superior dos cilindros superiores e pela parte inferior dos cilindros inferiores. A folha úmida passa pelas duas fileiras de cilindros secadores até atingir um teor seco de aproximadamente $90 \%$. A água é gradualmente evaporada e arrastada pelo 
ar quente. Na passagem do papel pelos cilindros secadores, a folha absorve o calor sensível do vapor que aquece os cilindros. Em seguida ocorre a evaporação com liberação de vapor no espaço entre os cilindros, provocando dessa maneira, um esfriamento na folha, que fica apta a absorver calor sensível novamente.

\subsection{Dados coletados}

Foram necessárias visitas técnicas de alguns dias à unidade fabril com o objetivo de coletar os dados mais importantes para o balanço no simulador. Houve algumas ocorrências inesperadas durante a produção diária, impedindo dessa maneira, a coleta de todas as informações em uma mesma base de produção final. Sendo assim, valores de diferentes datas e horários foram coletados. Quando possível, históricos de informações de processo foram analisados. Mas devido a indisponibilidade de tempo dos operadores e do curto período de visita, a grande parte dos dados provém de valores instantâneos coletados de um a quatro vezes em dias e horários diferentes dependendo da importância da corrente para o balanço no simulador.

A maior parte dos valores foi coletada em telas do SDCD - Sistema Digital de Controle Distribuído, que acompanha os valores de produção através de medidores de campo. Valores necessários, porém não disponíveis no SDCD, foram extraídos de históricos de produção. Houve valores baseados na experiência de operadores e engenheiros de cada área. A consistência de rejeitos e aceites de alguns depuradores, assim como a vazão de água para os chuveiros dos filtros, são exemplos de alguns dados não medidos sistematicamente, cujos valores foram anotados após reuniões com engenheiros e operadores.

O balanço mássico preliminar de Oliveira (2004) desta unidade fabril foi utilizado como referência para analisar diferenças. Outros dados não medidos e necessários para a simulação foram baseados em fluxogramas de projeto ou estimados, em último caso, através do diâmetro de tubulação. 
Em uma unidade industrial dificilmente há instalações completas com medidores de vazão, gerando assim, uma grande barreira para projetos que necessitem de um estudo para aumentar a eficiência no uso de água e energia.

Ainda assim, os dados são considerados coerentes com as faixas de variações naturais de uma unidade real, que nunca está em regime permanente total, e estas análises vêm da experiência do autor quando auxiliou Oliveira (2004) na análise preliminar deste trabalho de 2004. Por saber destas dificuldades de conciliação de dados industriais, os valores foram discutidos com os engenheiros, operadores e também com este autor do levantamento de 2004.

Portanto, tomou-se o cuidado de listar, na tabela 1, o modo como o dado foi coletado. Entretanto, deve-se lembrar de que, desde que os valores obtidos estejam consistentes com a experiência fabril, aqui o mais importante não são os valores em si destes dados, e sim, a coerência da construção do caso base de simulação, para ser utilizado em estudos de alternativas.

Por isso, mostra-se posteriormente, no presente trabalho, que o simulador apresenta bom fechamento geral dos valores das correntes, apesar da existência das inúmeras correntes de reciclos. Notadamente, para o usuário de simuladores de processos, reciclos são fontes de dificuldades de ajustes e "convergências" de resultados.

Naturalmente, nem todas as medidas coletadas foram utilizadas no trabalho. As tabelas 1 e 2 listam todos os valores coletados sem discriminar as que foram utilizadas para a construção do caso base. 


\subsubsection{Dados da produção de pasta termomecânica}

Tabela 1 - Dados coletados durante visita técnica no setor de TMP

\begin{tabular}{|c|c|c|c|c|}
\hline Geral & coletado & simulado & unidade & Observação \\
\hline Produção da TMP1 & 4,76 & 4,50 & $\mathrm{t} / \mathrm{h}$ & $\begin{array}{c}\text { SDCD } \\
\text { (média de 3 dias) }\end{array}$ \\
\hline Produção da TMP2 & 19,0 & 18,0 & $\%$ & $\begin{array}{c}\text { SDCD } \\
\text { (média de 3 dias) }\end{array}$ \\
\hline Água clara utilizada no período & 4948 & 4292 & $\mathrm{~m}^{3}$ & $\begin{array}{c}\text { boletim diário } \\
\text { (média 3 dias) }\end{array}$ \\
\hline $\begin{array}{c}\text { Água fresca utilizada } \\
\text { no período }\end{array}$ & 800 & 787 & $\mathrm{~m}^{3}$ & $\begin{array}{c}\text { boletim diário } \\
\text { (média 3 dias) }\end{array}$ \\
\hline $\begin{array}{c}\text { Toras consumidas no período } \\
\text { Gasto aproximado com energia } \\
\text { elétrica }\end{array}$ & 1780 & - & $\mathrm{m}^{3}$ & $\begin{array}{c}\text { SDCD } \\
\text { (média de 3 dias) }\end{array}$ \\
\hline $\begin{array}{c}\text { Vazão específica de químico } \\
\text { para branqueamento }\end{array}$ & 600000 & - & $\mathrm{US} \$ / \mathrm{mês}$ & $\begin{array}{c}\text { Informado pelo } \\
\text { engenheiro }\end{array}$ \\
\hline $\begin{array}{c}\text { Vapor para impregnação do } \\
\text { cavaco no dia }\end{array}$ & 106,0 & - & $\mathrm{t}$ & Coleta no SDCD \\
\hline
\end{tabular}

\begin{tabular}{|c|c|c|c|c|}
\hline Refinador primário (linha 2) & coletado & simulado & unidade & Observação \\
\hline Fluxo de entrada de cavaco & 280,0 & 260,0 & $\mathrm{~kg} / \mathrm{min}$ & $\begin{array}{c}\text { SDCD } \\
\text { (média de } 3 \text { dias) }\end{array}$ \\
\hline $\begin{array}{l}\text { Consistência de entrada } \\
\text { da polpa }\end{array}$ & 50 & 50 & $\%$ & $\begin{array}{l}\text { Informação de } \\
\text { projeto }\end{array}$ \\
\hline Consistência de saída da polpa & 45 & 45 & $\%$ & $\begin{array}{l}\text { Informação de } \\
\text { projeto }\end{array}$ \\
\hline $\begin{array}{l}\text { Água de diluição na } \\
\text { descarga do refinador }\end{array}$ & 185,0 & \multirow{2}{*}{356,2} & \multirow{2}{*}{$\mathrm{kg} / \mathrm{min}$} & \multirow{2}{*}{$\begin{array}{c}\text { SDCD } \\
\text { (média de } 3 \text { dias) }\end{array}$} \\
\hline Água de selagem & 180,0 & & & \\
\hline Rendimento do refinador & 98,0 & 98,9 & $\%$ & $\begin{array}{l}\text { Informação de } \\
\text { Projetos }\end{array}$ \\
\hline Potência consumida & 17,4 & 17,4 & MW & $\begin{array}{c}\text { SDCD } \\
\text { (média de } 3 \text { dias) }\end{array}$ \\
\hline
\end{tabular}

\begin{tabular}{|c|c|c|c|c|}
\hline Refinador secundário (linha 2) & coletado & simulado & unidade & \\
\hline $\begin{array}{c}\text { Consistência de entrada } \\
\text { da polpa }\end{array}$ & 45 & 45 & $\%$ & $\begin{array}{c}\text { Informação de } \\
\text { projeto }\end{array}$ \\
\hline Consistência de saída da polpa & 44 & 44 & $\%$ & $\begin{array}{c}\text { Informação de } \\
\text { projeto }\end{array}$ \\
\hline Água de selagem & 265,0 & 384,1 & $\mathrm{~kg} / \mathrm{min}$ & $\begin{array}{c}\mathrm{SDCD} \\
\text { (média de 3 dias) }\end{array}$ \\
\hline $\begin{array}{c}\text { Água de diluição na } \\
\text { descarga do refinador }\end{array}$ & 97,0 & 98,9 & $\%$ & $\begin{array}{c}\text { Informação de } \\
\text { Projetos }\end{array}$ \\
\hline Rendimento do refinador & 15,4 & 15,4 & $\mathrm{MW}$ & $\begin{array}{c}\text { SDCD } \\
\text { (média de 3 dias) }\end{array}$ \\
\hline Potência consumida & & &
\end{tabular}




\begin{tabular}{|c|c|c|c|c|}
\hline Refinador baixa consistência & coletado & simulado & unidade & \\
\hline Vazão de fibras & 286,8 & 271,9 & $\mathrm{~kg} / \mathrm{min}$ & Coleta no SDCD \\
\hline Consistência de saída da polpa & 3,5 & 2,8 & $\%$ & $\begin{array}{l}\text { Informação de } \\
\text { projeto }\end{array}$ \\
\hline Água de selagem & 174 & \multirow{2}{*}{200} & \multirow{2}{*}{$\mathrm{kg} / \mathrm{min}$} & \multirow{2}{*}{ Coleta no SDCD } \\
\hline $\begin{array}{l}\text { Água de diluição na } \\
\text { descarga do refinador }\end{array}$ & 177 & & & \\
\hline Rendimento do refinador & 97,0 & 98,9 & $\%$ & $\begin{array}{l}\text { Informação de } \\
\text { Projetos }\end{array}$ \\
\hline Potência consumida & 1,098 & 1,10 & MW & Coleta no SDCD \\
\hline
\end{tabular}

\begin{tabular}{|c|c|c|c|c|}
\hline Tanque de Latência (linha 2) & coletado & simulado & unidade & \\
\hline Temperatura de Latência & 90 & 87 & ${ }^{\circ} \mathrm{C}$ & $\begin{array}{c}\text { SDCD } \\
\text { (média de 3 dias) }\end{array}$ \\
\hline $\begin{array}{c}\text { Vazão de água adicionada } \\
\text { para diluição }\end{array}$ & 5400 & 8279,3 & $\mathrm{~kg} / \mathrm{min}$ & $\begin{array}{c}\text { SDCD } \\
\text { (média de 3 dias) }\end{array}$ \\
\hline Consistência da Polpa & 3,0 a 4,5 & 2,9 & $\%$ & $\begin{array}{c}\text { Informado por } \\
\text { Operador }\end{array}$ \\
\hline
\end{tabular}

\begin{tabular}{|c|c|c|c|c|}
\hline Refinador primário (linha 1) & coletado & simulado & unidade & \\
\hline Fluxo de entrada de cavaco & 235 & 62 & $\mathrm{~kg} / \mathrm{min}$ & $\begin{array}{l}\text { Informado por } \\
\text { Operador }\end{array}$ \\
\hline $\begin{array}{c}\text { Consistência de entrada } \\
\text { da polpa }\end{array}$ & 50 & 50 & $\%$ & $\begin{array}{l}\text { Informação de } \\
\text { projeto }\end{array}$ \\
\hline Vazão de saída da polpa & 43 a 45 & 40 & $\mathrm{~kg} / \mathrm{min}$ & Coleta no SDCD \\
\hline Consistência de saída da polpa & 30 a 35 & 38 & $\%$ & $\begin{array}{l}\text { Informação de } \\
\text { projeto }\end{array}$ \\
\hline $\begin{array}{l}\text { Água de diluição na } \\
\text { descarga do refinador }\end{array}$ & 150 & 94 & $\mathrm{~kg} / \mathrm{min}$ & Coleta no SDCD \\
\hline Rendimento do refinador & 97,0 & 98,9 & $\%$ & $\begin{array}{l}\text { Informação de } \\
\text { Projetos }\end{array}$ \\
\hline Potência consumida & 6,5 & 6,5 & MW & Coleta no SDCD \\
\hline
\end{tabular}

\begin{tabular}{|c|c|c|c|c|}
\hline Refinador de rejeitos & coletado & simulado & unidade & \\
\hline $\begin{array}{c}\text { Consistência de entrada } \\
\text { da polpa }\end{array}$ & 28 a 30 & 32 & $\%$ & $\begin{array}{c}\text { Informação de } \\
\text { projeto }\end{array}$ \\
\hline Consistência de saída da polpa & 26 a 28 & 29 & $\%$ & $\begin{array}{c}\text { Informação de } \\
\text { projeto }\end{array}$ \\
\hline água de diluição & 135,0 & 61,5 & $\mathrm{~kg} / \mathrm{min}$ & $\begin{array}{c}\text { Coleta no SDCD } \\
\text { Rendimento do refinador }\end{array}$ \\
\hline Potência consumida & 6 & 98,0 & $\%$ & $\begin{array}{c}\text { Informação de } \\
\text { Projetos }\end{array}$ \\
\hline Coleta no SDCD \\
\hline
\end{tabular}




\begin{tabular}{|c|c|c|c|c|}
\hline Depuração 1a (linha 2) & coletado & simulado & unidade & \\
\hline Vazão de entrada da polpa & 8440,0 & 9394,6 & $\mathrm{~kg} / \mathrm{min}$ & Coleta no SDCD \\
\hline $\begin{array}{l}\text { Consistência de entrada } \\
\text { da polpa }\end{array}$ & 3,5 a 4,5 & 2,9 & $\%$ & $\begin{array}{l}\text { Informado por } \\
\text { Operador }\end{array}$ \\
\hline Consistência do aceite & 2,5 a 3,0 & 2,2 & $\%$ & $\begin{array}{l}\text { Informado por } \\
\text { Operador }\end{array}$ \\
\hline$\%$ de rejeitos & 57,0 & 38,0 & $\%$ & Coleta no SDCD \\
\hline Vazão de aceite & 4260,0 & 5800,0 & $\mathrm{~kg} / \mathrm{min}$ & $\begin{array}{l}\text { Informação de } \\
\text { projeto }\end{array}$ \\
\hline Consistência do rejeito & 4,0 a 4,5 & 3,7 & $\%$ & $\begin{array}{l}\text { Informado por } \\
\text { Operador }\end{array}$ \\
\hline
\end{tabular}

\begin{tabular}{|c|c|c|c|c|}
\hline Depuração 1aㅗ (linha 1) & coletado & simulado & unidade & \\
\hline Vazão de entrada da polpa & 4440,0 & 5375,6 & $\mathrm{~kg} / \mathrm{min}$ & $\begin{array}{l}\text { Informação de } \\
\text { projeto }\end{array}$ \\
\hline $\begin{array}{l}\text { Consistência de entrada } \\
\text { da polpa }\end{array}$ & 3,5 a 4,5 & 2,93 & $\%$ & $\begin{array}{l}\text { Informado por } \\
\text { Operador }\end{array}$ \\
\hline Consistência do aceite & 2,70 & 2,88 & $\%$ & $\begin{array}{l}\text { Informado por } \\
\text { Operador }\end{array}$ \\
\hline \% vazão de rejeitos & 14,0 & 21,39 & $\%$ & Coleta no SDCD \\
\hline Vazão de aceite & 3260,0 & 4225,6 & $\mathrm{~kg} / \mathrm{min}$ & $\begin{array}{l}\text { Informação de } \\
\text { projeto }\end{array}$ \\
\hline Consistência do rejeito & 3,5 a 4,5 & 3,1 & $\%$ & $\begin{array}{l}\text { Informado por } \\
\text { Operador }\end{array}$ \\
\hline
\end{tabular}

\begin{tabular}{|c|c|c|c|c|}
\hline Depuração 2a (linha 2) & coletado & simulado & unidade & \\
\hline $\begin{array}{c}\text { Consistência de entrada } \\
\text { da polpa }\end{array}$ & 2,5 a 3,5 & 3,66 & $\%$ & $\begin{array}{c}\text { Informado por } \\
\text { Operador }\end{array}$ \\
\hline Consistência do aceite & 2,5 a 3,5 & 2,97 & $\%$ & $\begin{array}{c}\text { Informado por } \\
\text { Operador }\end{array}$ \\
\hline$\%$ de rejeitos & 62,0 & 40,0 & $\%$ & Coleta no SDCD \\
\hline Consistência do rejeito & 3,5 a 4,5 & 4,66 & $\%$ & $\begin{array}{c}\text { Informado por } \\
\text { Operador }\end{array}$ \\
\hline
\end{tabular}

\begin{tabular}{|c|c|c|c|c|}
\hline Filtros Engrossadores tambor & coletado & simulado & unidade & \\
\hline Vazão de entrada da polpa & 5520,0 & 5957,3 & $\mathrm{~kg} / \mathrm{min}$ & Coleta no SDCD \\
\hline $\begin{array}{c}\text { Consistência de entrada } \\
\text { da polpa }\end{array}$ & 2,5 a 3,5 & 2,4 & $\%$ & $\begin{array}{c}\text { Informado por } \\
\text { Operador }\end{array}$ \\
\hline Consistência da água filtrada & 0,05 & 0,05 & $\%$ & $\begin{array}{c}\text { Informado por } \\
\text { Operador }\end{array}$ \\
\hline Vazão de polpa engrossada & 2380,0 & 2071,4 & $\mathrm{~kg} / \mathrm{min}$ & Coleta no SDCD \\
\hline $\begin{array}{c}\text { Consistência da polpa } \\
\text { engrossada }\end{array}$ & 6,5 a 7,5 & 6,5 & $\%$ & Coleta no SDCD \\
\hline
\end{tabular}




\begin{tabular}{|c|c|c|c|c|}
\hline Filtros Engrossadores disco & coletado & simulado & unidade & \\
\hline Vazão de entrada da polpa & 3260 & 4225,6 & $\mathrm{~kg} / \mathrm{min}$ & $\begin{array}{c}\text { Informação de } \\
\text { projeto }\end{array}$ \\
\hline $\begin{array}{c}\text { Consistência de entrada } \\
\text { da polpa }\end{array}$ & 2,5 a 3,5 & 2,9 & $\%$ & $\begin{array}{c}\text { Informado por } \\
\text { Operador }\end{array}$ \\
\hline $\begin{array}{c}\text { Consistência da água } \\
\text { filtrada turva }\end{array}$ & 0,05 & 0,05 & $\%$ & $\begin{array}{c}\text { Informação de } \\
\text { projeto }\end{array}$ \\
\hline $\begin{array}{c}\text { Consistência da água } \\
\text { filtrada clara }\end{array}$ & 0,03 & 0,03 & $\%$ & $\begin{array}{c}\text { Informação de } \\
\text { projeto }\end{array}$ \\
\hline Consistência da polpa & 6,5 & 6,5 & $\%$ & $\begin{array}{c}\text { Informação de } \\
\text { projeto }\end{array}$ \\
\hline
\end{tabular}

\begin{tabular}{|c|c|c|c|c|}
\hline Prensa de Rejeitos & coletado & simulado & unidade & \\
\hline Vazão de entrada de rejeitos & 2950,0 & 2076,0 & $\mathrm{~kg} / \mathrm{min}$ & $\begin{array}{c}\text { Informação de } \\
\text { projeto }\end{array}$ \\
\hline $\begin{array}{c}\text { Consistência de entrada } \\
\text { da polpa }\end{array}$ & 2,5 a 3,5 & 2,4 & $\%$ & $\begin{array}{c}\text { Informação de } \\
\text { projeto }\end{array}$ \\
\hline Vazão de saída de água filtrada & 2400,0 & 1856,6 & $\mathrm{~kg} / \mathrm{min}$ & $\begin{array}{c}\text { Informação de } \\
\text { projeto }\end{array}$ \\
\hline Consistência da água filtrada & 0,5 & 0,5 & $\%$ & $\begin{array}{c}\text { Informado por } \\
\text { Operador }\end{array}$ \\
\hline Vazão de polpa prensada & 320,0 & 229,3 & $\mathrm{~kg} / \mathrm{min}$ & $\begin{array}{c}\text { Informação de } \\
\text { projeto }\end{array}$ \\
\hline Consistência da polpa prensada & $\begin{array}{c}28,0 \mathrm{a} \\
32,0\end{array}$ & 29,0 & $\%$ & $\begin{array}{c}\text { Informado por } \\
\text { Operador }\end{array}$ \\
\hline
\end{tabular}

\subsubsection{Dados da produção de Papel Imprensa}

Tabela 2 - Dados coletados durante visita técnica na máquina de papel

\begin{tabular}{|c|c|c|c|c|}
\hline Área da Produção de Papel & coletado & simulado & unidade & Observação \\
\hline Produção de Papel & 21,5 & 22,0 & $\mathrm{t} / \mathrm{h}$ & Coleta no SDCD \\
\hline Teor seco na saída da secagem & $\begin{array}{l}91,0 \mathrm{a} \\
91,5\end{array}$ & 91,2 & $\%$ & Coleta no SDCD \\
\hline Teor seco na saída das prensas & 42 a 43 & 44,0 & $\%$ & $\begin{array}{l}\text { Informação de } \\
\text { projeto }\end{array}$ \\
\hline $\begin{array}{l}\text { Teor seco na entrada } \\
\text { das prensas }\end{array}$ & $\begin{array}{c}13,5 \mathrm{a} \\
14,5\end{array}$ & 13,0 & $\%$ & $\begin{array}{l}\text { Informação de } \\
\text { projeto }\end{array}$ \\
\hline Largura da Máquina & 6,7 & - & $\mathrm{m}$ & $\begin{array}{l}\text { Informação de } \\
\text { projeto }\end{array}$ \\
\hline Gramatura do Papel & 2400 & - & $\mathrm{g} / \mathrm{cm}^{2}$ & $\begin{array}{l}\text { Informado por } \\
\text { Operador }\end{array}$ \\
\hline Velocidade da tela & 1190 & - & $\mathrm{m} / \mathrm{min}$ & Coleta no SDCD \\
\hline $\begin{array}{l}\text { Consistência da celulose para a } \\
\text { preparação de massa }\end{array}$ & 3,0 a 4,0 & 3,5 & $\%$ & $\begin{array}{l}\text { Informado por } \\
\text { Operador }\end{array}$ \\
\hline
\end{tabular}




\begin{tabular}{|c|c|c|c|c|}
\hline Área da Produção de Papel & coletado & simulado & unidade & Observação \\
\hline $\begin{array}{c}\text { Consistência da TMP para a } \\
\text { preparação de massa }\end{array}$ & 3,5 a 4,0 & 3,5 & $\%$ & $\begin{array}{c}\text { Informado por } \\
\text { Operador }\end{array}$ \\
\hline $\begin{array}{c}\text { Consistência da água branca } \\
\text { extraída da seção de formação }\end{array}$ & $\begin{array}{c}0,45 \text { a } \\
0,55\end{array}$ & 0,40 & $\%$ & $\begin{array}{c}\text { Informação de } \\
\text { projeto }\end{array}$ \\
\hline $\begin{array}{c}\text { Vazão de massa que entra na } \\
\text { caixa de entrada }\end{array}$ & 54234,0 & 54015,6 & $\mathrm{~kg} / \mathrm{min}$ & Coleta no SDCD \\
\hline $\begin{array}{c}\text { Consistência da massa que } \\
\text { entra na caixa de entrada }\end{array}$ & 0,98 a 1 & 1,00 & $\%$ & Coleta no SDCD \\
\hline $\begin{array}{c}\text { Consumo de água fresca } \\
\text { Vazão de água branca para } \\
\text { recup. de fibras (filtro 1) }\end{array}$ & 4927,7 & 4928,0 & $\mathrm{~m} / \mathrm{dia}$ & $\begin{array}{c}\text { boletim diário } \\
\text { (média 4 dias) }\end{array}$ \\
\hline $\begin{array}{c}\text { Potência consumida do } \\
\text { refinador 1 }\end{array}$ & 405 & 405 & $\mathrm{~kW}$ & Coleta no SDCD \\
\hline $\begin{array}{c}\text { Potência consumida do } \\
\text { refinador 2 }\end{array}$ & 420 & 420 & $\mathrm{~kW}$ & Coleta no SDCD \\
\hline $\begin{array}{c}\text { Potência consumida do } \\
\text { refinador 3 }\end{array}$ & 242 & 242 & $\mathrm{~kW}$ & Coleta no SDCD \\
\hline $\begin{array}{c}\text { Vazão de água branca para } \\
\text { recup. de fibras (filtro 2) }\end{array}$ & 9816,0 & 13626,2 & $\mathrm{~kg} / \mathrm{min}$ & Coleta no SDCD \\
\hline $\begin{array}{c}\text { \% de TMP na preparação de } \\
\text { massa }\end{array}$ & 68,0 & 65,0 & $\%$ & Coleta no SDCD \\
\hline $\begin{array}{c}\text { \% de celulose na preparação de } \\
\text { massa }\end{array}$ & 7,6 & 5,7 & $\%$ & Coleta no SDCD \\
\hline
\end{tabular}

Obs: a coluna de valores simulados refere-se a resultados obtidos na seção "3.5 - Resultados da Simulação do Caso Base" 


\subsection{Simulação}

Um simulador de processo, para os engenheiros químicos, é um programa de computador que calcula balanços de massa e energia do processo produtivo. Esses simuladores, em comparação a cálculos manuais por calculadoras e planilhas eletrônicas, aumentam a qualidade e reduzem os custos de projeto de um processo. As documentações ficam mais compreensíveis, especialmente para problemas complexos e em larga escala. Permitem facilmente as análises de alternativas, além de uma poderosa padronização de estudo ao se calcular balanços mássicos e energéticos. Conseqüentemente, a interação entre o objeto de estudo e as pessoas passa a ser de forma dinâmica e padronizada.

As técnicas de simulação podem ser classificadas quanto à linguagem de computador como orientadas a equações ou orientada a correntes, e também quanto a processos como dinâmico ou estacionário. Na simulação dinâmica pode ser classificada como sistema contínuo ou discreto, e na simulação em regime estacionário como simultâneo ou seqüencial.

\subsubsection{Simulador CadSim}

O CadSim ${ }^{1}$, orientado ao processo dinâmico, foi escolhido para analisar os balanços mássicos e energéticos. O software foi utilizado para simular a integração das duas linhas de produção de TMP com a máquina de papel imprensa da fábrica em análise.

Esse simulador possui uma eficiente interface gráfica que permite ao usuário construir um fluxograma de processo de forma rápida e dinâmica, possibilitando a criação de simulações de processos existentes ou em projeto. É uma ferramenta capaz de fazer balanços mássicos e energéticos em vários processos químicos em condições dinâmicas. Pode ser utilizado

\footnotetext{
${ }^{1}$ www.aurelsystems.com
} 
para projetar, encontrar soluções para processo de desgargalamento, analisar problemas de controle, aumentar eficiência de processo, e treinar operadores de uma unidade fabril.

O Cadsim proporciona uma interface de simulação em tempo real, onde o desenho original se torna uma ferramenta de simulação animada e interativa. O usuário pode alterar condições do processo durante a simulação, oferecendo um método eficaz de análise. Os resultados são atualizados automaticamente a cada iteração e podem ser posicionados em qualquer local do desenho.

É possível acessar as funções em tempo real de qualquer objeto de simulação para alterar, por exemplo, as propriedades de um controlador ou set-points. É possível incluir animações para demonstrar nível de tanque, condições de bombas ou a abertura e o fechamento de válvulas.

O simulador é de interesse especial a engenheiros de processos para analisar problemas operacionais, predizer futuras condições de processo, e pesquisar soluções para controle dinâmico ou problemas de estabilidade em uma unidade industrial. Alguns exemplos de usos de simulação dinâmica em projetos e operação de processos incluem:

- Análise e otimização:

- Processo para otimizar a qualidade e custo de operação.

- Estudo de condições futuras de operação.

- Gerenciamento de água através do controle de redução e uso.

- Estudos de condições transientes

- Estudos de condições operacionais por conceito: "What if"

- Análise de requisitos para parada e partida da unidade industrial.

- Gerenciamento de produção através de interações entre áreas

- Estudos energéticos

- Estudos para fechamento de circuitos 
- Programação de seqüências de operações

- Treinamento de operadores

- Controle de processo e ajuste de propriedades.

- Desenvolvimento de estratégia para controle e construção de modelos.

\subsubsection{Objetos para simulação do Caso Base}

A interpretação do desenho no Cadsim é feita através de bibliotecas dinamicamente carregadas com blocos de simulação como equipamentos, controladores, lógicas, etc. O simulador possui uma biblioteca específica com módulos para simular processos da área de celulose e papel. Portanto, o software é adequado para o estudo de caso do presente trabalho, onde o foco é a polpação mecânica para fabricação de papel imprensa.

O Cadsim possui modo de desenho para construir o modelo do fluxograma de processo. É possível inserir de forma rápida um objeto de trabalho a partir das bibliotecas incluídas no Cadsim, ou fazer seu próprio desenho com características e formas desejadas. Formas mais familiares para visualização são importantes durante o processo de simulação. Os módulos mais importantes utilizados durante a simulação do presente trabalho foram:

- Refinador de Cavacos

- Depurador

- Tanques

- Filtros, Prensas e Lavadores

- Máquina de Papel (subdivididos em vários objetos)

As seguintes variáveis na entrada e na saída são atribuídas para cada corrente de polpa: vazões de água, fibras e sólidos dissolvidos, temperatura, consistência, concentração de sólidos dissolvidos, entalpia e fluxo total da 
corrente. Para o componente vapor, as principais variáveis são: vazão, temperatura e pressão, fluxo volumétrico e entalpia do vapor.

\subsubsection{Refinador de Cavacos}

O módulo simula a refinação de cavacos para produzir pasta refinada, gerando vapor como subproduto. Quando frações de fibras estão presentes, a redução das grandes frações sujeita a um alto nível energético é descrita por relações exponenciais. Se mais energia é aplicada, a redução da fração de fibra tende a ser mais severa, e vice versa. A natureza dessa variação é específica para cada refinador e deve ser caracterizado em cada caso.

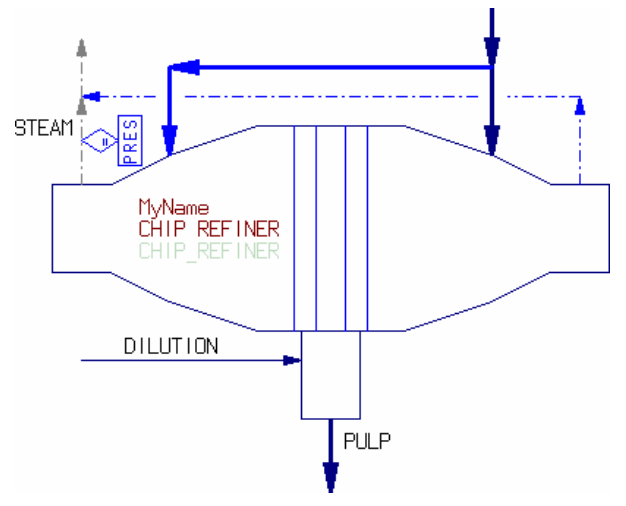

Correntes de entrada:

Cavacos ou polpa em alta consistência Água de diluição

Correntes de saída:

Vapor

Polpa refinada

Parâmetros do módulo:

Energia elétrica consumida

Rendimento do refinador

Consistência de entrada e saída do refinador

Figura 3.4 - Refinação de cavacos do Cadsim

A técnica adotada pelo objeto é baseada em um caso onde descreve-se a redução de fibras em um refinador particular sob condições típicas. Em essência, o caso típico diz que se uma alimentação com fração de fibra é refinada nesse refinador operando sob uma energia típica de refino, a polpa refinada conterá uma determinada fração.

A diluição da polpa é feita após o refino. Qualquer fibra que entra na água de diluição não será refinada. As fibras que são perdidas durante o refino são adicionadas ao componente previamente definido como ORGANIC. Se tal definição não for encontrada pelo objeto simulado, ele procura um 
componente definido como INORGANIC. Portanto, é de responsabilidade do usuário a definição correta dos componentes de simulação.

No estudo de caso foram utilizados cinco refinadores para simular as duas linhas de produção de TMP. No total há um refinador de cavacos na linha 1 e dois refinadores na linha 2, além de dois responsáveis pela refinação de rejeito de pastas de ambas as linhas.

\subsubsection{Depuração e Lavagem}

A depuração é uma etapa importante para alcançar uma boa qualidade de polpa e uma operação contínua da máquina de papel. Um único resíduo nocivo na polpa de aceite pode causar problemas na qualidade da operação e do produto.

A principal diferença entre depuração e lavagem está no objetivo de cada etapa. Enquanto a depuração rejeita fibras visando à homogeneidade nas propriedades dimensionais como espessura e comprimento, a lavagem proporciona uma adequação de densidade e área superficial das fibras. A configuração do sistema de depuração e lavagem depende da qualidade da polpa de aceita, da matéria prima utilizada, e do processo de polpação.

O módulo SCREEN realiza o balanço de aceites e rejeitos da polpa. $O$ módulo WASHER simula a lavagem de polpa usando a relação entre o fator de diluição e a taxa de deslocamento da manta formada nos filtros lavadores. Essa relação pode ser alterada de acordo com cada lavador, sendo possível, portanto, modelar diferentes equipamentos. 


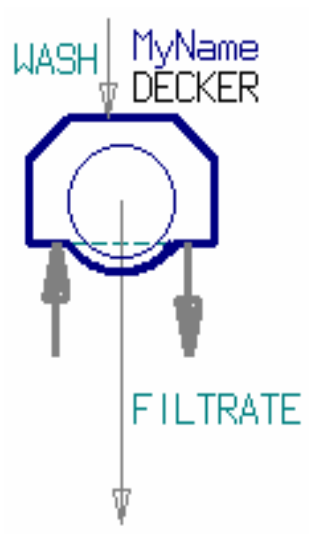

Correntes de entrada:

Polpa não lavada

Água para lavagem

Correntes de saída:

Filtrado

Polpa lavada

Parâmetros do módulo:

Consistência do filtrado

Consistência da polpa lavada

Taxa de deslocamento típico

Taxa de diluição típica

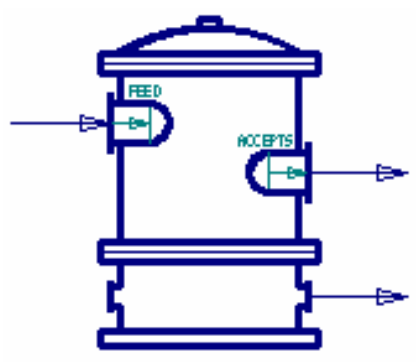

MyName

SCREEN
Correntes de entrada:

Polpa não depurada

Correntes de saída:

Aceites

Rejeitos

Parâmetros do módulo:

Consistência do aceite ou do rejeito

Figura 3.5 - Depuração e Lavagem do Cadsim

\subsubsection{Tanques}

O objeto CHEST modela o comportamento de uma mistura perfeita. Cada componente (M) é acumulado em um tanque pela diferença entre a entrada e saída:

$\frac{d m_{\mathrm{tank}}}{d t}=M_{\text {in }}-M_{\text {out }}$

As concentrações de saída e internas ao tanque são as mesmas, levando em consideração o conceito de mistura perfeita. 


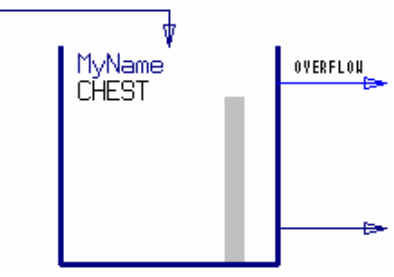

Figura 3.6 - Tanques do Cadsim

\subsubsection{Filtros Savel-all}

O objetivo principal é recuperar as fibras e a água, que pode ser reutilizada como fonte de diluição e lavagem. $\mathrm{O}$ objeto pode ser utilizado para analisar dois ou três tipos de filtrados, operação muito comum durante a fabricação de polpa e papel. Como observado na figura 3.7, há geração de água turva, água clara e água super clara. É aconselhável o usuário ter certeza de que a consistência de entrada da polpa está sempre entre a consistência da manta produzida e a consistência do filtrado.
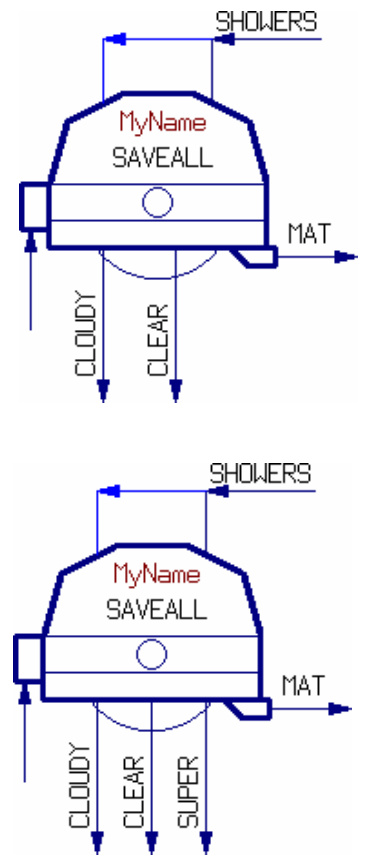

\section{Correntes de entrada:}

Água com baixa concentração de fibras

Água para chuveiros do filtro

\section{Correntes de saída:}

Água com maior concentração de fibras

Filtrado supeclaro (baixa concentração de fibras)

Filtrado claro (concentração de fibras maior que o superclaro)

Filtrado turvo (concentração de fibras maior que o claro)

Polpa com fibras recuperadas

\section{Parâmetros do módulo:}

Consistência da manta

Consistência dos dois filtrados

Porcentagem mássica do filtrado mais claro

Figura 3.7 - Filtros Save-all do Cadsim 


\subsubsection{Máquina de Papel}

A máquina de papel foi construída a partir de vários objetos, não possuindo portanto um módulo específico para a máquina. No Cadsim, é possível construir uma estrutura adequada ao processo em estudo. $O$ exemplo pode ser observado na montagem da simulação, que está representada pelas figuras 3.8 e 3.9 .

A máquina consiste principalmente de mesa de formação de folhas, sistema de prensas e secagem. Sendo assim, seus blocos podem ser representados basicamente por objetos que simulem extração de água e fibras.

\subsubsection{Estruturação do processo produtivo em CadSim}

Nas figuras 3.8 e 3.9 estão apresentados os processos desenvolvidos no simulador CadSim. A figura 3.8 descreve a produção de pasta termomecânica, a preparação de massa e a figura 3.9 o circuito da máquina de papel, perfazendo dessa maneira, uma estrutura única desenvolvida no simulador.

As principais etapas do processo produtivo da unidade fabril em estudo foram inseridas na simulação do balanço de massa. A partir dos objetos do Cadsim descritos nessa seção, juntamente com os dados coletados, iniciouse o processo de estruturação de correntes e equipamentos, como pode ser observado nas figuras 3.8 e 3.9 . 


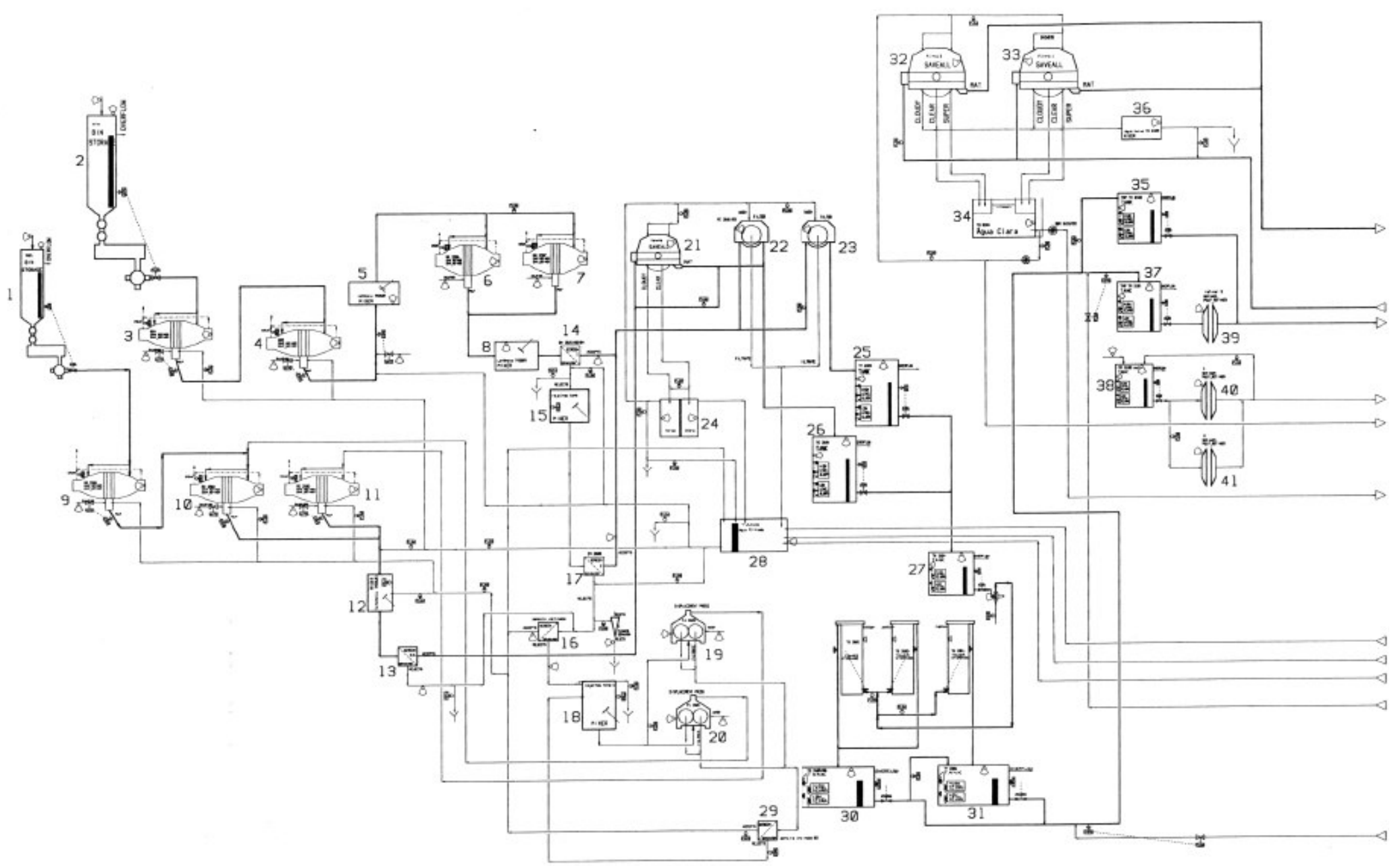

Figura 3.8 - Simulação do processo de refinação de cavaco, lavagem, filtração e preparação de massa em Cadsim 


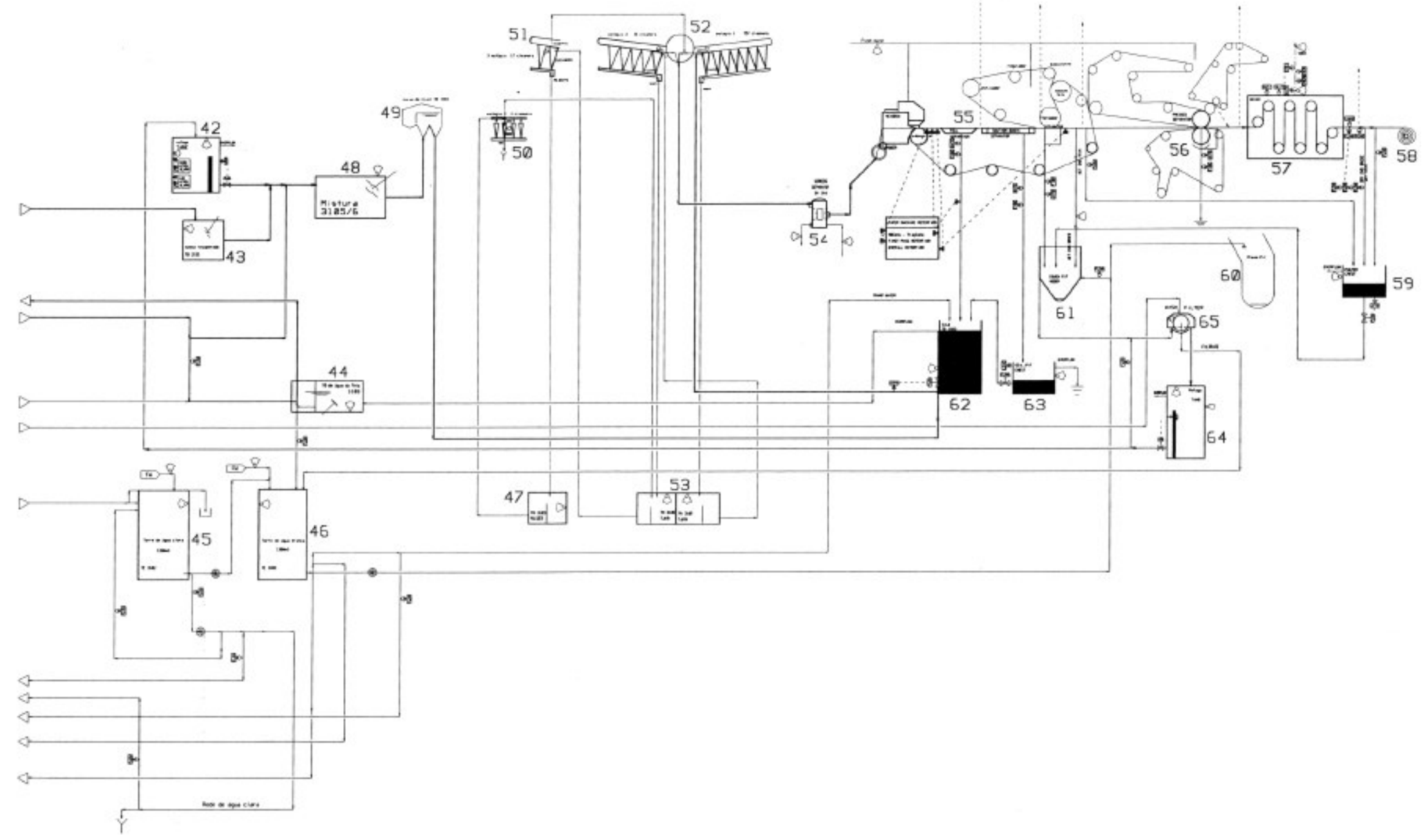

Figura 3.9 - Simulação do processo de fabricação de papel em Cadsim 
A estrutura foi dividida em três componentes: polpa, vapor, e produto químico para branqueamento. As variáveis mais importantes da corrente de polpa são vazões de sólidos dissolvidos, de fibras, de água e a temperatura, onde posteriormente são calculadas as consistências de cada corrente de polpa. O vapor é o componente gerado durante a etapa de refinação de cavacos, onde há um consumo de grande parte da energia elétrica utilizada na fábrica. Durante a simulação, é possível observar a vazão de vapor que é extraída como subproduto durante a refinação, assim como sua temperatura e pressão. E foi constatado que muitos valores estão bem próximos da realidade. O componente representado pelo produto químico possui importância menor para o resultado da simulação, pois sua vazão pode ser desconsiderada em relação às correntes de polpa e o processo produtivo não exige altos níveis de branqueamento.

As correntes de água fresca são representadas por correntes de polpa com concentração nula de fibras. A concentração de fibras em outras águas varia de acordo com o tipo de água gerado em determinados equipamentos do processo tais como, filtro prensa, filtro engrossador, máquina de papel, e peneiras inclinadas.

O cavaco proveniente do pátio de madeiras é considerado uma corrente de polpa com aproximadamente $50 \%$ fibras e $50 \%$ água, com uma concentração de sólidos dissolvidos nula. Após os refinadores, os sólidos passam a ser diferente de zero, pois dependendo do rendimento e da potência consumida no equipamento, sua concentração pode variar.

Os pontos de maior interesse estão nas etapas onde os diferentes tipos de água são gerados ou consumidos. Através de dados históricos de diferentes fábricas, sabe-se que o maior consumidor está no silo de água branca, onde a polpa misturada é diluída para atingir uma consistência adequada para a caixa de entrada. Ao mesmo tempo, sabe-se que o maior gerador de água está na seção de formação da máquina de papel. Através da tabela 3 de resultados da simulação, esse fato pode ser observado. Porém a ausência 
de medidores de vazão na fábrica impede a comparação de valores com dados reais da unidade fabril em estudo.

A água fresca é utilizada principalmente nos chuveiros de lavagem de rolos e telas da máquina. Quando há um desbalanceamento entre a produção de pastas e a produção de papel, água fresca também pode ser utilizada para make-up das torres de água branca. Porém isso ocorre de forma esporádica.

Como os dados foram coletados de diferentes fontes e datas, resultados mais coerentes com a produção real são conseguidos através de análises minuciosas da simulação. Dificilmente o modelo no simulador é estruturado com a complexidade de uma indústria existente, mas é possível chegar a um resultado bastante expressivo através de análises das correntes e etapas mais importantes do processo.

A produção final do balanço simulado é coerente com a produção de três dias normais. Porém isso foi feito após várias análises do processo integrado, pois alguns dados foram fornecidos verbalmente através de operadores especialistas.

\subsection{Resultados da Simulação do Caso Base}

Na tabela 3 estão listados os principais resultados da simulação envolvendo a produção de pasta mecânica e papel imprensa. A associação das correntes com as figuras 3.8 e 3.9 pode ser feita através da primeira coluna da tabela 3. Os dados de entrada coletados foram introduzidos na simulação e o sistema foi ajustado para atingir valores coerentes com a realidade. 
Tabela 3 - Resultados da simulação do processo produtivo para caso-base

\begin{tabular}{|c|c|c|c|c|c|}
\hline Módulo & Corrente & $\begin{array}{l}\text { Vazão } \\
\text { mássica } \\
\text { de água }\end{array}$ & $\begin{array}{l}\text { Vazão mássica } \\
\text { de Sólidos } \\
\text { dissolvidos }\end{array}$ & $\begin{array}{c}\text { Vazão } \\
\text { mássica } \\
\text { de fibras }\end{array}$ & Consistência \\
\hline № & Descrição & $\mathrm{kg} / \mathrm{min}$ & $\begin{array}{l}\mathrm{kg} / \mathrm{min} \text { ou } \\
\mathrm{ppm}\end{array}$ & $\mathrm{kg} / \mathrm{min}$ & $\%$ \\
\hline 2 & $\begin{array}{l}\text { Saída de cavaco do silo } \\
\text { (linha 2) }\end{array}$ & 260,0 & 0,00 & 260,00 & 50,000 \\
\hline 3 & $\begin{array}{l}\text { Entrada de polpa no } \\
\text { refinador primário (linha 2) }\end{array}$ & 260,0 & 0,00 & 260,00 & 50,000 \\
\hline 3 & $\begin{array}{l}\text { Água de diluição no } \\
\text { refinador primário (linha 2) }\end{array}$ & 356,2 & 4066 ppm & 0,30 & 0,082 \\
\hline 3 & $\begin{array}{l}\text { Saída de polpa do refinador } \\
\text { primário (linha 2) }\end{array}$ & 311,1 & 4,32 & 257,40 & 45,000 \\
\hline 4 & $\begin{array}{c}\text { Entrada de polpa no refinador } \\
\text { secundário (linha 2) }\end{array}$ & 311,1 & 4,32 & 257,40 & 45,000 \\
\hline 4 & $\begin{array}{c}\text { Água de diluição no refinador } \\
\text { secundário (linha 2) }\end{array}$ & 384,1 & 4066 ppm & 0,32 & 0,082 \\
\hline 4 & $\begin{array}{l}\text { Saída de polpa do refinador } \\
\text { secundário (linha 2) }\end{array}$ & 328,4 & 8,70 & 264,90 & 44,000 \\
\hline 5 & $\begin{array}{l}\text { Água de diluição antes do } \\
\text { tanque de latência }\end{array}$ & 8279,3 & 4066 ppm & 6,93 & 0,082 \\
\hline--- & Água fresca para TMP & 786,8 & 0,00 & 0,00 & 0,000 \\
\hline 5 & $\begin{array}{c}\text { Saída de polpa do tanque } \\
\text { de latência }\end{array}$ & 9394,3 & 42,50 & 271,90 & 2,800 \\
\hline 6 & $\begin{array}{l}\text { Entrada de polpa no } \\
\text { refinador baixa consistência }\end{array}$ & 4556,5 & 20,60 & 131,90 & 2,800 \\
\hline 6 & $\begin{array}{c}\text { Saída da polpa do refinador } \\
\text { baixa consistência }\end{array}$ & 4556,5 & 22,20 & 130,30 & 2,770 \\
\hline 7 & $\begin{array}{l}\text { Entrada de polpa no } \\
\text { refinador baixa consistência }\end{array}$ & 4838,1 & 21,90 & 140,00 & 2,800 \\
\hline 7 & $\begin{array}{c}\text { Saída de polpa do refinador } \\
\text { baixa consistência }\end{array}$ & 4838,1 & 23,60 & 138,30 & 2,770 \\
\hline 8 & $\begin{array}{l}\text { Saída de polpa do tanque } \\
\text { de latência }\end{array}$ & 9394,6 & 45,80 & 268,60 & 2,770 \\
\hline 14 & $\begin{array}{l}\text { Entrada de polpa na } \\
\text { depuração primária }\end{array}$ & 9394,6 & 45,80 & 268,60 & 2,770 \\
\hline 14 & $\begin{array}{c}\text { Aceite da } \\
\text { depuração primária }\end{array}$ & 5800,0 & 28,30 & 130,00 & 2,180 \\
\hline 14 & $\begin{array}{c}\text { Rejeito da } \\
\text { depuração primária }\end{array}$ & 3594,6 & 17,50 & 138,60 & 3,700 \\
\hline 14 & $\begin{array}{l}\text { Diluição de } \\
\text { rejeito primária }\end{array}$ & 39,8 & 4066 ppm & 0,03 & 0,082 \\
\hline 17 & $\begin{array}{l}\text { Entrada de polpa na } \\
\text { depuração secundária }\end{array}$ & 3511,1 & 17,10 & 133,90 & 3,660 \\
\hline 17 & $\begin{array}{l}\text { Aceite da depuração } \\
\text { secundária }\end{array}$ & 2100,0 & 10,20 & 64,50 & 2,970 \\
\hline 17 & $\begin{array}{l}\text { Rejeito da depuração } \\
\text { secundária }\end{array}$ & 1411,0 & 6,87 & 69,40 & 4,660 \\
\hline
\end{tabular}




\begin{tabular}{|c|c|c|c|c|c|}
\hline Módulo & Corrente & $\begin{array}{l}\text { Vazão } \\
\text { mássica } \\
\text { de água }\end{array}$ & $\begin{array}{l}\text { Vazão mássica } \\
\text { de Sólidos } \\
\text { dissolvidos }\end{array}$ & $\begin{array}{c}\text { Vazão } \\
\text { mássica } \\
\text { de fibras }\end{array}$ & Consistência \\
\hline № & Descrição & $\mathrm{kg} / \mathrm{min}$ & $\begin{array}{c}\mathrm{kg} / \mathrm{min} \text { ou } \\
\mathrm{ppm}\end{array}$ & $\mathrm{kg} / \mathrm{min}$ & $\%$ \\
\hline 17 & $\begin{array}{l}\text { Diluição de rejeito da } \\
\text { depuração secundária }\end{array}$ & 54,7 & $4066 \mathrm{ppm}$ & 0,05 & 0,082 \\
\hline 9 & $\begin{array}{l}\text { Entrada de polpa no } \\
\text { refinador primário (linha 1) }\end{array}$ & 62,0 & 0,00 & 62,00 & 50,000 \\
\hline 9 & $\begin{array}{l}\text { Água de diluição no } \\
\text { refinador primário (linha 1) }\end{array}$ & 94,0 & 4747 ppm & 0,28 & 0,300 \\
\hline 9 & $\begin{array}{l}\text { Saída de polpa do refinador } \\
\text { primário (linha 1) }\end{array}$ & 114,3 & 1,19 & 61,50 & 34,800 \\
\hline 10 & $\begin{array}{c}\text { Entrada de polpa no refinador } \\
\text { secundário (linha 1) }\end{array}$ & 244,5 & 1,77 & 114,90 & 31,800 \\
\hline 10 & $\begin{array}{c}\text { Água de diluição no refinador } \\
\text { secundário (linha 1) }\end{array}$ & 61,5 & 4747 ppm & 0,19 & 0,300 \\
\hline 10 & $\begin{array}{l}\text { Saída de polpa do refinador } \\
\text { secundário (linha 1) }\end{array}$ & 275,4 & 3,45 & 113,80 & 29,000 \\
\hline 11 & $\begin{array}{l}\text { Entrada de polpa no } \\
\text { refinador de rejeitos }\end{array}$ & 109,1 & 0,47 & 44,80 & 29,000 \\
\hline 11 & $\begin{array}{l}\text { Água de diluição no } \\
\text { refinador de rejeitos }\end{array}$ & 47,2 & $4747 \mathrm{ppm}$ & 0,14 & 0,300 \\
\hline 11 & $\begin{array}{c}\text { Saída de polpa do refinador } \\
\text { de rejeitos }\end{array}$ & 153,9 & 1,25 & 44,40 & 22,200 \\
\hline 12 & $\begin{array}{l}\text { Água de diluição do } \\
\text { tanque de latência }\end{array}$ & 4946,3 & 4066 ppm & 3,79 & 0,080 \\
\hline 13 & $\begin{array}{c}\text { Entrada de polpa na } \\
\text { depuração primária (linha 1) }\end{array}$ & 5375,6 & 25,20 & 163,20 & 2,930 \\
\hline 13 & $\begin{array}{l}\text { Aceite da depuração } \\
\text { primária (linha 1) }\end{array}$ & 4225,6 & 19,80 & 126,20 & 2,880 \\
\hline 13 & $\begin{array}{l}\text { Rejeito da depuração } \\
\text { primária (linha 1) }\end{array}$ & 1150,0 & 5,39 & 37,00 & 3,100 \\
\hline 19 & $\begin{array}{l}\text { Entrada de polpa } \\
\text { na prensa } 2\end{array}$ & 946,4 & 4,51 & 49,00 & 4,900 \\
\hline 19 & $\begin{array}{l}\text { Saída da Polpa } \\
\text { da Prensa } 2\end{array}$ & 109,1 & 0,47 & 44,80 & 29,000 \\
\hline 19 & Filtrado da Prensa 2 & 847,3 & 4747 ppm & 4,28 & 0,500 \\
\hline 20 & $\begin{array}{l}\text { Entrada de polpa } \\
\text { na prensa } 1\end{array}$ & 1129,6 & 5,39 & 58,50 & 4,900 \\
\hline 20 & $\begin{array}{l}\text { Saída da Polpa } \\
\text { da Prensa } 1\end{array}$ & 120,2 & 0,57 & 53,40 & 29,000 \\
\hline 16 & $\begin{array}{l}\text { Aceite da peneira inclinada } \\
\text { (após depuração) }\end{array}$ & 605,7 & $4747 \mathrm{ppm}$ & 2,44 & 0,400 \\
\hline 16 & $\begin{array}{l}\text { Rejeito da peneira inclinada } \\
\text { (após depuração) }\end{array}$ & 2000,6 & 9,54 & 103,60 & 4,900 \\
\hline 29 & $\begin{array}{c}\text { Entrada na peneira } \\
\text { inclinada (após prensa) }\end{array}$ & 1856,7 & 8,86 & 9,37 & 0,500 \\
\hline 29 & $\begin{array}{l}\text { Aceite da peneira inclinada } \\
\text { (após prensa) }\end{array}$ & 1781,2 & $4747 \mathrm{ppm}$ & 5,38 & 0,300 \\
\hline
\end{tabular}




\begin{tabular}{|c|c|c|c|c|c|}
\hline Módulo & Corrente & $\begin{array}{l}\text { Vazão } \\
\text { mássica } \\
\text { de água }\end{array}$ & $\begin{array}{l}\text { Vazão mássica } \\
\text { de Sólidos } \\
\text { dissolvidos }\end{array}$ & $\begin{array}{c}\text { Vazão } \\
\text { mássica } \\
\text { de fibras }\end{array}$ & Consistência \\
\hline № & Descrição & $\mathrm{kg} / \mathrm{min}$ & $\begin{array}{c}\mathrm{kg} / \mathrm{min} \text { ou } \\
\mathrm{ppm}\end{array}$ & $\mathrm{kg} / \mathrm{min}$ & $\%$ \\
\hline 29 & $\begin{array}{l}\text { Rejeito da peneira inclinada } \\
\text { (após prensa) }\end{array}$ & 75,4 & 0,36 & 3,99 & 5,000 \\
\hline 21 & $\begin{array}{l}\text { Entrada de polpa no } \\
\quad \text { filtro a disco }\end{array}$ & 4225,6 & 19,80 & 126,20 & 2,900 \\
\hline 21 & $\begin{array}{l}\text { Saída da polpa do } \\
\text { filtro a disco }\end{array}$ & 1795,0 & 8,41 & 125,40 & 6,500 \\
\hline 21 & Filtrado claro do filtro disco & 2537,3 & $4662 \mathrm{ppm}$ & 0,76 & 0,030 \\
\hline 21 & Filtrado turvo do filtro disco & 1087,2 & $4662 \mathrm{ppm}$ & 0,55 & 0,050 \\
\hline 21 & $\begin{array}{l}\text { Água do chuveiro do } \\
\text { filtro disco }\end{array}$ & 1193,9 & $4662 \mathrm{ppm}$ & 0,51 & 0,040 \\
\hline 22 & $\begin{array}{c}\text { Entrada de polpa no } \\
\text { conjunto de filtro a tambor } 1\end{array}$ & 5957,3 & 29,03 & 146,70 & 2,390 \\
\hline 22 & $\begin{array}{l}\text { Saída da polpa do conjunto } \\
\text { de filtro a tambor } 1\end{array}$ & 2071,4 & 10,05 & 144,70 & 6,500 \\
\hline 22 & $\begin{array}{l}\text { Filtrado do conjunto de filtro } \\
\text { tambor } 1\end{array}$ & 4097,7 & 4849 ppm & 2,06 & 0,050 \\
\hline 22 & $\begin{array}{l}\text { Água do chuveiro do } \\
\text { conjunto de filtro tambor } 1\end{array}$ & 211,8 & $4662 \mathrm{ppm}$ & 0,09 & 0,040 \\
\hline 23 & $\begin{array}{l}\text { Entrada de polpa no } \\
\text { conjunto de filtro tambor } 2\end{array}$ & 1942,7 & 9,47 & 47,80 & 2,390 \\
\hline 23 & $\begin{array}{c}\text { Saída da polpa do conjunto } \\
\text { de filtro tambor } 2\end{array}$ & 675,4 & 3,26 & 47,20 & 6,500 \\
\hline 23 & $\begin{array}{l}\text { Filtrado do conjunto de } \\
\text { filtro tambor } 2\end{array}$ & 1446,4 & 4849 ppm & 0,73 & 0,050 \\
\hline 23 & $\begin{array}{l}\text { Água do chuveiro do } \\
\text { conjunto de filtro tambor } 2\end{array}$ & 179,1 & $4662 \mathrm{ppm}$ & 0,08 & 0,040 \\
\hline 32 & $\begin{array}{l}\text { Entrada de polpa no } \\
\quad \text { filtro save all } 2\end{array}$ & 13626,2 & 34,00 & 139,90 & 1,010 \\
\hline 32 & $\begin{array}{l}\text { Saída da polpa do } \\
\text { filtro save all } 2\end{array}$ & 3500,5 & 8,73 & 131,10 & 3,600 \\
\hline 32 & $\begin{array}{l}\text { Filtrado claro do } \\
\text { filtro save all } 2\end{array}$ & 7933,5 & 2487 ppm & 3,98 & 0,050 \\
\hline 32 & $\begin{array}{l}\text { Filtrado superclaro do } \\
\text { filtro save all } 2\end{array}$ & 1058,1 & 2487 ppm & 0,27 & 0,025 \\
\hline 32 & $\begin{array}{l}\text { Filtrado turvo do } \\
\text { filtro save all } 2\end{array}$ & 1582,7 & 2487 ppm & 4,77 & 0,300 \\
\hline 32 & $\begin{array}{l}\text { Água do chuveiro do } \\
\text { filtro save all } 2\end{array}$ & 449,0 & $2487 \mathrm{ppm}$ & 0,21 & 0,050 \\
\hline 33 & $\begin{array}{l}\text { Entrada de polpa no } \\
\quad \text { filtro save all } 1\end{array}$ & 16186,7 & 40,40 & 166,10 & 1,010 \\
\hline 33 & $\begin{array}{l}\text { Saída da polpa do } \\
\text { filtro save all } 1\end{array}$ & 4053,7 & 10,10 & 151,80 & 3,600 \\
\hline 33 & $\begin{array}{l}\text { Filtrado claro do } \\
\text { filtro save all } 1\end{array}$ & 9517,2 & $2487 \mathrm{ppm}$ & 4,78 & 0,050 \\
\hline
\end{tabular}




\begin{tabular}{|c|c|c|c|c|c|}
\hline Módulo & Corrente & $\begin{array}{l}\text { Vazão } \\
\text { mássica } \\
\text { de água }\end{array}$ & $\begin{array}{c}\text { Vazão mássica } \\
\text { de Sólidos } \\
\text { dissolvidos }\end{array}$ & $\begin{array}{c}\text { Vazão } \\
\text { mássica } \\
\text { de fibras }\end{array}$ & Consistência \\
\hline № & Descrição & $\mathrm{kg} / \mathrm{min}$ & $\begin{array}{c}\mathrm{kg} / \mathrm{min} \text { ou } \\
\mathrm{ppm}\end{array}$ & $\mathrm{kg} / \mathrm{min}$ & $\%$ \\
\hline 33 & $\begin{array}{l}\text { Filtrado superclaro do } \\
\text { filtro save all } 1\end{array}$ & 1258,1 & $2487 \mathrm{ppm}$ & 0,27 & 0,025 \\
\hline 33 & $\begin{array}{l}\text { Filtrado turvo do } \\
\text { filtro save all } 1\end{array}$ & 1894,9 & $2487 \mathrm{ppm}$ & 9,55 & 0,500 \\
\hline 33 & $\begin{array}{l}\text { Água do chuveiro do } \\
\text { filtro save all } 1\end{array}$ & 548,4 & 2487 ppm & 0,26 & 0,050 \\
\hline 27 & $\begin{array}{l}\text { Saída de polpa do } \\
\text { tanque } 3 \text { de TMP }\end{array}$ & 4541,8 & 21,70 & 317,20 & 6,500 \\
\hline 35 & $\begin{array}{l}\text { Saída de polpa do } \\
\text { tanque } 2 \text { de TMP }\end{array}$ & 3311,1 & 13,90 & 175,00 & 5,000 \\
\hline 37 & $\begin{array}{l}\text { Saída de polpa do } \\
\text { tanque } 1 \text { de TMP }\end{array}$ & 3969,3 & 14,50 & 144,50 & 3,500 \\
\hline 37 & $\begin{array}{l}\text { Água de diluição para } \\
\text { tanque } 1 \text { de TMP }\end{array}$ & 1254,9 & 2451 ppm & 1,03 & 0,082 \\
\hline 31 & $\begin{array}{c}\text { Água de diluição para tanque } \\
\text { de massa branqueada }\end{array}$ & 1483,3 & 2451 ppm & 1,21 & 0,082 \\
\hline 38 & $\begin{array}{l}\text { Saída de polpa do tanque } \\
\text { de celulose }\end{array}$ & 980,0 & 0,01 & 36,00 & 3,540 \\
\hline 48 & $\begin{array}{l}\text { Saída de polpa do tanque } \\
\text { de mistura }\end{array}$ & 11002,0 & 31,70 & 430,00 & 3,720 \\
\hline 43 & $\begin{array}{c}\text { Saída do tanque } \\
\text { de massa recuperada }\end{array}$ & 7554,3 & 18,80 & 282,80 & 3,600 \\
\hline 44 & $\begin{array}{l}\text { Saída do tanque } \\
\text { de água da tela }\end{array}$ & 23452,5 & 54,20 & 70,50 & 0,300 \\
\hline 50 & $\begin{array}{l}\text { Entrada no cleaner } 4^{\circ} \\
\text { estágio (4 cleaners) }\end{array}$ & 1516,5 & 3,70 & 6,00 & 0,390 \\
\hline 50 & $\begin{array}{l}\text { Aceite do cleaner } \\
4^{\circ} \text { estágio }\end{array}$ & 607,2 & 1,47 & 1,80 & 0,300 \\
\hline 51 & $\begin{array}{l}\text { Entrada no cleaner } 3^{\circ} \\
\text { estágio ( } 31 \text { cleaners) }\end{array}$ & 3371,2 & 8,17 & 12,00 & 0,350 \\
\hline 51 & $\begin{array}{l}\text { Aceite do cleaner } \\
3^{\circ} \text { estágio }\end{array}$ & 1854,8 & 4,50 & 6,00 & 0,320 \\
\hline 51 & $\begin{array}{l}\text { Rejeito do cleaner } \\
3^{\circ} \text { estágio }\end{array}$ & 1516,5 & 3,67 & 6,00 & 0,390 \\
\hline 52 & $\begin{array}{l}\text { Entrada no cleaner } 2^{\circ} \\
\text { estágio ( } 49 \text { cleaners) }\end{array}$ & 11024,2 & 26,70 & 73,00 & 0,660 \\
\hline 52 & Aceite do cleaner $2^{\circ}$ estágio & 8260,1 & 20,00 & 62,80 & 0,750 \\
\hline 52 & $\begin{array}{c}\text { Rejeito do cleaner } \\
2^{\circ} \text { estágio }\end{array}$ & 2764,1 & 6,69 & 10,20 & 0,370 \\
\hline 52 & $\begin{array}{l}\text { Entrada no cleaner } 1^{\circ} \\
\text { estágio ( } 157 \text { cleaners) }\end{array}$ & 54924,9 & 133,10 & 561,80 & 1,000 \\
\hline 52 & $\begin{array}{l}\text { Aceite do cleaner } \\
1^{\circ} \text { estágio }\end{array}$ & 43900,7 & 106,40 & 488,70 & 1,100 \\
\hline 52 & $\begin{array}{c}\text { Rejeito do cleaner } \\
1^{\circ} \text { estágio }\end{array}$ & 11024,2 & 26,70 & 73,00 & 0,660 \\
\hline
\end{tabular}




\begin{tabular}{|c|c|c|c|c|c|}
\hline Módulo & Corrente & $\begin{array}{l}\text { Vazão } \\
\text { mássica } \\
\text { de água }\end{array}$ & $\begin{array}{l}\text { Vazão mássica } \\
\text { de Sólidos } \\
\text { dissolvidos }\end{array}$ & $\begin{array}{l}\text { Vazão } \\
\text { mássica } \\
\text { de fibras }\end{array}$ & Consistência \\
\hline № & Descrição & $\mathrm{kg} / \mathrm{min}$ & $\begin{array}{c}\mathrm{kg} / \mathrm{min} \text { ou } \\
\mathrm{ppm}\end{array}$ & $\mathrm{kg} / \mathrm{min}$ & $\%$ \\
\hline 55 & $\begin{array}{l}\text { Água branca na seção de } \\
\text { formação } 1\end{array}$ & 41310,4 & 2273 ppm & 160,20 & 0,386 \\
\hline 55 & $\begin{array}{l}\text { Água branca na seção de } \\
\text { formação } 2\end{array}$ & 13012,8 & 2273 ppm & 31,40 & 0,240 \\
\hline 55 & $\begin{array}{c}\text { Polpa após seção de } \\
\text { formação }\end{array}$ & 2283,9 & 5,20 & 343,00 & 13,000 \\
\hline 61 & Saída do couch Pit & 1765,4 & 4,20 & 20,40 & 1,140 \\
\hline 56 & $\begin{array}{c}\text { Água branca na seção de } \\
\text { prensa }\end{array}$ & 1859,1 & 2273 ppm & 8,58 & 0,460 \\
\hline 56 & $\begin{array}{c}\text { Polpa após seção de } \\
\text { prensa }\end{array}$ & 424,8 & 0,90 & 334,40 & 44,000 \\
\hline 57 & Polpa após secador & 31,3 & 0,97 & 334,40 & 91,200 \\
\hline 62 & $\begin{array}{l}\text { Após o silo: mistura para } \\
1 \% \text { de consistência }\end{array}$ & 54924,9 & $2417 \mathrm{ppm}$ & 561,80 & 1,000 \\
\hline 64 & $\begin{array}{c}\text { Saída do Tanque } \\
\text { de refugo }\end{array}$ & 754,4 & 1,83 & 23,40 & 3,000 \\
\hline 65 & Entrada filtro de refugo & 1862,1 & 4,44 & 23,40 & 1,240 \\
\hline 65 & $\begin{array}{l}\text { Saída da polpa do } \\
\text { filtro de refugo }\end{array}$ & 754,4 & 1,83 & 23,40 & 3,000 \\
\hline 65 & $\begin{array}{c}\text { Filtrado do filtro } \\
\text { de refugo }\end{array}$ & 1406,8 & 2380 ppm & 0,14 & 0,010 \\
\hline 65 & $\begin{array}{c}\text { Água do chuveiro do filtro } \\
\text { de refugo }\end{array}$ & 299,1 & 2487 ppm & 0,14 & 0,050 \\
\hline 54 & $\begin{array}{l}\text { Entrada na depuração, } \\
\text { antes da caixa de entrada }\end{array}$ & 54015,6 & 130,90 & 557,50 & 1,000 \\
\hline 54 & Aceite da depuração & 53955,6 & 130,70 & 552,50 & 1,000 \\
\hline--- & Água fresca para MP & 3420,0 & 0,00 & 0,00 & 0,000 \\
\hline
\end{tabular}

\subsubsection{Comparação de dados simulados com dados reais}

Como já foi explicado no subcapítulo referente à coleta de dados, um outro grande desafio na simulação de uma unidade fabril é a manipulação de resultados confiáveis, ou seja, a obtenção de valores próximos dos dados reais de processo. Sendo assim, uma comparação gráfica pode ser demonstrada para analisar os desvios dos dados coletados em relação aos simulados, o que pode ser feito a partir de gráficos demonstrados na figura 3.10 . 

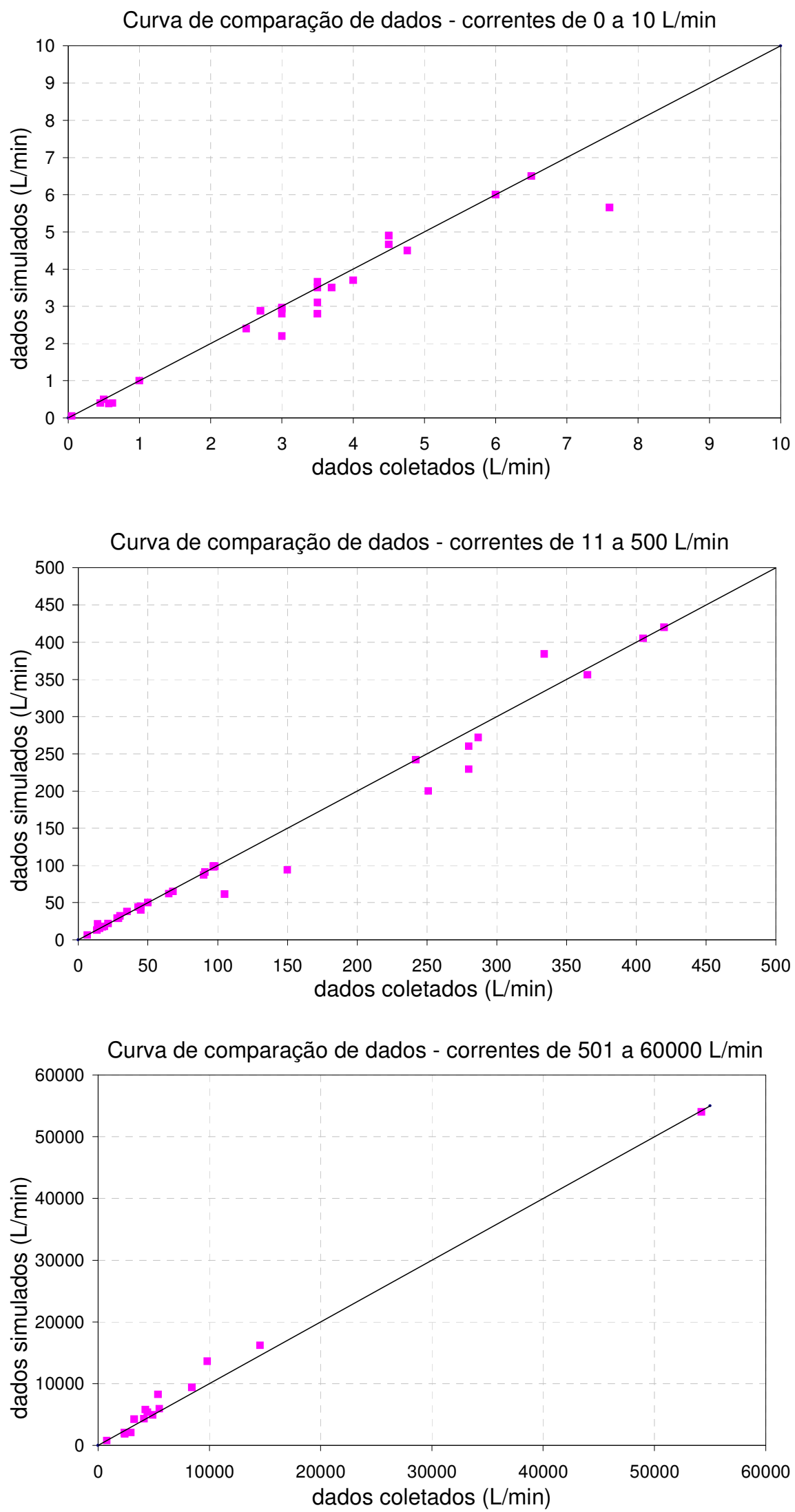

Figura 3.10 - Comparação gráfica de dados coletados e simulados. 
Sempre haverá desvios entre os dados dependendo da forma como os valores são coletados na unidade fabril. É recomendável definir períodos e coletar as informações de diferentes instrumentos na mesma base de tempo. Indústrias com padrões básicos de controle de processo possuem bancos de dados operacionais armazenados em computadores. Porém a unidade em estudo armazena apenas dados de correntes mais importantes para análise de problemas. Sendo assim, foram utilizadas diferentes fontes de coleta de dados para completar a simulação, o que gerou determinados desvios em algumas correntes simuladas.

Um outro modo de tratar com estes dados, após uma coleta estatisticamente significativa, e coerente com a possibilidade de se efetuar co-aptação das variáveis não medidas, seria o cálculo com reconciliação de dados. Esta abordagem está fora do escopo do presente trabalho, que busca obter um caso base de simulação para analisar as possibilidades da redução de uso de água através de Integração de Processos. 


\section{ANÁLISE DO CIRCUITO DE ÁGUA}

\subsection{Generalidades sobre o circuito de água}

O setor de Papel e Celulose, independente do tipo de pasta produzida, é um consumidor intenso de água. Isso ocorre porque extrair fibras de uma estrutura vegetal exige processos de diluição e lavagem com constante controle de consistência. É necessário possuir na entrada da máquina de papel, por exemplo, uma vazão controlada de polpa com aproximadamente $99 \%$ constituída de água.

Ao mesmo tempo, etapas relevantes como filtração e extração se tornam fontes de águas que devem, ao máximo possível, ser aproveitadas no circuito para reduzir o impacto sobre o custo operacional e principalmente sobre o meio ambiente. $\mathrm{O}$ grande desafio está em analisar possibilidades de reutilizar essas águas residuais e, ao mesmo tempo, reduzir o consumo de água fresca. Conseqüentemente, a captação de água do rio pode ser diminuída e a eficiência no uso de recursos naturais aumentada.

Portanto, com a existência do circuito de águas, o objetivo do trabalho é analisar e manipular as diferentes correntes de água para reduzir o consumo de água fresca. Tal possibilidade será baseada nas concentrações limites de fibras e sólidos dissolvidos em cada etapa de consumo de água. Como a unidade fabril atualmente não demonstra confiança para utilizar toda a água residual da máquina devido a restrições de contaminantes, o presente estudo possibilitará uma análise mais profunda para tentar substituir parte do consumo de água fresca através das ferramentas de otimização.

\subsubsection{Circuito de água na produção de TMP}

Os principais pontos de consumo de água considerados durante a produção de TMP estão na diluição e lavagem de polpa e chuveiros dos filtros engrossadores. A reutilização da água proveniente da lavagem de cavacos 
não será considerada no trabalho por ser uma água com alto teor de areia ou outros tipos de resíduos que compromete a qualidade da polpa ou o funcionamento de equipamentos. A água para lavagem de cavacos é composta em grande parte por água fresca, porém água residual da máquina de papel pode ser enviada para complementar a fonte.

$\mathrm{Na}$ etapa de fabricação de TMP altas vazões de água são geradas principalmente nos filtros de engrossamento e prensas de rejeitos, porém, 0 consumo de água para diluição e lavagem de polpa, diluição de rejeitos e chuveiros de filtros é maior que a vazão de água gerada no setor de produção de TMP. Sendo assim, água clara do setor de produção de papel é enviada para complementar a vazão de consumo. Mas não é recomendável a completa substituição da água fresca no circuito, o que pode ocasionar, por exemplo, o acúmulo de elementos inorgânicos não processuais, prejudicando dessa maneira, a qualidade da polpa e o funcionamento de alguns equipamentos.

\subsubsection{Circuito de água na Produção de Papel}

A máquina de papel é um dos principais objetos para análise de redução no consumo de água, pois a cada etapa do processo, ou seja, as seções de formação, prensagem e secagem, águas com qualidades diferentes são extraídas da polpa com o intuito de atingir gradativamente a conformidade do papel. As etapas de filtração para recuperar fibras e refugos são outras fontes geradoras de água de processo e são classificadas como clara, turva ou super clara. Por outro lado, água fresca é consumida principalmente no chuveiro das telas da máquina.

A água extraída da seção de formação, denominada água branca, possui a concentração de fibras mais alta entre as águas. Quanto aos sólidos dissolvidos, a concentração é maior nas águas geradas na etapa de produção de pasta mecânica. 
Grande parte da água branca extraída na seção de formação é enviada para a bomba de mistura localizada no tanque de água branca, responsável pela diluição da massa para aproximadamente $1 \%$ de consistência. O objetivo é diluir e adequar a polpa para a caixa de entrada da máquina de papel. A água branca restante da seção de formação é direcionada para o tanque de água da tela. Desse tanque, grande parte da água é enviada para o sistema de recuperação de fibras, onde paralelamente são geradas as águas citadas anteriormente. O excedente é enviado para a torre de água branca, com capacidade para $1200 \mathrm{~m}^{3}$.

A água turva retorna para o filtro de recuperação de fibras. Porém a maior parte das águas claras e superclaras procedentes da recuperação é enviada para uma outra torre de mesma capacidade, denominada torre de água clara. Dessa torre, a água é distribuída para diferentes pontos da fábrica, inclusive para o setor de fabricação de TMP. O transbordo dessa torre de água clara pode ser reduzido durante a análise do circuito de água da unidade fabril, pois o fluxo transbordado é totalmente direcionado para o tratamento de efluentes. Não há medição na fábrica que indique exatamente o fluxo perdido, porém através do balanço no CadSim, foi possível estimar uma perda de aproximadamente $1400 \mathrm{~L} / \mathrm{min}$.

É bom enfatizar que não é recomendável reutilizar a água extraída da seção de prensas por estar contaminada com resíduos de feltros, que são telas que facilitam a remoção de água extraída durante a prensagem da folha. Outro efluente atualmente gerado que também não será reutilizado é o rejeito proveniente do circuito de baixa consistência, responsável por retirar os últimos resíduos prejudiciais da polpa para produção de papel. 


\subsection{Integração de Processos}

Integração de Processos é uma ferramenta de gerenciamento utilizada para otimizar recursos mássicos e energéticos em unidades industriais através de tecnologias convencionais. Com a integração de processos (PI), é possível desenvolver sistemas eficientes de massa e energia em grandes complexos industriais. A PI é baseada na aplicação de metodologias que facilitam a seleção e modificação de processos.

O lado crítico da integração de processos é o fato dela ser baseada em técnicas de análises sistemáticas e rigorosas, e não somente nas boas idéias e experiências. Mas ela oferece ao engenheiro uma técnica estruturada para identificar ineficiências no processo, onde é possível selecionar as melhores oportunidades para futuras otimizações.

Porém há algumas barreiras que podem ser citadas quanto ao uso do $\mathrm{PI}$, como:

- Preocupações com equipamento de informática adicional, causando problemas de alto custo.

- Falta de entendimento das técnicas em muitas indústrias, o que gera repulsão do engenheiro de fábrica ao uso de ferramentas científicas.

- O impacto da mudança na confiabilidade, flexibilidade e manutenção de processos industriais.

- O risco de distúrbios no processo produtivo.

- Longo período de retorno financeiro em alguns casos.

Portanto, uma análise minuciosa sempre deve ser feita antes de iniciar um projeto através de $\mathrm{PI}$, lembrando que, apesar de barreiras, há vantagens que possam justificar os investimentos.

- A integração de processos pode ser usada para projetos de novas unidades fabris ou modificações de instalações já existentes, e pode 
ser aplicada para vários tipos de problemas industriais. A seguir, são citados alguns exemplos de aplicação:

- Diminuir consumo de energia e emissão de gases;

- Recuperar energia de um dado processo, entre processos, e em toda a unidade industrial;

- Otimizar a configuração de utilidades, incluindo co-geração, minimização do dimensionamento de caldeiras e geração de vapor de processo;

- Eliminação de gargalos do processo ou equipamentos (coluna de destilação, por exemplo), assim como do sistema de utilidades;

- Minimização do consumo de água e da geração de efluente;

- Identificação de estratégias de investimentos a médio e longo prazo.

Os métodos mais comuns para o estudo através de Integração de Processos são:

- Análise Pinch: é utilizada para otimizar sistemas através de métodos gráficos. Esta técnica conduz a uma análise sistemática do sistema, enquanto leva em consideração não somente a quantidade, mas também a qualidade da energia e da massa.

- Análise Exergética e outras técnicas termodinâmicas são capazes de comparar em uma base comum, a eficiência de vários processos incluindo a transferência de calor, reações químicas, operações de separações (membranas, coluna de destilação, etc), ou outros processos mecânicos como compressão e expansão. A análise exergética facilita a avaliação de perdas (ou irreversibilidades) na maioria dos sistemas, e a escolha de soluções para reduzir essas ineficiências.

- Técnicas de programação matemática são usadas para modelar e otimizar um processo ou parte dele, incluindo métodos de otimização determinísticos (programação linear e não linear, com ou sem variáveis inteiras) e algoritmos genéticos.

A tecnologia por Integração de Processo pode ser estruturada da seguinte forma: 


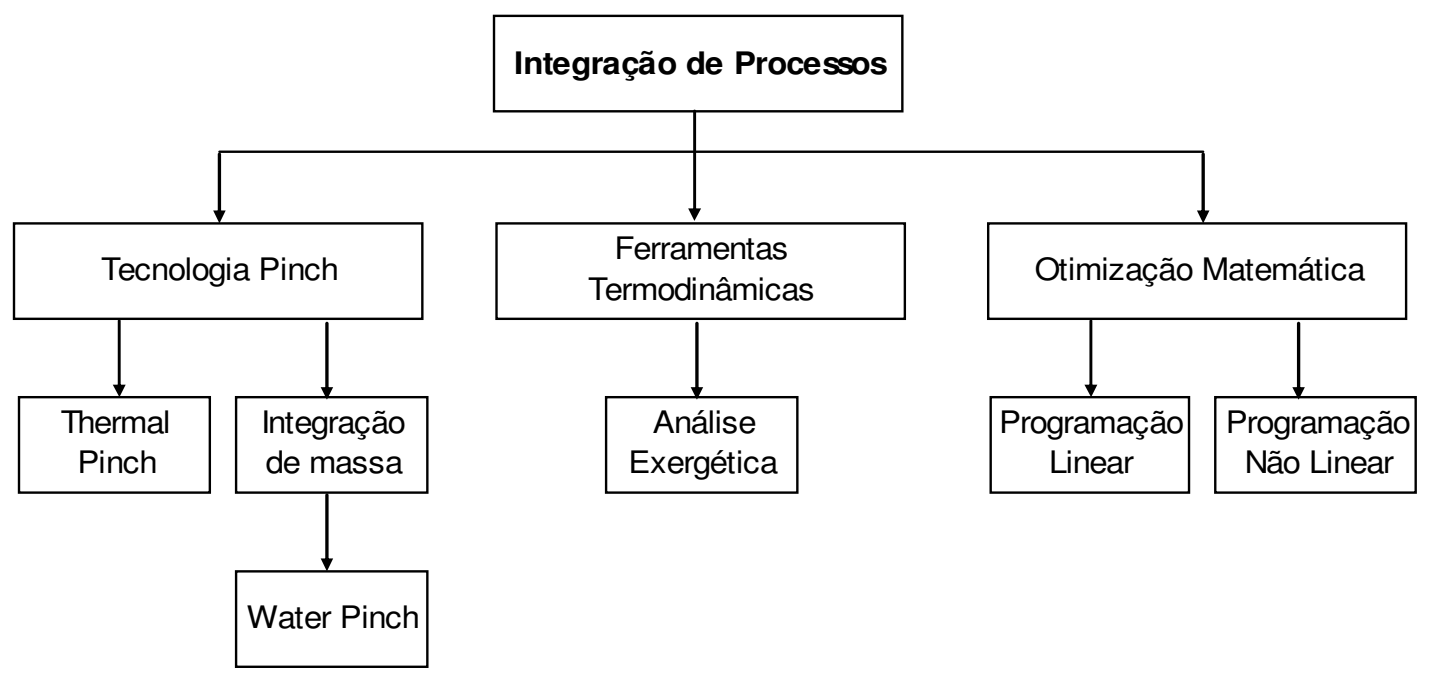

Figura 4.1 - Estrutura da Integração de Processos

As técnicas utilizadas no presente trabalho são relativas ao método "Water Pinch" e na programação matemática.

\subsection{Análise por método Pinch}

Grandes progressos têm marcado os estudos sobre configurações de circuitos de água para minimizar o consumo de água fresca e geração de efluentes ao mesmo tempo em que restrições de processo como concentrações críticas de contaminantes são respeitadas. A ferramenta "Water Pinch", foi desenvolvida a partir do método "Thermal Pinch", uma ferramenta que se mostrou eficaz para análises e otimização de sistemas complexos de troca térmica. Sendo assim, a mesma metodologia foi desenvolvida para sistemas de troca de massa, dando-se origem aos estudos através do método Pinch para sistemas com troca de massa.

\subsubsection{Conceito de Water Pinch}

Segundo Mann, Liu (1999), a tecnologia "Water Pinch", também chamada de ponto de mínimo consumo de água, fornece respostas para inúmeras questões sobre o gerenciamento de água quando há necessidade do 
desenvolvimento de novas unidades industiais ou reformas de fábricas existentes. Para sistemas de água e efluentes, é possível responder questões como:

- Como seria uma nova estrutura para distribuição de água ou como a estrutura existente deve ser alterada?

- Qual é o potencial para máximo reuso e mínima geração de efluentes em processo produtivo?

- Qual é a mínima vazão de tratamento em um sistema de tratamento de efluentes de um processo produtivo?

- Como desenvolver um novo sistema de tratamento de efluentes ou como modificar o sistema existente para atingir a mínima vazão?

- Como um processo produtivo deve ser modificado para maximizar o reuso de água e minimizar a geração de efluentes?

É importante observar que, isoladamente, a avaliação do ponto de mínimo consumo de água não é suficiente para responder à última pergunta, pois não considera a eficiência de utilização de água no processo.

Para responder essas questões, Mann, Liu(1999) dividem a tecnologia "water pinch" em três partes: análise, síntese, e alteração.

Análise: Identificando, a priori, o consumo mínimo de água fresca e geração de efluentes em operações que utilizam água (water-pinch analysis).

Síntese: Desenvolvendo uma estrutura de distribuição de água e coleta de efluentes que atenda os fluxos mínimos previamente identificados, por meio da prática de reuso e regeneração. (water-pinch synthesis).

Alteração: Modificando de modo efetivo uma estrutura de distribuição de água e coleta de efluentes existente para maximizar o reúso e minimizar a geração de efluentes através da real modificação do processo (water-pinch retrofit). 
Caso haja algum tipo de desperdício em qualquer operação, o ponto de mínimo consumo será obtido incorporando-se este desperdício. Por essa razão, durante a etapa de avaliação, é necessário identificar e eliminar os desperdícios de água para que os resultados sejam os melhores possíveis.

\subsubsection{Aplicação do Método Pinch}

A hipótese para a determinação do "water pinch" é que a água é utilizada para assimilar contaminantes. Fazendo uma analogia entre sistemas com a troca de calor (Thermal Pinch), pode-se dizer que correntes com tendência de "doar" contaminantes equivalem a correntes com maior temperatura do método Thermal Pinch. Similarmente, correntes com tendência de "receber" contaminantes, equivalem a correntes com menor temperatura.

O método pode ser aplicado sem ou com reuso de água, porém como o enfoque é a minimização de água e efluentes em um sistema, o maior interesse está na aplicação do método com reuso. Para descrever os casos com reuso, duas técnicas Pinch serão descritas: a tradicional, introduzida por Wang, Smith (1994) para analisar a carga de contaminantes de maneira facilitada, e outra apresentada por Dhole et al (1996) para os sistemas onde há maior importância no fluxo de água e onde a troca de massa ocorre entre correntes miscíveis. É importante mencionar que a segunda técnica possui maior aplicabilidade para o setor de Celulose e Papel e será implementada nesse trabalho.

\subsubsection{Water Pinch com reuso de água e foco na carga de contaminantes}

Para este caso, é possível utilizar o efluente gerado em um determinado processo diretamente em outro, desde que a concentração do contaminante no efluente seja inferior à concentração limite na entrada de outro processo. Ao mesmo tempo em que esse procedimento se realiza, ocorre a redução da 
demanda de água e da geração de efluentes, ressaltando-se que a carga de contaminante não é alterada.

O método Pinch para esse caso consiste na técnica gráfica apresentada por Wang; Smith (1994), que relaciona a variação de concentração do contaminante na água utilizada nos processos com a carga transferida para a água. Através do método, gera-se uma curva composta de concentração onde o objetivo é encontrar um ponto de mínimo consumo de água em um determinado sistema com trocas de massa.

Em sua publicação sobre o reuso de água, Mierzwa; Hespanhol (2005) mencionam a determinação da curva em quatro etapas. Na primeira, constrói-se um gráfico que considere todos os processos onde a água é utilizada, relacionando a concentração de contaminante em função da carga acumulada. Nesse gráfico a variação da concentração é absoluta, enquanto a carga de contaminante é relativa, o que significa que um processo é iniciado no ponto em que o anterior foi encerrado.

Na segunda etapa, divide-se o eixo das ordenadas do gráfico em intervalos, nos quais estão representados os valores de concentração do contaminante na entrada e saída de cada processo. Na terceira etapa, determina-se a carga de contaminante para cada intervalo de concentração definido e constrói-se uma nova curva de variação da carga de contaminante. $\mathrm{Na}$ quarta e última etapa, as curvas compostas de concentração podem ser construídas, eliminando-se as curvas originais de variação da concentração do contaminante com a carga e mantendo apenas os intervalos nos quais as curvas não se sobrepõem.

\section{Exemplo 1: Método gráfico de curva composta de concentração}

A partir de um simples exemplo, também publicado no livro de Mierzwa; Hespanhol (2005), serão ilustradas as quatro etapas citadas anteriormente para a construção da curva composta de concentração. 
Tabela 4 - Demanda de água para os processos desenvolvidos no exemplo.

\begin{tabular}{|c|c|c|c|c|c|}
\hline Processo & $\begin{array}{l}D_{\text {mi, total }} \\
(\mathrm{kg} / \mathrm{h})\end{array}$ & $\begin{array}{l}\text { Condições lir } \\
C_{i, \text { entra }}(\mathrm{mg} / \mathrm{L})\end{array}$ & $\begin{array}{l}\text { para água } \\
\mathrm{C}_{\mathrm{i}, \text { sai }}(\mathrm{mg} / \mathrm{L})\end{array}$ & $\begin{array}{l}\mathbf{f}_{\mathrm{H} 2 \mathrm{O}} \\
(\mathrm{t} / \mathrm{h})\end{array}$ & $\begin{array}{c}\text { Carga } \\
\text { Acumulada } \\
(\mathrm{kg} / \mathrm{h})\end{array}$ \\
\hline 1 & 2,50 & 0 & 75 & 33,33 & 2,50 \\
\hline 2 & 1,50 & 50 & 100 & 30,00 & 4,00 \\
\hline 3 & 1,25 & 80 & 150 & 17,86 & 5,25 \\
\hline
\end{tabular}

As duas primeiras etapas referem-se aos intervalos de concentrações de contaminantes e carga acumulada para a construção do gráfico. Uma análise inicial pode ser observada no gráfico a seguir:

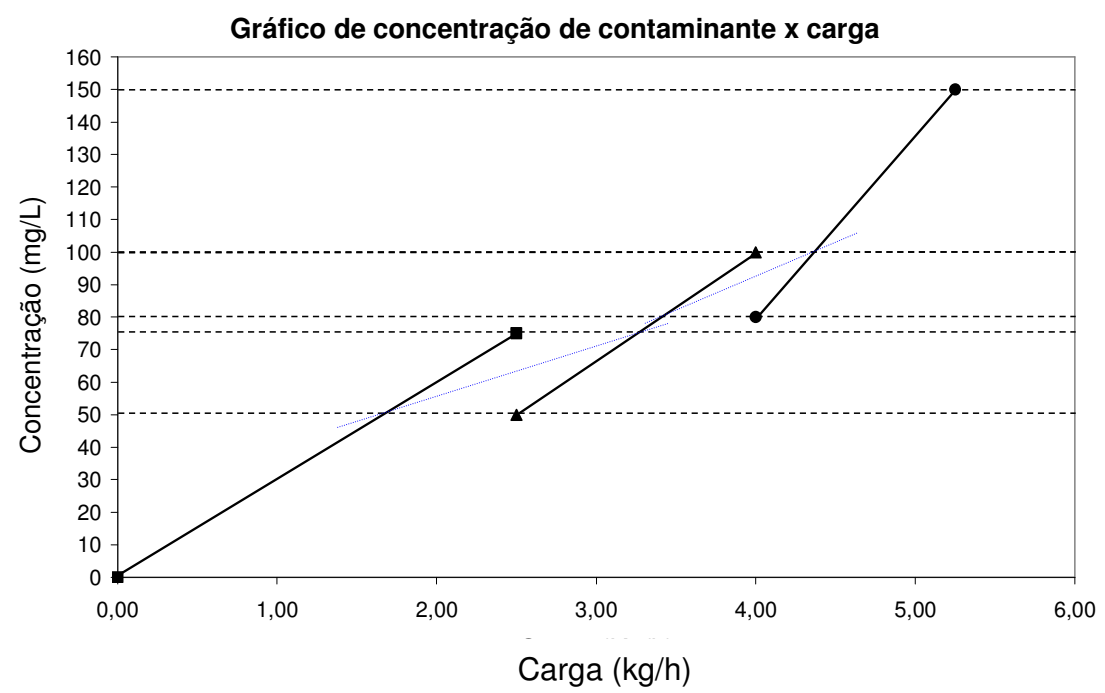

(a)

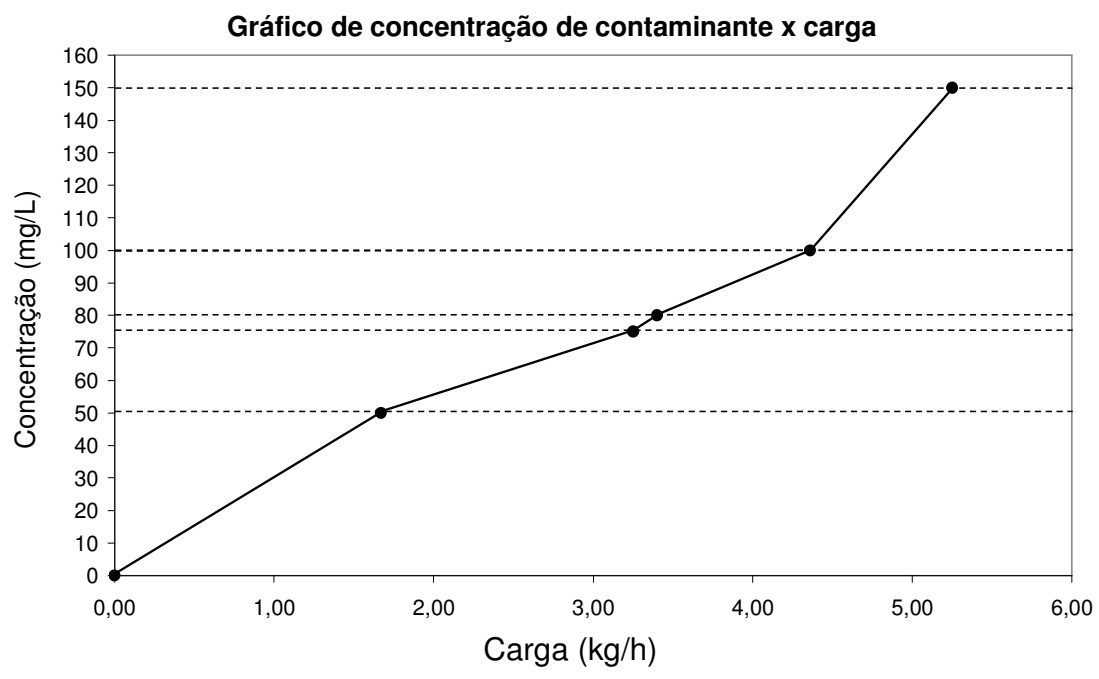

(b)

Figura 4.2 - (a) Variação da concentração do contaminante e, (b) curva composta de concentração. Fonte: Wang; Smith (1994). 
A terceira etapa refere-se à determinação da carga de contaminante para cada intervalo de concentração. Como podem ser observadas, as colunas de fluxo e da carga de contaminante da tabela 5 estão indicadas na abcissa da figura $4.2(b)$.

Tabela 5 - Carga de contaminante para todos os intervalos de concentração.

\begin{tabular}{|c|c|c|c|c|}
\hline $\begin{array}{c}\text { Intervalo de } \\
\text { concentração }\end{array}$ & Processo & $\begin{array}{c}\text { Fluxo } \\
\mathbf{( t / h )}\end{array}$ & $\begin{array}{c}\text { Carga de } \\
\text { contaminante } \\
(\mathbf{k g} / \mathbf{h})\end{array}$ & $\begin{array}{c}\text { Carga } \\
\text { Acumulada } \\
\mathbf{( k g / h )}\end{array}$ \\
\hline $0-50$ & 1 & 33,33 & 1,67 & 1,67 \\
\hline $50-75$ & 1 e 2 & 63,33 & 1,58 & 3,25 \\
\hline $75-80$ & 2 & 30 & 0,15 & 3,40 \\
\hline $80-100$ & 2 e 3 & 47,86 & 0,96 & 4,36 \\
\hline $100-150$ & 3 & 17,86 & 0,89 & 5,25 \\
\hline
\end{tabular}

Finalmente, a quarta etapa refere-se à construção do gráfico da curva composta de concentração, como pode ser visto na figura 4.3. Após a construção da curva, é possível determinar o ponto de mínimo consumo de água (water pinch) construindo uma curva que representa a variação da concentração do contaminante na água utilizada no sistema versus carga de contaminante acumulada. A curva relacionada à água de alimentação passa pela origem, ou seja, a concentração inicial do contaminante é zero e vai aumentando à medida que a água vai incorporando o contaminante. Quanto menor a vazão de água limpa utilizada no sistema, para a mesma carga de sais transferida, maior será a inclinação da curva de alimentação. Desta forma, quanto mais próxima da curva composta de concentração estiver a curva de água de alimentação, menor será a necessidade de água limpa, ressaltando-se que a curva de água de alimentação deve permanecer abaixo ou no mesmo nível da curva composta de concentração, para que o contaminante possa ser transferido.

Com base nesses conceitos, e observando a figura 4.3, quando a curva de alimentação de água sofre uma rotação em relação à origem, aproximandose da curva composta de concentração, o ponto de mínimo consumo de água será aquele em que a curva de alimentação tangencia a curva composta de concentração. 


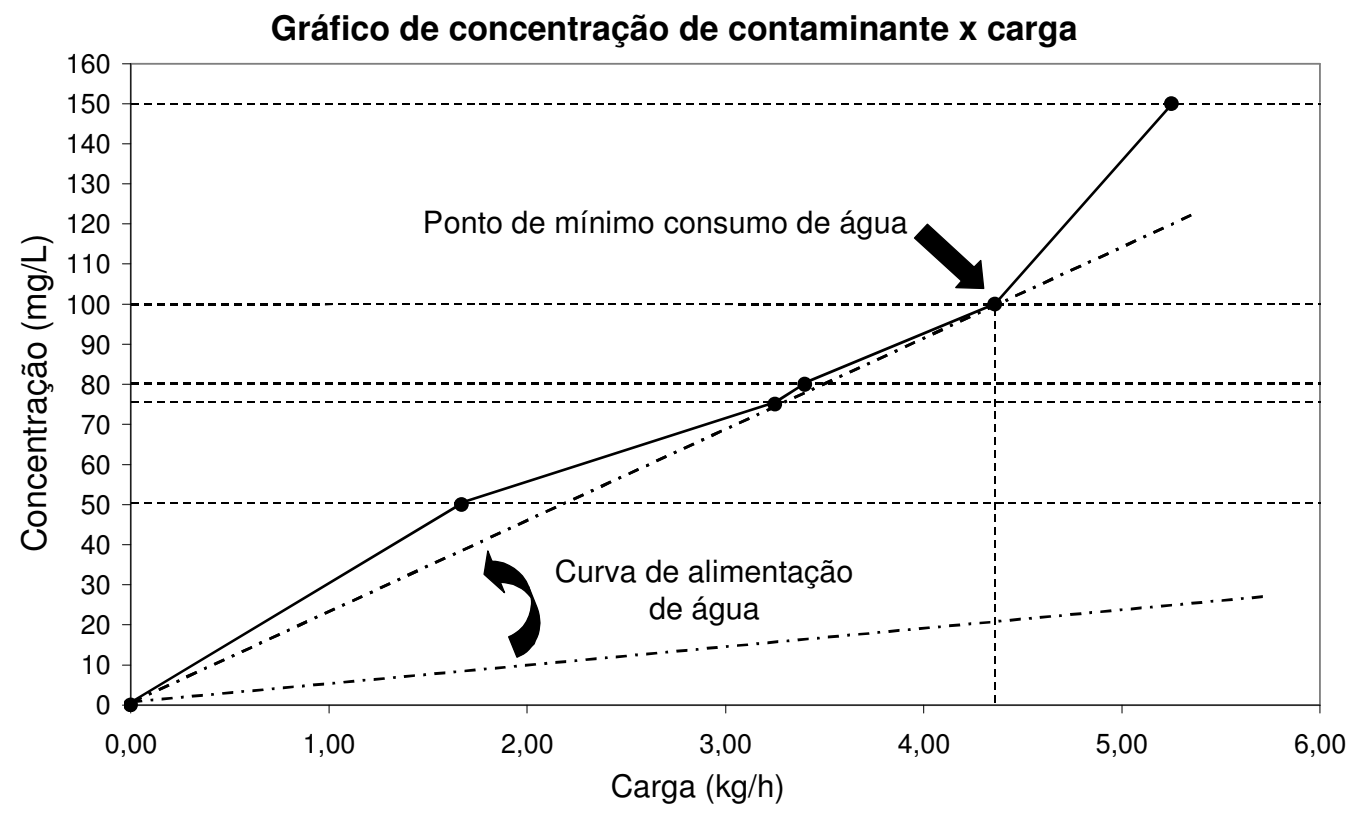

Figura 4.3 - Obtenção do ponto de mínimo consumo de água. Fonte: Wang; Smith (1994).

Esta condição indica que não é necessário adicionar água fresca ao sistema acima do ponto de mínimo consumo de água. A leitura dos valores relacionados à carga de contaminante e à respectiva concentração proporciona a mínima vazão de água a ser alimentada. Pelo gráfico, a carga de contaminantes acumulada até o ponto de mínimo consumo de água é 4,36 kg/h e a concentração do contaminante na água é de $100 \mathrm{mg} / \mathrm{L}$. Portanto, considerando a massa específica da corrente $1000 \mathrm{mg} / \mathrm{L}$, o fluxo mínimo de água será:

$$
f_{\text {min }}=\frac{\Delta_{m i, \text { min }}}{C_{i, \text { min }}} \cdot 10^{3}=43,6 \mathrm{t} / \mathrm{h}
$$

Conforme a tabela 4, antes do reuso, se o consumo total de água fresca nos três processos era de $81,16 \mathrm{t} / \mathrm{h}$, conclui-se que houve uma redução de aproximadamente $46 \%$ no consumo de água fresca.

O método citado acima pode ser aplicado em casos onde as correntes doadoras e receptoras de contaminantes não se misturam, como por exemplo, em circuitos de lavagem de correntes em indústrias petroquímicas, 
onde uma fase orgânica e outra aquosa são de grande interesse. Mas em operações onde ocorre mistura, as correntes vão constantemente perdendo suas identidades à medida que são misturados em etapas do processo. $\mathrm{E}$ para a indústria de celulose e papel, onde há grandes circuitos miscíveis de água-água, esse método pode se tornar um obstáculo. Para superar essa dificuldade, foi apresentado um método onde a maior importância está na análise de vazões de água e não na carga de contaminantes. Esse método, onde são definidas as fontes e as demandas de água de processo, está descrita na próxima seção.

\subsubsection{Water Pinch com reuso de água e foco na vazão de água}

Essa seção apresenta um método gráfico introduzido por Dhole et al (1996) para lidar com condições onde há uma importância maior na vazão de água e onde uma determinada corrente terá diferentes concentrações de contaminantes na entrada e na saída de um processo. Essa ferramenta gráfica, segundo Jacob et al (2002), tem sido aplicada com sucesso na área de Celulose e Papel, onde sistemas miscíveis de água-água são bastante comuns.

A partir do gráfico em questão, é possível gerar uma curva composta dupla, formada por fontes e demandas de água em determinados processos. A curva pode ser utilizada para encontrar o consumo desejado de água fresca com vazões fixas e para analisar os potenciais de sistemas existentes que utilizam água com vazões fixas. A saída de cada operação que utiliza água pode ser considerada uma fonte de água. Analogamente, a entrada de cada operação que utiliza água é considerada uma demanda que possui um limite de concentração e deve ser satisfeita com uma determinada fonte. Esse é o princípio básico de funcionamento do método.

As vazões das fontes e demandas são indicadas na abscissa, enquanto as respectivas purezas ficam indicadas na ordenada em ordem decrescente. 


\section{Exemplo 2: Método gráfico de fonte e demanda de água (curva composta dupla)}

Tabela 6 - Dados limites para o exemplo. Fonte: Mann; Liu (1999).

\begin{tabular}{|c|c|c|c|c|}
\hline Processo & $\begin{array}{c}\text { Carga de } \\
\text { contaminante } \\
(\mathbf{k g} / \mathbf{h})\end{array}$ & $\begin{array}{c}\mathbf{C}_{\mathrm{i}, \text { entra }} \\
(\mathbf{p p m})\end{array}$ & $\begin{array}{c}\mathbf{C}_{\mathrm{i}, \text { sai }} \\
\mathbf{( \mathbf { p p m } )}\end{array}$ & $\begin{array}{c}\text { Fluxo } \\
\mathbf{( t / h )}\end{array}$ \\
\hline 1 & 1,0 & 0 & 50 & 20 \\
\hline 2 & 0,8 & 20 & 100 & 10 \\
\hline 3 & 1,5 & 0 & 75 & 20 \\
\hline 4 & 3,0 & 40 & 100 & 5 \\
\hline
\end{tabular}

A tabela 6 apresenta dados de concentrações limites de entrada e saída de um circuito de água assim como as vazões fixas de quatro processos operacionais. As concentrações são especificações do processo e podem ser modificadas para proporcionar um consumo de água fresca e geração de efluentes menores. No esquema da figura 4.4, o sistema opera com água fresca nos quatro processos. O Water Pinch será implementado nesse exemplo para demonstrar o método e sua capacidade em otimizar sistemas através de manipulação de vazão e concentração das correntes. Quando o sistema opera em circuito aberto como o exemplo citado nessa seção, a ferramenta pode trazer resultados satisfatórios.

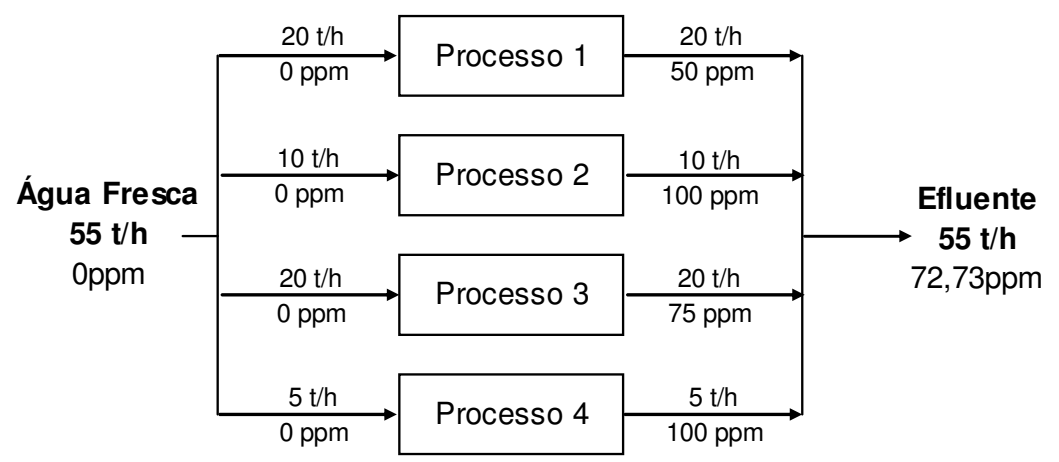

Figura 4.4 - Representação esquemática do exemplo 2. Fonte: Mann; Liu (1999).

$\mathrm{Na}$ figura 4.5, os dados de vazão das fontes e demandas foram colocados na abcissa enquanto as concentrações das respectivas correntes foram inseridas na ordenada. Observa-se que no topo da ordenada está representada a água fresca, sendo que a concentração de contaminantes diminui à medida que se aproxima da origem do eixo. A linha sólida da figura 
4.5 representa as fontes de água. Por exemplo, o trecho 1 da linha sólida corresponde à fonte de água do processo 1, ou seja, 20 t/h de água disponível a 50 ppm. É importante ressaltar que o valor da vazão é representado pela distância do trecho, ou seja, para o trecho 1 tem-se (65 45) $t / h$, o que equivale a $20 \mathrm{t} / \mathrm{h}$.

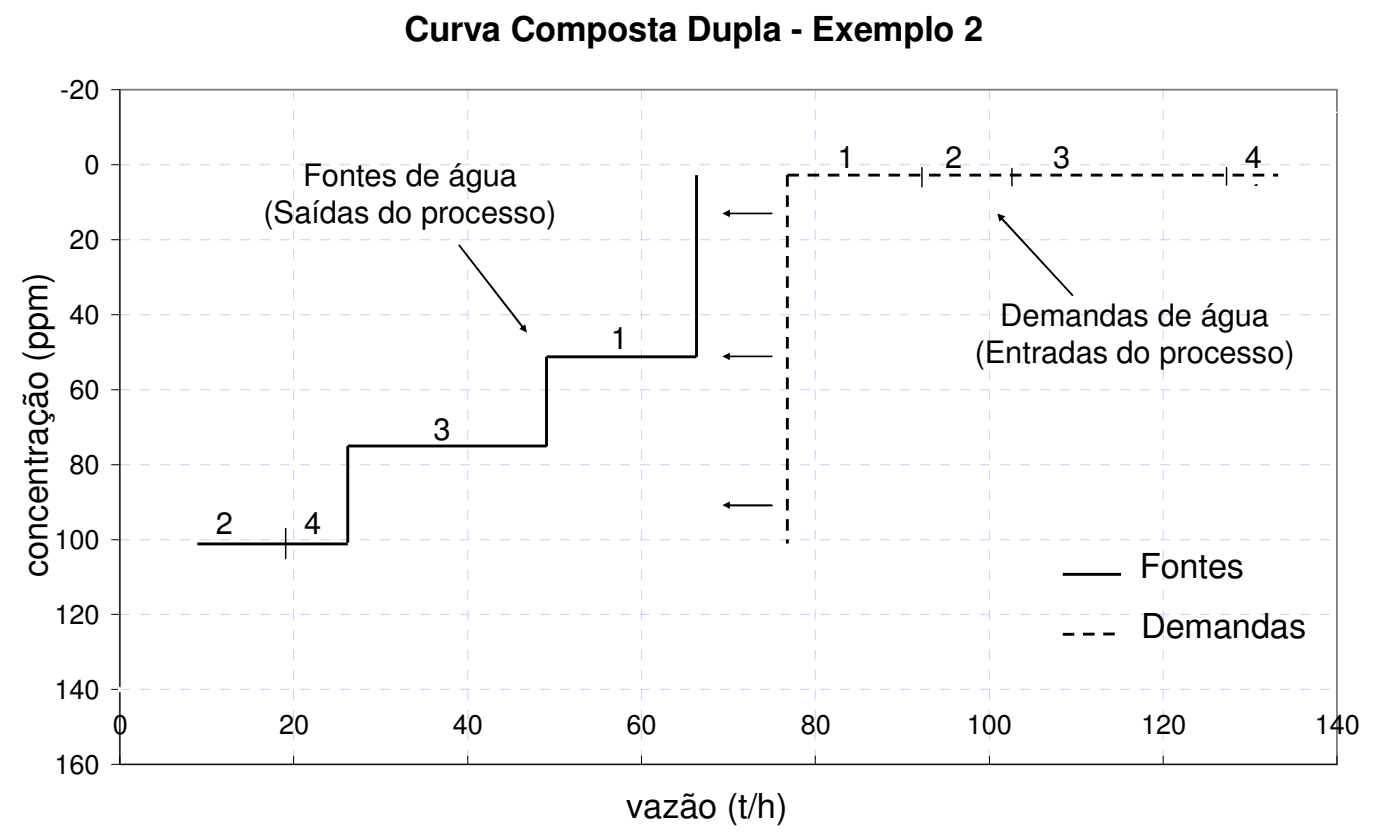

Figura 4.5 - Representação gráfica do exemplo 2 (passo 1). Fonte: Mann; Liu (1999).

À direita da curva, traçam-se as curvas referentes às demandas. Nesse caso são inseridas as vazões e concentrações das demandas que são requeridas. O trecho 1 da linha tracejada da figura 4.5 representa uma demanda pelo processo 1 de $20 \mathrm{t} / \mathrm{h}$, que deve ser alimentado por água fresca por limitar a concentração em 0 ppm.

Para identificar oportunidades de reuso de água e minimizar a geração de efluentes através da curva composta dupla, move-se a linha de demanda para a esquerda, como representado na figura 4.5, até encontrar a linha de fontes na região denominada "water pinch". Para esse exemplo, a região é chamada de "freshwater pinch" por não possuir fontes que satisfaçam as entradas das demandas, que pode ser observada na figura 4.6. 
Curva Composta Dupla - Exemplo 2

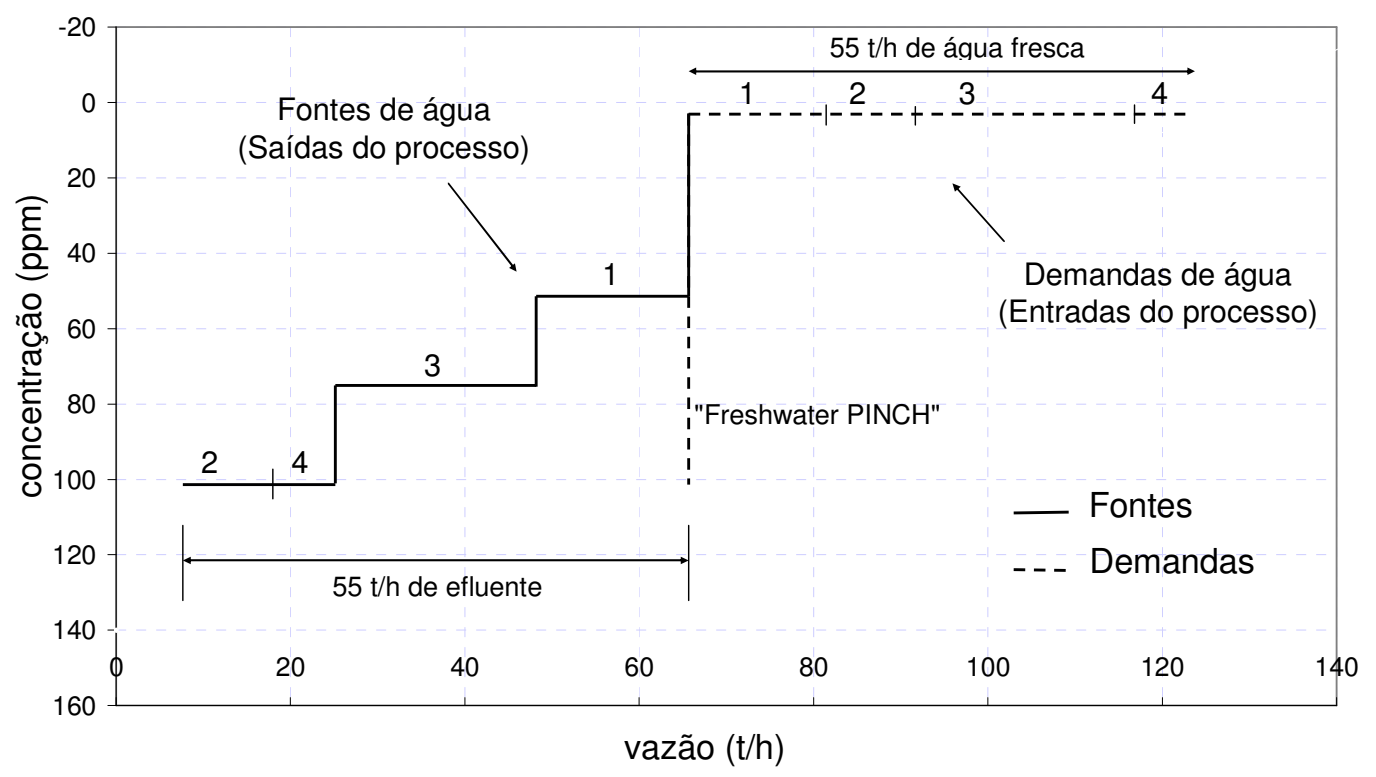

Figura 4.6 - Representação gráfica do exemplo 2 (passo 2). Fonte: Mann; Liu (1999).

Deve-se ter cuidado para reconhecer as diferenças entre o water pinch da curva composta de concentração e o water pinch da curva composta dupla. Nessa última, o water pinch não é definido pela concentração de contaminantes e sim por uma linha vertical que indica na abcissa o valor da vazão requerida.

Em circuitos onde grande parte dos processos utiliza água fresca, há uma grande possibilidade do Water Pinch se tornar uma ferramenta eficiente. $\mathrm{Na}$ figura 4.7, estão sendo mostradas as linhas de demanda e fontes nas condições limites de cada processo, como indica a tabela 6. Para esse exemplo, uma boa parte das correntes de fontes pode ser reutilizada. Isso será observado através da exibição no gráfico de cada demanda com sua concentração máxima de entrada e de cada fonte com sua concentração máxima de saída. 
Curva Composta Dupla - Exemplo 2

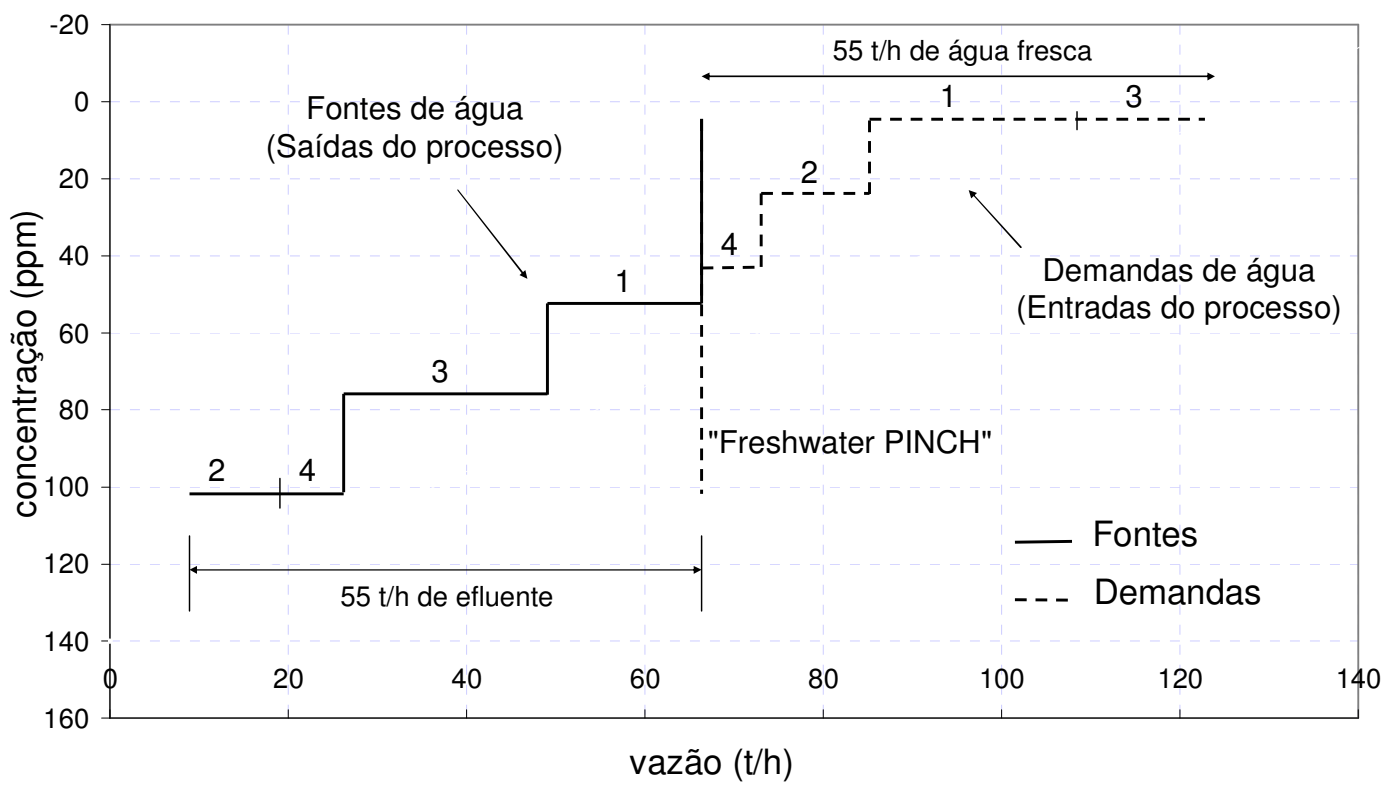

Figura 4.7 - Representação gráfica do exemplo 2 (passo 3). Fonte: Mann; Liu (1999).

Para esse exemplo, foi escolhido aumentar a concentração de entrada do processo 3 acima da concentração de saída do processo 1 para que a água seja reutilizada. Mas para isso, é preciso modificar o processo para que os valores limites da tabela 6 não sejam violados. Nesse caso, modifica-se o processo 3 para permitir o reuso da água que sai do processo 1 para 0 processo 3. Tabela 7 de novos limites pode ser construída.

Tabela 7 - Novos dados limites para o exemplo, modificando o processo 3

\begin{tabular}{|c|c|c|c|c|}
\hline Processo & $\begin{array}{c}\text { Carga de } \\
\text { contaminante } \\
(\mathbf{k g} / \mathbf{h})\end{array}$ & $\begin{array}{c}\mathbf{C}_{\mathrm{i}, \text { entra }} \\
(\mathbf{p p m})\end{array}$ & $\begin{array}{c}\mathbf{C}_{\mathbf{i}, \text { sai }} \\
(\mathbf{p p m})\end{array}$ & $\begin{array}{c}\text { Fluxo } \\
(\mathbf{t} / \mathbf{h})\end{array}$ \\
\hline 1 & 1,0 & 0 & 50 & 20 \\
\hline 2 & 0,8 & 20 & 100 & 10 \\
\hline 3 & 1,5 & 50 & $\mathbf{1 2 5}$ & 20 \\
\hline 4 & 3,0 & 40 & 100 & 5 \\
\hline
\end{tabular}

A curva para a nova condição é mostrada na figura 4.8. Observa-se que agora o consumo de água fresca passou de $55 \mathrm{t} / \mathrm{h}$ para $35 \mathrm{t} / \mathrm{h}$. Na figura, foi introduzido um "reuse pinch", que significa um ponto onde o reuso de água termina e a geração de efluentes se inicia. Em outras palavras, a esquerda da "reuse pinch", todas as fontes vão para o tratamento de efluentes. 
Curva Composta Dupla - Exemplo 2

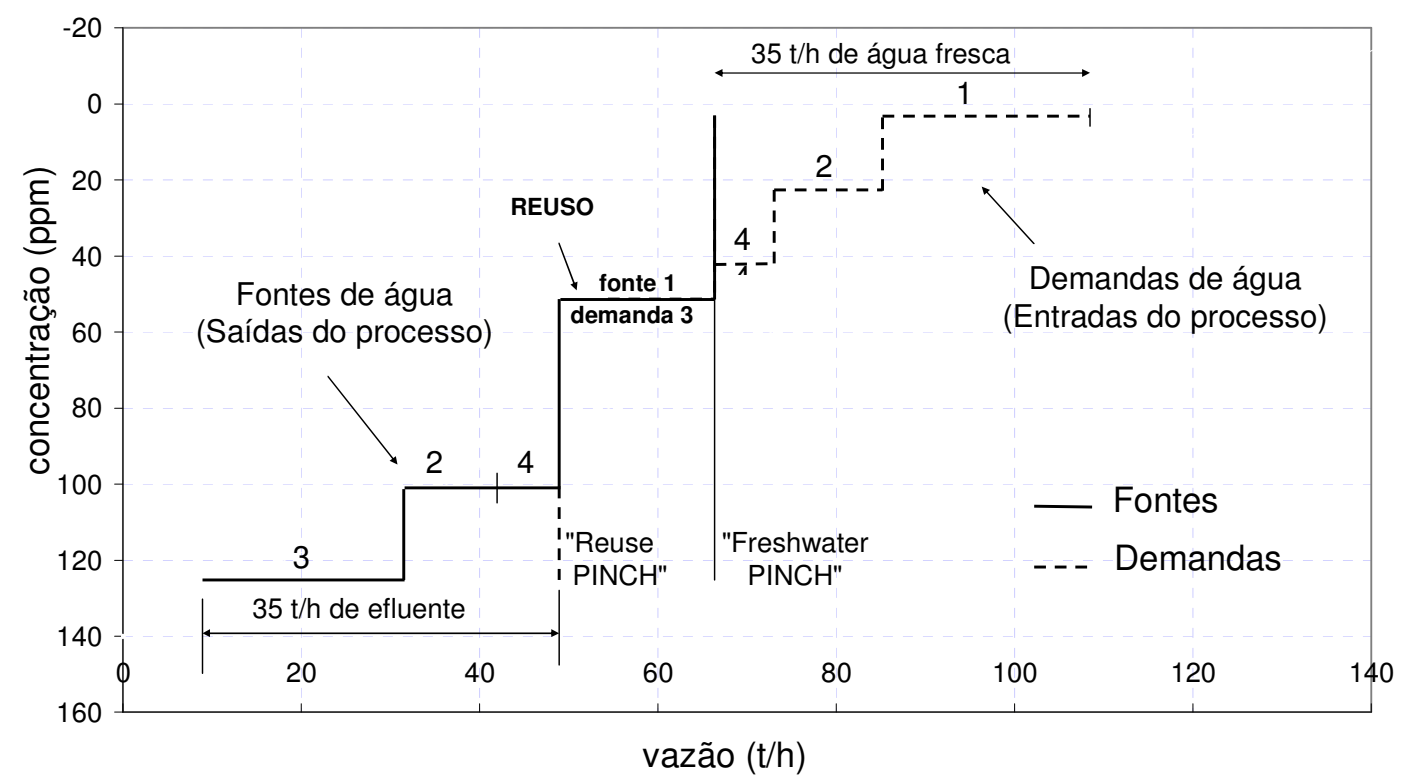

Figura 4.8 - Curva composta dupla após alteração no processo 3. Fonte: Mann; Liu (1999).

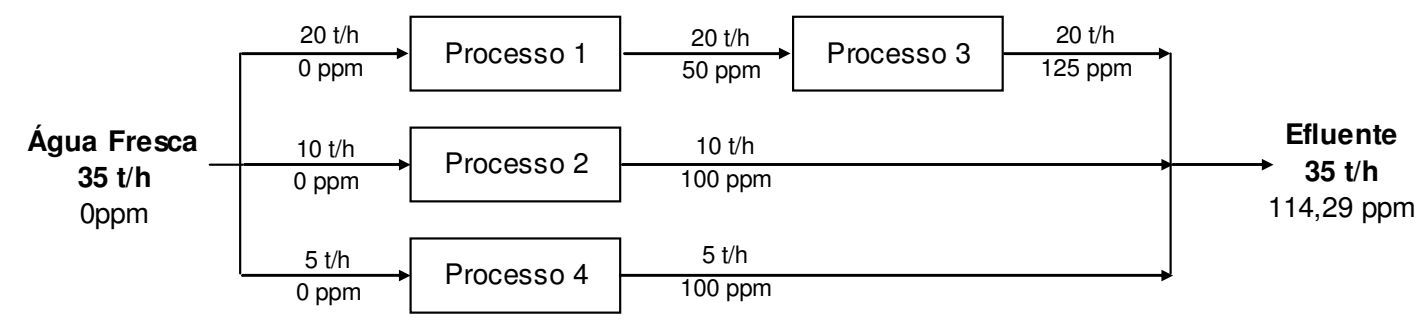

Figura 4.9 - Representação esquemática do exemplo 2 após a alteração no processo 3. Fonte: Mann; Liu (1999).

\section{Exemplo 3: Método gráfico de curva composta dupla para desagregação e lavagem de polpa celulósica}

Para exemplificar um sistema relacionado com o setor de celulose e papel, o caso a seguir demonstra a aplicação da curva composta dupla em processamento de polpa. Paralelamente, um artifício de mistura de correntes de fontes será mencionado para possibilitar a manipulação de valores de concentrações. O objetivo é adequar as concentrações de contaminantes das fontes aos limites de entradas de cada demanda. 


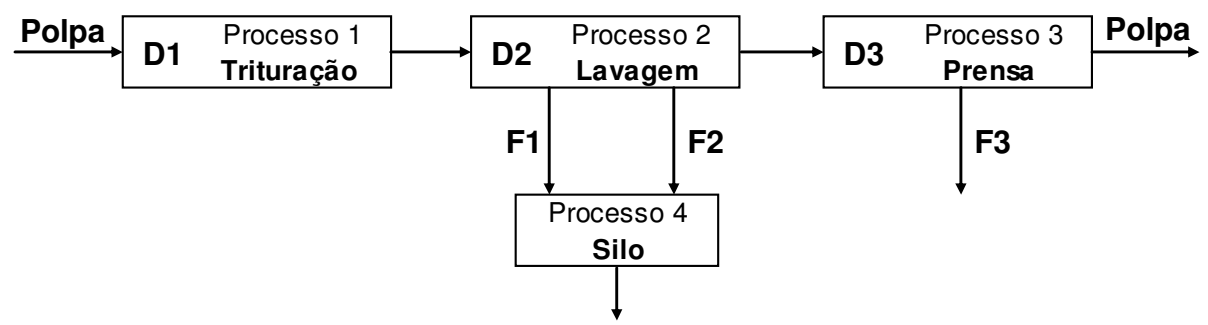

Figura 4.10 - Representação esquemática do exemplo 3. Fonte: Jacob et al. (2002)

A curva de fontes e demandas para esse exemplo está descrita na figura 4.11. O mesmo procedimento do exemplo 2 foi adotado para esse caso. É importante notar que as linhas de fontes e de demandas foram iniciadas na vazão zero. Mas para encontrar o resultado, o importante é fazer com que as duas linhas não se cruzem, ou seja, deslocar a linha tracejada, de demanda, para a direita e encontrar a região de "pinch", como pode ser observado na figura 4.12.

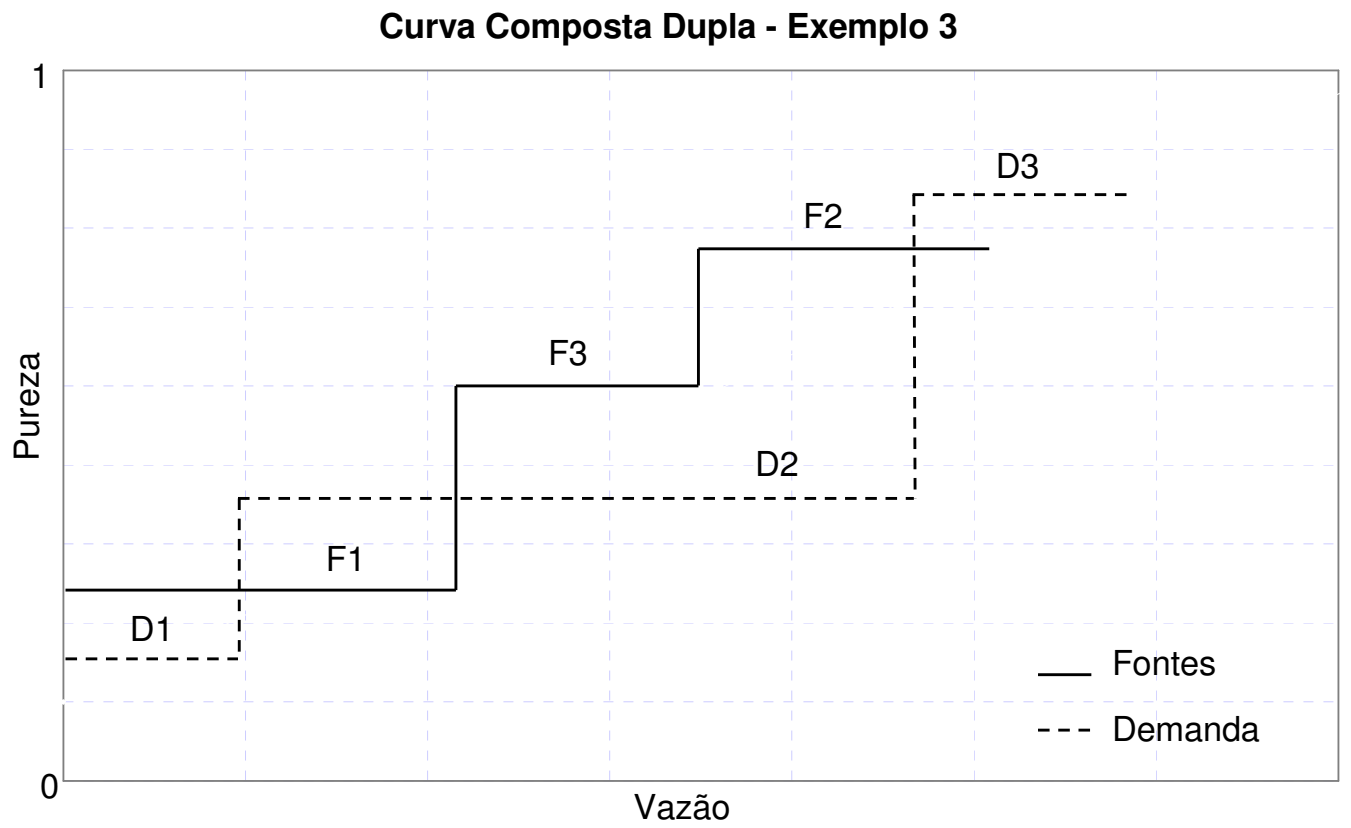

Figura 4.11 - Construção da curva composta dupla para o exemplo 3. Fonte: Jacob et al. (2002) 


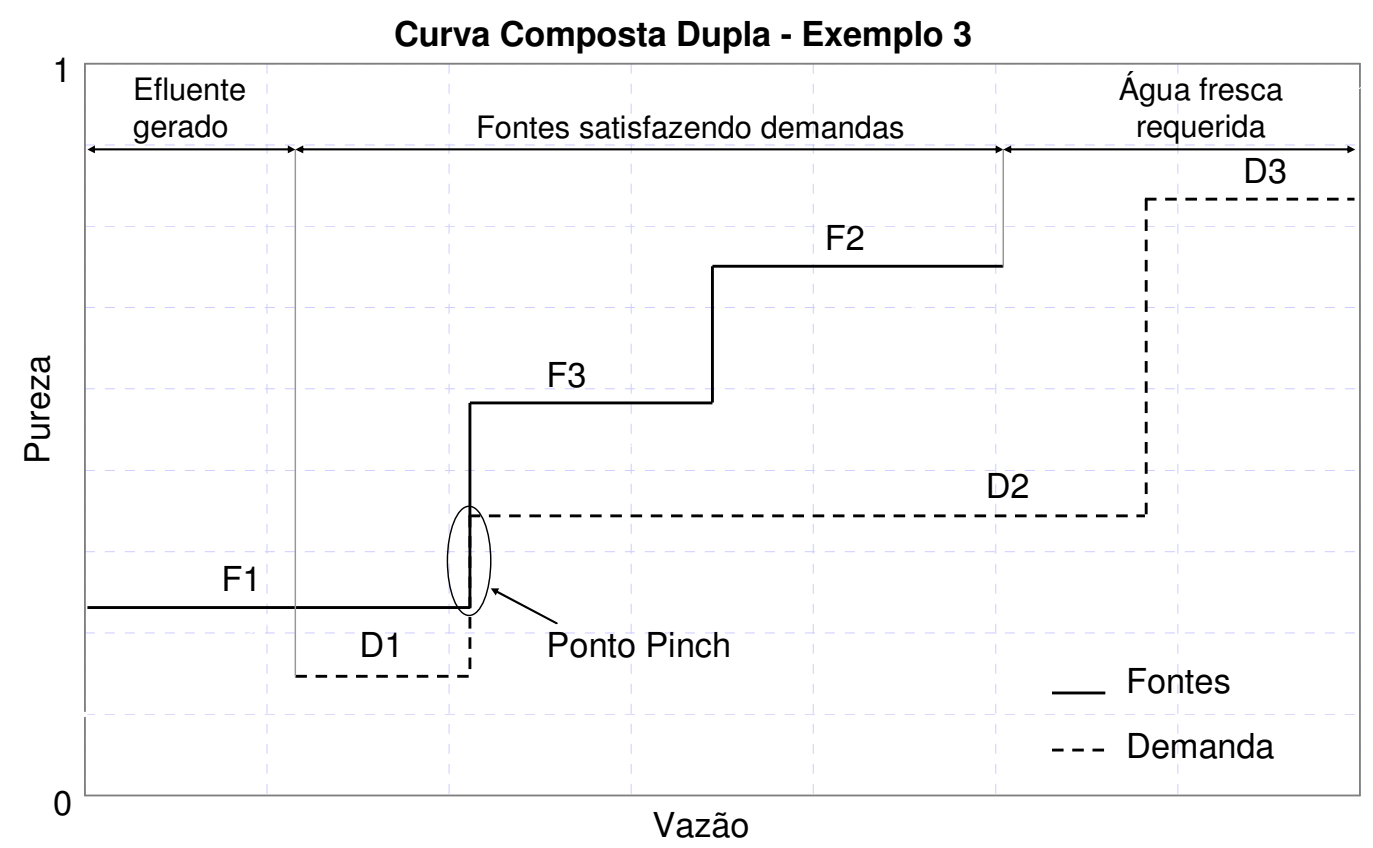

Figura 4.12 - Ponto Pinch da curva composta dupla para o exemplo 3. Fonte: Jacob et al. (2002)

Observa-se que três regiões aparecem na figura 4.12, podendo dessa maneira, fornecer as seguintes informações:

- O consumo mínimo requerido de água fresca pelo processo. A água fresca é utilizada acima do ponto de pinch para satisfazer as demandas que exigem alto grau de pureza, ou seja, D3 e parte de D2.

- A vazão mínima de efluente gerada pelo processo. O efluente aparece abaixo do ponto de pinch e origina da fonte de menor pureza $(\mathrm{F} 1)$;

- As demandas que podem ser satisfeitas pelas fontes disponíveis, ou seja, D1 satisfeita por parte de F1 e D2 satisfeita em parte por F2 e F3;

Esse sistema pode ser melhorado para reduzir o consumo de água fresca e geração de efluentes se o "water pinch" for alterado. Isso pode ser feito ou aumentando a pureza de parte de F1 ou diminuindo as restrições de pureza de D2. Com isso, é possível deslocar a linha de demanda para a esquerda até encontrar um novo ponto de pinch. A primeira opção pode ser satisfeita, 
como mencionado anteriormente, através de uma técnica de mistura entre corrente de fontes ou através da extração de contaminantes de F1. A segunda opção requer mudanças nas condições do processo 2, ou seja, na etapa de lavagem do exemplo em questão.

A segunda opção geralmente requer maiores investimentos por provocar alterações no equipamento e possuir maiores riscos, o que tornaria a sua prática menos atrativa. Portanto, a primeira opção tende a ser mais consistente.

Na figura 4.13, a quantidade mínima requerida de $F 1$ (F1') foi misturada com uma fonte com pureza mais próxima da sua, ou seja, com F3. Com isso criase a fonte $(F 1$ ' + F3) para atingir a pureza de D2 e assim, deslocar a linha de demanda para a esquerda e encontrar um novo "pinch point". O restante do circuito se manteve intacto.

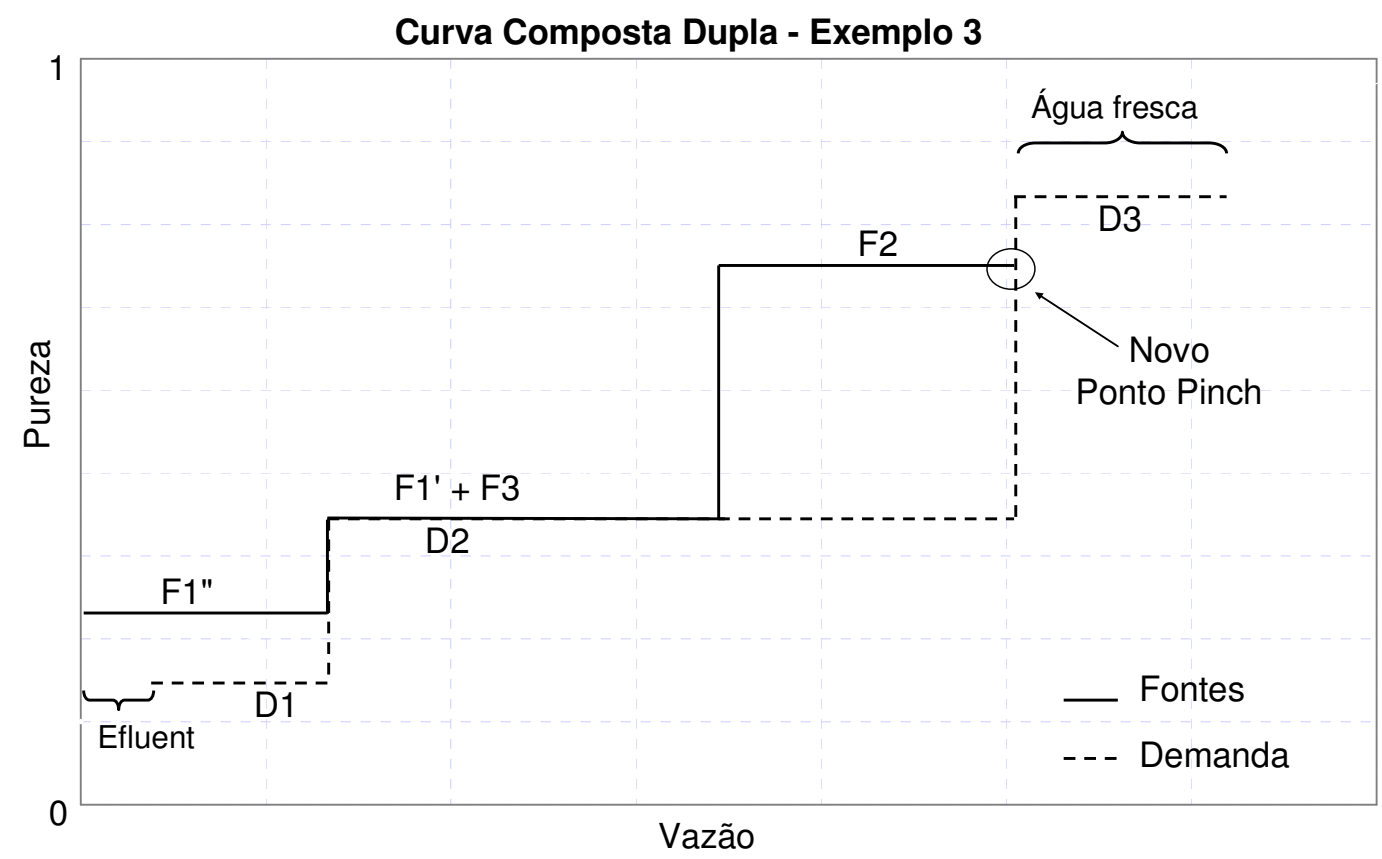

Figura 4.13 - Mistura de fontes para atingir limites do exemplo 3. Fonte: Jacob et al. (2002) 


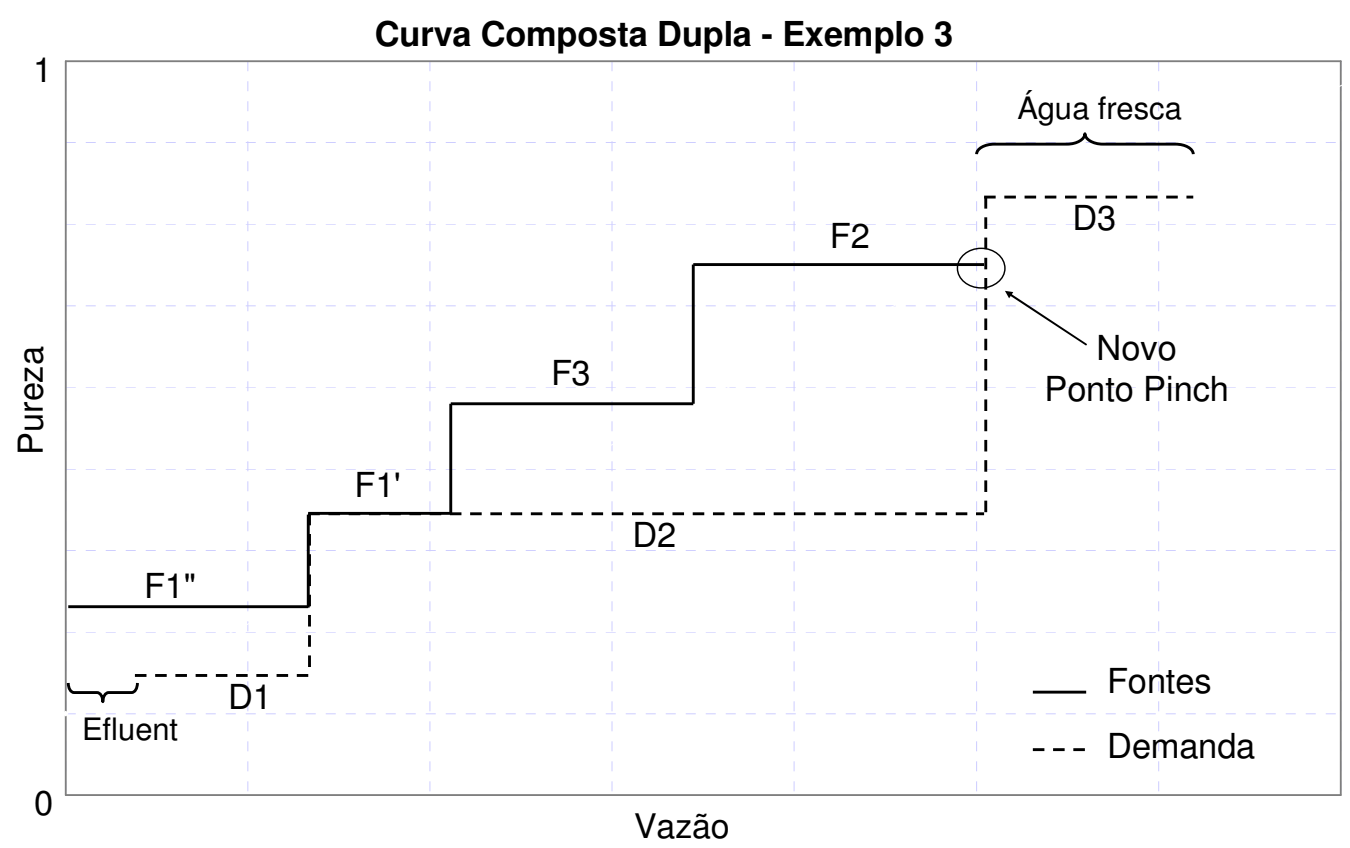

Figura 4.14 - Extração de contaminantes para atingir limites. Fonte: Jacob et al. (2002)

Apesar de o exemplo enfatizar a técnica de mistura, a figura 4.14 demonstra uma outra técnica, a de extração. A mesma quantidade de $F 1$ ( $\left.F 1^{\prime}\right)$ foi tratada em uma etapa de extração para atingir a pureza da demanda D2. Os resultados são bastante semelhantes.

Observando as figuras 4.13 e 4.14, é possível dizer que a análise pode informar locais ótimos para uma etapa de extração, a vazão mínima a ser tratada, e a quantidade mínima de contaminantes a ser extraída.

O ponto Pinch e a curva composta ajudam a identificar pontos que possam ser aperfeiçoados em projetos de unidades fabris existentes. É importante que as fontes abasteçam as demandas do mesmo lado do ponto pinch, ou seja, utilizar a vazão de água de uma fonte acima do ponto pinch em uma demanda abaixo do mesmo ponto, aumentará o consumo além do pretendido. Além disso, utilizar água fresca para satisfazer demandas abaixo do ponto pinch, ou enviar água de fontes acima do ponto para o tratamento de efluentes terá o mesmo efeito. 
Além do método utilizado na figura 4.13, outras saídas para melhorar a configuração do sistema podem ser desenvolvidas. É possível, por exemplo, aumentar a pureza da fonte F2 ou diminuir as restrições de entrada em D3. O processo iterativo pode ser repetido para cada ponto de pinch até a geração de efluente e a água fresca requerida, se reduzirem a zero. No exemplo 3, o efluente poderia ser eliminado primeiro e a água fresca requerida seria reduzida para seu valor mínimo. Mas cada saída dependerá do custo de investimento e facilidades para alterar o sistema e atingir os valores desejados.

O método da curva composta segundo Jacob et al. (2002), pode ser aplicado de duas maneiras diferentes dependendo da configuração do processo inicial:

- Se a configuração inicial do processo for completamente aberta, onde nenhuma corrente de saída das fontes é reutilizada e todas as demandas são atendidas por água fresca, como mostrada na figura 4.4 do exemplo 2, a configuração ótima pode ser encontrada. Porém como o fluxograma do sistema otimizado seria muito diferente do original, altos investimentos seriam necessários.

- Se a configuração da fábrica de celulose e papel já possuir níveis de fechamento razoáveis, com algumas fontes já reaproveitadas internamente e algumas demandas sendo satisfeitas por água fresca. Nesse caso, a configuração otimizada pode não ser atingida.

Porém a possibilidade de reabrir um circuito fechado e estudar novas alternativas que otimizem a configuração do sistema também pode ser viável. Mas também depende, como mencionado, do custo de investimento e tempo para modificações.

\subsection{Análise com programação matemática}

\subsubsection{Conceito}

Essa seção enfatiza o conceito de otimização matemática, considerada um método efetivo para análise, síntese, e alteração em sistemas industriais que 
visam o reuso de água e a minimização de efluentes. Para utilizar o método, duas ferramentas podem ser inseridas no conceito de otimização: a programação matemática linear (LP) ou não linear (NLP).

A LP pode ser utilizada para determinar a mínima vazão de água fresca em uma operação que envolva um contaminante. Quando há necessidade de uma ferramenta para resolver problemas mais complexos, a NLP é a mais indicada.

Técnicas de Otimização matemática são efetivas para minimizar uma função objetivo sujeita a restrições entre variáveis independentes. Programação Linear é uma ferramenta eficiente capaz de encontrar valores mínimos de uma função objetivo linear sujeita a restrições lineares, enquanto que a Programação Não Linear é utilizada para minimizar funções não lineares sujeita a restrições não lineares.

Segundo Jacob et al. (2002), a programação matemática linear é uma ferramenta eficiente para analisar, simultaneamente, a redução de água industrial ao mesmo tempo em que fibras contidas em águas residuais podem ser recuperadas.

\subsubsection{Programação Linear}

Em sua forma básica, um problema de LP consiste de três grupos de equações: função objetivo, restrições implícitas e restrições explícitas. A função objetivo, $y(x)$, é a propriedade funcional a ser maximizada ou minimizada. Como exemplo, é possível aplicar em equações simples e representar graficamente os valores mínimos de uma função objetivo:

$\begin{array}{ll}\text { Minimizar: } & \mathrm{y}(\mathrm{x})=2 \mathrm{x}_{1}+\mathrm{x}_{2} \\ \text { sujeitos a } & \mathrm{A}: \mathrm{x}_{1}+\mathrm{x}_{2} \geq 1 \\ & \mathrm{~B}:-\mathrm{x}_{1}+\mathrm{x}_{2} \leq 1 \\ & \mathrm{C}: \mathrm{x}_{2} \leq 1 \\ & \mathrm{D}: \mathrm{x}_{1} \geq 0 \\ & \mathrm{E}: \mathrm{x}_{2} \geq 0\end{array}$


Para esse caso, pede-se para encontrar valores de $x_{1}$ e $x_{2}$ que minimizem a função objetivo $\mathrm{y}(\mathrm{x})$.

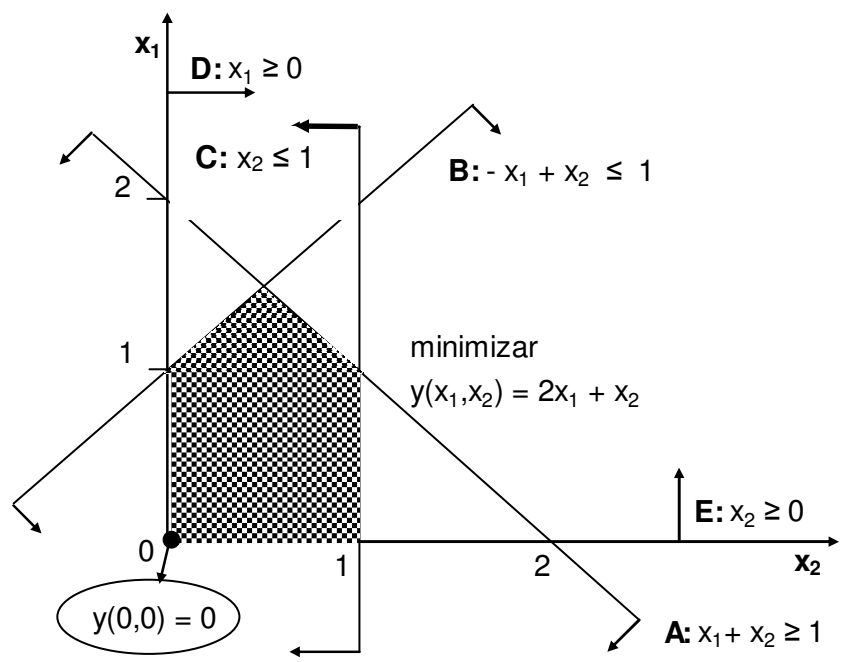

Figura 4.15 - Representação gráfica para programação linear. Fonte: Man; Liu (1999)

A partir da região hachurada, limitada pelas restrições implícitas e explícitas, é possível observar que os valores de x que minimizam a função y está no ponto $(0,0)$.

Tanto a técnica de programação não linear quanto linear é habilitada para lidar com problemas de reuso de água e tratamento de efluentes. Há sistemas com múltiplos contaminantes e com operações que utilizam água que podem não se adequar ao conceito Pinch, mas podem ser complementadas com a programação matemática.

Essa dissertação descreve uma comparação entre a técnica Pinch e a programação matemática, a fim de abordar um estudo eficiente para 0 presente estudo de caso, ou seja, a avaliação do circuito de água em uma fabricação de TMP e papel imprensa.

Para o presente trabalho, além da análise para redução de água fresca no processo, a programação matemática também permite realizar análises de perda de fibras, o que reduziria a quantidade de fibras previamente tratadas para o efluente. 


\subsubsection{Aplicação do método de programação linear}

A Programação Linear é uma ferramenta capaz de superar as desvantagens do método gráfico na aplicação em uma máquina de papel. A técnica pode ser usada para otimizar um circuito de água através da análise por multicomponentes, ao contrário do método Pinch, onde somente um componente era restringido.

O objetivo da tecnologia é encontrar uma configuração ótima de um circuito de água, minimizando o consumo de água fresca, maximizando o reciclo de fibras e satisfazendo a máxima quantidade demandada de água pelo processo através das fontes de água disponíveis. Para formular um problema, Jacob et al. (2002) mencionam que as seguintes informações devem ser fornecidas:

Para cada fonte de água devem ser informadas: a vazão $\mathbf{s}_{\mathbf{i}}$, a concentração de contaminantes $\mathbf{c}_{i}$, e a concentração de sólidos finos $\mathbf{f}_{\mathbf{i}}$, onde $\mathrm{i}=1$ até $\mathrm{m}$ é o número de fontes de água existentes no processo. No caso dos sólidos finos, uma função objetivo pode ser desenvolvida para analisar a perda de fibras durante o processo produtivo.

Para cada demanda: a vazão $D_{i}$, a máxima concentração de contaminantes admissível $\mathrm{C}_{\mathrm{i}}$, e a máxima concentração de sólidos finos admissível $\mathrm{F}_{\mathrm{i} . \text {,onde }}$ i=1 até n é o número de demandas.

As máximas concentrações $\mathrm{Ci}$ e Fi representam os limites reais de sólidos dissolvidos e fibras em determinadas etapas de processo. Por exemplo: A máxima quantidade de fibras na água para que não ocorra o entupimento dos bocais, e a máxima quantidade de sólidos finos na caixa de entrada para que não ocorram deficiências na qualidade do papel. 
Um valor para $\mathrm{Ci}$ e $\mathrm{Fi}$ deve ser especificado para fins computacionais, mesmo se nenhuma corrente é requerida para a operação do processo. Esse valor é importante para não criar restrições artificiais.

O resultado da otimização será uma lista de variáveis definindo a configuração do circuito de água. Essas variáveis, superiores ou iguais a zero, correspondem aos valores de vazão da fonte i que satisfaz a demanda j. Há $n(m+1)$ variáveis que são simbolizados por $p_{i j}(i=0, m ; j=1, n$, onde $i=0$ corresponde à água fresca). As restrições podem ser formuladas da seguinte maneira:

- A vazão total de demandas alimentada por uma fonte i não deve superar a vazão disponível dessa fonte:

$$
\sum_{j=1}^{n} p_{i j} \leq F_{i}
$$

- Cada demanda j deve ser totalmente satisfeita:

$$
\sum_{i=0}^{m} p_{i j}=D_{j}
$$

- A quantidade de contaminante fornecida a uma demanda j não deve ser superior ao valor máximo admissível definido para essa demanda:

$$
\sum_{i=1}^{m} c_{i} p_{i j} \leq D_{j} C_{j}
$$

- A quantidade de fibras celulósicas fornecida a uma demanda j não deve ser superior ao valor máximo admissível definido para essa demanda:

$$
\sum_{i=1}^{m} f_{i} p_{i j} \leq D_{j} F_{j}
$$


A função objetivo $f(x)$ é a quantidade que deve ser minimizada sob restrições definidas por equações lineares nas equações (4.3) a (4.6). Como o objetivo da análise é minimizar o consumo de água fresca, tem-se a seguinte função objetivo:

$$
f(x)=\sum_{j=1}^{n} p_{0 j}(\text { Consumo de água fresca })
$$

Para um estudo mais abrangente, uma função objetivo para o minimizar as perdas de fibras pode ser implementada:

$$
f(x)=-\sum_{i=1}^{m}\left(\alpha_{i} f_{i} \sum_{j=1}^{n} p_{i j}\right) \text { (Rejeição de finos) }
$$

Uma técnica para resolver o problema é encontrar o mínimo da função objetivo (4.7) e depois executar uma nova etapa de otimização com a função objetivo (4.8) usando o mínimo valor como uma restrição adicional.

Para gerar diferentes soluções, uma técnica consiste em executar a etapa de otimização com diferentes valores iniciais de variáveis. As variáveis de $\mathrm{p}_{\mathrm{ij}}$ podem ser impostas como zero para valores iniciais.

O principal objetivo da técnica mencionada acima é reduzir a vazão de efluentes e o consumo de água fresca através de restrições qualitativas e quantitativas impostas pelo programa. Apesar da possibilidade de analisar profundamente a recuperação de fibras no circuito, tal estudo não será focado no presente trabalho.

\section{Exemplo 4: Aplicação de programação matemática para otimização de rede de água para lavagem de polpa celulósica.}

A Programação Matemática Linear pode ser aplicada em casos simples como apresentado por Jacob et al. (2002), onde foi utilizado um programa desenvolvido em Visual Basic para minimizar as funções citadas 
anteriormente. A implementação do método no presente trabalho é executada através da função linprog do programa MatLab.

Valores de vazões e concentrações de fontes e demandas do exemplo apresentado por Jacob et al. (2002) está representado na tabela 8. O sistema possui quatro fontes de águas residuais e três demandas. O objetivo é, através da Programação Matemática Linear, gerar uma combinação de correntes que minimize o uso de água fresca através das restrições impostas pelo programa. A vazão inicial de água fresca é de $1300 \mathrm{~L} / \mathrm{min}$.

O exemplo a seguir possui quatro fontes $(i=4)$ e três demandas $(j=3)$ e está esquematizado na figura 4.16.

Tabela 8 - Dados para exemplificar programação matemática

\begin{tabular}{|c|c|c|c|}
\hline Fontes & $\begin{array}{c}\text { vazão disponível } \\
(\text { L/min) }\end{array}$ & $\begin{array}{c}\text { concentração de fibras } \\
(\%)\end{array}$ & $\begin{array}{c}\text { concentração de } \\
\text { contaminates (ppm) }\end{array}$ \\
\hline F1 & 500 & 0,3 & 100 \\
\hline F2 & 2000 & 0,1 & 110 \\
\hline F3 & 400 & 0,5 & 110 \\
\hline F4 & 300 & 0,5 & 60 \\
\hline
\end{tabular}

\begin{tabular}{|c|c|c|c|}
\hline Demandas & $\begin{array}{c}\text { vazão requerida } \\
\text { (L/min) }\end{array}$ & $\begin{array}{c}\text { concentração de fibras } \\
\text { limite (\%) }\end{array}$ & $\begin{array}{c}\text { concentração de } \\
\text { contaminates limite (ppm) }\end{array}$ \\
\hline D1 & 1200 & 0,5 & 120 \\
\hline D2 & 800 & 0,4 & 105 \\
\hline D3 & 500 & 0,1 & 80 \\
\hline
\end{tabular}

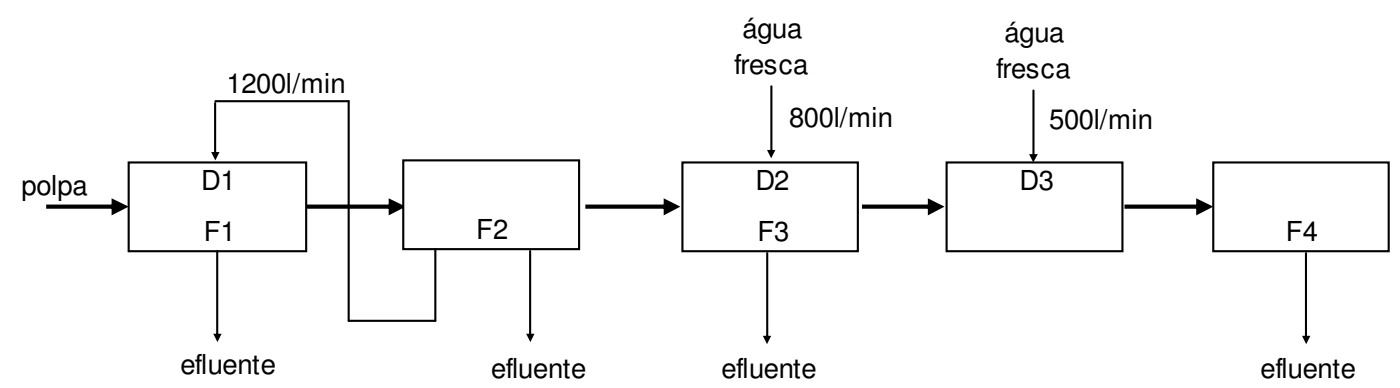

Figura 4.16.- Representação do exemplo 4 para circuito aberto. Fonte: Jacob et al.(2002) 
As restrições citadas na metodologia são detalhadas a seguir, onde cada variável $\mathrm{p}_{\mathrm{ij}}$ significa a vazão de água da fonte i que será utilizada na demanda j para atender o objetivo da função linear, que é minimizar o consumo de água fresca $\mathrm{p}_{0 \mathrm{j}}$. A princípio, o principal objetivo é minimizar a função $p_{01}+p_{02}+p_{03}+p_{04}$

$$
f(x)=\sum_{j=1}^{n} p_{0 j}
$$

sujeitos a,

$$
\begin{aligned}
& \sum_{i=1}^{n} p_{i j} \leq F_{i} \quad\left\{\begin{array}{l}
\mathrm{p}_{01}+\mathrm{p}_{02}+\mathrm{p}_{03} \leq \mathrm{F}_{0} \\
\mathrm{p}_{11}+\mathrm{p}_{12}+\mathrm{p}_{13} \leq \mathrm{F}_{1} \\
\mathrm{p}_{21}+\mathrm{p}_{22}+\mathrm{p}_{23} \leq \mathrm{F}_{2} \\
\mathrm{p}_{31}+\mathrm{p}_{32}+\mathrm{p}_{33} \leq \mathrm{F}_{3} \\
\mathrm{p}_{41}+\mathrm{p}_{42}+\mathrm{p}_{43} \leq \mathrm{F}_{4}
\end{array}\right. \\
& \sum_{i=0}^{m} p_{i j}=D_{j}\left\{\begin{array}{l}
\mathrm{p}_{01}+\mathrm{p}_{11}+\mathrm{p}_{21}+\mathrm{p}_{31}+\mathrm{p}_{41}=\mathrm{D}_{1} \\
\mathrm{p}_{02}+\mathrm{p}_{12}+\mathrm{p}_{22}+\mathrm{p}_{32}+\mathrm{p}_{42}=\mathrm{D}_{2} \\
\mathrm{p}_{03}+\mathrm{p}_{13}+\mathrm{p}_{23}+\mathrm{p}_{33}+\mathrm{p}_{43}=\mathrm{D}_{3}
\end{array}\right. \\
& \sum_{i=1}^{m} c_{i} p_{i j} \leq D_{j} C_{j}\left\{\begin{array}{l}
\mathrm{c}_{1} \mathrm{p}_{11}+\mathrm{c}_{2} \mathrm{p}_{21}+\mathrm{c}_{3} \mathrm{p}_{31}+\mathrm{c}_{4} \mathrm{p}_{41} \leq \mathrm{D}_{1} \mathrm{C}_{1} \\
\mathrm{c}_{1} \mathrm{p}_{12}+\mathrm{c}_{2} \mathrm{p}_{22}+\mathrm{c}_{3} \mathrm{p}_{32}+\mathrm{c}_{4} \mathrm{p}_{42} \leq \mathrm{D}_{2} \mathrm{C}_{2} \\
\mathrm{c}_{1} \mathrm{p}_{13}+\mathrm{c}_{2} \mathrm{p}_{23}+\mathrm{c}_{3} \mathrm{p}_{33}+\mathrm{c}_{4} \mathrm{p}_{43} \leq \mathrm{D}_{3} \mathrm{C}_{3}
\end{array}\right. \\
& \sum_{i=1}^{m} f_{i} p_{i j} \leq D_{j} F_{j}\left\{\begin{array}{l}
\mathrm{c}_{1} \mathrm{p}_{11}+\mathrm{c}_{2} \mathrm{p}_{21}+\mathrm{c}_{3} \mathrm{p}_{31}+\mathrm{c}_{4} \mathrm{p}_{41} \leq \mathrm{D}_{1} \mathrm{C}_{1} \\
\mathrm{c}_{1} \mathrm{p}_{12}+\mathrm{c}_{2} \mathrm{p}_{22}+\mathrm{c}_{3} \mathrm{p}_{32}+\mathrm{c}_{4} \mathrm{p}_{42} \leq \mathrm{D}_{2} \mathrm{C}_{2} \\
\mathrm{c}_{1} \mathrm{p}_{13}+\mathrm{c}_{2} \mathrm{p}_{23}+\mathrm{c}_{3} \mathrm{p}_{33}+\mathrm{c}_{4} \mathrm{p}_{43} \leq \mathrm{D}_{3} \mathrm{C}_{3}
\end{array}\right.
\end{aligned}
$$

Para complementar a análise do circuito, a recuperação de fibras para minimizar seu fluxo para o efluente pode ser feita. A função objetivo a ser minimizada será: $-\alpha_{1} f_{1}\left(p_{11}+p_{12}+p_{13}\right)-\alpha_{2} f_{2}\left(p_{22}+p_{22}+p_{23}\right)-\alpha_{3} f_{3}\left(p_{33}+p_{32}+p_{33}\right)-$ $\alpha_{4} f_{4}\left(p_{44}+p_{42}+p_{43}\right)$, ou seja :

$$
f(x)=-\sum_{i=1}^{m}\left(\alpha_{i} f_{i} \sum_{j=1}^{n} p_{i j}\right)
$$


Onde $\alpha_{i}$ é o valor que determinará o potencial de recuperação em cada processo, ou seja, pode ser igual a 1 para maximizar o reciclo em cada etapa do processo ou 0 em caso de não reciclo.

Dependendo dos valores iniciais de $p_{\mathrm{ij}}$ e de $\alpha_{\mathrm{i}}$, diferentes resultados podem ser gerados. Na tabela 9 são demonstrados resultados com diferentes condições iniciais. O programa foi executado em MatLab através de um programa elaborado para esse fim.

Tabela 9 - Resultados obtidos após aplicar programação linear no exemplo 4

\begin{tabular}{|c|c|c|c|c|}
\hline \multicolumn{5}{|c|}{ Sem reciclo de fibras e condições iniciais $\mathrm{pij}=0$} \\
\hline $\mathbf{p}_{\text {ij }}(\mathbf{L} / \mathbf{m i n})$ & $\mathbf{D} 1$ & $\mathbf{D 2}$ & $\mathbf{D 3}$ & Efluente \\
\hline FW & 0,0000 & 0,0000 & 122,4490 & 0,0000 \\
\hline F1 & 195,9977 & 139,9333 & 0,0000 & 165,0690 \\
\hline F2 & 783,0074 & 420,3484 & 346,9388 & 449,7054 \\
\hline F3 & 157,7913 & 85,5597 & 0,0000 & 156,6490 \\
\hline F4 & 63,2036 & 154,1586 & 30,6122 & 52,0255 \\
\hline Total Efluente & \multicolumn{5}{|c|}{$\mathbf{8 2 2 , 4 4 9} \mathbf{L} / \mathbf{m i n}$} \\
\hline Total água fresca & $\mathbf{1 2 2 , 4 4 9} \mathbf{L} / \mathbf{m i n}$ \\
\hline Fibras p/ efluente & $\mathbf{1 , 9 8 5} \mathbf{~ k g} / \mathbf{m i n}$ \\
\hline
\end{tabular}

\begin{tabular}{|c|c|c|c|c|}
\hline \multicolumn{5}{|c|}{ Com reciclo de fibras $\left(\alpha=\left[\begin{array}{llll}0 & 0 & 1 & 1\end{array}\right]\right)$ e condições iniciais $\mathrm{pij}=$ resultado sem reciclo } \\
\hline$p_{i j}(L / m i n)$ & D1 & D2 & D3 & Efluente \\
\hline FW & 0,0000 & 0,0000 & 122,4490 & 0,0000 \\
\hline F1 & 190,1311 & 124,0233 & 0,0000 & 185,8456 \\
\hline F2 & 586,4622 & 429,9956 & 346,9388 & 636,6034 \\
\hline F3 & 272,9742 & 127,0258 & 0,0000 & 0,0000 \\
\hline F4 & 150,4324 & 118,9553 & 30,6122 & 0,0000 \\
\hline Total Efluente & \multicolumn{4}{|c|}{$822,449 \mathrm{~L} / \mathrm{min}$} \\
\hline Total Água fresca & \multicolumn{4}{|c|}{$122,449 \mathrm{~L} / \mathrm{min}$} \\
\hline Fibras $\mathrm{p} /$ efluente & \multicolumn{4}{|c|}{$1,194 \mathrm{~kg} / \mathrm{min}$} \\
\hline
\end{tabular}

\begin{tabular}{|c|c|c|c|c|}
\hline \multicolumn{5}{|c|}{ Com reciclo de fibras $\left(\alpha=\left[\begin{array}{llll}1 & 1 & 1 & 1\end{array}\right]\right)$ e condições iniciais $\mathrm{pij}=$ resultado sem reciclo } \\
\hline$p_{i j}(L / m i n)$ & D1 & D2 & D3 & Efluente \\
\hline FW & 0,0000 & 0,0000 & 122,4490 & 0,0000 \\
\hline F1 & 311,6406 & 188,3594 & 0,0000 & 0,0000 \\
\hline F2 & 454,2587 & 376,3535 & 346,9388 & 822,4490 \\
\hline F3 & 274,8416 & 125,1584 & 0,0000 & 0,0000 \\
\hline F4 & 159,2591 & 110,1286 & 30,6122 & 0,0000 \\
\hline Total Efluente & \multicolumn{4}{|c|}{$822,449 \mathrm{~L} / \mathrm{min}$} \\
\hline Total Água fresca & \multicolumn{4}{|c|}{$122,449 \mathrm{~L} / \mathrm{min}$} \\
\hline Fibras $\mathrm{p} /$ efluente & \multicolumn{4}{|c|}{$0,822 \mathrm{~kg} / \mathrm{min}$} \\
\hline
\end{tabular}

O esquema do processo otimizado pode ser ilustrado na figura 4.17, onde 0 aumento do grau de reciclo pode ser observado. 


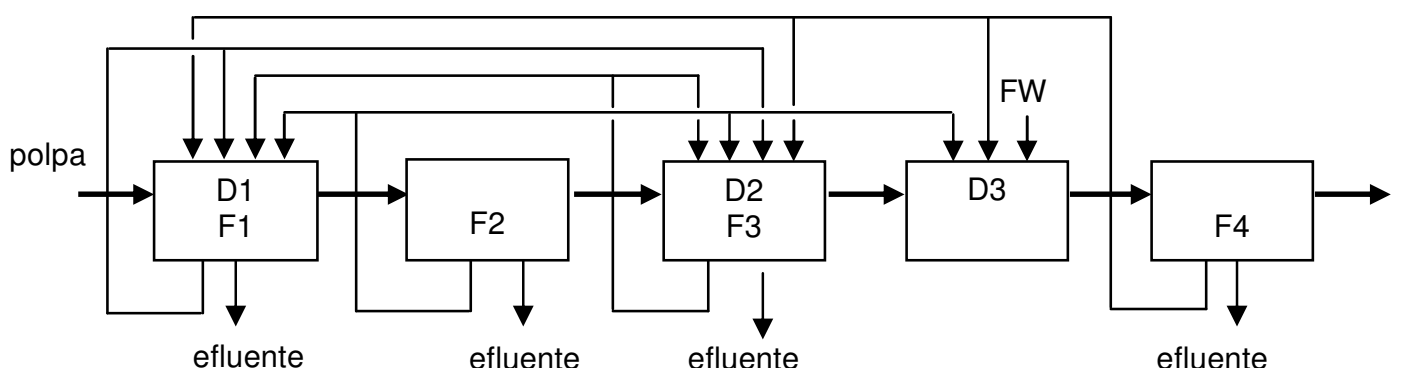

Figura 4.17.- Representação esquemática do exemplo para circuito fechado ( $\left.\alpha=\left[\begin{array}{llll}0 & 0 & 1 & 1\end{array}\right]\right)$ após a aplicação de programação linear

Aqui a vazão de água fresca passou de $1300 \mathrm{~L} / \mathrm{min}$ para $122,5 \mathrm{~L} / \mathrm{min}$, ou seja, uma redução de $90,6 \%$. Porém deve-se lembrar que as condições limites que foram impostas no exemplo permitem uma redução significativa de água fresca no processo.

Aqui ilustrou-se os principais métodos de integração de processos para rede de uso de água, que serão aplicados na máquina de papel e na fabricação TMP. Ambos os métodos, pinch e programação linear, podem ser utilizados para minimizar o consumo de água fresca em relação a restrição dada pelos contaminantes críticos. Tal como observado pelo Jacob et al. (2002), o método gráfico pinch pode ser parcialmente automatizado mas é aplicável apenas a um contaminante. Por outro lado, programação linear aqui aplicado a um contaminante adicionado de uma concentração de finos de fibras de celulose, é totalmente automatizado e é melhor adaptado a problemas maiores, desde que haja julgamento de engenharia para não aceitar soluções não realísticas. 


\section{ANÁLISE DAS ALTERNATIVAS PARA O CIRCUITO DE ÁGUAS DA FÁBRICA DE TMP E PAPEL IMPRENSA}

Esse capítulo é dedicado à apresentação de resultados da aplicação de integração de processos para minimizar o uso de água fresca nos processos de máquina de papel e de fabricação TMP, assim como a descrição de vantagens e dificuldades encontradas durante o trabalho. O circuito de água do estudo de caso encontra-se em um bom grau de fechamento, onde a única possibilidade seria substituir a água fresca que é utilizada no sistema de lavagem dos rolos, feltro e telas da máquina. Portanto, é possível que não se encontre a configuração ótima do sistema.

\subsection{Principais fontes e demandas}

Para iniciar o tratamento de dados, é preciso definir primeiramente as correntes de água que formam o circuito do estudo de caso. A figura 5.1 mostra a simplificação do processo produtivo com os fluxos de água a serem analisados. Os valores de cada corrente estão mostrados na tabela 10. É possível observar que as fontes são basicamente originadas de processos de filtração e extração, e as demandas, oriundas principalmente de etapas de diluição e lavagem de polpa. No processo real, a máquina de papel da unidade fabril convive com um desperdício contínuo de água, comprovado pelo transbordo da torre de água clara. Sendo assim, houve uma motivação para simular o caso e tentar reduzir a vazão para o efluente. Mas infelizmente a vazão de desperdício não é medida durante o processo, sendo necessário aproximar seu valor através da simulação, sempre analisando sua influência em outros valores simulados. A vazão foi de aproximadamente $1400 \mathrm{~L} / \mathrm{min}$.

Para a aplicação dos métodos de otimização, algumas correntes citadas na tabela 10 não serão utilizadas, pois são consideradas intermediárias por não influenciar o balanço macroscópico de fontes e demandas. O circuito de água existente possui algumas correntes de reciclo como, por exemplo, a corrente 32 da figura 5.1. Essa corrente, descrita como o transbordo de água branca 
da torre para o silo, permite uma leve diluição da água branca proveniente da seção de formação. A mistura dessa corrente com a água existente no silo será a responsável pelo ajuste da consistência da polpa em 1\%, ou seja, pela maior demanda de água do circuito. Para evitar confusões e altos níveis de complexidade ao analisar o circuito de água, os fluxos intermediários e de reciclo não devem ser considerados. A corrente 32, por exemplo, pode ser ao mesmo tempo uma fonte da torre de água branca ou uma demanda do silo. Portanto, foram somente consideradas fontes as correntes realmente originadas do processo, como operações de filtração ou extração. E o mesmo se aplica a demandas, que são correntes responsáveis principalmente por processo de diluição ou lavagem de polpa.

O circuito de água em uma fábrica de papel pode operar de forma eficiente por haver fontes e demandas com vazões mássicas altas, ou seja, com grandes chances de aproveitamento em circuito. É preciso somente analisar os níveis de contaminantes para limitar seu grau de fechamento. Para exemplificar, as correntes 28 e 37 da tabela 10, ou seja, o filtrado claro da recuperação de fibras e a água branca da seção de formação úmida do papel, são fontes potenciais para suprir as demandas com a mesma ordem de grandeza. Essas demandas são principalmente as correntes 31 e 44, ou seja, a vazão de água para os filtros de recuperação de fibras, e a água utilizada para diluir a polpa antes da caixa de entrada. E o objetivo dos métodos é justamente adequar as fontes para as demandas através de técnicas gráficas e matemáticas.

Consumidores potenciais de água também estão presente no setor de TMP, onde o objetivo é diluir e lavar a polpa após refinação. As correntes 3 e 8 são as vazões necessárias para a operação e serão muito importantes para a análise do circuito. O filtrado do filtro a tambor, representado pela corrente 17 , é uma fonte atualmente utilizada para a operação de diluição e lavagem. Porém através do presente estudo, essa e outras fontes podem ser combinadas com o objetivo de minimizar o consumo de água fresca, representados na tabela 10 pelas correntes 40 e 41 . 
Tabela 10 - Tabela com as correntes de água

\begin{tabular}{|c|c|c|c|c|}
\hline № & $\begin{array}{c}\text { Vazão } \\
\text { (L/min) }\end{array}$ & $\begin{array}{c}\text { [Fibras] } \\
(\%)\end{array}$ & $\begin{array}{c}\text { [SD] } \\
\text { (ppm) }\end{array}$ & Corrente \\
\hline 1 & 356,2 & 0,082 & 4066 & $\begin{array}{l}\text { Diluição e selagem do refinador primário } \\
\text { (linha 2) }\end{array}$ \\
\hline 2 & 384,1 & 0,082 & 4066 & $\begin{array}{c}\text { Diluição e selagem do refinador secundário } \\
\text { (linha 2) }\end{array}$ \\
\hline 3 & 8279,3 & 0,082 & 4066 & Diluição do tanque de latência (linha 2) \\
\hline 4 & 39,8 & 0,082 & 4066 & $\begin{array}{l}\text { Diluição de rejeitos da depuração primária } \\
\qquad \text { (linha 2) }\end{array}$ \\
\hline 5 & 54,7 & 0,082 & 4066 & $\begin{array}{l}\text { Diluição de rejeitos da depuração secundária } \\
\qquad(\text { linha 2) }\end{array}$ \\
\hline 6 & 94,0 & 0,300 & 4747 & Diluição do refinador primário (linha 1) \\
\hline 7 & 108,7 & 0,300 & 4747 & Diluição dos refinadores de rejeito \\
\hline 8 & 4946,3 & 0,080 & 4066 & Diluição do tanque de latência da linha 1 \\
\hline 9 & 605,7 & 0,400 & 4747 & Água da peneira inclinada pós depuração \\
\hline 10 & 202,7 & 0,300 & 4747 & Diluição de refinadores da linha 1 \\
\hline 11 & 1781,2 & 0,300 & 4747 & Água da prensa de rejeitos \\
\hline 12 & 1087,2 & 0,050 & 4662 & Filtrado turvo do filtro a disco \\
\hline 13 & 9114,1 & 0,082 & 4066 & Água filtrada para a linha 2 \\
\hline 14 & 1584,8 & 0,040 & 4662 & Água para chuveiro do filtro a disco \\
\hline 15 & 2537,3 & 0,030 & 4662 & Filtrado claro do filtro a disco \\
\hline 16 & 1840,8 & 0,030 & 4662 & Água do filtro a disco \\
\hline 17 & 5544,1 & 0,050 & 4849 & Filtrado do filtro a tambor \\
\hline 18 & 1483,6 & 0,082 & 2451 & Diluição após o branqueamento \\
\hline 19 & 1254,9 & 0,082 & 2451 & Diluição para o tanque 1 de TMP \\
\hline 20 & 1781,2 & 0,300 & 4747 & Água da peneira inclinada pós prensa \\
\hline 21 & 4292,3 & 0,047 & 2487 & Água clara para tanque de água filtrada \\
\hline 22 & 0,0 & 0,000 & 0 & Água branca para tanque de água filtrada \\
\hline 23 & 18481,9 & 0,047 & 2487 & Água do tanque para a torre de água clara \\
\hline
\end{tabular}




\begin{tabular}{|c|c|c|c|c|}
\hline № & $\begin{array}{l}\text { Vazão } \\
\text { (L/min) }\end{array}$ & $\begin{array}{c}\text { [Fibras] } \\
(\%)\end{array}$ & $\begin{array}{l}\text { [SD] } \\
\text { (ppm) }\end{array}$ & Corrente \\
\hline 24 & 12793,8 & 0,047 & 2487 & $\begin{array}{l}\text { Água da torre de água clara para torre de } \\
\text { água branca }\end{array}$ \\
\hline 25 & 1395,9 & 0,047 & 2487 & Transbordo da torre de água clara \\
\hline 26 & 997,4 & 0,050 & 2487 & Água para chuveiro dos filtros Save-All \\
\hline 27 & 2316,2 & 0,025 & 2487 & Filtrado Superclaro dos filtros Save-All \\
\hline 28 & 17450,7 & 0,050 & 2487 & Filtrado claro dos filtros Save-All \\
\hline 29 & 3477,6 & 0,300 & 2487 & Filtrado turvo dos filtros Save-All \\
\hline 30 & 2486,8 & 0,300 & 2307 & Água para torre de água branca \\
\hline 31 & 20965,7 & 0,300 & 2307 & Água para recuperação de fibras \\
\hline 32 & 12952,1 & 0,245 & 2451 & Transbordo de água branca para o silo \\
\hline 33 & 996,7 & 0,082 & 2451 & Diluição do couch pit \\
\hline 34 & 1406,8 & 0,010 & 2380 & Filtrado do Filtro de refugo \\
\hline 35 & 23452,5 & 0,300 & 2307 & $\begin{array}{l}\text { Água p/ recuperação de fibras e torre de } \\
\text { água branca }\end{array}$ \\
\hline 36 & 909,3 & 0,460 & 2417 & Efluente do sistema de baixa consistência \\
\hline 37 & 54323,2 & 0,351 & 2273 & Água branca extraída da seção de formação \\
\hline 38 & 3420 & 0,000 & 0 & Água fresca para máquina de papel \\
\hline 39 & 299,1 & 0,050 & 2487 & Água para chuveiro do filtro de refugo \\
\hline 40 & 3420 & 0,000 & 0 & ÁGUA FRESCA \\
\hline 41 & 786,8 & 0,000 & 0 & ÁGUA FRESCA \\
\hline 42 & 1859,1 & 0,458 & 2273 & Efluente da seção de prensas \\
\hline 43 & 3477,6 & 0,300 & 2487 & $\begin{array}{c}\text { Água turva para os filtros de recuperação de } \\
\text { fibras }\end{array}$ \\
\hline 44 & 43822,8 & 0,300 & 2307 & Água branca para bomba de mistura \\
\hline
\end{tabular}




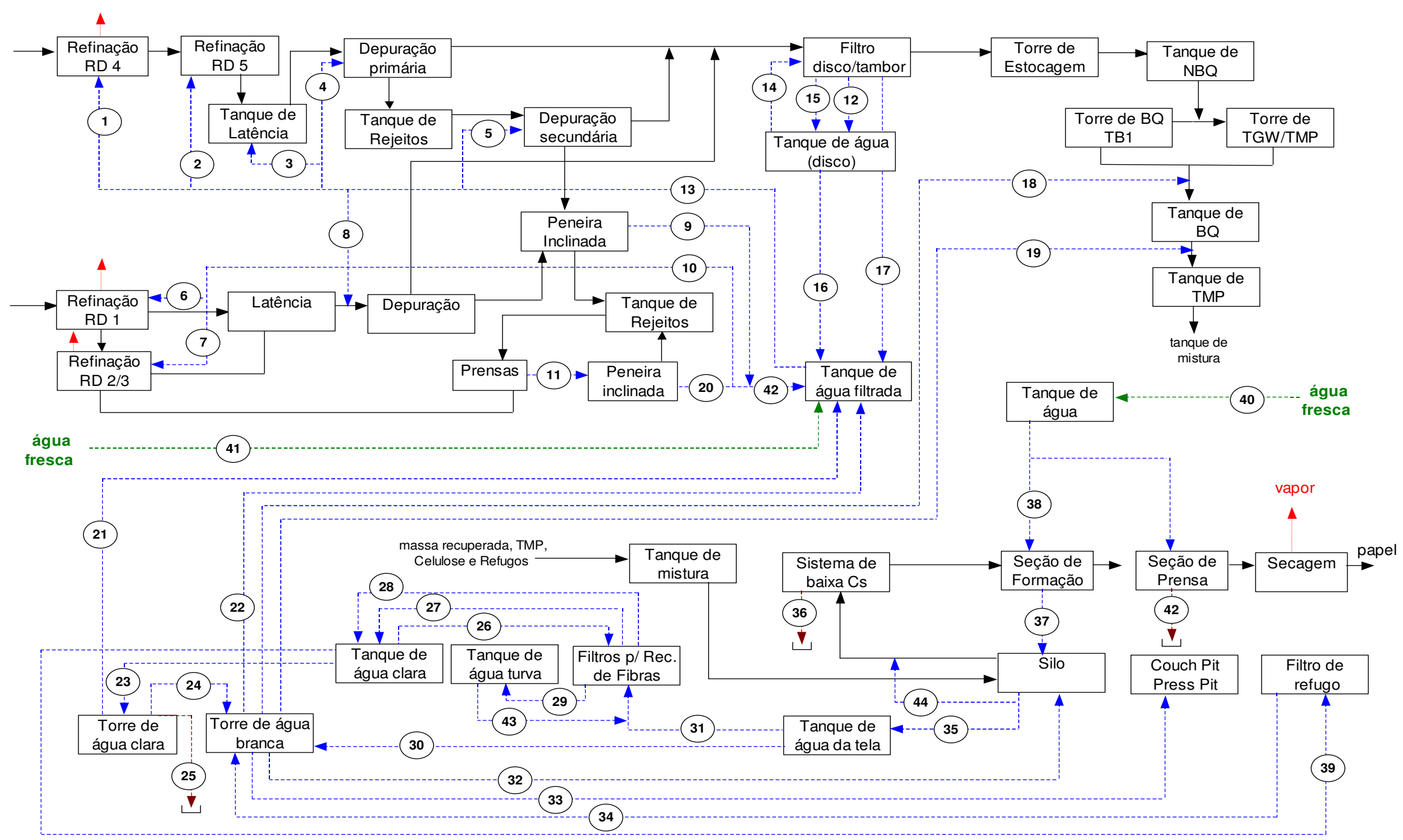

Figura 5.1 - Esquema ilustrando as principais correntes de água do processo. 


\subsection{Resultados do método Pinch}

Como já mencionado, a técnica de curva composta dupla para Fontes e Demandas, (Dhole et al., 1996), será utilizada no estudo de caso. A metodologia foi aplicada para dois casos: $(i)$ as correntes de águas residuais e frescas somente para a máquina de papel, e (ii) as correntes para o processo da máquina está integrada com a produção de TMP.

\subsubsection{Análise somente para a máquina de papel aplicando pinch}

As fontes e demandas para aplicação do método Pinch devem ser ordenadas na ordem decrescente dos valores de concentração limites da substância. As principais fontes e demandas identificadas na produção de papel estão ordenadas de acordo com a concentração de fibras nas tabelas 11 e 12:

Tabela 11 - Fontes de água ordenadas para fibras em de produção de papel

\begin{tabular}{|c|c|c|c|c|}
\hline & Descrição & $\begin{array}{c}\text { Vazão } \\
\text { (L/min) }\end{array}$ & $\begin{array}{c}\text { [fibras] } \\
\text { (\%) }\end{array}$ & $\begin{array}{c}\text { [SD] } \\
\text { ppm }\end{array}$ \\
\hline F1 & Água branca extraída da seção de formação & 54323,2 & 0,351 & 2273 \\
\hline F2 & Filtrado claro dos filtros Save-All & 17450,7 & 0,050 & 2487 \\
\hline F3 & Filtrado Superclaro dos filtros Save-All & 2316,2 & 0,025 & 2487 \\
\hline F4 & Filtrado do Filtro de refugo & 1406,8 & 0,010 & 2380 \\
\hline
\end{tabular}

Tabela 12 - Demandas ordenadas para fibras em produção de papel

\begin{tabular}{|c|c|c|c|c|c|c|}
\hline & Descrição & $\begin{array}{l}\text { Vazão } \\
\text { (L/min) }\end{array}$ & $\begin{array}{c}\text { [fibras] } \\
(\%)\end{array}$ & $\begin{array}{c}\text { limite } \\
\text { [fibras] (\%) }\end{array}$ & $\begin{array}{l}{[\mathrm{SD}]} \\
\mathrm{ppm}\end{array}$ & $\begin{array}{l}\text { limite [SD] } \\
\text { ppm }\end{array}$ \\
\hline D1 & $\begin{array}{l}\text { Diluição após o } \\
\text { branqueamento }\end{array}$ & 1483,7 & 0,082 & 0,800 & 2451 & 3000 \\
\hline D2 & $\begin{array}{c}\text { Diluição para o tanque } 1 \\
\text { de TMP }\end{array}$ & 1255,0 & 0,082 & 0,800 & 2451 & 3000 \\
\hline D3 & $\begin{array}{c}\text { Água para chuveiro dos } \\
\text { filtros Save-All }\end{array}$ & 997,4 & 0,050 & 0,800 & 2487 & 3000 \\
\hline D4 & Diluição do couch pit & 996,7 & 0,082 & 0,800 & 2451 & 3000 \\
\hline D5 & $\begin{array}{l}\text { Água para chuveiro do } \\
\text { filtro de refugo }\end{array}$ & 299,0 & 0,050 & 0,800 & 2487 & 3000 \\
\hline D6 & $\begin{array}{l}\text { Água branca para } \\
\text { recuperação de fibras }\end{array}$ & 20966,0 & 0,300 & 0,300 & 2487 & 3000 \\
\hline D7 & $\begin{array}{c}\text { Água branca para bomba } \\
\text { de mistura }\end{array}$ & 43823,0 & 0,300 & 0,300 & 2307 & 3000 \\
\hline D8 & $\begin{array}{l}\text { Água da torre de água } \\
\text { clara para linha de TMP }\end{array}$ & 4292,0 & 0,047 & 0,100 & 2487 & 3000 \\
\hline D9 & $\begin{array}{l}\text { Água fresca para a } \\
\text { máquina de papel }\end{array}$ & 3420,0 & 0,000 & 0,018 & 0 & 2500 \\
\hline
\end{tabular}


Como pode ser observado na figura 5.2, cada valor de concentração de sólidos dissolvidos (SD) é inferior a todos os valores limites para a mesma substância. Dessa maneira, a ordenação das correntes e o tratamento gráfico para sólidos dissolvidos não serão necessários.

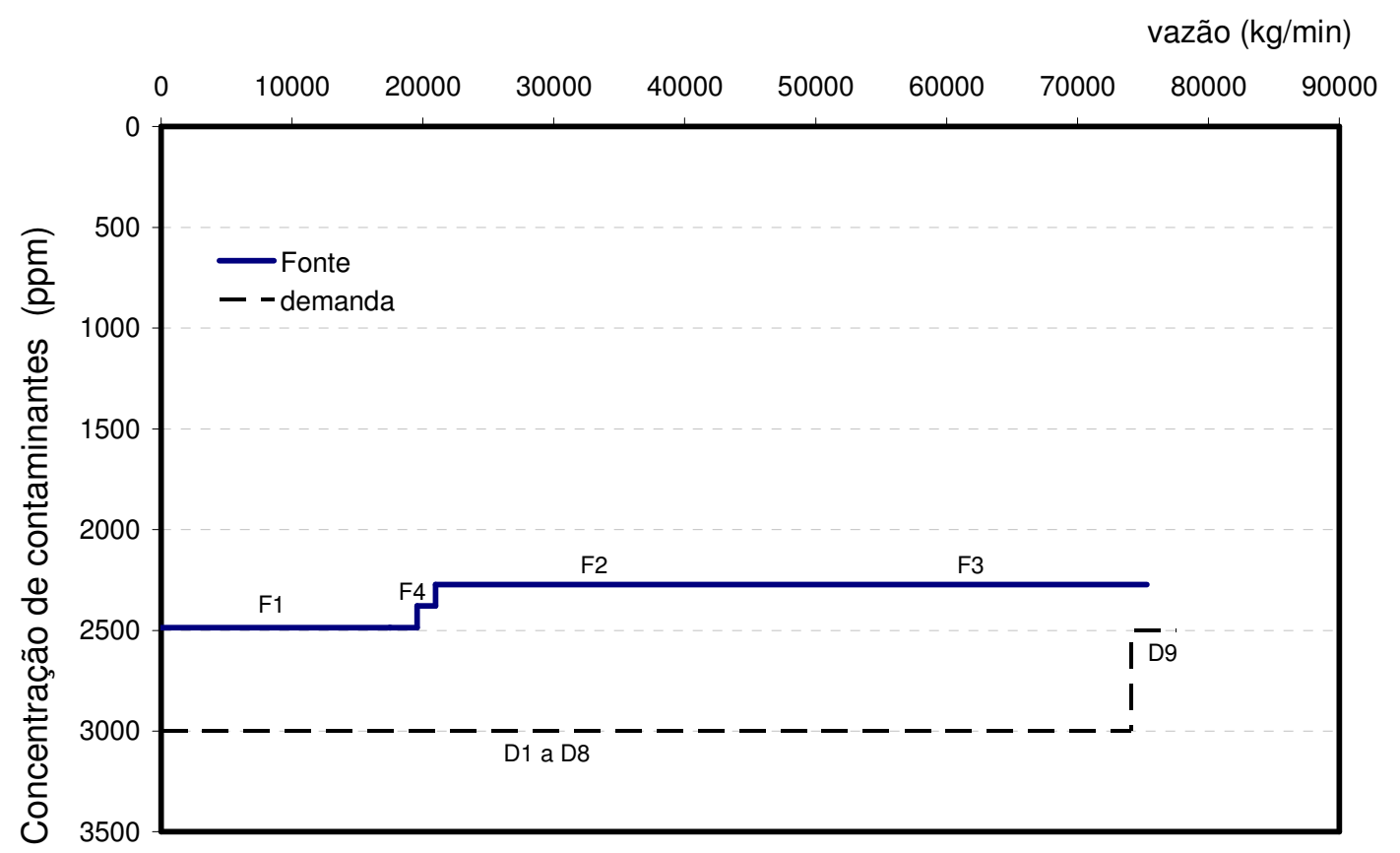

Figura 5.2 - Curva composta dupla para sólidos dissolvidos em máquina de papel

O valor limite de 5000 ppm para sólidos dissolvidos foi utilizado pelo trabalho de Jacob et at (2002) e é considerado um valor aceitável em uma unidade produtiva de papel imprensa. Porém como as demandas para produzir papel não ultrapassaram o valor de 3000 ppm durante a simulação, essa concentração foi adotada como valor limite, conforme mostra a figura 5.2 e a tabela 12. A exceção é a corrente de água fresca, onde foi adotada uma pureza maior.

Para a concentração de fibras, observa-se através da figura 5.3 que o comportamento não é similar ao ocorrido com os sólidos dissolvidos. Portanto, é possível manipular o ponto pinch para tentar reduzir o consumo de água fresca. 


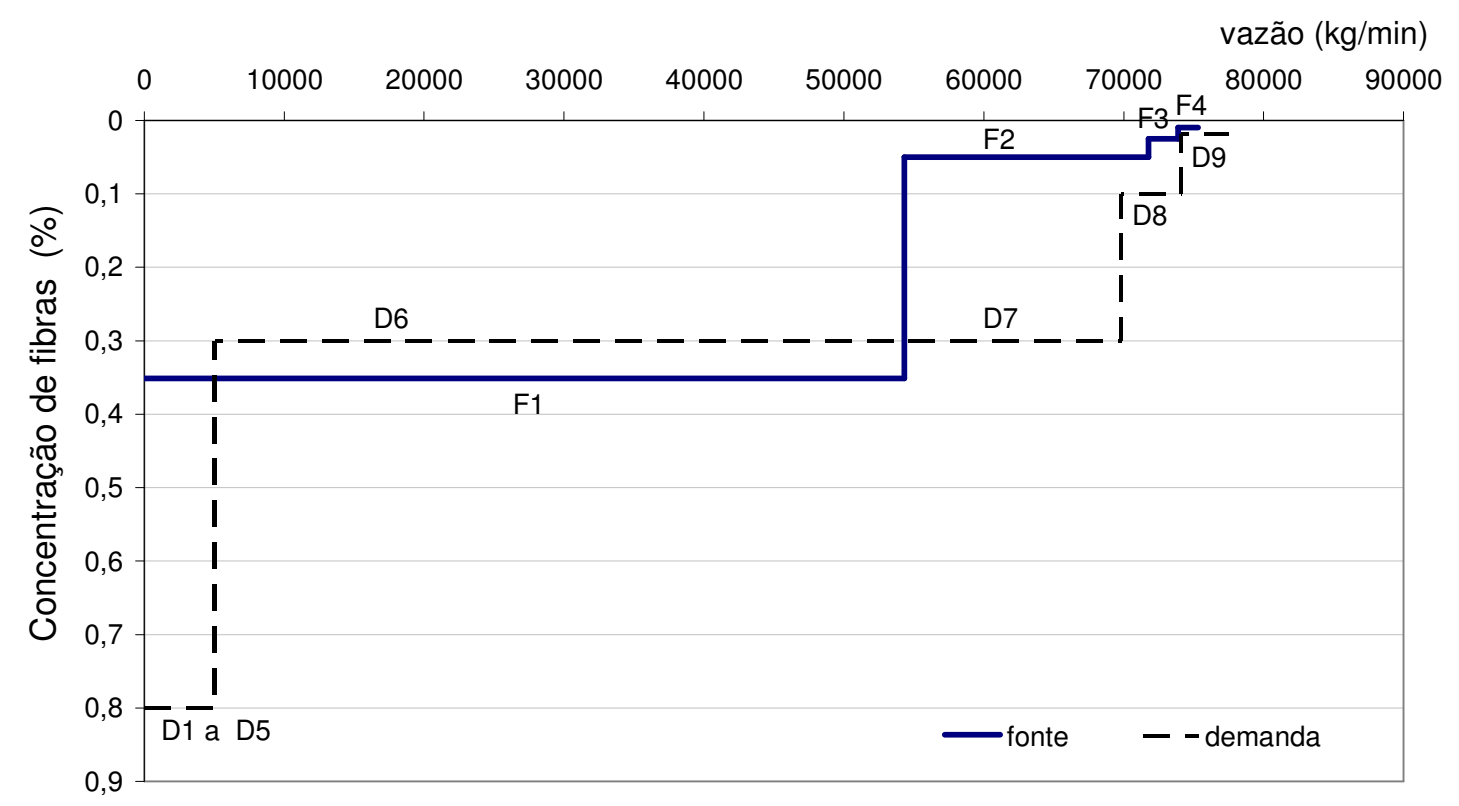

Figura 5.3 - Curva composta dupla para fibras em máquina de papel (passo 1)

Para atingir o ponto pinch, desloca-se a curva de demanda do gráfico anterior para a direita até eliminar o cruzamento entre as curvas. Após o deslocamento, o ponto pinch pode ser identificado conforme figura 5.4.

Com exceção da demanda D9 para os chuveiros da máquina de papel, um valor limite aceitável para concentração de fibras está na ordem de $1 \%$. 0 valor é também utilizado por Jacob et at (2002). Porém no presente trabalho, diferentes valores limites foram utilizados, conforme mostra a tabela 12. Para correntes de altas vazões como D6, D7 e D8, a decisão foi adotar valores iguais ou próximos ao do resultado simulado. O motivo se baseia no fato de que as correntes são utilizadas para diluição (D7 e D8) ou recuperação de fibras (D6), ou seja, processos controlados pela concentração de fibras. Como o método Pinch focaliza somente a vazão das correntes, é importante atribuir valores limites iguais ou próximos ao original para evitar incoerências da simulação com o processo real. Para exemplificar, consideremos um limite para a demanda D7 de 0,351\%, ou seja, igual a da fonte F1. Essa fonte é responsável pela principal diluição da polpa antes da caixa de entrada, uma etapa vital do processo de produção de papel. Se fosse utilizado o valor limite de $0,351 \%$ para $D 7$, o consumo de água branca teria que ser 
aproximadamente 25\% maior para atingir a mesma consistência de polpa utilizando o valor de $0,3 \%$. Porém o método Pinch atribuiria a mesma vazão para ambos os casos. Sendo assim, o valor limite de 0,3 \% foi considerado.

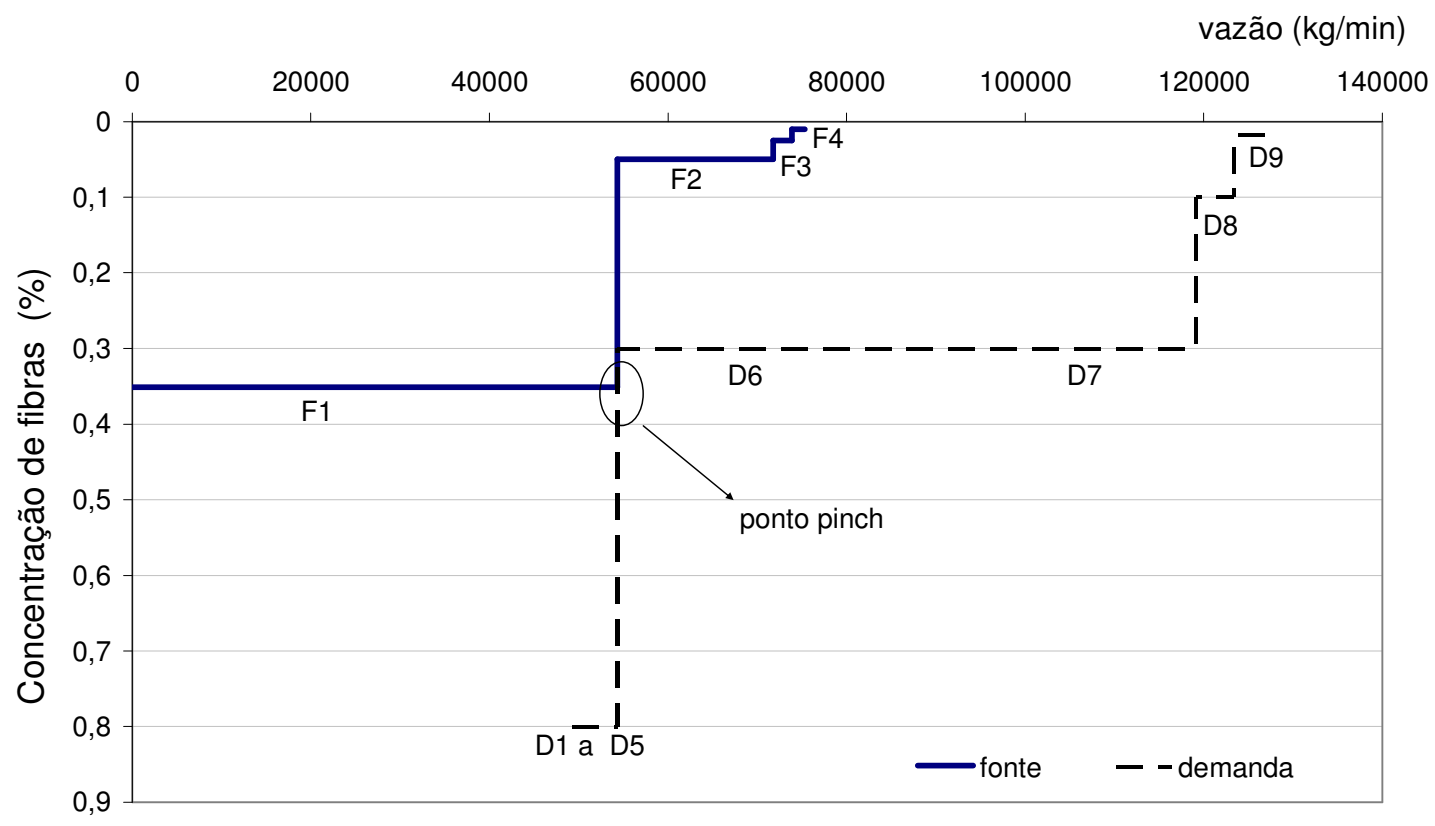

Figura 5.4 - Curva composta dupla para fibras em máquina de papel (passo 2)

O objetivo da aplicação do método Pinch é, através das fontes e demandas consideradas, construir um novo circuito de água baseado na concentração limite de contaminantes. Portanto, o próximo passo do método é manipular a curva das fontes da figura 5.4. Deste gráfico, é fácil perceber a possibilidade de misturar a fonte F1 com parte de F2 para atingir a concentração limite de fibras de D6 e D7, como mostra a figura 5.5. 


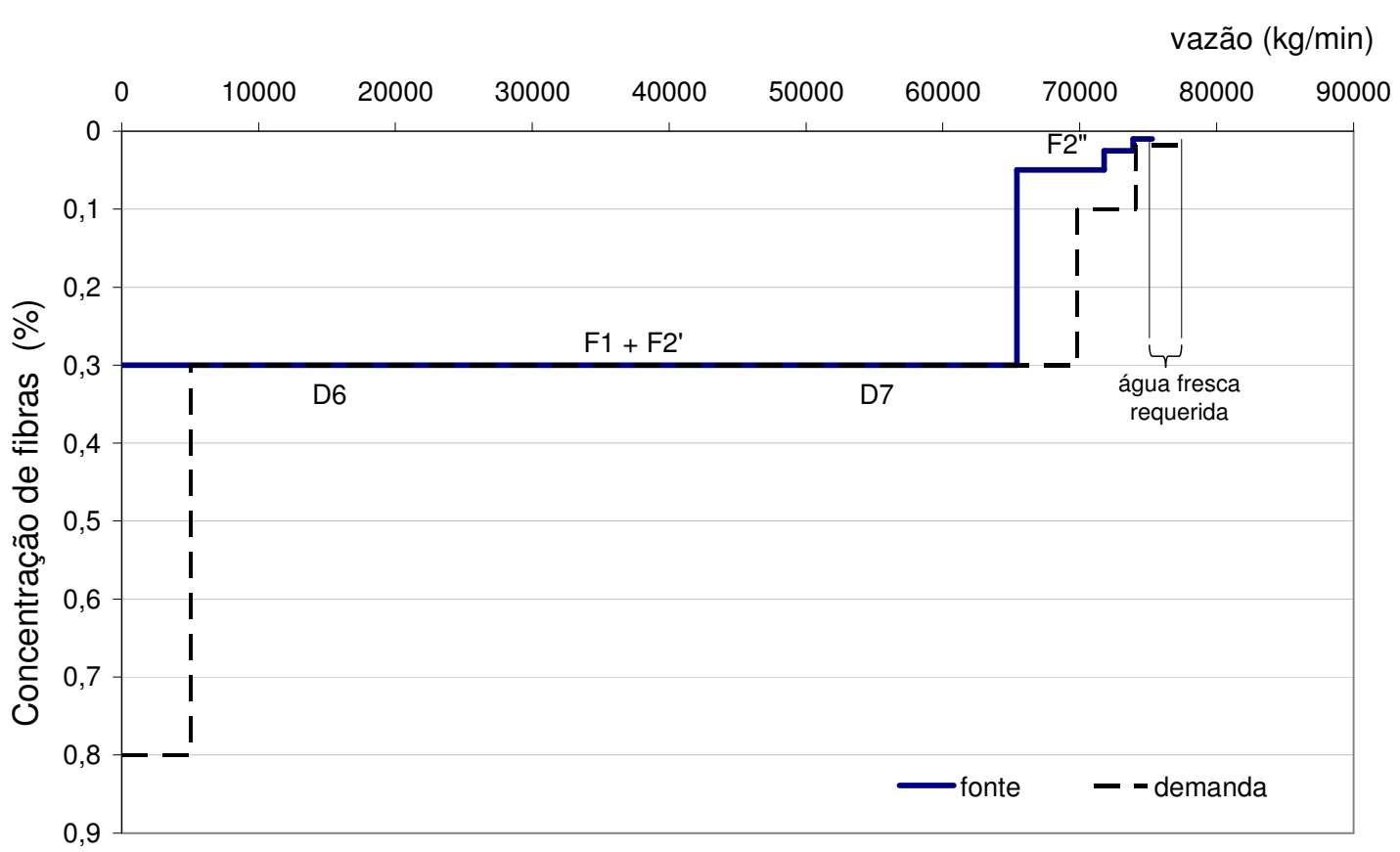

Figura 5.5 - Mistura de fontes para atingir limite de concentração de fibras (passo 3)

Após o balanço feito para atingir o limite de concentração de fibras, as novas fontes encontradas foram:

Tabela 13 - Subdivisão da fonte 2 após a aplicação do método Pinch

\begin{tabular}{|c|c|c|}
\hline Fontes & Descrição & $\begin{array}{c}\text { Vazão } \\
\text { (L/min) }\end{array}$ \\
\hline F2' & Filtrado claro dos filtros Save-All parte 1 & 11081,6 \\
\hline F2" & Filtrado claro dos filtros Save-All parte 2 & 6369,1 \\
\hline
\end{tabular}

Os valores finais foram obtidos a partir do gráfico e relacionados na tabela 14:

Tabela 14 - Distribuição das fontes para as demandas com método Pinch

\begin{tabular}{|c|c|c|c|c|c|c|c|c|c|c|}
\hline & Valores após aplicação de PINCH (L/min) \\
\hline & D1 & D2 & D3 & D4 & D5 & D6 & D7 & D8 & D9 & TOTAL \\
\hline F1 + F2' & 1484 & 1255 & 997,4 & 996,7 & 299 & 20966 & 39406,8 & 0 & 0 & 65404,9 \\
\hline F2" & 0 & 0 & 0 & 0 & 0 & 0 & 4416,2 & 1952,9 & 0 & 6369,1 \\
\hline F3 & 0 & 0 & 0 & 0 & 0 & 0 & 0 & 2316 & 0 & 2316 \\
\hline F4 & 0 & 0 & 0 & 0 & 0 & 0 & 0 & 23,1 & 1383,9 & 1407 \\
\hline TOTAL & $\mathbf{1 4 8 4}$ & $\mathbf{1 2 5 5}$ & $\mathbf{9 9 7 , 4}$ & $\mathbf{9 9 6 , 7}$ & $\mathbf{2 9 9}$ & $\mathbf{2 0 9 6 6}$ & $\mathbf{4 3 8 2 3}$ & $\mathbf{4 2 9 2}$ & $\mathbf{1 3 8 3 , 9}$ & $\mathbf{7 5 4 9 7}$ \\
\hline Água fresca & $\mathbf{0}$ & $\mathbf{0}$ & $\mathbf{0}$ & $\mathbf{0}$ & $\mathbf{0}$ & $\mathbf{0}$ & $\mathbf{0}$ & $\mathbf{0}$ & $\mathbf{2 0 3 6 , 1}$ & $\mathbf{2 0 3 6 , 1}$ \\
\hline
\end{tabular}


Observa-se pelos resultados que o consumo de água fresca na máquina de papel foi reduzido de $3420 \mathrm{~L} / \mathrm{min}$ para $2036,1 \mathrm{~L} / \mathrm{min}$, ou seja, uma redução de $30 \%$. Muitos trabalhos são finalizados nessa etapa de análise do circuito, ou seja, sem testar e comprovar os resultados através de sua simulação. Sendo assim, não é possível definir nesse momento, o ponto ótimo do método utilizado.

Com o resultado, novos tanques podem ser necessários assim como torres existentes podem ser removidas ou reaproveitadas para o novo circuito. Isso deve ser verificado através da inclusão dos valores da tabela 14 no simulador Cadsim antes de aceitar como solução do problema pelo seguinte motivo: o resultado da nova simulação após configuração otimizada por método Pinch pode ser observado no apêndice A. É importante observar que dificilmente os valores de fluxo das correntes de polpa se igualam aos da simulação original. Porém os valores são bastante semelhantes.

\subsubsection{Análise para processo TMP integrada à máquina de papel aplicando pinch}

Ao aplicar as ferramentas de otimização somente para máquina de papel, verificou-se que a análise pôde ser feita somente para um contaminante, ou seja, as fibras. Quando o processo integrado é analisado, é possível estabelecer duas condições de trabalho: considerar um valor limite para concentração de sólidos dissolvidos igual a 5000 ppm para todas as correntes, ou definir limites menores para concentração de sólidos dissolvidos para algumas correntes de demanda. Dependendo de como a segunda condição de trabalho for criada para análise, o critério de otimização por múltiplos contaminantes deve ser adotado.

As tabelas 15 e 16 mostram as fontes e demandas consideradas para a otimização do processo integrado. A partir dessas tabelas, é possível elaborar diferentes casos para melhorar o circuito de água. 
Tabela 15 - Fontes de água consideradas em processo integrado

\begin{tabular}{|c|c|c|c|c|c|}
\hline $\begin{array}{c}\text { Ordem para } \\
\text { fibras }\end{array}$ & $\begin{array}{c}\text { Ordem } \\
\text { para SD }\end{array}$ & Descrição & $\begin{array}{c}\text { [fibras] } \\
\text { (\%) }\end{array}$ & $\begin{array}{c}\text { [SD] } \\
\text { ppm }\end{array}$ & $\begin{array}{c}\text { Vazão } \\
\text { (L/min) }\end{array}$ \\
\hline F1 & F3 & $\begin{array}{c}\text { Água da peneira inclinada } \\
\text { pós-depuração }\end{array}$ & 0,400 & 4747 & 605,7 \\
\hline F2 & F9 & $\begin{array}{c}\text { Água branca extraída da } \\
\text { seção de formação }\end{array}$ & 0,351 & 2273 & 54323,0 \\
\hline F3 & F2 & $\begin{array}{c}\text { Água da peneira inclinada } \\
\text { pós prensa }\end{array}$ & 0,300 & 4747 & 1781,2 \\
\hline F4 & F7 & $\begin{array}{c}\text { Filtrado claro dos filtros } \\
\text { Save-All }\end{array}$ & 0,050 & 2487 & 17450,7 \\
\hline F5 & F4 & $\begin{array}{c}\text { Filtrado turvo do filtro } \\
\text { a disco }\end{array}$ & 0,050 & 4662 & 1087,2 \\
\hline F6 & F1 & Filtrado do filtro a tambor & 0,050 & 4849 & 5544,1 \\
\hline F7 & F5 & $\begin{array}{c}\text { Filtrado claro do filtro } \\
\text { a disco }\end{array}$ & 0,030 & 4662 & 2537,3 \\
\hline F8 & F6 & $\begin{array}{c}\text { Filtrado Superclaro dos } \\
\text { filtros Save-All }\end{array}$ & 0,025 & 2487 & 2316,2 \\
\hline F9 & F8 & Filtrado do Filtro de refugo & 0,010 & 2380 & 1406,8 \\
\hline
\end{tabular}

Tabela 16 - Demandas ordenadas para fibras e SD em processo integrado

\begin{tabular}{|c|c|c|c|c|c|c|c|}
\hline $\begin{array}{c}\text { Ordem } \\
\text { para } \\
\text { fibras }\end{array}$ & $\begin{array}{c}\text { Ordem } \\
\text { para } \\
\text { SD }\end{array}$ & Descrição & $\begin{array}{c}\text { Vazão } \\
\text { (L/min) }\end{array}$ & $\begin{array}{c}\text { [fibras] } \\
\text { (\%) }\end{array}$ & $\begin{array}{c}\text { [fibras] } \\
\text { limite } \\
\text { (\%) }\end{array}$ & $\begin{array}{c}\text { [SD] } \\
\text { ppm }\end{array}$ & $\begin{array}{c}\text { [SD] } \\
\text { limite } \\
\text { ppm }\end{array}$ \\
\hline D1 & D1 & $\begin{array}{c}\text { Diluição do refinador } \\
\text { primário (linha 1) }\end{array}$ & 94,0 & 0,300 & 0,800 & 4747 & 5000 \\
\hline D2 & D2 & $\begin{array}{c}\text { Diluição dos } \\
\text { refinadores de rejeito }\end{array}$ & 108,7 & 0,300 & 0,800 & 4747 & 5000 \\
\hline D3 & D14 & $\begin{array}{c}\text { Água do chuveiro do } \\
\text { filtro de refugo }\end{array}$ & 299,1 & 0,050 & 0,800 & 2487 & 3000 \\
\hline D4 & D3 & $\begin{array}{c}\text { Água do chuveiro } \\
\text { dos filtros da TMP }\end{array}$ & 1585,0 & 0,040 & 0,800 & 4662 & 5000 \\
\hline D5 & D4 & $\begin{array}{c}\text { Diluição do refinador } \\
\text { primário (linha 2) }\end{array}$ & 356,2 & 0,082 & 0,800 & 4066 & 5000 \\
\hline D6 & D5 & $\begin{array}{c}\text { Diluição do refinador } \\
\text { secundário (linha 2) }\end{array}$ & 384,1 & 0,082 & 0,800 & 4066 & 5000 \\
\hline D7 & D7 & $\begin{array}{c}\text { Diluicao de rejeitos da } \\
\text { depuração primária }\end{array}$ & 39,8 & 0,082 & 0,800 & 4066 & 5000 \\
\hline D8 & D8 & $\begin{array}{c}\text { Diluicao de rejeitos da } \\
\text { depuração secundária }\end{array}$ & 54,7 & 0,082 & 0,800 & 4066 & 5000 \\
\hline D9 & D10 & $\begin{array}{c}\text { Diluição após 0 } \\
\text { branqueamento }\end{array}$ & 1483,6 & 0,082 & 0,800 & 2451 & 3000 \\
\hline D10 & D11 & $\begin{array}{c}\text { Diluição para o } \\
\text { tanque 1 de TMP }\end{array}$ & 1254,9 & 0,082 & 0,800 & 2451 & 3000 \\
\hline D11 & D12 & $\begin{array}{c}\text { Diluição do couch pit } \\
\text { Dina }\end{array}$ & 996,7 & 0,082 & 0,800 & 2451 & 3000 \\
\hline
\end{tabular}




\begin{tabular}{|c|c|c|c|c|c|c|c|}
\hline $\begin{array}{c}\text { Ordem } \\
\text { para } \\
\text { fibras }\end{array}$ & $\begin{array}{c}\text { Ordem } \\
\text { para } \\
\text { SD }\end{array}$ & Descrição & $\begin{array}{c}\text { Vazão } \\
\text { (L/min) }\end{array}$ & $\begin{array}{c}\text { [fibras] } \\
\text { (\%) }\end{array}$ & $\begin{array}{c}\text { [fibras] } \\
\text { limite } \\
(\%)\end{array}$ & $\begin{array}{c}\text { [SD] } \\
\text { ppm }\end{array}$ & $\begin{array}{c}\text { [SD] } \\
\text { limite } \\
\text { ppm }\end{array}$ \\
\hline D12 & D13 & $\begin{array}{c}\text { Água do chuveiro } \\
\text { dos filtros Save-All }\end{array}$ & 997,4 & 0,050 & 0,800 & 2487 & 3000 \\
\hline D13 & D16 & $\begin{array}{c}\text { Água branca para } \\
\text { recup. de fibras }\end{array}$ & 20966 & 0,300 & 0,300 & 2307 & 3000 \\
\hline D14 & D15 & $\begin{array}{c}\text { Água branca para } \\
\text { bomba de mistura }\end{array}$ & 43822,8 & 0,300 & 0,300 & 2307 & 3000 \\
\hline D15 & D6 & $\begin{array}{c}\text { Diluição do tanque } \\
\text { de latência linha 2 }\end{array}$ & 8279,3 & 0,082 & 0,100 & 4066 & 5000 \\
\hline D16 & D9 & $\begin{array}{c}\text { Diluição do tanque } \\
\text { de latência linha 1 }\end{array}$ & 4946,1 & 0,080 & 0,100 & 4066 & 5000 \\
\hline D17 & D17 & $\begin{array}{c}\text { Água fresca para a } \\
\text { linha de TMP }\end{array}$ & 787,0 & 0,000 & 0,018 & 0 & 2500 \\
\hline D18 & D18 & $\begin{array}{c}\text { Água fresca para a } \\
\text { máquina de papel }\end{array}$ & 3420,0 & 0,000 & 0,018 & 0 & 2500 \\
\hline
\end{tabular}

\subsubsection{Caso com contaminante simples aplicando pinch}

Observando a tabela 15, é conveniente adotar o valor limite de 3000 ppm para demandas que possuem valores originais abaixo desse valor e manter $5000 \mathrm{ppm}$ para as demandas com valores acima de $3000 \mathrm{ppm}$. Apesar de adotar esse critério, o problema ainda pode ser analisado por contaminante simples conforme figura 5.6, onde a curva de demanda não cruza a curva de fontes.

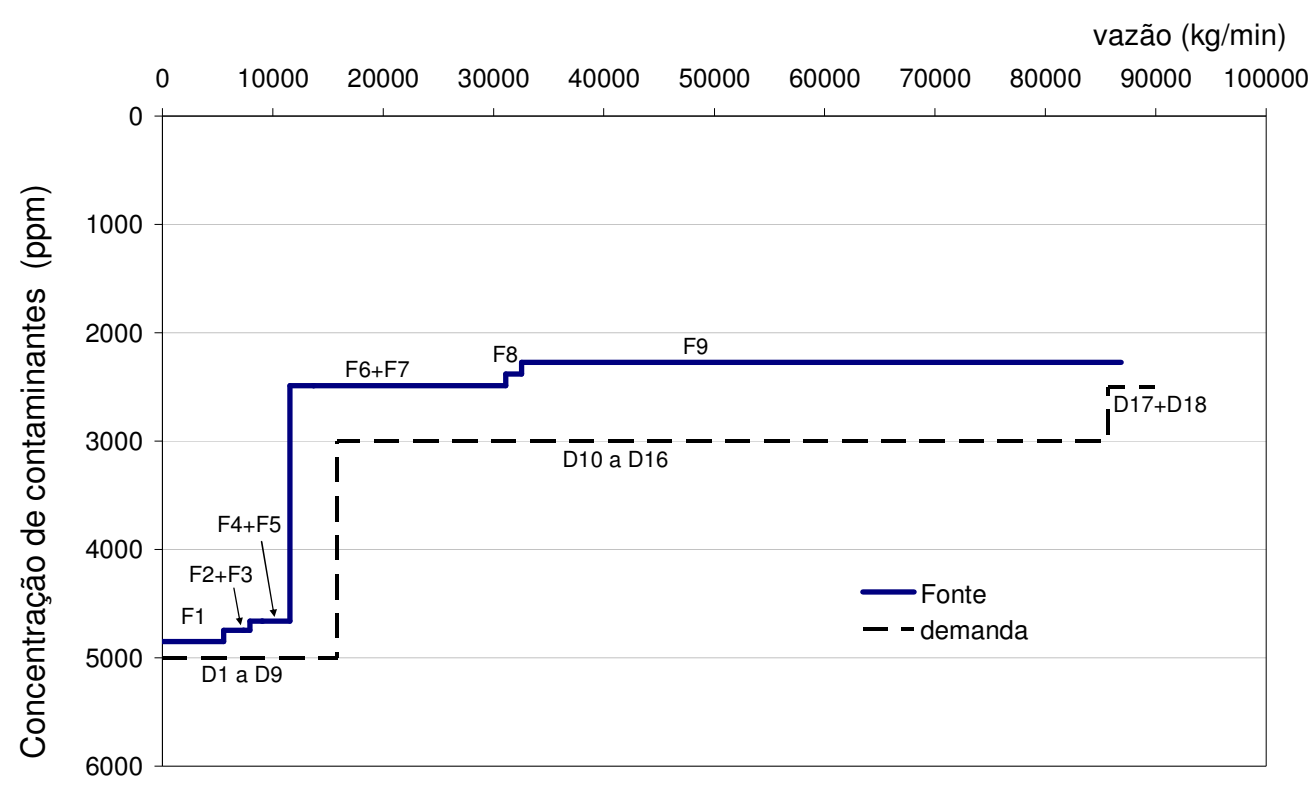

Figura 5.6 - Curvas de concentração de sólidos dissolvidos em processo integrado. Caso para um contaminante. 
A curva composta dupla para concentração de fibras das fontes e demandas pode ser observada na figura 5.7:

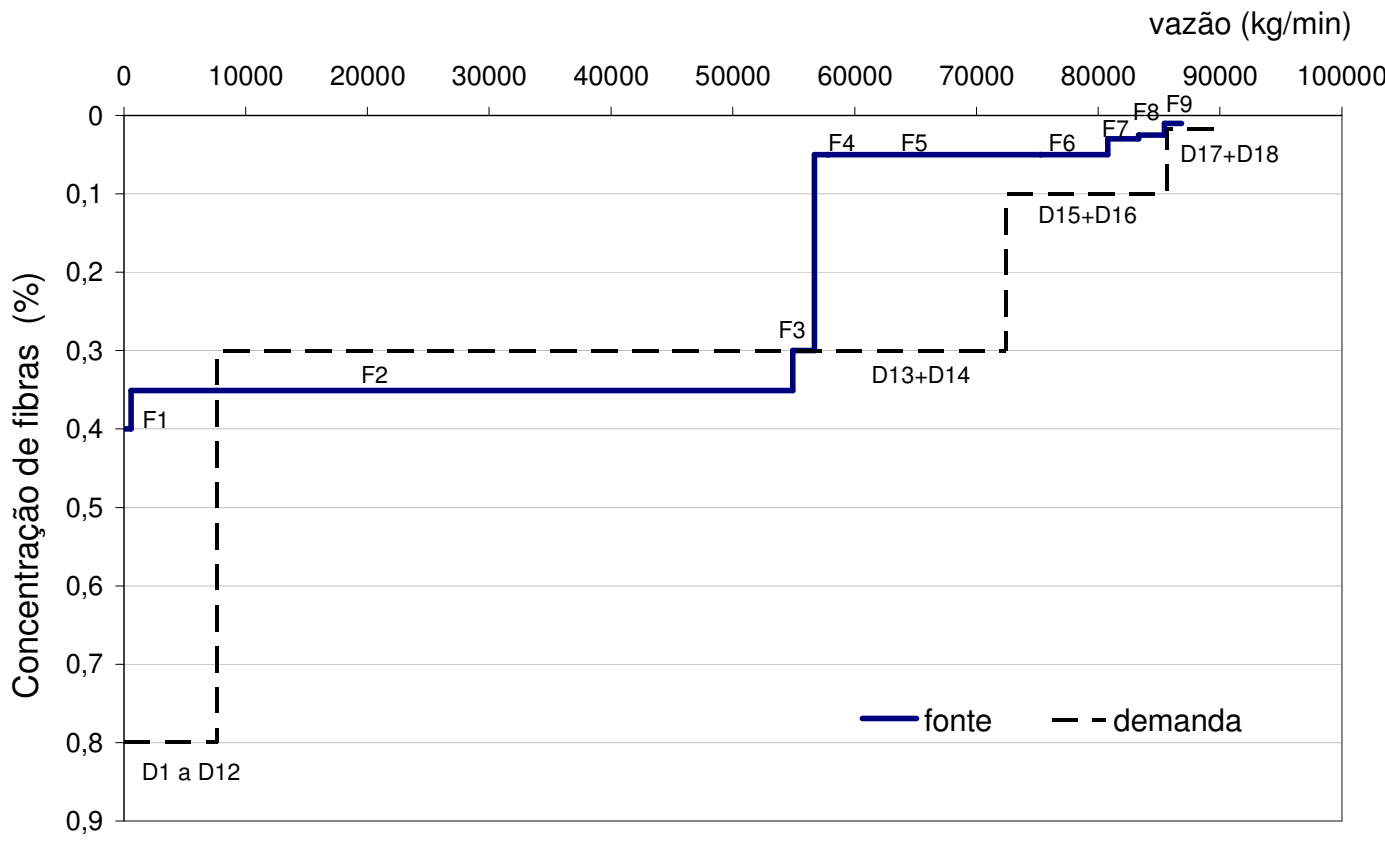

Figura 5.7. Curvas de concentração de fibras em processo integrado

Com o balanço feito para atingir o limite de concentração de fibras, verifica-se que a fonte F4 pode ser manipulada para encontrar o ponto Pinch e gerar a figura 5.8 .

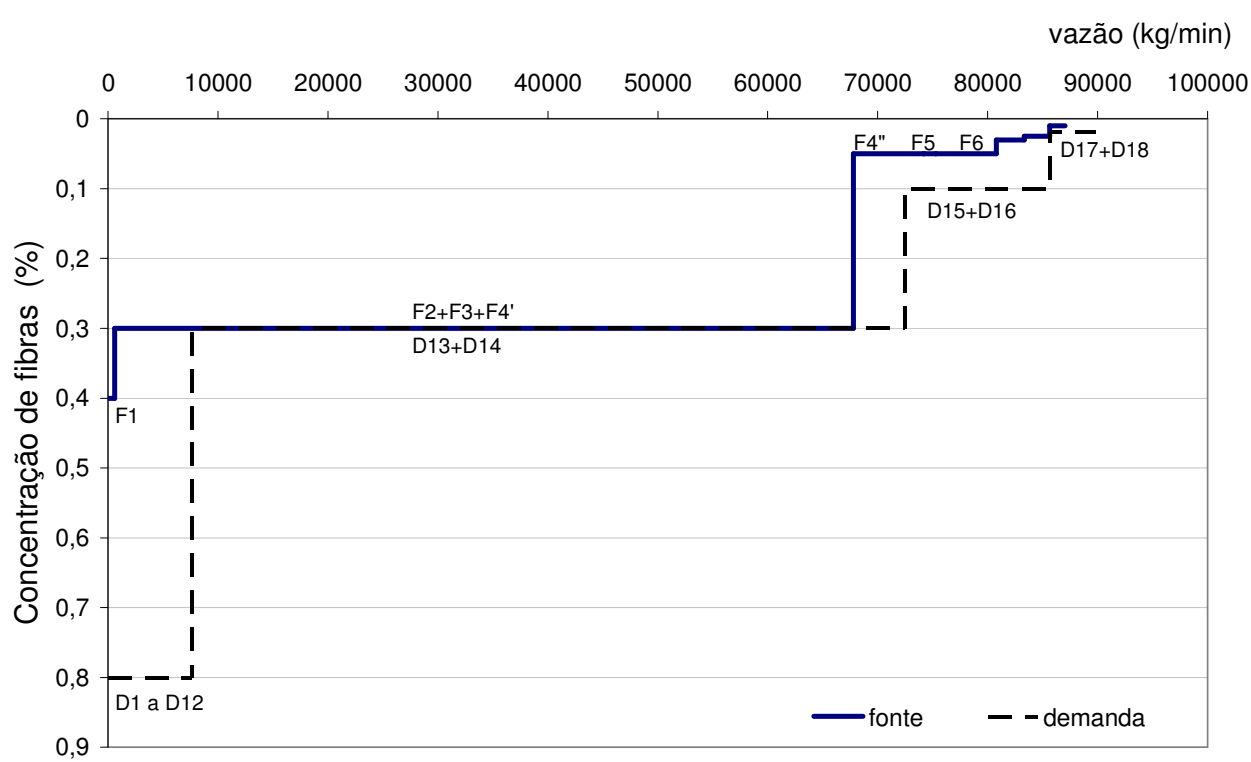

Figura 5.8 - Curva para atingir limite de concentração de fibras em processo integrado 
As novas fontes necessárias para esse processo otimizado estão mencionadas na tabela 17, onde houve uma divisão da fonte de água branca da seção de formação para poder atingir o limite de concentração de fibras nas demandas. Os valores finais das correntes otimizadas são mostradas na tabela 18.

Tabela 17. Subdivisão da fonte 4 após a aplicação do método Pinch

\begin{tabular}{|c|c|c|}
\hline Fontes & Descrição & $\begin{array}{c}\text { Vazão } \\
\text { (L/min) }\end{array}$ \\
\hline F4' & Filtrado claro dos filtros Save-All parte 1 & 11081,9 \\
\hline F4" & Filtrado claro dos filtros Save-All parte 2 & 6369,1 \\
\hline
\end{tabular}


Tabela 18 - Distribuição das fontes para as demandas com método Pinch em processo integrado (valores de vazão de água em kg/min)

\begin{tabular}{|c|c|c|c|c|c|c|c|c|c|c|c|c|c|c|c|c|c|c|c|}
\hline & D1 & D2 & D3 & D4 & D5 & D6 & D7 & D8 & D9 & D10 & D11 & D12 & D13 & D14 & D15 & D16 & D17 & D18 & Total \\
\hline F1 & 94 & 108,7 & 299,1 & 104,2 & 0 & 0 & 0 & 0 & 0 & 0 & 0 & 0 & 0 & 0 & 0 & 0 & 0 & 0 & 606 \\
\hline $\begin{array}{c}\text { F2+F3+ } \\
\text { F4' }\end{array}$ & 0 & 0 & 0 & 1480,8 & 356,2 & 384,1 & 40 & 55 & 1484 & 1255 & 996,7 & 997,4 & 20966 & 39170,8 & 0 & 0 & 0 & 0 & 67186 \\
\hline F4" & 0 & 0 & 0 & 0 & 0 & 0 & 0 & 0 & 0 & 0 & 0 & 0 & 0 & 4652,2 & 1716,8 & 0 & 0 & 0 & 6369 \\
\hline F5 & 0 & 0 & 0 & 0 & 0 & 0 & 0 & 0 & 0 & 0 & 0 & 0 & 0 & 0 & 1087 & 0 & 0 & 0 & 1087 \\
\hline F6 & 0 & 0 & 0 & 0 & 0 & 0 & 0 & 0 & 0 & 0 & 0 & 0 & 0 & 0 & 5475,2 & 68,8 & 0 & 0 & 5544 \\
\hline F7 & 0 & 0 & 0 & 0 & 0 & 0 & 0 & 0 & 0 & 0 & 0 & 0 & 0 & 0 & 0 & 2537 & 0 & 0 & 2537 \\
\hline F8 & 0 & 0 & 0 & 0 & 0 & 0 & 0 & 0 & 0 & 0 & 0 & 0 & 0 & 0 & 0 & 2316 & 0 & 0 & 2316 \\
\hline F9 & 0 & 0 & 0 & 0 & 0 & 0 & 0 & 0 & 0 & 0 & 0 & 0 & 0 & 0 & 0 & 24,2 & 787 & 595,8 & 1407 \\
\hline TOTAL & 94 & 108,7 & 299,1 & 1585 & 356,2 & 384,1 & 40 & 55 & 1484 & 1255 & 996,7 & 997,4 & 20966 & 43823 & 8279 & 4946 & 787 & 595,8 & 87052 \\
\hline $\begin{array}{l}\text { Água } \\
\text { fresca }\end{array}$ & 0 & 0 & 0 & 0 & 0 & 0 & 0 & 0 & 0 & 0 & 0 & 0 & 0 & 0 & 0 & 0 & 0 & 2824 & 2824 \\
\hline
\end{tabular}




\subsubsection{Caso com múltiplo contaminante}

Para gerar um problema com múltiplo contaminante, consideremos, por exemplo, um novo limite para concentração de sólidos dissolvidos em demandas onde ocorre a diluição da polpa nos tanques de latência. Com o objetivo de aumentar a pureza da polpa após a refinação, a alternativa é recomendada para fins operacionais.

Consideremos a tabela 16, porém com uma modificação na concentração limite de sólidos dissolvidos na diluição dos tanques de latência. Os valores limites de 5000 ppm para as duas demandas serão alterados para 3000 ppm. Nesse caso, a análise do processo integrado da produção de papel com pasta termomecânica exige uma análise mais elaborada. Diferentemente da aplicação do método para máquina de papel, é necessário ordenar as demandas de acordo com as concentrações de sólidos dissolvidos, pois ao considerarmos o processo integrado, observa-se a seguinte curva composta dupla:

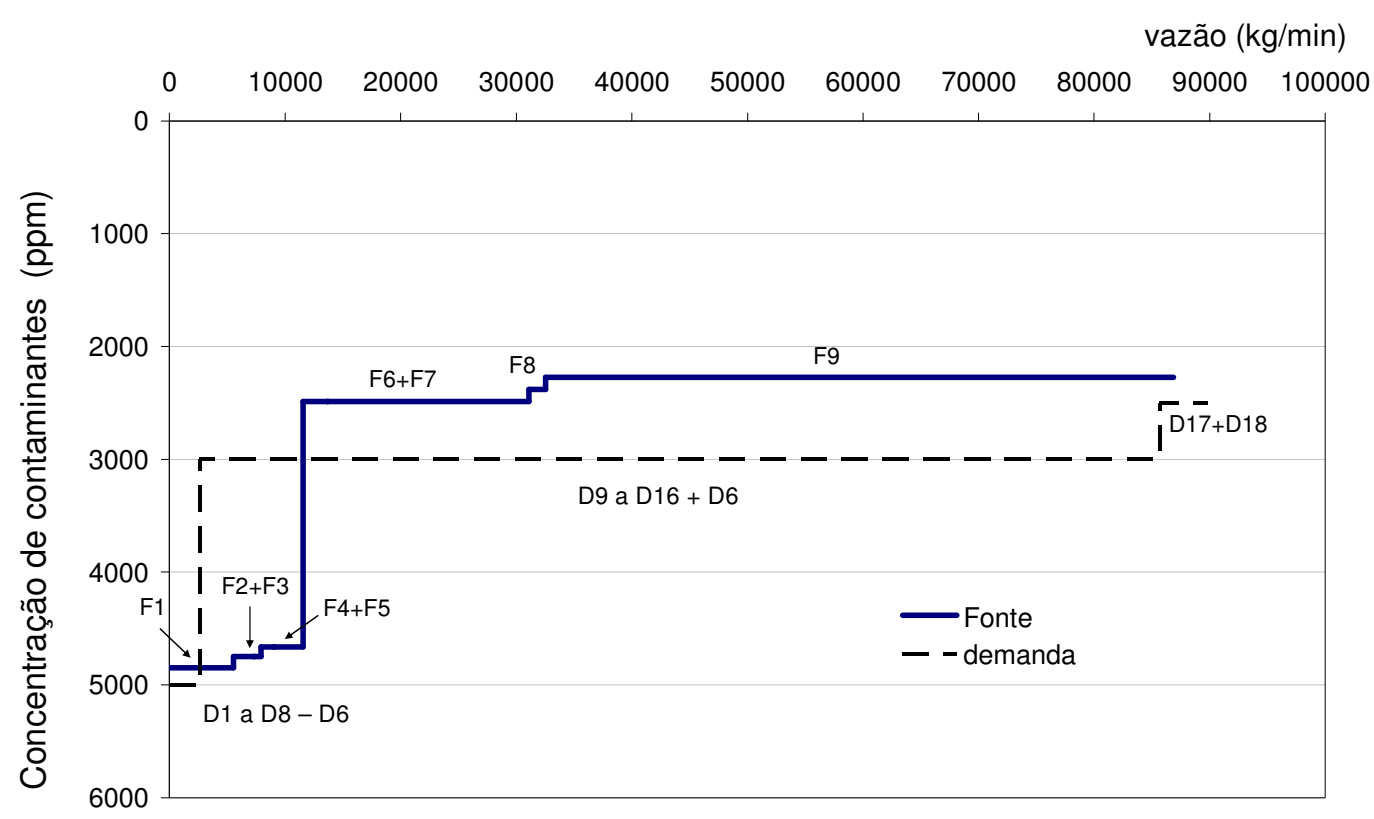

Figura 5.9 - Curvas de concentração de sólidos dissolvidos em processo integrado. Caso para múltiplo contaminante. 
Considerando as figuras 5.7 e 5.9, o problema deve ser analisado para dois contaminantes, sendo necessária uma análise conjunta das curvas para atingir um resultado global. Isso geraria um trabalho a mais, pois não há possibilidade de sobrepor as curvas de diferentes contaminantes para encontrar os resultados graficamente. Sendo assim, o método Pinch não será utilizado para esse fim, uma vez que a programação matemática é preparada para enfrentar essa dificuldade.

\subsection{Resultados do método por programação linear}

Os mesmos casos aplicados no método Pinch serão analisados através de programação matemática para comparar vantagens e dificuldades de cada ferramenta. As discussões do método Pinch envolvendo as definições de valores limites também se aplica à programação matemática. Porém nesse método não é necessário ordenar as demandas, pois os dados de entrada do programa são definidos em forma de vetores. A formulação do programa com as restrições apresentadas anteriormente pode ser observada no apêndice $B$ :

\subsubsection{Análise somente para máquina de papel aplicando programação linear}

Após a execução do programa utilizando os dados de entrada da tabela 18 , obtêm-se os valores otimizados da tabela 19.

Tabela 19 - Distribuição das fontes para as demandas com programação matemática

\begin{tabular}{|c|c|c|c|c|c|c|c|c|c|c|}
\hline \multicolumn{10}{|c|}{ Valores após aplicação de Programação Matemática (L/min) } \\
\hline & D1 & D2 & D3 & D4 & D5 & D6 & D7 & D8 & D9 & Total \\
\hline F1 & 605 & 179 & 33 & 1 & 0 & 16693 & 36125 & 656 & 31 & 54323 \\
\hline F2 & 579 & 678 & 604 & 619 & 182 & 3965 & 7077 & 3207 & 540 & 17451 \\
\hline F3 & 270 & 383 & 355 & 370 & 117 & 13 & 27 & 201 & 581 & 2317 \\
\hline F4 & 29 & 15 & 5 & 6 & 0 & 159 & 196 & 223 & 773 & 1406 \\
\hline TOTAL & $\mathbf{1 4 8 3}$ & $\mathbf{1 2 5 5}$ & $\mathbf{9 9 7}$ & $\mathbf{9 9 6}$ & $\mathbf{2 9 9}$ & $\mathbf{2 0 8 3 0}$ & $\mathbf{4 3 4 2 5}$ & $\mathbf{4 2 8 7}$ & $\mathbf{1 9 2 5}$ & $\mathbf{7 5 4 9 7}$ \\
\hline Água fresca & $\mathbf{1}$ & $\mathbf{0}$ & $\mathbf{0}$ & $\mathbf{0}$ & $\mathbf{0}$ & $\mathbf{1 3 6}$ & $\mathbf{3 9 8}$ & $\mathbf{6}$ & $\mathbf{1 4 9 5}$ & $\mathbf{2 0 3 6}$ \\
\hline
\end{tabular}


De acordo com a tabela 19, verifica-se que as fontes são divididas para suprir parcialmente cada demanda, o que pode dificultar a implantação do projeto por questões de custo e viabilidade operacional.

Somando-se as frações de água fresca para cada demanda da tabela 19, encontramos uma vazão de $2036 \mathrm{~L} / \mathrm{min}$ para a máquina de papel, ou seja, o mesmo valor encontrado utilizando a técnica gráfica Pinch.

\subsubsection{Análise para processo TMP integrado à máquina de papel aplicando programação linear}

A dificuldade observada na aplicação do método Pinch para processo integrado com dois contaminantes pode ser resolvida utilizando-se a programação matemática. Porém a quantidade de correntes a serem manipuladas aumenta de forma considerável como observado na tabela 20.

O resultado pode acarretar em alto custo de investimento para novas tubulações ou rearranjo de tanques e bombas. 
Tabela 20. Distribuição das fontes utilizando programação matemática em processo integrado (valores de vazão de água em kg/min)

\begin{tabular}{|c|c|c|c|c|c|c|c|c|c|c|c|c|c|c|c|c|c|c|c|}
\hline & D1 & D2 & D3 & D4 & D5 & D6 & D7 & D8 & D9 & D10 & D11 & D12 & D13 & D14 & D15 & D16 & D17 & D18 & Total \\
\hline F1 & 0 & 0 & 17 & 44 & 33 & 34 & 0 & 0 & 47 & 46 & 43 & 43 & 90 & 84 & 57 & 59 & 1 & 7 & 606 \\
\hline F2 & 0 & 0 & 35 & 575 & 33 & 37 & 0 & 0 & 480 & 376 & 244 & 244 & 14431 & 35414 & 851 & 1596 & 1 & 5 & 54323 \\
\hline F3 & 0 & 0 & 22 & 84 & 44 & 46 & 0 & 0 & 93 & 86 & 71 & 71 & 661 & 270 & 126 & 194 & 2 & 11 & 1781 \\
\hline F4 & 0 & 0 & 19 & 60 & 39 & 40 & 0 & 0 & 66 & 63 & 63 & 63 & 196 & 165 & 105 & 113 & 165 & 74 & 1087 \\
\hline F5 & 0 & 0 & 33 & 332 & 35 & 40 & 0 & 0 & 259 & 207 & 164 & 164 & 1298 & 6554 & 6275 & 1951 & 31 & 106 & 17451 \\
\hline F6 & 94 & 109 & 48 & 101 & 71 & 73 & 40 & 55 & 132 & 104 & 104 & 104 & 3373 & 434 & 158 & 374 & 66 & 124 & 5544 \\
\hline F7 & 0 & 0 & 21 & 82 & 44 & 46 & 0 & 0 & 71 & 86 & 71 & 71 & 482 & 307 & 153 & 242 & 86 & 776 & 2537 \\
\hline F8 & 0 & 0 & 29 & 139 & 31 & 35 & 0 & 0 & 143 & 123 & 107 & 107 & 251 & 336 & 269 & 233 & 89 & 434 & 2316 \\
\hline F9 & 0 & 0 & 24 & 76 & 23 & 26 & 0 & 0 & 77 & 72 & 66 & 66 & 105 & 132 & 105 & 97 & 146 & 392 & 1407 \\
\hline TOTAL & 94 & 108,7 & 299,1 & 1585 & 356,2 & 384,1 & 40 & 55 & 1484 & 1255 & 996,7 & 997,4 & 20966 & 43823 & 8279 & 4946 & 787 & 1929 & 86852 \\
\hline $\begin{array}{c}\text { Água } \\
\text { fresca }\end{array}$ & 0 & 0 & 51 & 93 & 3 & 7 & 0 & 0 & 116 & 93 & 81 & 81 & 78 & 128 & 180 & 86 & 330 & 1488 & 2815 \\
\hline
\end{tabular}




\subsection{Discussão de resultados}

Como observado na seção anterior, quatro diferentes resultados foram encontrados através de dois métodos de otimização. Porém, uma desvantagem é encontrada em ambos os métodos quando os resultados são transferidos para o simulador. Isso ocorre porque quando as fontes originais são manipuladas para satisfazer as demandas desejadas, as vazões das fontes otimizadas são alteradas. Como novas concentrações de fibras são impostas pelo usuário através de valores limites, a etapa do processo operando com válvulas de controle de consistência são afetadas, causando dessa maneira, alterações nos fluxos das fontes. Além disso, fontes provenientes de filtros possuem suas consistências fixas por ser um parâmetro de entrada do objeto de simulação, contribuindo dessa forma, para o desbalanceamento das correntes otimizadas em relação aos originais.

Tabela 21 - Alterações observadas nas vazões das fontes pós otimizadas (em L/min)

\begin{tabular}{|c|c|c|c|c|c|c|}
\hline & Descrição da fonte & $\begin{array}{c}\text { Vazão } \\
\text { Original }\end{array}$ & $\begin{array}{c}\text { Pinch } \\
\text { Máquina } \\
\text { de Papel }\end{array}$ & $\begin{array}{c}\text { LP } \\
\text { Máquina } \\
\text { de Papel }\end{array}$ & $\begin{array}{c}\text { Pinch } \\
\text { Processo } \\
\text { integrado }\end{array}$ & $\begin{array}{c}\text { LP } \\
\text { Processo } \\
\text { Integrado }\end{array}$ \\
\hline F1 & $\begin{array}{c}\text { Água da peneira inclinada } \\
\text { pós-depuração }\end{array}$ & $\mathbf{6 0 5 , 7}$ & 599,4 & 629,5 & 579,8 & 455,1 \\
\hline F2 & $\begin{array}{c}\text { Água branca extraída da } \\
\text { seção de formação }\end{array}$ & $\mathbf{5 4 3 2 3 , 0}$ & 54322,0 & 53597,3 & 54640,5 & 53622,8 \\
\hline F3 & $\begin{array}{c}\text { Água da peneira inclinada } \\
\text { pós prensa }\end{array}$ & $\mathbf{1 7 8 1 , 2}$ & 1789,7 & 1820,3 & 1782,4 & 1627,0 \\
\hline F4 & $\begin{array}{c}\text { Filtrado turvo do filtro a } \\
\text { disco }\end{array}$ & $\mathbf{1 0 8 7 , 2}$ & 1084,3 & 1074,3 & 1071,6 & 1118,5 \\
\hline F5 & $\begin{array}{c}\text { Filtrado claro dos filtros } \\
\text { Save-All }\end{array}$ & $\mathbf{1 7 4 5 0 , 7}$ & 17322,5 & 17467,6 & 17534,9 & 17297,1 \\
\hline F6 & Filtrado do filtro a tambor & $\mathbf{5 5 4 4 , 1}$ & 5544,9 & 5535,1 & 5533,6 & 5714,9 \\
\hline F7 & Filtrado claro do filtro a & $\mathbf{2 5 3 7 , 3}$ & 2530,6 & 2507,1 & 2500,8 & 2610,3 \\
\hline f8 & Filtrado Superclaro dos & $\mathbf{2 3 1 6 , 2}$ & 2310,2 & 2326,6 & 2338,6 & 1757,0 \\
\hline filtros Save-All & Filtrado do Filtro de refugo & $\mathbf{1 4 0 6 , 8}$ & 1537,2 & 1408,9 & 1276,3 & 1210,6 \\
\hline
\end{tabular}

Portanto, não é correto utilizar diretamente os resultados encontrados a partir dos métodos de otimização. Para exemplificar, supõe-se que o método pede 
para misturar duas fontes originais com vazões $x$ e y com 0 intuito de satisfazer a demanda de uma diluição de polpa. Entretanto, após estabelecer no simulador que a demanda necessita de $(x+y)$, a vazão das fontes são alteradas para novos valores x'e y', podendo dessa maneira, alterar o valor previamente estabelecido. A tabela 21 mostra as alterações nas vazões de fontes em cada caso estudado.

Tabela 22 - Alterações observadas nas consistências das fontes (em \%)

\begin{tabular}{|c|c|c|c|c|c|c|}
\hline & Descrição da fonte & $\begin{array}{c}\text { Pfibras] } \\
\text { Original }\end{array}$ & $\begin{array}{c}\text { Pinch } \\
\text { Máquina } \\
\text { de Papel }\end{array}$ & $\begin{array}{c}\text { LP } \\
\text { Máquina } \\
\text { de Papel }\end{array}$ & $\begin{array}{c}\text { Pinch } \\
\text { Processo } \\
\text { integrado }\end{array}$ & $\begin{array}{c}\text { LP } \\
\text { Integrado }\end{array}$ \\
\hline F1 & $\begin{array}{c}\text { Água da peneira } \\
\text { inclinada pós-depuração }\end{array}$ & $\mathbf{0 , 4 0 0}$ & 0,400 & 0,400 & 0,400 & 0,400 \\
\hline F2 & $\begin{array}{c}\text { Água branca extraída da } \\
\text { seção de formação }\end{array}$ & $\mathbf{0 , 3 5 1}$ & 0,348 & 0,357 & 0,349 & 0,346 \\
\hline F3 & $\begin{array}{c}\text { Água da peneira } \\
\text { inclinada pós prensa }\end{array}$ & $\mathbf{0 , 3 0 0}$ & 0,300 & 0,300 & 0,300 & 0,300 \\
\hline F4 & $\begin{array}{c}\text { Filtrado turvo do filtro a } \\
\text { disco }\end{array}$ & $\mathbf{0 , 0 5 0}$ & 0,050 & 0,050 & 0,050 & 0,050 \\
\hline F5 & $\begin{array}{c}\text { Filtrado claro dos filtros } \\
\text { Save-All }\end{array}$ & $\mathbf{0 , 0 5 0}$ & 0,050 & 0,050 & 0,050 & 0,050 \\
\hline F6 & $\begin{array}{c}\text { Filtrado do filtro a } \\
\text { tambor }\end{array}$ & $\mathbf{0 , 0 5 0}$ & 0,050 & 0,050 & 0,050 & 0,050 \\
\hline F7 & $\begin{array}{c}\text { Filtrado claro do filtro a } \\
\text { disco }\end{array}$ & $\mathbf{0 , 0 3 0}$ & 0,030 & 0,030 & 0,030 & 0,030 \\
\hline F8 & $\begin{array}{c}\text { Filtrado Superclaro dos } \\
\text { filtros Save-All }\end{array}$ & $\mathbf{0 , 0 2 5}$ & 0,025 & 0,025 & 0,025 & 0,025 \\
\hline F9 & $\begin{array}{r}\text { Filtrado do Filtro de } \\
\text { refugo }\end{array}$ & $\mathbf{0 , 0 1 0}$ & 0,010 & 0,010 & 0,010 & 0,010 \\
\hline
\end{tabular}

Para fibras, é possível notar na tabela 22 que as consistências das fontes não foram alteradas, exceto pela água branca extraída da seção de formação da máquina de papel, que possui a consistência variável de acordo com a vazão de água e contaminantes da polpa na caixa de entrada.

A variação da concentração de sólidos dissolvidos (SD) já é mais acentuada, conforme mostra a tabela 23. É importante enfatizar que devido ao maior fechamento do circuito, as concentrações de sólidos dissolvidos dentro do circuito aumentam. 
Tabela 23. Alterações observadas nas concentrações de SD das fontes (em ppm)

\begin{tabular}{|c|c|c|c|c|c|c|}
\hline & Descrição da fonte & $\begin{array}{c}\text { [SD] } \\
\text { Original }\end{array}$ & $\begin{array}{c}\text { Pinch } \\
\text { Máquina } \\
\text { de Papel }\end{array}$ & $\begin{array}{c}\text { LP } \\
\text { Máquina } \\
\text { de Papel }\end{array}$ & $\begin{array}{c}\text { Pinch } \\
\text { Processo } \\
\text { integrado }\end{array}$ & $\begin{array}{c}\text { LP } \\
\text { Processo } \\
\text { Integrado }\end{array}$ \\
\hline F1 & $\begin{array}{c}\text { Água da peneira inclinada } \\
\text { pós-depuração }\end{array}$ & $\mathbf{4 7 4 7}$ & 5817 & 5890 & 5295 & 4189 \\
\hline F2 & $\begin{array}{c}\text { Água branca extraída da } \\
\text { seção de formação }\end{array}$ & $\mathbf{2 2 7 3}$ & 3322 & 3400 & 3196 & 3226 \\
\hline F3 & $\begin{array}{c}\text { Água da peneira inclinada } \\
\text { pós prensa }\end{array}$ & $\mathbf{4 7 4 7}$ & 5817 & 5890 & 5294 & 4189 \\
\hline F4 & $\begin{array}{c}\text { Filtrado turvo do } \\
\text { filtro a disco }\end{array}$ & $\mathbf{4 6 6 2}$ & 5695 & 5755 & 4197 & 3807 \\
\hline F5 & $\begin{array}{c}\text { Filtrado claro dos filtros } \\
\text { Save-All }\end{array}$ & $\mathbf{2 4 8 7}$ & 3478 & 3559 & 3338 & 3399 \\
\hline F6 & $\begin{array}{c}\text { Filtrado do filtro a tambor } \\
\text { Caso 4 }\end{array}$ \\
\hline F7 & $\begin{array}{c}\text { Filtrado claro do } \\
\text { filtro a disco }\end{array}$ & $\mathbf{4 6 6 2}$ & 5695 & 5755 & 4197 & 3807 \\
\hline F8 & $\begin{array}{c}\text { Filtrado Superclaro dos } \\
\text { filtros Save-All }\end{array}$ & $\mathbf{2 4 8 7}$ & 3478 & 3558 & 3338 & 3399 \\
\hline F9 & Filtrado do Filtro de refugo & $\mathbf{2 3 8 0}$ & 3338 & 3494 & 3285 & 3222 \\
\hline
\end{tabular}

Sendo assim, é inconveniente considerar as demandas originais como entradas para encontrar um processo otimizado. O método gera valores teoricamente corretos, porém inconvenientes após simulação do sistema otimizado. Os dados simulados das vazões de água das demandas pós otimizadas podem ser verificadas na próxima tabela 24 .

A vazão de 2823,0 L/min para os casos 1 e 2 da tabela 24 foi calculada considerando um consumo de água fresca igual a $787,0 \mathrm{~L} / \mathrm{min}$ na unidade de produção de TMP, pois ambos os casos não contemplam a otimização do processo de fabricação de pasta termomecânica.

O consumo total de água fresca para o caso 4 engloba, além da demanda D17 e D18, a demanda D1 e parte de D2 e D6. Isso ocorre porque algumas fontes do processo otimizado não foram suficientes para satisfazer totalmente as demandas D1, D2 e D3. Como a vazão é controlada conforme consistência das correntes, parte da demanda deve ser suprida com água fresca. 
Tabela 24- Alterações observadas nas vazões das demandas pós otimizadas(em L/min)

\begin{tabular}{|c|c|c|c|c|c|c|}
\hline & $\begin{array}{l}\text { Descrição da } \\
\text { demanda }\end{array}$ & $\begin{array}{l}\text { Vazão } \\
\text { Original }\end{array}$ & $\begin{array}{c}\text { Pinch } \\
\text { Máquina } \\
\text { de Papel }\end{array}$ & $\begin{array}{c}\text { LP } \\
\text { Máquina } \\
\text { de Papel }\end{array}$ & $\begin{array}{c}\text { Pinch } \\
\text { Processo } \\
\text { integrado }\end{array}$ & $\begin{array}{c}\text { LP } \\
\text { Processo } \\
\text { Integrado }\end{array}$ \\
\hline & & & Caso 1 & Caso 2 & Caso 3 & Caso 4 \\
\hline D1 & $\begin{array}{l}\text { Diluição do refinador } \\
\text { primário (linha 1) }\end{array}$ & 94,0 & 94,0 & 94,0 & 94,0 & $94,3^{(a)}$ \\
\hline D2 & $\begin{array}{c}\text { Diluição dos refinadores } \\
\text { de rejeito }\end{array}$ & 108,7 & 108,6 & 109,0 & 110,9 & $107,7^{(b)}$ \\
\hline D3 & $\begin{array}{l}\text { Água do chuveiro do } \\
\text { filtro de refugo }\end{array}$ & 299,1 & 299,1 & 299,1 & 272,0 & 300 \\
\hline D4 & $\begin{array}{l}\text { Água do chuveiro dos } \\
\text { filtros da TMP }\end{array}$ & 1585,0 & 1581,4 & 1571,3 & 1585,0 & 1768,2 \\
\hline D5 & $\begin{array}{l}\text { Diluição do refinador } \\
\text { primário (linha 2) }\end{array}$ & 356,2 & 355,9 & 355,8 & 356,0 & 358,3 \\
\hline D6 & $\begin{array}{l}\text { Diluição do refinador } \\
\text { secundário (linha 2) }\end{array}$ & 384,1 & 383,7 & 383,6 & 381,3 & $370,6^{(c)}$ \\
\hline D7 & $\begin{array}{l}\text { Diluicao de rejeitos da } \\
\text { depuração primária }\end{array}$ & 40,0 & 39,8 & 39,8 & 40,0 & 39,8 \\
\hline D8 & $\begin{array}{l}\text { Diluicao de rejeitos da } \\
\text { depuração secundária }\end{array}$ & 55,0 & 54,7 & 54,7 & 55,0 & 55,2 \\
\hline D9 & $\begin{array}{l}\text { Diluição após o } \\
\text { branqueamento }\end{array}$ & 1483,3 & 1484 & 1503,4 & 1552,7 & 1479,3 \\
\hline D10 & $\begin{array}{l}\text { Diluição para o } \\
\text { tanque } 1 \text { de TMP }\end{array}$ & 1254,9 & 1252,1 & 1309,0 & 1379,0 & 794,0 \\
\hline D11 & Diluição do couch pit & 996,7 & 996,7 & 998,1 & 990,8 & 812,0 \\
\hline D12 & $\begin{array}{l}\text { Água do chuveiro dos } \\
\text { filtros Save-All }\end{array}$ & 997,4 & 997,4 & 955,0 & 999,9 & 992,0 \\
\hline D13 & $\begin{array}{l}\text { Água branca para } \\
\text { recup. de fibras }\end{array}$ & 20966,0 & 20937 & 20965 & 20966,0 & 20936,7 \\
\hline D14 & $\begin{array}{l}\text { Água branca para } \\
\text { bomba de mistura }\end{array}$ & 43823,0 & 43823 & 43269 & 43824,0 & 43730,8 \\
\hline D15 & $\begin{array}{l}\text { Diluição do tanque de } \\
\text { latência da linha } 2\end{array}$ & 8279,0 & 8479,0 & 8600,5 & 8261,9 & 8158,8 \\
\hline D16 & $\begin{array}{l}\text { Diluição do tanque de } \\
\text { latência linha } 1\end{array}$ & 4946,0 & 4941,3 & 4900,2 & 4885,2 & 4991,6 \\
\hline D17 & Água fresca na TMP & 787,0 & 568,3 & 510,7 & 66,6 & 150,0 \\
\hline \multirow[t]{3}{*}{ D18 } & $\begin{array}{l}\text { Água fresca para a } \\
\text { máquina de papel }\end{array}$ & 3420,0 & 2036,0 & 2036,0 & 2824,0 & 2585,0 \\
\hline & Água fresca total & 4207,0 & 2604,3 & 2546,7 & 2890,6 & 2878,5 \\
\hline & $\begin{array}{l}\text { Antes da simulação } \\
\text { dos resultados }\end{array}$ & 4207,0 & 2823,0 & 2823,0 & 2824,0 & 2815,0 \\
\hline
\end{tabular}

(a) valor teve de ser suprido por água fresca. (b) uma parte de corrente, 14,3 L/min do total da corrente de 107,7 L/min, teve de ser suprido por água fresca. (c) uma parte de corrente, $34,9 \mathrm{~L} / \mathrm{min}$ do total da corrente de $370,6 \mathrm{~L} / \mathrm{min}$, teve de ser suprido por água fresca.

Na tabela 24, nota-se também a diferença entre os consumos "teóricos" e novamente simulados de água fresca, ressaltando dessa maneira, a 
importância da simulação de resultados. Quanto às concentrações de contaminantes das demandas, os valores pós-otimizados podem ser verificados na tabela 25 :

Tabela 25- Alterações observadas nas concentrações de SD das demandas (em ppm)

\begin{tabular}{|c|c|c|c|c|c|c|}
\hline & $\begin{array}{l}\text { Descrição da } \\
\text { demanda }\end{array}$ & $\begin{array}{l}\text { [SD] } \\
\text { limite }\end{array}$ & $\begin{array}{c}\text { Pinch } \\
\text { Máquina } \\
\text { de Papel }\end{array}$ & $\begin{array}{c}\text { LP } \\
\text { Máquina } \\
\text { de Papel }\end{array}$ & $\begin{array}{c}\text { Pinch } \\
\text { Processo } \\
\text { integrado }\end{array}$ & $\begin{array}{c}\text { LP } \\
\text { Processo } \\
\text { Integrado } \\
\end{array}$ \\
\hline & & & Caso 1 & Caso 2 & Caso 3 & Caso 4 \\
\hline D1 & $\begin{array}{l}\text { Diluição do refinador } \\
\text { primário (linha 1) }\end{array}$ & 5000 & 5816 & 5890 & 5294 & 0 \\
\hline D2 & $\begin{array}{c}\text { Diluição dos } \\
\text { refinadores de rejeito }\end{array}$ & 5000 & 5816 & 5890 & 5294 & 4456 \\
\hline D3 & $\begin{array}{l}\text { Água do chuveiro do } \\
\text { filtro de refugo }\end{array}$ & 3000 & 3348 & 3558 & 5294 & 3117 \\
\hline D4 & $\begin{array}{l}\text { Água do chuveiro dos } \\
\text { filtros da TMP }\end{array}$ & 5000 & 5695 & 5755 & 3408 & 3378 \\
\hline D5 & $\begin{array}{l}\text { Diluição do refinador } \\
\text { primário (linha 2) }\end{array}$ & 5000 & 5092 & 5144 & 3275 & 3953 \\
\hline D6 & $\begin{array}{l}\text { Diluição do refinador } \\
\text { secundário (linha 2) }\end{array}$ & 5000 & 5092 & 5144 & 3275 & 3953 \\
\hline D7 & $\begin{array}{l}\text { Diluicao de rejeitos da } \\
\text { depuração primária }\end{array}$ & 5000 & 5092 & 5144 & 3275 & 4456 \\
\hline D8 & $\begin{array}{l}\text { Diluicao de rejeitos da } \\
\text { depuração secundária }\end{array}$ & 5000 & 5092 & 5144 & 3275 & 4456 \\
\hline D9 & $\begin{array}{l}\text { Diluição após o } \\
\text { branqueamento }\end{array}$ & 3000 & 3348 & 3524 & 3275 & 3238 \\
\hline D10 & $\begin{array}{l}\text { Diluição para o } \\
\text { tanque } 1 \text { de TMP }\end{array}$ & 3000 & 3348 & 3502 & 3275 & 3318 \\
\hline D11 & Diluição do couch pit & 3000 & 3343 & 3554 & 3275 & 3218 \\
\hline D12 & $\begin{array}{l}\text { Água do chuveiro dos } \\
\text { filtros Save-All }\end{array}$ & 3000 & 3348 & 3513 & 3275 & 3290 \\
\hline D13 & $\begin{array}{l}\text { Água branca para } \\
\text { recup. de fibras }\end{array}$ & 3000 & 3348 & 3426 & 3275 & 3478 \\
\hline D14 & $\begin{array}{l}\text { Água branca para } \\
\text { bomba de mistura }\end{array}$ & 3000 & 3361 & 3382 & 3282 & 3269 \\
\hline D15 & $\begin{array}{l}\text { Diluição do tanque de } \\
\text { latência da linha } 2\end{array}$ & 5000 & 5092 & 5144 & 5298 & 3344 \\
\hline D16 & $\begin{array}{c}\text { Diluição do tanque de } \\
\text { latência da linha } 1\end{array}$ & 5000 & 5092 & 5144 & 3811 & 3486 \\
\hline D17 & Água fresca na TMP & 2500 & 0 & 0 & 3011 & 2710 \\
\hline D18 & $\begin{array}{l}\text { Água fresca para a } \\
\text { máquina de papel }\end{array}$ & 2500 & 1157 & 1833 & 574 & 1707 \\
\hline
\end{tabular}

$\mathrm{Na}$ tabela 25, muitos valores ultrapassaram os limites de concentração impostos para sólidos dissolvidos. O caso mais simples de ser transferido para o simulador (caso 1) teve praticamente todas as suas correntes de 
demanda acima do limite para sólidos dissolvidos. Alguns motivos contribuem para esse resultado. Primeiramente, o método Pinch não considerou a concentração do contaminante durante a otimização, pois originalmente todas as fontes continham as concentrações de sólidos abaixo do limite estabelecido. O segundo motivo, como explicado anteriormente e válido para todos os casos, refere-se aos dados de fontes originais que são alterados após a manipulação de suas correntes, podendo dessa maneira, ultrapassar os limites. O terceiro motivo é o fato de somente as correntes do setor de produção de papel serem consideradas, ocasionando dessa maneira alguns desvios significativos nas correntes do setor de TMP.

O caso 2, onde o setor de papel foi otimizado pelo método de programação linear, os motivos citados anteriormente também são válidos. Mas por haver um número maior de correntes manipuladas, os resultados diferem do caso 1.

No processo integrado otimizado através da técnica gráfica, ou seja, caso 3 , algumas correntes respeitaram o limite estabelecido para sólidos dissolvidos. Mas como a curva de sólidos dissolvidos não foi novamente considerada, o método permitiu a distribuição de uma única fonte para várias demandas, como observado na tabela 25 . Todas as concentrações de sólidos dissolvidos ultrapassaram os valores limites de forma proporcional ao original, ou seja, sem muitos desvios. A exceção foi a demanda para o chuveiro do filtro de refugo, que ultrapassou significativamente o limite. Mas deve-se lembrar que o método Pinch manipulou fontes somente para satisfazer a consistência limite. 
Tabela 26 - Alterações observadas nas consistências das demandas (em \%)

\begin{tabular}{|c|c|c|c|c|c|c|}
\hline & $\begin{array}{l}\text { Descrição da } \\
\text { demanda }\end{array}$ & $\begin{array}{c}\text { Consistência } \\
\text { limite }\end{array}$ & $\begin{array}{c}\text { Pinch } \\
\text { Máquina } \\
\text { de Papel }\end{array}$ & $\begin{array}{c}\text { LP } \\
\text { Máquina } \\
\text { de Papel }\end{array}$ & $\begin{array}{c}\text { Pinch } \\
\text { Processo } \\
\text { integrado }\end{array}$ & $\begin{array}{c}\text { LP } \\
\text { Processo } \\
\text { Integrado }\end{array}$ \\
\hline & & & Caso 1 & Caso 2 & Caso 3 & Caso 4 \\
\hline D1 & $\begin{array}{l}\text { Diluição do refinador } \\
\text { primário (linha 1) }\end{array}$ & 0,800 & 0,300 & 0,300 & 0,400 & 0,000 \\
\hline D2 & $\begin{array}{l}\text { Diluição dos } \\
\text { refinadores de rejeito }\end{array}$ & 0,800 & 0,300 & 0,300 & 0,398 & 0,400 \\
\hline D3 & $\begin{array}{l}\text { Água do chuveiro do } \\
\text { filtro de refugo }\end{array}$ & 0,800 & 0,298 & 0,039 & 0,400 & 0,107 \\
\hline D4 & $\begin{array}{l}\text { Água do chuveiro dos } \\
\text { filtros da TMP }\end{array}$ & 0,800 & 0,042 & 0,042 & 0,305 & 0,177 \\
\hline D5 & $\begin{array}{l}\text { Diluição do refinador } \\
\text { primário (linha 2) }\end{array}$ & 0,800 & 0,079 & 0,097 & 0,298 & 0,077 \\
\hline D6 & $\begin{array}{l}\text { Diluição do refinador } \\
\text { secundário (linha 2) }\end{array}$ & 0,800 & 0,079 & 0,097 & 0,298 & 0,077 \\
\hline D7 & $\begin{array}{l}\text { Diluicao de rejeitos da } \\
\text { depuração primária }\end{array}$ & 0,800 & 0,079 & 0,097 & 0,298 & 0,050 \\
\hline D8 & $\begin{array}{l}\text { Diluicão de rejeitos da } \\
\text { depuração secundária }\end{array}$ & 0,800 & 0,079 & 0,097 & 0,298 & 0,050 \\
\hline D9 & $\begin{array}{l}\text { Diluição após o } \\
\text { branqueamento }\end{array}$ & 0,800 & 0,298 & 0,108 & 0,298 & 0,152 \\
\hline D10 & $\begin{array}{c}\text { Diluição para o } \\
\text { tanque } 1 \text { de TMP }\end{array}$ & 0,800 & 0,298 & 0,153 & 0,298 & 0,065 \\
\hline D11 & Diluição do couch pit & 0,800 & 0,308 & 0,046 & 0,298 & 0,148 \\
\hline D12 & $\begin{array}{l}\text { Água do chuveiro dos } \\
\text { filtros Save-All }\end{array}$ & 0,800 & 0,298 & 0,133 & 0,298 & 0,145 \\
\hline D13 & $\begin{array}{l}\text { Água branca para } \\
\text { recup. de fibras }\end{array}$ & 0,300 & 0,298 & 0,286 & 0,298 & 0,262 \\
\hline D14 & $\begin{array}{l}\text { Água branca para } \\
\text { bomba de mistura }\end{array}$ & 0,300 & 0,273 & 0,309 & 0,272 & 0,291 \\
\hline D15 & $\begin{array}{l}\text { Diluição do tanque de } \\
\text { latência da linha } 2\end{array}$ & 0,100 & 0,079 & 0,097 & 0,050 & 0,081 \\
\hline D16 & $\begin{array}{c}\text { Diluição do tanque de } \\
\text { latência da linha } 1\end{array}$ & 0,100 & 0,079 & 0,097 & 0,028 & 0,135 \\
\hline D17 & Água fresca na TMP & 0,018 & 0,000 & 0,000 & 0,009 & 0,021 \\
\hline D18 & $\begin{array}{l}\text { Água fresca para a } \\
\text { máquina de papel }\end{array}$ & 0,018 & 0,000 & 0,000 & 0,002 & 0,013 \\
\hline
\end{tabular}

As concentrações de fibras indicadas na tabela 26, com exceção das demandas D16 e D17 do caso 4, não ultrapassaram os limites estabelecidos. Porém é muito importante que correntes otimizadas de altas vazões não tenham suas consistências desviadas de forma significativa em relação aos originais, pois como já explicado anteriormente, as vazões controladas por consistências se alteram de forma proporcional à concentração de fibras. 
Os resultados da simulação do caso 4 foram os mais críticos. Mas devido à dificuldade para distribuir todas as fontes para cada demanda no simulador, os desvios eram esperados. Portanto, uma das grandes desvantagens do método por programação matemática é justamente a distribuição parcial de cada fonte em todas as demandas, o que pode gerar confusões no momento de distribuir ou corrigir os valores das correntes no simulador. Uma pequena fonte influencia todo o balanço integrado, sendo necessária grande atenção ao analisar o processo produtivo de papel integrado à TMP.

Como todos os casos ultrapassaram os limites estabelecidos, uma alternativa deve ser desenvolvida para finalizar o trabalho. Para solucionar o problema, o simulador dinâmico permite manipular vazões de água fresca ao mesmo tempo em que se analisa a redução das concentrações de contaminantes. Sendo assim, é possível aumentar a vazão de água em pontos estratégicos do processo até encontrar o valor limite inicialmente estabelecido.

Por ser um caso com poucas modificações físicas no processo, o método Pinch para o processo integrado será a base para encontrar a solução. 0 objetivo nesse momento é analisar a tabela 25 para o caso 3 e tentar reduzir as concentrações de sólidos dissolvidos até os valores limites permitidos, o que pode ser feito através da introdução de água fresca em pontos onde a concentração de sólidos está alta. Através da tabela 23, observa-se que a fonte do filtro a tambor contém uma quantidade relativamente alta de sólidos dissolvidos, podendo dessa maneira, incluir um ponto de entrada de água fresca para reduzir sua concentração.

As tabelas 27 e 28 mostram os resultados das modificações feitas para atingir o objetivo mencionado acima. Apesar das consistências não se alterarem, é possível notar que as concentrações de sólidos dissolvidos passaram a respeitar os limites estabelecidos. Devido à alta praticidade para manipular correntes em um simulador dinâmico, o resultado pode ser encontrado de forma relativamente rápida. Isso ocorre porque diferentes correntes podem ser analisadas simultaneamente para cada alteração feita no circuito de água. 
Tabela 27 - Demandas do caso 3: corrigido para atingir limite estabelecido

\begin{tabular}{|c|c|c|c|c|c|c|c|c|c|c|}
\hline & Descrição da demanda & [SD] limite & $\begin{array}{c}\text { [SD] } \\
\text { sem } \\
\text { correção }\end{array}$ & $\begin{array}{c}{[\mathrm{SD}]} \\
\text { com } \\
\text { correção }\end{array}$ & $\begin{array}{l}\text { Consistência } \\
\text { limite }\end{array}$ & $\begin{array}{c}\text { Consistência } \\
\text { sem } \\
\text { correção }\end{array}$ & $\begin{array}{c}\text { Consistência } \\
\text { com } \\
\text { correção }\end{array}$ & $\begin{array}{l}\text { Vazão } \\
\text { original }\end{array}$ & \begin{tabular}{|c|} 
Vazão \\
sem \\
correção
\end{tabular} & $\begin{array}{l}\text { Vazão } \\
\text { com } \\
\text { correção }\end{array}$ \\
\hline & & ppm & ppm & ppm & $\%$ & $\%$ & $\%$ & kg/min & $\mathrm{kg} / \mathrm{min}$ & $\mathrm{kg} / \mathrm{min}$ \\
\hline D1 & Diluição do refinador primário (linha 1) & 5000 & 5294 & 4603 & 0,800 & 0,400 & 0,400 & 94,0 & 94,0 & 94,0 \\
\hline D2 & Diluição dos refinadores de rejeito & 5000 & 5294 & 4603 & 0,800 & 0,398 & 0,398 & 108,7 & 110,9 & 109,0 \\
\hline D3 & Água do chuveiro do filtro de refugo & 3000 & 5294 & 2749 & 0,800 & 0,400 & 0,400 & 299,1 & 271,6 & 272,3 \\
\hline D4 & Água do chuveiro dos filtros da TMP & 5000 & 3408 & 2930 & 0,800 & 0,305 & 0,305 & 1585,0 & 1585,0 & 1585,0 \\
\hline D5 & Diluição do refinador primário (linha 2) & 5000 & 3275 & 2812 & 0,800 & 0,298 & 0,299 & 356,2 & 356,0 & 356,0 \\
\hline D6 & Diluição do refinador secundário (linha 2) & 5000 & 3275 & 2812 & 0,800 & 0,298 & 0,299 & 384,1 & 381,3 & 373,8 \\
\hline D7 & Diluicao de rejeitos da depuração primária & 5000 & 3275 & 2812 & 0,800 & 0,298 & 0,299 & 40,0 & 40,0 & 40,0 \\
\hline D8 & Diluicao de rejeitos da depuração secundária & 5000 & 3275 & 2812 & 0,800 & 0,298 & 0,299 & 55,0 & 55,0 & 55,0 \\
\hline D9 & Diluição após o branqueamento & 3000 & 3275 & 2810 & 0,800 & 0,298 & 0,301 & 1483,3 & 1538,7 & 1549,8 \\
\hline D10 & Diluição para o tanque 1 de TMP & 3000 & 3275 & 2806 & 0,800 & 0,298 & 0,303 & 1254,9 & 1372,1 & 1372,5 \\
\hline D11 & Diluição do couch pit & 3000 & 3275 & 2812 & 0,800 & 0,298 & 0,299 & 996,7 & 990,8 & 991,2 \\
\hline D12 & Água do chuveiro dos filtros Save-All & 3000 & 3275 & 2812 & 0,800 & 0,298 & 0,299 & 997,4 & 999,9 & 1000,0 \\
\hline D13 & Água branca para recuper. de fibras & 3000 & 3275 & 2812 & 0,300 & 0,298 & 0,299 & 20966,0 & 20966,0 & 20966 \\
\hline D14 & Água branca para bomba de mistura & 3000 & 3282 & 2819 & 0,300 & 0,272 & 0,272 & 43823,0 & 43824,0 & 43824 \\
\hline D15 & Diluição do tanque de latência (linha 2) & 5000 & 5298 & 4457 & 0,100 & 0,050 & 0,049 & 8279,0 & 8262,0 & 8279,0 \\
\hline D16 & Diluição do tanque de latência (linha 1) & 5000 & 3811 & 3298 & 0,100 & 0,028 & 0,027 & 4946,0 & 4886,0 & 5076,6 \\
\hline D17 & Água fresca na TMP & 2500 & 3011 & 2500 & 0,018 & 0,009 & 0,009 & 787,0 & 62,1 & 99,3 \\
\hline \multirow[t]{3}{*}{ D18 } & Água fresca para a máquina de papel & 2500 & 574 & 505 & 0,018 & 0,002 & 0,002 & 3420,0 & 2824,0 & 2824,0 \\
\hline & ÁGUA FRESCA ADICIONAL & & & & & & & 0 & 0 & 320,0 \\
\hline & ÁGUA FRESCA TOTAL & & & & & & & 4207,0 & 2886,1 & 3243,3 \\
\hline
\end{tabular}


Tabela 28 - Fontes do caso 3: corrigido para atingir limite estabelecido

\begin{tabular}{|l|c|c|c|c|c|c|c|}
\hline & $\begin{array}{c}\text { Descrição da } \\
\text { fonte }\end{array}$ & $\begin{array}{c}\text { [SD] sem } \\
\text { correção }\end{array}$ & $\begin{array}{c}\text { [SD] } \\
\text { com } \\
\text { correção }\end{array}$ & $\begin{array}{c}\text { Consistência } \\
\text { sem correção }\end{array}$ & $\begin{array}{c}\text { Consistência } \\
\text { com correção }\end{array}$ & $\begin{array}{c}\text { Vazão } \\
\text { sem } \\
\text { correção }\end{array}$ & $\begin{array}{c}\text { Vazão } \\
\text { com } \\
\text { correção }\end{array}$ \\
\hline F1 & $\begin{array}{c}\text { Água da peneira pós- } \\
\text { depuração }\end{array}$ & 5295 & $\mathbf{p p m}$ & $\%$ & $\%$ & $\mathbf{k g} / \mathbf{m i n}$ & $\mathbf{k g} / \mathbf{m i n}$ \\
\hline F2 & $\begin{array}{c}\text { Água branca extraída } \\
\text { da seção de formação }\end{array}$ & 3196 & 2742 & 0,349 & 0,349 & 54640,5 & 54644,3 \\
\hline F3 & $\begin{array}{c}\text { Água da peneira } \\
\text { inclinada pós prensa }\end{array}$ & 5294 & 4603 & 0,300 & 0,300 & 1782,4 & 1771,9 \\
\hline F4 & $\begin{array}{c}\text { Filtrado turvo do filtro } \\
\text { a disco }\end{array}$ & 4197 & 3671 & 0,050 & 0,050 & 1071,6 & 1130,5 \\
\hline F5 & $\begin{array}{c}\text { Filtrado claro dos } \\
\text { filtros Save-All }\end{array}$ & 3338 & 2873 & 0,050 & 0,050 & 17534,9 & 17447,1 \\
\hline F6 & $\begin{array}{c}\text { Filtrado do filtro a } \\
\text { tambor }\end{array}$ & 6124 & 5108 & 0,050 & 0,048 & 5533,6 & 5532,1 \\
\hline F7 & $\begin{array}{c}\text { Filtrado claro do filtro } \\
\text { a disco }\end{array}$ & 4197 & 3671 & 0,030 & 0,030 & 2500,8 & 2638,4 \\
\hline F8 & $\begin{array}{c}\text { Filtrado Superclaro } \\
\text { dos filtros Save-All }\end{array}$ & 3338 & 2873 & 0,025 & 0,025 & 2338,6 & 2327,5 \\
\hline F9 & $\begin{array}{c}\text { Filtrado do Filtro de } \\
\text { refugo }\end{array}$ & 3285 & 2888 & 0,010 & 0,010 & 1276,3 & 1387,1 \\
\hline
\end{tabular}

Para atender os limites de concentração de sólidos dissolvidos, foram introduzidos $110 \mathrm{~kg} / \mathrm{min}$ de água fresca na demanda para o chuveiro do filtro de refugo. Porém antes da introdução de água, a mesma quantidade foi retirada de um ponto e desviada para o couch pit com o objetivo de manter 0 equilíbrio mássico. Paralelamente, foi necessário introduzir mais $210 \mathrm{~kg} / \mathrm{min}$ de água fresca no filtrado dos filtros tambor. Observando a tabela 23, essa fonte foi escolhida por conter grande quantidade de sólidos dissolvidos e baixa consistência. Novamente, parte dessa fonte deve ser extraída para manter o equilíbrio mássico. Percebe-se que para esse caso, é aceitável enviar a parte extraída para o efluente pelo fato de não haver perdas significativas de fibras, pois a concentração da mesma é baixa.

A figura 5.10 esquematiza as modificações feitas no caso 3 para atingir 0 limite estabelecido para os sólidos dissolvidos. 

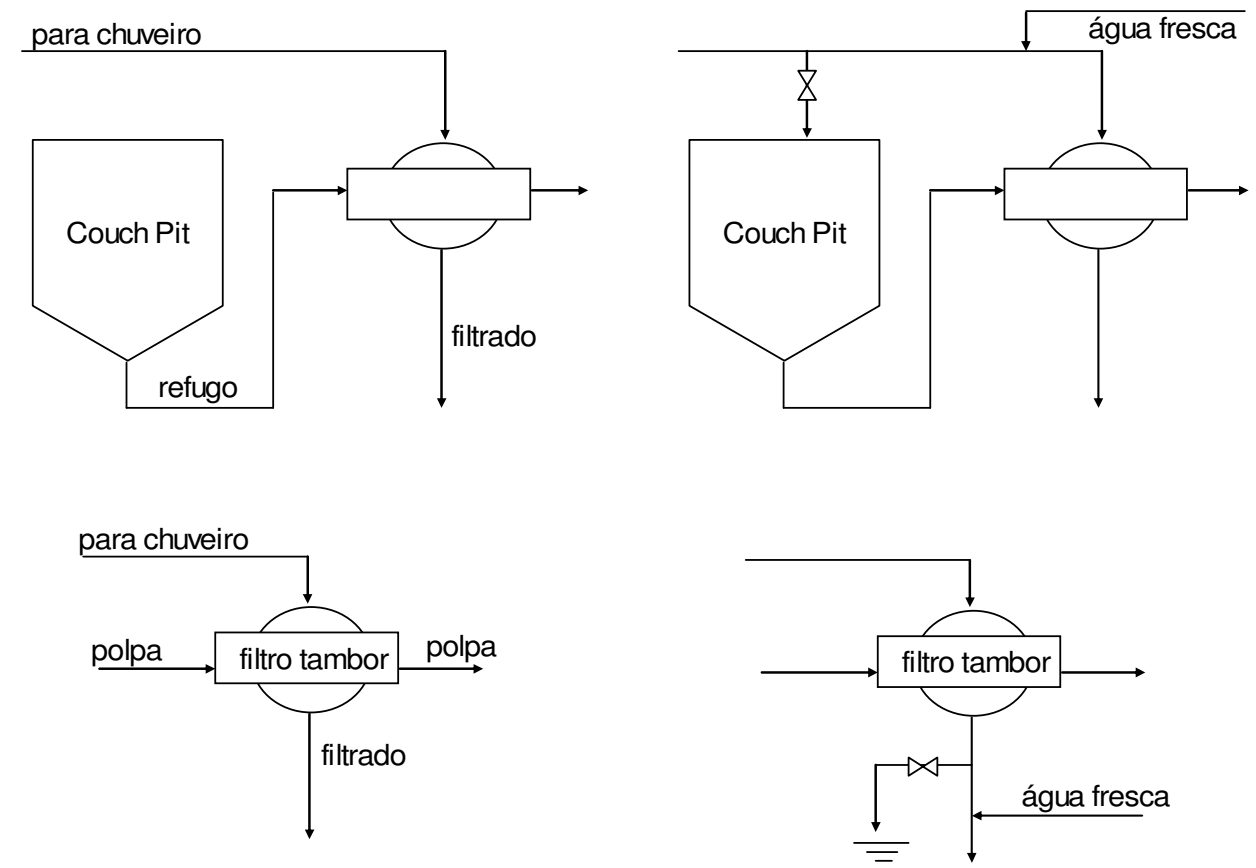

Figura 5.10 - Modificações no caso 3 para atingir limites permitidos para concentração de sólidos dissolvidos

Para verificar a influência dos métodos aplicados na vazão de efluentes, as tabelas 29 e 30 mostram a quantidade de água e fibras enviadas para 0 tratamento de efluentes:

Tabela 29 - Vazão total de água nos efluentes para cada caso (em kg/min)

\begin{tabular}{|c|c|c|c|c|c|c|}
\hline Descrição & Original & $\begin{array}{c}\text { Pinch } \\
\text { Máquina } \\
\text { de Papel }\end{array}$ & $\begin{array}{c}\text { LP } \\
\text { Máquina } \\
\text { de Papel }\end{array}$ & $\begin{array}{l}\text { Pinch } \\
\text { Processo } \\
\text { integrado }\end{array}$ & $\begin{array}{l}\text { Caso } 3 \\
\text { corrigido }\end{array}$ & $\begin{array}{c}\text { LP } \\
\text { Processo } \\
\text { Integrado }\end{array}$ \\
\hline & & Caso 1 & Caso 2 & Caso 3 & & Caso 4 \\
\hline $\begin{array}{l}\text { Transbordo da torre } \\
\text { de água clara }\end{array}$ & 1396,0 & 0,0 & 0,0 & 0,0 & 0,0 & 0,0 \\
\hline Depuração na TMP & 123,4 & 101,3 & 99,3 & 97,7 & 113,1 & 133,3 \\
\hline $\begin{array}{c}\text { Filtrado turvo do filtro } \\
\text { save-all }\end{array}$ & 0,0 & 13,6 & 7,62 & 0,0 & 0,0 & 0,0 \\
\hline $\begin{array}{l}\text { Saída dos filtros } \\
\text { tambores }\end{array}$ & 0,0 & 0,0 & 0,0 & 0,0 & 208,8 & 0,0 \\
\hline $\begin{array}{l}\text { Saída do tanque de } \\
\text { água filtrada }\end{array}$ & 0,0 & 0,0 & 0,0 & 101,2 & 235,9 & 0,0 \\
\hline $\begin{array}{l}\text { Saída dos cleaners } \\
\text { do } 4^{\circ} \text { estágio }\end{array}$ & 907,5 & 915,1 & 896,4 & 914,9 & 914,6 & 903,2 \\
\hline $\begin{array}{l}\text { Saída de água das } \\
\text { prensas da MP }\end{array}$ & 1855,7 & 1870,3 & 1838,8 & 1869,9 & 1868,4 & 1838,1 \\
\hline TOTAL Efluentes & 4282,6 & 2900,3 & 2842,1 & 2983,7 & 3340,8 & 2874,6 \\
\hline Água fresca TOTAL & 4207,0 & 2604,3 & 2546,7 & 2886,1 & 3243,3 & 2878,5 \\
\hline
\end{tabular}


Tabela 30 - Vazão total de fibras nos elfuentes para cada caso (em kg/min).

\begin{tabular}{|c|c|c|c|c|c|c|}
\hline Descrição & Original & $\begin{array}{c}\text { Pinch } \\
\text { Máquina } \\
\text { de Papel }\end{array}$ & $\begin{array}{c}\text { LP } \\
\text { Máquina } \\
\text { de Papel }\end{array}$ & $\begin{array}{c}\text { Pinch } \\
\text { Processo } \\
\text { integrado }\end{array}$ & $\begin{array}{c}\text { Caso 3 } \\
\text { corrigido }\end{array}$ & $\begin{array}{c}\text { LP } \\
\text { Processo } \\
\text { Integrado }\end{array}$ \\
\hline fibras & Caso 1 & Caso 2 & Caso 3 & & Caso 4 \\
\hline $\begin{array}{c}\text { Fibras no transbordo } \\
\text { da torre de água clara }\end{array}$ & 0,66 & 0,00 & 0,00 & 0,00 & 0,00 & 0,00 \\
\hline $\begin{array}{c}\text { Fibras na depuração } \\
\text { na TMP }\end{array}$ & 4,71 & 3,87 & 3,78 & 3,75 & 4,33 & 5,14 \\
\hline $\begin{array}{c}\text { Fibras no filtrado } \\
\text { turvo do filtro save-all }\end{array}$ & 0,00 & 0,06 & 0,03 & 0,00 & 0,00 & 0,00 \\
\hline $\begin{array}{c}\text { Fibras dos filtros } \\
\text { tambores }\end{array}$ & 0,00 & 0,00 & 0,00 & 0,00 & 0,11 & 0,00 \\
\hline $\begin{array}{c}\text { Fibras do tanque de } \\
\text { água filtrada }\end{array}$ & 0,00 & 0,00 & 0,00 & 0,05 & 0,10 & 0,00 \\
\hline $\begin{array}{c}\text { Fibras na saída dos } \\
\text { cleaners do estágio 4 }\end{array}$ & 4,20 & 4,21 & 4,55 & 4,22 & 4,21 & 4,42 \\
\hline $\begin{array}{c}\text { Fibras na saída das } \\
\text { prensas da MP }\end{array}$ & 8,56 & 8,56 & 9,46 & 8,59 & 8,59 & 9,18 \\
\hline TOTAL & $\mathbf{1 8 , 1 3}$ & $\mathbf{1 6 , 7 0}$ & $\mathbf{1 7 , 8 2}$ & $\mathbf{1 6 , 6 1}$ & $\mathbf{1 7 , 3 4}$ & $\mathbf{1 8 , 7 4}$ \\
\hline
\end{tabular}

Conforme mostra a tabela 29, a grande diferença do caso original em relação aos processos otimizados, está na quantidade de água que transborda da torre de água clara. Evitar o transbordo dessa grande quantidade de efluentes significa aumentar a quantidade de fibras e sólidos e dissolvidos dentro do circuito. Portanto, mais um motivo que influenciou o desbalanceamento das correntes otimizadas em relação às originais pode ser considerado, pois após eliminar o transbordo, as quantidades de fibras diminuíram na maioria dos casos. 


\section{CONCLUSÃO}

Um dos objetivos do trabalho foi utilizar os métodos pinch e programação linear para o circuito de água residual em máquina de papel e produção de pasta mecânica. Diferentemente de literatura prévia, onde um estudo de caso tratava do circuito de água praticamente aberto no sistema de vácuo da máquina de papel, o presente trabalho utiliza um sistema que opera com uma torre de resfriamento, além do caso industrial ser validado realisticamente apesar de toda a complexidade decorrente de tal abordagem.

Através dos resultados, demonstra-se que reduções de $38 \%$ são possíveis ao considerar os valores da otimização por método Pinch somente para a máquina de papel. Para o mesmo caso utilizando programação linear, a redução foi de $40 \%$. Considerando o processo integrado da máquina de papel com fabricação de TMP, ou seja, um caso mais interessante para a unidade industrial, a redução por método Pinch e por programação linear atingiu 31\%. Mas como muitas concentraçôes limites de finos e sólidos dissolvidos foram ultrapassadas após o teste por simulação, foi necessário escolher um caso para iniciar uma análise com correção do circuito de água. A partir do caso escolhido, ou seja, do processo integrado da máquina de papel com fabricação de TMP utilizando método Pinch, novos valores para as correntes foram encontrados para não ultrapassar os limites estabelecidos. A redução para esse caso foi de $23 \%$, ou seja, um valor ainda significativo para a unidade industrial.

Minimizar o consumo de água utilizando métodos de otimização gráfica ou através de programação matemática pode se tornar uma ferramenta eficaz na medida em que dados são coletados de forma confiável. Porém dados de vazão, temperatura e consistência de cada corrente não são suficientes para obter resultados expressivos que conduzam à implementação do processo otimizado em escala real. 
Para o método utilizado no presente trabalho, é muito importante definir valores limites para concentração de contaminantes de cada equipamento, assim como a concentração prejudicial para o processamento contínuo de pasta mecânica e papel imprensa. Infelizmente, esses valores não são de fácil acesso e devem ser cuidadosamente estudados e analisados antes de sua definição. Impor diferentes valores limites para o mesmo estudo de caso gera grandes impactos no resultado final, independente do método de otimização utilizado. Operacionalmente, o limite de concentração deve ser avaliado qualitativa e quantitativamente, pois tal valor pode ocasionar o mau funcionamento de um equipamento ou a contaminação do produto final.

Apesar de dados serem coletados de uma unidade fabril real, as incoerências dos primeiros resultados foram freqüentes, pois transportar um processo produtivo real para um simulador não foi uma tarefa simples. O que pôde ser feito foi uma aproximação, sob hipóteses, dos parâmetros de equipamentos e das correntes em questão. Além disso, lidar com uma corrente de polpa de madeira significa, por natureza, trabalhar com concentrações variáveis de contaminantes, fibras e outros compostos inorgânicos no decorrer do processo. Isso ocorre porque a matéria-prima é oriunda de diferentes tipos de árvores, que por sua vez é originada de diferentes climas e solos.

Sendo assim, o processo produtivo não foi reproduzido no modelo de forma detalhada, o que contribuiu com alguns desvios observados nos dados simulados. Outras divergências ocorreram pelo fato da unidade fabril não conter medidores de vazão e de concentração de contaminantes suficientes para analisar o processo de forma minuciosa, o que acarretou no uso de outras fontes de dados como referências bibliográficas, fluxogramas de projeto e dados de outras fábricas. A dificuldade em transferir os dados reais para o simulador causou desvios inevitáveis, decorrentes de variações imprevisíveis do processo real que não são reproduzidas na simulação.

Os desvios dos dados simulados também ocorreram devido à complexidade em fechar um balanço completamente integrado. A fábrica não foi simulada 
de forma detalhada com controles de nível, de pressão ou de temperatura, principalmente por falta de informações e por se tratar somente de um balanço de massa. Porém todas as etapas mais importantes da fabricação de papel imprensa e pasta mecânica foram incorporadas na simulação. $E$ quando correntes reais são manipuladas, é possível, apesar dos desvios, discutir a viabilidade dos resultados com mais confiança.

A utilização de um simulador é imprescindível para acompanhar e analisar os resultados do processo otimizado. O software Cadsim correspondeu com o objetivo do trabalho por se tratar de uma ferramenta desenvolvida para o setor de celulose e papel. Simular dados se torna bastante prático quando há possibilidade de analisar variáveis de forma dinâmica. O comportamento de determinada corrente pode ser acompanhado no momento em que uma variável em estudo é alterada, o que torna a análise mais visível.

Porém o tempo para atingir o processo em regime permanente foi relativamente alto, o que dificultou a execução do trabalho. Isso está relacionado principalmente com a complexidade do sistema em simulação, onde os ajustes dos parâmetros de controle não foram perfeitamente adequados. Alterações em algumas correntes foram feitas para estabilizar a simulação de forma mais rápida, porém cuidados foram tomados para que não houvesse divergências em outras correntes. Ajustar parâmetros de controladores e de equipamentos operacionais é um desafio que exige bons conhecimentos específicos e não foi contemplado de forma detalhada.

Quanto à praticidade dos métodos de otimização utilizados, vantagens e dificuldades foram encontradas durante o trabalho. Em todos os casos foi verificado um problema pelo fato das vazões e concentrações de fontes e demandas se alterarem a cada caso aplicado, conforme tabelas de 21 a 26 mostradas na seção anterior. Este resultado é justamente o que Hallale (2002) conclui em sua publicação. Sendo assim, há deficiências de aplicação dos métodos que, muitas vezes, não são consideradas por alguns autores justamente por não haver verificação dos resultados no simulador. 
O método Pinch demonstrou uma praticidade maior, pois foi possível manipular poucas correntes para tentar reduzir o consumo de água fresca. Além disso, a facilidade em utilizar graficamente a ferramenta de otimização pode motivar a equipe de engenheiros e operadores da unidade fabril. Não é o que ocorre com a programação matemática, onde a falta de familiaridade com funções e restrições lineares ou não lineares pode ocasionar erros durante a interpretação de resultados. A única desvantagem do método Pinch é que como há correntes atingindo valores até $55000 \mathrm{~kg} / \mathrm{min}$ e outros inferiores a $50 \mathrm{~kg} / \mathrm{min}$, ou seja, desprezível em relação à corrente de maior valor, a visualização no gráfico é dificultada.

Quando um objetivo é estabelecido, a preocupação com o custo de implantação e modificação no processo produtivo deve ser considerada. No presente trabalho, por exemplo, o objetivo principal foi a aplicação de técnicas gráficas e matemáticas como alternativas de auxílio aos engenheiros da unidade industrial. Não foi objeto de estudo a implantação de uma alternativa em que o consumo de água fresca seja reduzido ao mesmo tempo em que o custo de operação e implantação é minimizado. Ou seja, o custo para implantação de novas tubulações, válvulas, tanques ou bombas são desconsideradas. Porém, a inclusão de restrições de custos poderá futuramente ser incorporada em técnicas de programação matemática como complemento ao presente trabalho.

Apesar de resultados perfeitamente expressivos não serem encontrados, é possível dizer que todo o trabalho realizado contribuiu de forma positiva para a análise e aplicação de técnicas que minimizem o consumo de água e a geração de efluentes. Teoricamente, resultados mostraram que através de algumas modificações, o circuito de água pode ser otimizado. Porém sua aplicação em escala real ainda deve ser amplamente analisada por engenheiros da unidade fabril junto com pesquisadores.

Como mencionado anteriormente, o presente trabalho pode futuramente ser contemplado com estudos mais abrangentes envolvendo, por exemplo, a taxa 
de retorno de investimento e custos operacionais relacionados a novas alternativas. Outro trabalho interessante a ser feito futuramente para fabricantes de pasta mecânica é estudar a integração de processos envolvendo consumo de energia e fluxos mássicos. Como a indústria de pastas mecânicas é consumidora intensiva de energia elétrica e água, é importante analisar pontos ótimos de operação através de suas correlações. Um caso a ser estudado, por exemplo, é o local ótimo para utilizar o vapor extraído durante a refinação de cavacos, o que pode afetar fluxos mássicos em determinadas partes do processo.

Pesquisas com o intuito de beneficiar o uso consciente de recursos naturais em indústrias devem ser difundidas, principalmente em uma época em que a indústria brasileira investe de forma intensiva para aumentar suas capacidades produtivas. Como o consumo específico de energia e água deve ser preferencialmente minimizado, trabalhos como esse se tornam úteis ao serem desenvolvidos com seriedade. 


\section{REFERÊNCIAS BIBLIOGRÁFICAS}

Al-Redhwan, S.A.; Crittenden, B.D.; Lababidi, H.M.S. Wastewater minimization under uncertain operational conditions. Chemical Engineering Science 29 (5) 1009-1021 2005.

Aly. S.; Abeer, S.; Awad, M. A New Systematic Approach for Water Network Design. Clean Technology and Environmental Policy 7 (3) 154-161 2005.

Alva-Argaéz, A.; Kokossis, A.C.; Smith, R. Wastewater Minimization of Industrial Systems Using an Integrated Approach. Computers and Chemical Engineering. 22 (Suppl) S741-S744. 1998.

Andersen, M.; Kristensen, G.H.; Wenzel, H. Tools for evaluation of water reuse scenarios in industry. in: 2nd International Conference on Industrial Wastewater Recovery and Reuse. Cranfield University. 17 July 2002

Bagajewicz, M. A Review of Recent Procedures for Water Network in Refineries and Process Plants. Computer and Chemical Engineering 24 (9-10) 2093-2113. 2000.

Bagajewicz,M; Savelski, M.; On the use of linear models for the design of water utilization systems in process plants with a single contaminant. Chemical Engineering Research and. Design 79 (A5) 600-610. 2001.

Björkqvist, J.; Roslöf, J.; Söderman, J.; Petterson, F.; Westerlund, T. Mathematical Programming Methods for Industrial Applications. Proceedings of the International Conference on Process Integration, PI'99, Copenhagen, Denmark. 3p. 1999.

Cao, K.; Feng, X.; Ma, H. Pinch multi-agent genetic algorithm for optimizing water-using networks. Computers and Chemical Engineering (in press) 2007.

Dabros, M ; Perrier, M ; Forbes, F ; Fairbanks, M ; Stuart, P. Model-based direct search optimization of the broke recirculation system in a newsprint mill. Journal of Cleaner Production 13 (12) 1416 -1423. 2005

Dhole, V.R.; Ramchandani, N.; Tainsh, R. A.; Wasilewski, M. Make your process water pay for itself", Chemical Engineering, 103 (1) 100-103.1996.

Dunn, R.F.; Wenzel, H. Process Integration Design Methods for Water Conservation and Wastewater Reduction in Industry, Part 1: Design for Single Contaminants. Clean Products and Processes 3 (3) 307-318 2001.

Dunn, R.F; Wenzel, H.; Overcash, M.R. Process Integration Design Methods for Water Conservation and Wastewater Reduction in Industry, Part 2: Design for Multiple Contaminants. Clean Products and Processes 3 (3) 319-329 2001. 
Dunn, R.F; Wenzel, H. Process Integration Design Methods for Water Conservation and Wastewater Reduction in Industry, Part 3: Experience of industrial application. Clean Products and Processes 4 (1) 16-25. 2002

Dunn, F.R.; El-Halwagi, M.M. Process Integration Technology Review: BacKground and Applications in the Chemical Process Industry. J. Chemical Technology and Biotechnology 78 (9) 1011-1021. 2003.

El-Halwagi, M.M. Pollution prevention through process integration. Academic Press; 1997.

El-Halwagi, M.M.; Manousiouthakis, V. Synthesis of mass exchange networks. AIChE J. 35 (8) 1233-1244. 1989.

Feng, X.; Wang, B.; Liu, Y. Bottleneck and debottleneck of water-use system. APCChE2002 WCT $9^{\text {th }}$ Asian Pacific Confederation of Chemical Engineering. Christchurch, New Zealand, September 29-October 3, 2002.

Foo, C.Y.; Manan, Z.A.; Yunus, R.M.; Aziz, R.A. Maximising Water Recovery through Water Pinch Technology - The Use of Water Cascade Table. Environment 2003, Malaysia.

Hamad, A.; Aidan, A; Douboni, M. Cost-effective wastewater treatment and recycling in mini-plants using mass integration. Clean Technologies and Environmental Policy 4 (4) 246-256. 2003

Hallalle, N. A new graphical targeting method for water minimisation. Advances in Environment Research 6 (3) 377-390. 2002.

Jacob, J.; Kaipe, H.; Couderc, F.; Paris, J. Water Network Analysis in Pulp and Paper Processes by Pinch and Linear Programming Techniques. Chemical Engineering Communication 189 (2) 184 - 206. 2002

Jödicke, G.; Fischer, U.; Hungerbuhler, K. Wastewater reuse: a new approach to screen for designs with minimal total costs. Computers and Chemical Engineering 25 (2-3) 203-215. 2001

Jutila, L ; Leiviska,K. The Use of Computer Simulation in the Pulp and Paper Industry. Mathematics and Computers in Simulation 23 (1) 1-11. 1981

Kuo, J. A combined approach to water minimization and effluent treatment system design. PhD Thesis, Department of Process Integration, UMIST, Manchester, UK. 1996.

Lappalainen,T ; Mäkinen,M. Dynamic plant simulation of DCS on newsprint paper machine. The 47th Conference on Simulation and Modelling Conference, Helsinki, September 27-29, 2006

Majozi, T. An effective technique for wastewater minimisation in batch processes. Journal of Cleaner Production 13 (15) 1374-1380. 2005. 
Manan, Z.A.; Tan, Y.L.; Foo, D.C.Y. Targeting the minimum water flow rate using water cascade analysis technique AIChE Journal 50 (12) 3169-3183. 2004

Mann, J.G. and Y.A. Liu, Industrial Water Reuse and Wastewater Management. McGraw-Hill, 1999.

Mann, J. G. Process Integration: Unifying Concepts, Industrial Applications and Software Implementation. PhD Thesis, Blacksburg, VA.1999.

Mariano-Romero C.E.; Alcocer-Yamanaka, V.H.; Morales, E.F. Multi-objective optimization of water-using systems. European Journal of Operational Research 181 (3) 1691-1707. 2007.

Mierzwa, J.C; Hespanhol. I., Água na Indústria - Uso racional e reuso. São Paulo, Oficina de Textos, 2005.

Mutjé, P.; Pélach, M.A.; Turon, X.; Labidi, J. Analisis y optimizacion de redes de agua en fabricas de papel. Ciadicyp2002. Il Congreso IberoAmericano en Celulosa y Papel. 11p. Campinas, Oct 2002.

Oliveira, L.C. Estudo preliminar de balanços de consumo de água fresca na fabricação de papel imprensa. Monografia de Especialização em Papel e Celulose. Dep. Engenharia Química. Escola Politécnica da Universidade de São Paulo. 2004.

Papalexandri, K.P.; Pistikopoulos, E.N.; Floudas, C.A. Mass-exchange networks for waste minimization - a simultaneous approach. Chemical Engineering Research and. Design 72 (A3): 279-294 May 1994.

PAPRICAN. Water Use Reduction in the Pulp and Paper Industry. Pulp and Paper Research Institute of Canada, $2^{\text {nd }}$ ed, 2001

Prakash, R.; Shenoy V.U. Targeting and design of water networks for fixed flowrate and fixed contaminant load operations. Chemical Engineering Science 60 (1) 255-268. 2005.

Savulescu, L.; Poulin, B.; Hammache, A.; Bedard, S.; Gennaoui, S. Water and energy savings at a kraft paperboard mill using process integration. Pulp and Paper - Canada 106 (9): 29-31, 2005

Smith, R. State of the art in Process Integration. Applied Thermal Engineering $20(15-16) 1337-1345.2000$.

Sundholm, J. (ed.) Mechanical Pulping. Papermaking Science and Technology Series. Published in cooperation with the Finnish Paper Engineers' Association and TAPPI. Helsinki, Finland. 1999

Syberg, O.; Wild, N.W.; Simons, H.A. (eds.) Introduction to process Simulation. $2^{\text {nd }}$ edition. Tappi Press, Atlanta. 1992 
Tan, Y.L.; Zainuddin, A.M.; Foo, Y.C. Water Minimization by Pinch Technology - Water Cascade for Minimum Water and Wastewater Targeting. APCChE2002_WCT $9^{\text {th }}$ Asian Pacific Confederation of Chemical Engineering. Christchurch, New Zealand, September 29-October 3, 2002.

Turon, X.; Labidi, J.; Paris, J. Simulation and optimisation of a high grade coated paper mill. Journal of Cleaner Production 13 (12) 1424 -1433. 2005

Wang, Y.P.; Smith, R. Wastewater minimization with flowrate constraints. Chemical Engineering Research and Design 73 (A8) 889-904. 1995

Wang, Y.P.; Smith, R. Waste-water Minimization. Chemical Engineering Science. 49 (7) 981-1006. 1994.

Yang, Y.H.; Lou, H.H.; Huang, Y.L. Synthesis of an Optimal Wastewater Reuse Network", Waste Management 38 (5) 311-319. 2000. 


\section{APÊNDICE A}

Esse apêndice mostra a comparação de dados simulados para os quatro estudos de casos. Estão tabelados os dados de vazão mássica de água e de concentrações de fibras e sólidos dissolvidos.

Tabela A1 - Comparação de vazões de água dos casos pós otimizados (em kg/min)

\begin{tabular}{|c|c|c|c|c|c|}
\hline Corrente & $\begin{array}{c}\text { Vazão } \\
\text { mássica de } \\
\text { água }\end{array}$ & $\begin{array}{c}\text { Pinch } \\
\text { Máquina } \\
\text { de Papel }\end{array}$ & $\begin{array}{c}\text { Láquina de } \\
\text { Papel }\end{array}$ & $\begin{array}{c}\text { Pinch } \\
\text { Processo } \\
\text { integrado }\end{array}$ & $\begin{array}{c}\text { LP } \\
\text { Processo } \\
\text { Integrado }\end{array}$ \\
\hline Descrição & Original & Caso 1 & Caso 2 & Caso 3 & Caso 4 \\
\hline $\begin{array}{c}\text { Saída de cavaco do silo } \\
\text { (linha 1) }\end{array}$ & $\mathbf{2 6 0 , 0}$ & 260,0 & 260,0 & 260,0 & 260,0 \\
\hline $\begin{array}{c}\text { Entrada de polpa no refinador } \\
\text { primário (linha 2) }\end{array}$ & $\mathbf{2 6 0 , 0}$ & 260,0 & 260,0 & 260,0 & 260,0 \\
\hline $\begin{array}{c}\text { Água de diluição no refinador } \\
\text { primário (linha 2) }\end{array}$ & $\mathbf{3 5 6 , 2}$ & 355,9 & 355,8 & 356,0 & 358,3 \\
\hline $\begin{array}{c}\text { Saída de polpa do refinador } \\
\text { primário (linha 2) }\end{array}$ & $\mathbf{3 1 1 , 1}$ & 309,9 & 310,0 & 317,1 & 330,3 \\
\hline $\begin{array}{c}\text { Entrada de polpa no } \\
\text { refinador secundário (linha 2) }\end{array}$ & $\mathbf{3 1 1 , 1}$ & 309,9 & 310,0 & 317,1 & 330,3 \\
\hline $\begin{array}{c}\text { Água de diluição no refinador } \\
\text { secundário (linha 2) }\end{array}$ & $\mathbf{3 8 4 , 1}$ & 383,7 & 383,6 & 381,1 & 335,7 (a) \\
\hline $\begin{array}{c}\text { Saída de polpa do refinador } \\
\text { secundário (linha 2) }\end{array}$ & $\mathbf{3 2 8 , 4}$ & 327,3 & 327,8 & 335,1 & 317,1 \\
\hline $\begin{array}{c}\text { Água de diluição do tanque } \\
\text { de Latência linha 1 }\end{array}$ & $\mathbf{8 2 7 9 , 3}$ & 8479,0 & 8600,5 & 8261,9 & 8158,8 \\
\hline $\begin{array}{c}\text { Água fresca } \\
\text { para TMP }\end{array}$ & $\mathbf{7 8 6 , 8}$ & 568,3 & 510,7 & 66,6 & 150,1 \\
\hline $\begin{array}{c}\text { Saída de polpa do tanque de } \\
\text { latência }\end{array}$ & $\mathbf{9 3 9 4 , 3}$ & 9375,0 & 9438,9 & 9343,3 & 9078,9 \\
\hline $\begin{array}{c}\text { Entrada de polpa no } \\
\text { refinador baixa consistência }\end{array}$ & $\mathbf{4 5 5 6 , 5}$ & 4542,2 & 4606,5 & 4511,5 & 4238,9 \\
\hline $\begin{array}{c}\text { Saída da polpa do refinador } \\
\text { baixa consistência }\end{array}$ & $\mathbf{4 5 5 6 , 5}$ & 4542,2 & 4606,5 & 4511,5 & 4238,9 \\
\hline $\begin{array}{c}\text { Entrada de polpa no } \\
\text { refinador baixa consistência }\end{array}$ & $\mathbf{4 8 3 8 , 1}$ & 4832,7 & 4832,3 & 4831,8 & 4840,0 \\
\hline $\begin{array}{c}\text { Saída de polpa do refinador } \\
\text { baixa consistência }\end{array}$ & $\mathbf{4 8 3 8 , 1}$ & 4832,7 & 4832,7 & 4831,8 & 4840,0 \\
\hline $\begin{array}{c}\text { Saída de polpa do tanque de } \\
\text { latência linha 2 }\end{array}$ & $\mathbf{9 3 9 4 , 6}$ & 9374,9 & 9438,9 & 9343,3 & 9079,0 \\
\hline $\begin{array}{c}\text { Entrada de polpa na } \\
\text { depuração primária (linha 2) }\end{array}$ & $\mathbf{9 3 9 4 , 6}$ & 9374,9 & 9438,9 & 9343,3 & 9079,0 \\
\hline $\begin{array}{c}\text { Aceite da depuração } \\
\text { primária (linha 2) }\end{array}$ & $\mathbf{5 8 0 0 , 0}$ & 5800,0 & 5800,0 & 5800,0 & 5800,0 \\
\hline $\begin{array}{c}\text { Rejeito da depuracão primária } \\
\text { (linha 2) }\end{array}$ & $\mathbf{3 5 9 4 , 6}$ & 3574,6 & 3638,9 & 3543,3 & 3278,9 \\
\hline
\end{tabular}




\begin{tabular}{|c|c|c|c|c|c|}
\hline Corrente & $\begin{array}{l}\text { Vazão } \\
\text { mássica de } \\
\text { água }\end{array}$ & $\begin{array}{c}\text { Pinch } \\
\text { Máquina } \\
\text { de Papel }\end{array}$ & $\begin{array}{c}\text { LP } \\
\text { Máquina de } \\
\text { Papel }\end{array}$ & $\begin{array}{l}\text { Pinch } \\
\text { Processo } \\
\text { integrado }\end{array}$ & $\begin{array}{c}\text { LP } \\
\text { Processo } \\
\text { Integrado }\end{array}$ \\
\hline Descrição & Original & Caso 1 & Caso 2 & Caso 3 & Caso 4 \\
\hline $\begin{array}{l}\text { Diluição de rejeito } \\
\text { (linha 2) }\end{array}$ & 39,8 & 39,8 & 39,8 & 40,0 & 39,8 \\
\hline $\begin{array}{l}\text { Entrada polpa na depuração } \\
\text { secundária (linha 2) }\end{array}$ & 3511,1 & 3514,4 & 3579,3 & 3485,8 & 3184,7 \\
\hline $\begin{array}{l}\text { Aceite da depuração } \\
\text { secundária (linha 2) }\end{array}$ & 2100,0 & 2100,0 & 2100,0 & 2100,0 & 2100,0 \\
\hline $\begin{array}{l}\text { Rejeito da depuração } \\
\text { secundária (linha 2) }\end{array}$ & 1411,0 & 1414,4 & 1479,6 & 1385,8 & 1084,7 \\
\hline $\begin{array}{l}\text { Diluição rejeito da depuração } \\
\text { secundária (linha 2) }\end{array}$ & 54,7 & 54,7 & 54,7 & 55,0 & 55,2 \\
\hline $\begin{array}{l}\text { Entrada de polpa no } \\
\text { refinador primário (linha 1) }\end{array}$ & 62,0 & 62,0 & 62,0 & 62,0 & 62,0 \\
\hline $\begin{array}{c}\text { Água de diluição no refinador } \\
\text { primário (linha 1) }\end{array}$ & 94,0 & 93,9 & 93,4 & 94,0 & $94,3^{(b)}$ \\
\hline $\begin{array}{l}\text { Saída de polpa do refinador } \\
\text { primário (linha 1) }\end{array}$ & 114,3 & 113,7 & 113,2 & 113,3 & 113,1 \\
\hline $\begin{array}{l}\text { Entrada de polpa no } \\
\text { refinador primário (linha 1) }\end{array}$ & 244,5 & 245,2 & 248,9 & 243,8 & 222,5 \\
\hline $\begin{array}{c}\text { Água de diluição no refinador } \\
\text { secundário (linha 1) }\end{array}$ & 61,5 & 61,5 & 61,9 & 63,3 & $45,7^{(\mathrm{c})}$ \\
\hline $\begin{array}{l}\text { Saída de polpa do refinador } \\
\text { secundário (linha 1) }\end{array}$ & 275,4 & 276,2 & 280,3 & 282,7 & 253,9 \\
\hline $\begin{array}{l}\text { Entrada de polpa no } \\
\text { refinador de rejeitos }\end{array}$ & 109,1 & 109,0 & 108,9 & 109,1 & 109,2 \\
\hline $\begin{array}{l}\text { Água de diluição no } \\
\text { refinador de rejeitos }\end{array}$ & 47,2 & 47,1 & 47,1 & 47,1 & 47,3 \\
\hline $\begin{array}{c}\text { Saída de polpa do refinador } \\
\text { de rejeitos }\end{array}$ & 153,9 & 153,9 & 153,1 & 154,0 & 153,3 \\
\hline $\begin{array}{c}\text { Água de diluição do tanque } \\
\text { de Latência }\end{array}$ & 4946,3 & 4941,3 & 4900,2 & 4885,2 & 4991,6 \\
\hline $\begin{array}{c}\text { Entrada de polpa na } \\
\text { depuração primária (linha 1) }\end{array}$ & 5375,6 & 5370,5 & 5373,6 & 5321,8 & 5398,7 \\
\hline $\begin{array}{l}\text { Aceite da depuração } \\
\text { primária (linha 1) }\end{array}$ & 4225,6 & 4220,5 & 4223,6 & 4171,8 & 4248,7 \\
\hline $\begin{array}{l}\text { Rejeito da depuração } \\
\text { primária (linha 1) }\end{array}$ & 1150,0 & 1150,0 & 1150,0 & 1150,0 & 1150,0 \\
\hline Entrada de polpa na prensa 2 & 946,4 & 945,4 & 945,4 & 945,9 & 946,9 \\
\hline Saída da Polpa da Prensa 2 & 109,1 & 109,1 & 109,0 & 109,1 & 109,2 \\
\hline Filtrado da Prensa 2 & 847,3 & 846,4 & 846,4 & 846,9 & 847,8 \\
\hline Entrada de polpa na prensa 1 & 1129,6 & 1140,7 & 1177,0 & 1131,8 & 947,3 \\
\hline Saída da Polpa da Prensa 1 & 120,2 & 131,5 & 135,7 & 130,5 & 109,2 \\
\hline
\end{tabular}




\begin{tabular}{|c|c|c|c|c|c|}
\hline Corrente & $\begin{array}{c}\text { Vazão } \\
\text { mássica de } \\
\text { água }\end{array}$ & $\begin{array}{c}\text { Pinch } \\
\text { Máquina } \\
\text { de Papel }\end{array}$ & $\begin{array}{c}\text { LP } \\
\text { Máquina de } \\
\text { Papel }\end{array}$ & $\begin{array}{l}\text { Pinch } \\
\text { Processo } \\
\text { integrado }\end{array}$ & $\begin{array}{c}\text { LP } \\
\text { Processo } \\
\text { Integrado }\end{array}$ \\
\hline Descrição & Original & Caso 1 & Caso 2 & Caso 3 & Caso 4 \\
\hline $\begin{array}{l}\text { Aceite da peneira inclinada } \\
\text { (após depuração) }\end{array}$ & 605,7 & 599,3 & 629,5 & 570,0 & 455,1 \\
\hline $\begin{array}{l}\text { Rejeito da peneira inclinada } \\
\text { (após depuração) }\end{array}$ & 2000,6 & 2010,3 & 2045,3 & 2002,3 & 1825,4 \\
\hline $\begin{array}{l}\text { Entrada na peneira inclinada } \\
\text { (após prensa) }\end{array}$ & 1856,7 & 1865,6 & 1897,7 & 1858,2 & 1695,9 \\
\hline $\begin{array}{l}\text { Aceite da peneira inclinada } \\
\text { (após prensa) }\end{array}$ & 1781,2 & 1789,8 & 1820,6 & 1782,7 & 1627,0 \\
\hline $\begin{array}{l}\text { Rejeito da peneira inclinada } \\
\text { (após prensa) }\end{array}$ & 75,4 & 75,8 & 77,1 & 75,5 & 68,9 \\
\hline $\begin{array}{l}\text { Entrada de polpa no } \\
\text { filtro a disco }\end{array}$ & 4225,6 & 4220,5 & 4223,6 & 4171,8 & 4248,7 \\
\hline $\begin{array}{l}\text { Saída da polpa do } \\
\quad \text { filtro a disco }\end{array}$ & 1795,0 & 1798,3 & 1835,1 & 1793,7 & 1713,8 \\
\hline $\begin{array}{l}\text { Filtrado claro do } \\
\text { filtro a disco }\end{array}$ & 2537,3 & 2530,6 & 2506,9 & 2499,4 & 2610,3 \\
\hline $\begin{array}{l}\text { Filtrado turvo do } \\
\text { filtro a disco }\end{array}$ & 1087,2 & 1084,3 & 1074,2 & 1070,0 & 1118,5 \\
\hline $\begin{array}{l}\text { Água do chuveiro do } \\
\text { filtro a disco }\end{array}$ & 1193,9 & 1192,7 & 1192,6 & 1192,2 & 1183,8 \\
\hline $\begin{array}{l}\text { Entrada de polpa no conjunto } \\
\text { filtro tambor } 1\end{array}$ & 5957,3 & 5959,4 & 5959,5 & 5959,8 & 5956,5 \\
\hline $\begin{array}{l}\text { Saída da polpa do conjunto } \\
\text { filtro tambor } 1\end{array}$ & 2071,4 & 2069,3 & 2069,7 & 2078,2 & 2079,9 \\
\hline $\begin{array}{l}\text { Filtrado do conjunto } \\
\text { filtro tambor } 1\end{array}$ & 4097,7 & 4099,4 & 4089,6 & 4095,4 & 4271,9 \\
\hline $\begin{array}{l}\text { Água do chuveiro do conjunto } \\
\text { filtro tambor } 1\end{array}$ & 211,8 & 209,8 & 199,7 & 213,9 & 395,3 \\
\hline $\begin{array}{l}\text { Entrada de polpa no conjunto } \\
\text { filtro tambor } 2\end{array}$ & 1942,7 & 1940,6 & 1940,5 & 1940,2 & 1943,5 \\
\hline $\begin{array}{l}\text { Saída da polpa do conjunto } \\
\text { filtro tambor } 2\end{array}$ & 675,4 & 673,9 & 673,8 & 680,9 & 679,6 \\
\hline $\begin{array}{l}\text { Filtrado do filtro conjunto } \\
\text { filtro tambor } 2\end{array}$ & 1446,4 & 1445,6 & 1445,5 & 1438,1 & 1442,9 \\
\hline $\begin{array}{l}\text { Água do chuveiro do conjunto } \\
\text { filtro tambor } 2 \\
\end{array}$ & 179,1 & 178,9 & 178,9 & 178,8 & 179,1 \\
\hline $\begin{array}{l}\text { Entrada de polpa no } \\
\text { filtro save-all } 2\end{array}$ & 13626,2 & 13611,1 & 13613,2 & 13615,3 & 13611,7 \\
\hline $\begin{array}{l}\text { Saída da polpa do } \\
\text { filtro save-all } 2\end{array}$ & 3500,5 & 3569,7 & 3464,9 & 3503,2 & 3563,7 \\
\hline $\begin{array}{l}\text { Filtrado claro do } \\
\text { filtro save-all } 2\end{array}$ & 7933,5 & 7871,9 & 7919,6 & 7926,9 & 7872,2 \\
\hline $\begin{array}{l}\text { Filtrado superclaro do } \\
\quad \text { filtro save-all } 2\end{array}$ & 1058,1 & 1049,8 & 1056,2 & 1057,2 & 1049,9 \\
\hline $\begin{array}{c}\text { Filtrado turvo do filtro } \\
\text { save-all } 2\end{array}$ & 1582,7 & 1570,4 & 1579,9 & 1581,4 & 1570,5 \\
\hline
\end{tabular}




\begin{tabular}{|c|c|c|c|c|c|}
\hline Corrente & $\begin{array}{l}\text { Vazão } \\
\text { mássica de } \\
\text { água }\end{array}$ & $\begin{array}{c}\text { Pinch } \\
\text { Máquina } \\
\text { de Papel }\end{array}$ & $\begin{array}{c}\text { LP } \\
\text { Máquina de } \\
\text { Papel }\end{array}$ & $\begin{array}{l}\text { Pinch } \\
\text { Processo } \\
\text { integrado }\end{array}$ & $\begin{array}{c}\text { LP } \\
\text { Processo } \\
\text { Integrado }\end{array}$ \\
\hline Descrição & Original & Caso 1 & Caso 2 & Caso 3 & Caso 4 \\
\hline $\begin{array}{c}\text { Água do chuveiro do filtro } \\
\text { save-all } 2\end{array}$ & 449,0 & 450,9 & 407,7 & 453,4 & 444,6 \\
\hline $\begin{array}{l}\text { Entrada de polpa no filtro } \\
\text { save-all } 1\end{array}$ & 16186,7 & 16166,8 & 16191,1 & 16358,8 & 16131,1 \\
\hline $\begin{array}{c}\text { Saída da polpa do filtro } \\
\text { save-all } 1\end{array}$ & 4053,7 & 4137,1 & 4017,2 & 4103,8 & 4120,2 \\
\hline $\begin{array}{l}\text { Filtrado claro do filtro } \\
\text { save-all } 1\end{array}$ & 9517,2 & 9438,4 & 9547,1 & 9607,4 & 9424,8 \\
\hline $\begin{array}{c}\text { Filtrado superclaro do filtro } \\
\text { save-all } 1\end{array}$ & 1058,1 & 1258,8 & 1273,3 & 1281,3 & 1257,1 \\
\hline $\begin{array}{c}\text { Filtrado turvo do filtro } \\
\text { save-all } 1\end{array}$ & 1894,9 & 1879,2 & 1900,8 & 1912,8 & 1876,5 \\
\hline $\begin{array}{l}\text { Água do chuveiro do } \\
\text { filtro save-all } 1\end{array}$ & 548,4 & 546,5 & 547,3 & 546,6 & 547,4 \\
\hline $\begin{array}{l}\text { Saída de polpa do } \\
\text { tanque } 3 \text { de TMP }\end{array}$ & 4541,8 & 4542,0 & 4578,6 & 4552,9 & 4473,3 \\
\hline $\begin{array}{l}\text { Saída de polpa do } \\
\text { tanque } 2 \text { de TMP }\end{array}$ & 3311,1 & 3306,0 & 3307,3 & 3309,5 & 3312,2 \\
\hline $\begin{array}{l}\text { Saída de polpa do } \\
\text { tanque } 1 \text { de TMP }\end{array}$ & 3969,3 & 3972,6 & 4083,9 & 4175,1 & 3434,4 \\
\hline $\begin{array}{l}\text { Água de diluição para } \\
\text { tanque } 1 \text { de TMP }\end{array}$ & 1254,9 & 1252,1 & 1309,0 & 1379,0 & 794,9 \\
\hline $\begin{array}{l}\text { Água de diluição para } \\
\text { tanque de branqueado }\end{array}$ & 1483,3 & 1484 & 1503,4 & 1552,7 & 1479,3 \\
\hline $\begin{array}{l}\text { Saída de polpa do } \\
\text { tanque de celulose }\end{array}$ & 980,0 & 980,0 & 980,0 & 980,0 & 980,0 \\
\hline $\begin{array}{l}\text { Saída de polpa do } \\
\text { tanque de mistura }\end{array}$ & 11002,0 & 11383,9 & 11135,1 & 11463,4 & 10711,8 \\
\hline $\begin{array}{l}\text { Saída do tanque de } \\
\text { massa recuperada }\end{array}$ & 7554,3 & 7487,1 & 7482,2 & 7607,0 & 7683,9 \\
\hline $\begin{array}{c}\text { Saída do tanque de } \\
\text { água da tela }\end{array}$ & 26382,7 & 26328,6 & 26330,9 & 26479,8 & 26295,8 \\
\hline $\begin{array}{c}\text { Entrada no cleaner } 4^{\circ} \text { estágio } \\
\text { (4 cleaners) }\end{array}$ & 1516,5 & 1524,2 & 1495,8 & 1526,4 & 1508,9 \\
\hline Aceite do cleaner $4^{0}$ estágio & 607,2 & 610,3 & 599,4 & 611,2 & 604,6 \\
\hline $\begin{array}{c}\text { Entrada no cleaner } 3^{0} \text { estágio } \\
\text { ( } 31 \text { cleaners })\end{array}$ & 3371,2 & 3388,5 & 3325,2 & 3393,4 & 3354,3 \\
\hline $\begin{array}{c}\text { Aceite do cleaner } \\
3^{\circ} \text { estágio } \\
\end{array}$ & 1854,8 & 1864,3 & 1829,4 & 1867,0 & 1845,4 \\
\hline $\begin{array}{c}\text { Rejeito do cleaner } \\
3^{0} \text { estágio }\end{array}$ & 1516,5 & 1524,2 & 1495,8 & 1526,4 & 1508,9 \\
\hline $\begin{array}{c}\text { Entrada no cleaner } 2^{\circ} \text { estágio } \\
\text { (49 cleaners) }\end{array}$ & 11024,2 & 11080,6 & 10870,8 & 11096,8 & 10967,3 \\
\hline $\begin{array}{l}\text { Aceite do cleaner } \\
2^{\circ} \text { estágio }\end{array}$ & 8260,1 & 8302,4 & 8145,0 & 8314,6 & 8217,6 \\
\hline $\begin{array}{c}\text { Rejeito do cleaner } \\
2^{\circ} \text { estágio } \\
\end{array}$ & 2764,1 & 2778,2 & 2725,7 & 2782,3 & 2749,13 \\
\hline
\end{tabular}




\begin{tabular}{|c|c|c|c|c|c|}
\hline Corrente & $\begin{array}{c}\text { Vazão } \\
\text { mássica de } \\
\text { água }\end{array}$ & $\begin{array}{c}\text { Pinch } \\
\text { Máquina } \\
\text { de Papel }\end{array}$ & $\begin{array}{c}\text { LP } \\
\text { Máquina de } \\
\text { Papel }\end{array}$ & $\begin{array}{l}\text { Pinch } \\
\text { Processo } \\
\text { integrado }\end{array}$ & $\begin{array}{l}\text { LP } \\
\text { Processo } \\
\text { Integrado }\end{array}$ \\
\hline Descrição & Original & Caso 1 & Caso 2 & Caso 3 & Caso 4 \\
\hline $\begin{array}{c}\text { Entrada no cleaner } 1^{\circ} \text { estágio } \\
\text { (157 cleaners) }\end{array}$ & 54924,9 & 55206,7 & 54157,2 & 55287,4 & 54645,6 \\
\hline $\begin{array}{c}\text { Aceite do cleaner } \\
1^{\circ} \text { estágio } \\
\end{array}$ & 43900,7 & 44126,0 & 43286,4 & 44190,6 & 43678,2 \\
\hline Rejeito do cleaner $1^{\circ}$ estágio & 11024,2 & 11080,6 & 10870,8 & 11096,8 & 10967,3 \\
\hline $\begin{array}{l}\text { Água branca na seção de } \\
\text { formação } 1\end{array}$ & 41310,4 & 41509,2 & 40752,6 & 41567,1 & 40777,8 \\
\hline $\begin{array}{l}\text { Água branca na seção de } \\
\text { formação } 2\end{array}$ & 13012,8 & 13075,4 & 12837,1 & 13093,3 & 12845,0 \\
\hline $\begin{array}{l}\text { Polpa após seção de } \\
\text { formação }\end{array}$ & 2283,9 & 2294,9 & 2253,1 & 2298,1 & 2254,5 \\
\hline Saída do couch Pit & 1765,4 & 2031,1 & 1756,3 & 1764,1 & 1570,7 \\
\hline $\begin{array}{c}\text { Água branca na seção de } \\
\text { prensa }\end{array}$ & 1859,1 & 1868,1 & 1838,5 & 1870,7 & 1839,6 \\
\hline Polpa após seção de prensa & 424,8 & 426,9 & 414,6 & 427,4 & 414,8 \\
\hline Polpa após secador & 31,3 & 30,7 & 30,8 & 31,0 & 29,9 \\
\hline $\begin{array}{l}\text { Após silo: mistura para } \\
\text { consistência 1\% }\end{array}$ & 54924,9 & 52206,7 & 54157,2 & 55287,4 & 54645,5 \\
\hline $\begin{array}{c}\text { Saída do tanque } \\
\text { de refugo }\end{array}$ & 754,4 & 877,4 & 744,4 & 857,2 & 756,8 \\
\hline Entrada filtro de refugo & 1862,1 & 2127,8 & 1852,9 & 1860,8 & 1667,4 \\
\hline $\begin{array}{l}\text { Saída da polpa do } \\
\text { filtro de refugo }\end{array}$ & 754,4 & 877,4 & 744,4 & 857,2 & 756,8 \\
\hline $\begin{array}{l}\text { Filtrado do filtro } \\
\text { de refugo }\end{array}$ & 1406,8 & 1549,4 & 1407,6 & 1275,6 & 1210,6 \\
\hline $\begin{array}{l}\text { Água do chuveiro } \\
\text { do filtro de refugo }\end{array}$ & 299,1 & 299,1 & 299,1 & 272,0 & 300 \\
\hline $\begin{array}{l}\text { Entrada na depuração antes } \\
\text { da caixa de entrada }\end{array}$ & 54015,6 & 54292,7 & 53260,9 & 54372,1 & 53741,2 \\
\hline Aceite da depuração & 53955,6 & 54232,7 & 53200,9 & 54312,2 & 53681,2 \\
\hline $\begin{array}{l}\text { Água fresca para } \\
\text { Máquina de Papel }\end{array}$ & 3420,0 & 2236,0 & 2240,0 & 2824,0 & 2585,0 \\
\hline
\end{tabular}

(a) uma parte de corrente, $34,9 \mathrm{~L} / \mathrm{min}$ do total da corrente de $370,6 \mathrm{~L} / \mathrm{min}$, teve de ser suprido por água fresca. (b) valor teve de ser suprido por água fresca. (c) uma parte de corrente, 14,7 $\mathrm{L} /$ min do total da corrente de $61,5 \mathrm{~L} / \mathrm{min}$, teve de ser suprido por água fresca 
Tabela A2 - Comparação para consistências dos casos pós otimizados (em \%)

\begin{tabular}{|c|c|c|c|c|c|}
\hline Corrente & Consistência & $\begin{array}{c}\text { Pinch } \\
\text { Máquina } \\
\text { de Papel }\end{array}$ & $\begin{array}{c}\text { LP } \\
\text { Máquina de } \\
\text { Papel }\end{array}$ & $\begin{array}{c}\text { Pinch } \\
\text { Processo } \\
\text { integrado }\end{array}$ & $\begin{array}{c}\text { LP } \\
\text { Processo } \\
\text { Integrado }\end{array}$ \\
\hline Descrição & Original & Caso 1 & Caso 2 & Caso 3 & Caso 4 \\
\hline $\begin{array}{l}\text { Saída de cavaco do silo } \\
\text { (linha 1) }\end{array}$ & 50,000 & 50,000 & 50,000 & 50,000 & 50,000 \\
\hline $\begin{array}{l}\text { Entrada de polpa no refinador } \\
\text { primário (linha 2) }\end{array}$ & 50,000 & 50,000 & 50,000 & 50,000 & 50,000 \\
\hline $\begin{array}{l}\text { Água de diluição no refinador } \\
\text { primário (linha 2) }\end{array}$ & 0,082 & 0,0790 & 0,097 & 0,299 & 0,077 \\
\hline $\begin{array}{l}\text { Saída de polpa do refinador } \\
\text { primário (linha 2) }\end{array}$ & 45,000 & 45,000 & 45,000 & 44,565 & 45,000 \\
\hline $\begin{array}{l}\text { Entrada polpa no refinador } \\
\text { secundário (linha 2) }\end{array}$ & 45,000 & 45,000 & 45,000 & 44,565 & 45,000 \\
\hline $\begin{array}{l}\text { Água de diluição no refinador } \\
\text { secundário (linha 2) }\end{array}$ & 0,082 & 0,079 & 0,097 & 0,299 & 0,077 \\
\hline $\begin{array}{l}\text { Saída de polpa do refinador } \\
\text { secundário (linha 2) }\end{array}$ & 44,000 & 44,000 & 44,000 & 43,700 & 44,000 \\
\hline $\begin{array}{l}\text { Água de diluição do tanque } \\
\text { de latência (linha 1) }\end{array}$ & 0,082 & 0,079 & 0,097 & 0,050 & 0,081 \\
\hline $\begin{array}{l}\text { Água fresca } \\
\text { para TMP }\end{array}$ & 0,000 & 0,000 & 0,000 & 0,000 & 0,000 \\
\hline $\begin{array}{c}\text { Saída de polpa do tanque de } \\
\text { latência }\end{array}$ & 2,800 & 2,800 & 2,800 & 2,800 & 2,800 \\
\hline $\begin{array}{c}\text { Entrada de polpa no } \\
\text { refinador baixa consistência }\end{array}$ & 2,800 & 2,800 & 2,800 & 2,800 & 2,800 \\
\hline $\begin{array}{l}\text { Saída da polpa do refinador } \\
\text { baixa consistência }\end{array}$ & 2,770 & 2,770 & 2,770 & 2,766 & 2,766 \\
\hline $\begin{array}{l}\text { Entrada de polpa no } \\
\text { refinador baixa consistência }\end{array}$ & 2,800 & 2,800 & 2,800 & 2,800 & 2,800 \\
\hline $\begin{array}{l}\text { Saída de polpa do refinador } \\
\text { baixa consistência }\end{array}$ & 2,770 & 2,760 & 2,766 & 2,766 & 2,766 \\
\hline $\begin{array}{l}\text { Saída de polpa do tanque de } \\
\text { latência (linha 2) }\end{array}$ & 2,770 & 2,770 & 2,766 & 2,766 & 2,770 \\
\hline $\begin{array}{c}\text { Entrada de polpa na } \\
\text { depuração primária (linha 2) } \\
\end{array}$ & 2,770 & 2,770 & 2,766 & 2,766 & 2,770 \\
\hline $\begin{array}{l}\text { Aceite da depuração } \\
\text { primária (linha 2) }\end{array}$ & 2,180 & 2,180 & 2,179 & 2,179 & 2,182 \\
\hline $\begin{array}{l}\text { Rejeito da depuração primária } \\
\text { (linha 2) }\end{array}$ & 3,700 & 3,700 & 3,688 & 3,713 & 3,782 \\
\hline $\begin{array}{c}\text { Diluição de rejeito na } \\
\text { depuração primária (linha 2) }\end{array}$ & 0,082 & 0,079 & 0,097 & 0,299 & 0,005 \\
\hline $\begin{array}{l}\text { Entrada polpa na depuração } \\
\text { secundária (linha 2) }\end{array}$ & 3,660 & 3,665 & 3,650 & 3,676 & 3,739 \\
\hline $\begin{array}{l}\text { Aceite da depuração } \\
\text { secundária (linha 2) }\end{array}$ & 2,970 & 2,962 & 2,962 & 2,962 & 2,967 \\
\hline $\begin{array}{l}\text { Rejeito da depuração } \\
\text { secundária (linha 2) }\end{array}$ & 4,660 & 4,667 & 4,610 & 4,738 & 5,199 \\
\hline $\begin{array}{l}\text { Diluição rejeito da depuração } \\
\text { secundária (linha 2) }\end{array}$ & 0,082 & 0,079 & 0,097 & 0,299 & 0,005 \\
\hline
\end{tabular}




\begin{tabular}{|c|c|c|c|c|c|}
\hline Corrente & $\begin{array}{l}\text { Consistên } \\
\text { cia }\end{array}$ & $\begin{array}{c}\text { Pinch } \\
\text { Máquina } \\
\text { de Papel }\end{array}$ & $\begin{array}{c}\text { LP } \\
\text { Máquina de } \\
\text { Papel }\end{array}$ & $\begin{array}{l}\text { Pinch } \\
\text { Processo } \\
\text { integrado }\end{array}$ & $\begin{array}{c}\text { LP } \\
\text { Processo } \\
\text { Integrado }\end{array}$ \\
\hline Descrição & Original & Caso 1 & Caso 2 & Caso 3 & Caso 4 \\
\hline $\begin{array}{l}\text { Entrada de polpa no } \\
\text { refinador primário (linha 1) }\end{array}$ & 50,000 & 50,000 & 50,000 & 50,000 & 50,000 \\
\hline $\begin{array}{l}\text { Água de diluição no refinador } \\
\text { primário (linha 1) }\end{array}$ & 0,300 & 0,300 & 0,300 & 0,400 & 0 \\
\hline $\begin{array}{l}\text { Saída de polpa do refinador } \\
\text { primário (linha 1) }\end{array}$ & 34,800 & 34,860 & 34,950 & 34,980 & 35,000 \\
\hline $\begin{array}{c}\text { Entrada de polpa no } \\
\text { refinador secundário (linha 1) }\end{array}$ & 31,800 & 31,800 & 31,844 & 31,920 & 32,200 \\
\hline $\begin{array}{c}\text { Água de diluição no refinador } \\
\text { secundário (linha 1) }\end{array}$ & 0,300 & 0,300 & 0,300 & 0,398 & 0,050 \\
\hline $\begin{array}{l}\text { Saída de polpa do refinador } \\
\text { secundário (linha 1) }\end{array}$ & 29,000 & 29,000 & 29,000 & 28,491 & 29,000 \\
\hline $\begin{array}{l}\text { Entrada de polpa no } \\
\text { refinador de rejeitos }\end{array}$ & 29,000 & 29,000 & 29,000 & 29,000 & 29,000 \\
\hline $\begin{array}{c}\text { Água de diluição no refinador } \\
\text { de rejeitos }\end{array}$ & 0,300 & 0,300 & 0,300 & 0,398 & 0,050 \\
\hline $\begin{array}{c}\text { Saída de polpa do refinador } \\
\text { de rejeitos }\end{array}$ & 22,200 & 22,320 & 22,300 & 22,237 & 22,270 \\
\hline $\begin{array}{c}\text { Água de diluição do tanque } \\
\text { de latência }\end{array}$ & 0,080 & 0,079 & 0,097 & 0,028 & 0,135 \\
\hline $\begin{array}{c}\text { Entrada de polpa na } \\
\text { depuração primária (linha 1) }\end{array}$ & 2,930 & 2,940 & 2,981 & 2,903 & 2,795 \\
\hline $\begin{array}{l}\text { Aceite da depuração } \\
\text { primária (linha 1) }\end{array}$ & 2,880 & 2,894 & 2,950 & 2,848 & 2,710 \\
\hline \begin{tabular}{|c|} 
Rejeito da depuração primária \\
(linha 1)
\end{tabular} & 3,100 & 3,100 & 3,100 & 3,104 & 3,105 \\
\hline Entrada de polpa na prensa 2 & 4,900 & 4,900 & 4,900 & 4,904 & 4,904 \\
\hline Saída da Polpa da Prensa 2 & 29,000 & 29,000 & 29,000 & 29,000 & 29,000 \\
\hline Filtrado da Prensa 2 & 0,500 & 0,500 & 0,500 & 0,500 & 0,500 \\
\hline Entrada de polpa na prensa 1 & 4,900 & 4,900 & 4,900 & 4,904 & 4,903 \\
\hline Saída da Polpa da Prensa 1 & 29,000 & 29,000 & 29,000 & 29,000 & 29,000 \\
\hline $\begin{array}{l}\text { Aceite da peneira inclinada } \\
\text { (após depuração) }\end{array}$ & 0,400 & 0,400 & 0,400 & 0,400 & 0,400 \\
\hline $\begin{array}{l}\text { Rejeito da peneira inclinada } \\
\text { (após depuração) }\end{array}$ & 4,900 & 4,900 & 4,900 & 4,900 & 4,900 \\
\hline $\begin{array}{c}\text { Entrada na peneira inclinada } \\
\text { (após prensa) }\end{array}$ & 0,500 & 0,500 & 0,500 & 0,500 & 0,500 \\
\hline $\begin{array}{l}\text { Aceite da peneira inclinada } \\
\text { (após prensa) }\end{array}$ & 0,300 & 0,300 & 0,300 & 0,300 & 0,300 \\
\hline $\begin{array}{l}\text { Rejeito da peneira inclinada } \\
\text { (após prensa) }\end{array}$ & 5,000 & 5,000 & 5,000 & 5,000 & 5,000 \\
\hline
\end{tabular}




\begin{tabular}{|c|c|c|c|c|c|}
\hline Corrente & $\begin{array}{l}\text { Consistên } \\
\text { cia }\end{array}$ & $\begin{array}{c}\text { Pinch } \\
\text { Máquina } \\
\text { de Papel }\end{array}$ & \begin{tabular}{|c|} 
LP \\
Máquina de \\
Papel
\end{tabular} & $\begin{array}{c}\text { Pinch } \\
\text { Processo } \\
\text { integrado }\end{array}$ & $\begin{array}{c}\text { LP } \\
\text { Processo } \\
\text { Integrado }\end{array}$ \\
\hline Descrição & Original & Caso 1 & Caso 2 & Caso 3 & Caso 4 \\
\hline $\begin{array}{l}\text { Entrada de polpa no } \\
\quad \text { filtro a disco }\end{array}$ & 2,900 & 2,897 & 2,949 & 2,845 & 2,710 \\
\hline Saída da polpa do filtro disco & 6,500 & 6,500 & 6,500 & 6,500 & 6,500 \\
\hline Filtrado claro do filtro disco & 0,030 & 0,030 & 0,030 & 0,030 & 0,030 \\
\hline Filtrado turvo do filtro disco & 0,050 & 0,050 & 0,050 & 0,050 & 0,050 \\
\hline $\begin{array}{l}\text { Água do chuveiro } \\
\text { do filtro disco }\end{array}$ & 0,040 & 0,042 & 0,042 & 0,306 & 0,177 \\
\hline $\begin{array}{l}\text { Entrada de polpa no conjunto } \\
\text { filtro tambor } 1\end{array}$ & 2,390 & 2,390 & 2,388 & 2,388 & 2,392 \\
\hline $\begin{array}{l}\text { Saída da polpa do conjunto } \\
\text { filtro tambor } 1\end{array}$ & 6,500 & 6,500 & 6,500 & 6,500 & 6,500 \\
\hline $\begin{array}{c}\text { Filtrado do conjunto filtro } \\
\text { tambor } 1\end{array}$ & 0,050 & 0,050 & 0,050 & 0,050 & 0,050 \\
\hline $\begin{array}{l}\text { Água do chuveiro do conjunto } \\
\text { filtro tambor } 1\end{array}$ & 0,040 & 0,042 & 0,042 & 0,306 & 0,177 \\
\hline $\begin{array}{l}\text { Entrada de polpa no conjunto } \\
\text { filtro tambor } 2\end{array}$ & 2,390 & 2,390 & 2,388 & 2,388 & 2,392 \\
\hline $\begin{array}{l}\text { Saída da polpa do conjunto } \\
\text { filtro tambor } 2\end{array}$ & 6,500 & 6,500 & 6,500 & 6,500 & 6,500 \\
\hline $\begin{array}{l}\text { Filtrado do filtro conjunto filtro } \\
\text { tambor } 2\end{array}$ & 0,050 & 0,050 & 0,050 & 0,050 & 0,050 \\
\hline $\begin{array}{l}\text { Água do chuveiro do conjunto } \\
\text { filtro tambor } 2\end{array}$ & 0,040 & 0,042 & 0,042 & 0,306 & 0,177 \\
\hline $\begin{array}{c}\text { Entrada de polpa no filtro } \\
\text { save-all } 2\end{array}$ & 1,010 & 1,024 & 1,002 & 1,007 & 1,028 \\
\hline $\begin{array}{l}\text { Saída da polpa do filtro } \\
\text { save-all } 2\end{array}$ & 3,600 & 3,600 & 3,600 & 3,600 & 3,600 \\
\hline $\begin{array}{c}\text { Filtrado claro do filtro } \\
\text { save-all } 2\end{array}$ & 0,050 & 0,050 & 0,050 & 0,050 & 0,050 \\
\hline $\begin{array}{c}\text { Filtrado superclaro do filtro } \\
\text { save-all } 2\end{array}$ & 0,025 & 0,025 & 0,025 & 0,025 & 0,025 \\
\hline $\begin{array}{l}\text { Filtrado turvo do filtro } \\
\text { save-all } 2\end{array}$ & 0,300 & 0,300 & 0,300 & 0,300 & 0,300 \\
\hline $\begin{array}{c}\text { Água do chuveiro do filtro } \\
\text { save-all } 2\end{array}$ & 0,050 & 0,050 & 0,050 & 0,299 & 0,145 \\
\hline $\begin{array}{l}\text { Entrada de polpa no filtro } \\
\text { save-all } 1\end{array}$ & 1,010 & 1,012 & 1,002 & 1,007 & 1,028 \\
\hline $\begin{array}{c}\text { Saída da polpa do filtro } \\
\text { save-all } 1\end{array}$ & 3,600 & 3,600 & 3,600 & 3,600 & 3,600 \\
\hline $\begin{array}{l}\text { Filtrado claro do filtro } \\
\text { save-all } 1\end{array}$ & 0,050 & 0,050 & 0,050 & 0,050 & 0,050 \\
\hline $\begin{array}{c}\text { Filtrado superclaro do filtro } \\
\text { save-all } 1\end{array}$ & 0,025 & 0,025 & 0,025 & 0,025 & 0,025 \\
\hline
\end{tabular}




\begin{tabular}{|c|c|c|c|c|c|}
\hline Corrente & $\begin{array}{l}\text { Consistên } \\
\text { cia }\end{array}$ & $\begin{array}{c}\text { Pinch } \\
\text { Máquina } \\
\text { de Papel }\end{array}$ & \begin{tabular}{|c|} 
LP \\
Máquina de \\
Papel
\end{tabular} & $\begin{array}{c}\text { Pinch } \\
\text { Processo } \\
\text { integrado }\end{array}$ & $\begin{array}{c}\text { LP } \\
\text { Processo } \\
\text { Integrado }\end{array}$ \\
\hline Descrição & Original & Caso 1 & Caso 2 & Caso 3 & Caso 4 \\
\hline $\begin{array}{c}\text { Filtrado turvo do filtro } \\
\text { save-all } 1\end{array}$ & 0,500 & 0,500 & 0,500 & 0,500 & 0,500 \\
\hline $\begin{array}{c}\text { Água do chuveiro do filtro } \\
\text { save-all } 1\end{array}$ & 0,050 & 0,050 & 0,133 & 0,299 & 0,145 \\
\hline $\begin{array}{l}\text { Saída de polpa do } \\
\text { tanque } 3 \text { de TMP }\end{array}$ & 6,500 & 6,500 & 6,500 & 6,500 & 6,500 \\
\hline $\begin{array}{l}\text { Saída de polpa do } \\
\text { tanque } 2 \text { de TMP }\end{array}$ & 5,000 & 5,000 & 5,000 & 5,000 & 5,000 \\
\hline $\begin{array}{l}\text { Saída de polpa do } \\
\text { tanque } 1 \text { de TMP }\end{array}$ & 3,500 & 3,600 & 3,500 & 3,500 & 3,900 \\
\hline $\begin{array}{l}\text { Água de diluição para } \\
\text { tanque } 1 \text { de TMP }\end{array}$ & 0,082 & 0,290 & 0,152 & 0,304 & 0,065 \\
\hline $\begin{array}{l}\text { Água de diluição para } \\
\text { tanque de branqueado }\end{array}$ & 0,082 & 0,290 & 0,108 & 0,301 & 0,152 \\
\hline $\begin{array}{l}\text { Saída de polpa do } \\
\text { tanque de celulose }\end{array}$ & 3,540 & 3,540 & 3,543 & 3,540 & 3,540 \\
\hline $\begin{array}{l}\text { Saída de polpa do } \\
\text { tanque de mistura }\end{array}$ & 3,720 & 3,729 & 3,722 & 3,715 & 3,752 \\
\hline $\begin{array}{l}\text { Saída do tanque de } \\
\text { massa recuperada }\end{array}$ & 3,600 & 3,600 & 3,600 & 3,600 & 3,600 \\
\hline $\begin{array}{l}\text { Saída do tanque de } \\
\text { água da tela }\end{array}$ & 1,091 & 1,074 & 1,080 & 1,109 & 1,108 \\
\hline $\begin{array}{c}\text { Entrada no cleaner } 4^{\circ} \text { estágio } \\
\text { (4 cleaners) }\end{array}$ & 0,390 & 0,390 & 0,378 & 0,393 & 0,364 \\
\hline $\begin{array}{l}\text { Aceite do cleaner } \\
4^{\circ} \text { estágio }\end{array}$ & 0,300 & 0,300 & 0,189 & 0,295 & 0,182 \\
\hline $\begin{array}{c}\text { Entrada no cleaner } 3^{\circ} \text { estágio } \\
\text { (31 cleaners) }\end{array}$ & 0,350 & 0,353 & 0,341 & 0,354 & 0,328 \\
\hline $\begin{array}{l}\text { Aceite do cleaner } \\
3^{\circ} \text { estágio }\end{array}$ & 0,320 & 0,321 & 0,309 & 0,321 & 0,298 \\
\hline $\begin{array}{c}\text { Rejeito do cleaner } \\
3^{0} \text { estágio }\end{array}$ & 0,390 & 0,392 & 0,378 & 0,393 & 0,364 \\
\hline $\begin{array}{c}\text { Entrada no cleaner } 2^{\circ} \text { estágio } \\
\text { (49 cleaners })\end{array}$ & 0,660 & 0,654 & 0,667 & 0,654 & 0,642 \\
\hline $\begin{array}{c}\text { Aceite do cleaner } \\
2^{\circ} \text { estágio }\end{array}$ & 0,750 & 0,750 & 0,765 & 0,750 & 0,736 \\
\hline $\begin{array}{c}\text { Rejeito do cleaner } \\
2^{\circ} \text { estágio }\end{array}$ & 0,370 & 0,366 & 0,374 & 0,366 & 0,359 \\
\hline $\begin{array}{c}\text { Entrada no cleaner } 1^{\circ} \text { estágio } \\
\text { (157 cleaners) }\end{array}$ & 1,000 & 1,000 & 1,027 & 1,007 & 0,988 \\
\hline $\begin{array}{l}\text { Aceite do cleaner } \\
1^{\circ} \text { estágio }\end{array}$ & 1,100 & 1,090 & 1,117 & 1,095 & 1,074 \\
\hline $\begin{array}{c}\text { Rejeito do cleaner } \\
1^{\circ} \text { estágio } \\
\end{array}$ & 0,660 & 0,654 & 0,667 & 0,654 & 0,642 \\
\hline $\begin{array}{l}\text { Água branca na seção de } \\
\text { formação } 1\end{array}$ & 0,386 & 0,383 & 0,392 & 0,384 & 0,380 \\
\hline $\begin{array}{l}\text { Água branca na seção de } \\
\text { formação } 2\end{array}$ & 0,240 & 0,240 & 0,244 & 0,239 & 0,237 \\
\hline
\end{tabular}




\begin{tabular}{|c|c|c|c|c|c|}
\hline Corrente & $\begin{array}{l}\text { Consistên } \\
\text { cia }\end{array}$ & $\begin{array}{c}\text { Pinch } \\
\text { Máquina } \\
\text { de Papel }\end{array}$ & $\begin{array}{c}\text { LP } \\
\text { Máquina de } \\
\text { Papel }\end{array}$ & $\begin{array}{l}\text { Pinch } \\
\text { Processo } \\
\text { integrado }\end{array}$ & $\begin{array}{c}\text { LP } \\
\text { Processo } \\
\text { Integrado }\end{array}$ \\
\hline Descrição & Original & Caso 1 & Caso 2 & Caso 3 & Caso 4 \\
\hline $\begin{array}{l}\text { Polpa após seção de } \\
\text { formação }\end{array}$ & 13,000 & 12,966 & 13,229 & 13,001 & 12,880 \\
\hline Saída do couch Pit & 1,140 & 1,139 & 1,129 & 1,263 & 1,271 \\
\hline $\begin{array}{c}\text { Água branca na seção } \\
\text { de prensa }\end{array}$ & 0,460 & 0,455 & 0,511 & 0,457 & 0,496 \\
\hline Polpa após seção de prensa & 44,000 & 43,840 & 44,000 & 43,927 & 43,859 \\
\hline Polpa após secador & 91,200 & 91,200 & 91,200 & 91,200 & 91,200 \\
\hline $\begin{array}{l}\text { Após silo: mistura para } \\
\text { consistência 1\% }\end{array}$ & 1,000 & 1,000 & 1,026 & 1,007 & 0,988 \\
\hline Saída do tanque de refugo & 3,000 & 3,000 & 3,000 & 3,000 & 3,000 \\
\hline Entrada filtro de refugo & 1,240 & 1,225 & 1,228 & 1,355 & 1,373 \\
\hline $\begin{array}{l}\text { Saída da polpa do } \\
\text { filtro de refugo }\end{array}$ & 3,000 & 3,000 & 3,000 & 3,000 & 3,000 \\
\hline Filtrado do filtro de refugo & 0,010 & 0,29 & 0,010 & 0,010 & 0,010 \\
\hline $\begin{array}{l}\text { Água do chuveiro do } \\
\text { filtro de refugo }\end{array}$ & 0,050 & 0,050 & 0,050 & 0,400 & 0,107 \\
\hline $\begin{array}{l}\text { Entrada na depuração antes } \\
\text { da caixa de entrada }\end{array}$ & 1,000 & 1,000 & 1,036 & 1,016 & 0,996 \\
\hline Aceite da depuração & 1,000 & 1,000 & 1,028 & 1,008 & 0,989 \\
\hline $\begin{array}{l}\text { Água fresca para } \\
\text { Máquina de Papel }\end{array}$ & 0,000 & 0,000 & 0,000 & 0,000 & 0,000 \\
\hline
\end{tabular}


Tabela A3 - Comparação para concentração de sólidos dissolvidos (SD) dos casos pós otimizados (em ppm ou kg/min)

\begin{tabular}{|c|c|c|c|c|c|}
\hline Corrente & [SD] & $\begin{array}{c}\text { Pinch } \\
\text { Máquina } \\
\text { de Papel }\end{array}$ & $\begin{array}{c}\text { LP } \\
\text { Máquina de } \\
\text { Papel }\end{array}$ & $\begin{array}{c}\text { Pinch } \\
\text { Processo } \\
\text { integrado }\end{array}$ & $\begin{array}{c}\text { LP } \\
\text { Processo } \\
\text { Integrado }\end{array}$ \\
\hline Descrição & Original & Caso 1 & Caso 2 & Caso 3 & Caso 4 \\
\hline $\begin{array}{l}\text { Saída de cavaco do } \\
\quad \text { silo (linha 1) }\end{array}$ & 0,00 & 0,00 & 0,00 & 0,00 & 0,00 \\
\hline $\begin{array}{c}\text { Entrada de polpa no refinador } \\
\text { primário (linha 2) }\end{array}$ & 0,00 & 0,00 & 0,00 & 0,00 & 0,00 \\
\hline $\begin{array}{c}\text { Água de diluição no refinador } \\
\text { primário (linha 2) }\end{array}$ & 4066 ppm & 5091 ppm & 5144 ppm & 3289 ppm & 3953 ppm \\
\hline $\begin{array}{l}\text { Saída de polpa do refinador } \\
\text { primário (linha 2) }\end{array}$ & 4,32 & 4,69 & 4,70 & 4,05 & 4,29 \\
\hline $\begin{array}{l}\text { Entrada polpa no refinador } \\
\text { secundário (linha 2) }\end{array}$ & 4,32 & 4,69 & 4,70 & 4,05 & 4,29 \\
\hline $\begin{array}{l}\text { Água de diluição no refinador } \\
\text { secundário (linha 2) }\end{array}$ & 4066 ppm & 5091 ppm & 5144 ppm & 3289 ppm & 3953 ppm \\
\hline $\begin{array}{l}\text { Saída de polpa do refinador } \\
\text { secundário (linha 2) }\end{array}$ & 8,70 & 9,50 & 9,54 & 8,17 & 8,47 \\
\hline $\begin{array}{l}\text { Água de diluição do tanque } \\
\text { de latência (linha 1) }\end{array}$ & 4066 ppm & 5091 ppm & 5144 ppm & $5311 \mathrm{ppm}$ & 3344 ppm \\
\hline $\begin{array}{l}\text { Água fresca } \\
\text { para TMP }\end{array}$ & 0,00 & 0,00 & 0,00 & 0,00 & 0,00 \\
\hline $\begin{array}{l}\text { Saída de polpa do } \\
\text { tanque de latência }\end{array}$ & 42,50 & 52,9 & 54,0 & 54,54 & 37,48 \\
\hline $\begin{array}{l}\text { Entrada de polpa no } \\
\text { refinador baixa consistência }\end{array}$ & 20,60 & 25,60 & 26,36 & 26,33 & 17,50 \\
\hline $\begin{array}{l}\text { Saída da polpa do refinador } \\
\text { baixa consistência }\end{array}$ & 22,20 & 27,20 & 27,96 & 27,90 & 18,97 \\
\hline $\begin{array}{l}\text { Entrada de polpa no } \\
\text { refinador baixa consistência }\end{array}$ & 21,90 & 27,30 & 27,65 & 28,20 & 19,99 \\
\hline $\begin{array}{l}\text { Saída de polpa do refinador } \\
\text { baixa consistência }\end{array}$ & 23,60 & 28,90 & 29,33 & 29,88 & 21,66 \\
\hline $\begin{array}{l}\text { Saída de polpa do tanque de } \\
\text { latência (linha 2) }\end{array}$ & 45,80 & 56,15 & 57,29 & 57,78 & 40,63 \\
\hline $\begin{array}{c}\text { Entrada de polpa na } \\
\text { depuração primária (linha 2) }\end{array}$ & 45,80 & 56,15 & 57,29 & 57,78 & 40,63 \\
\hline $\begin{array}{l}\text { Aceite da depuração } \\
\text { primária (linha 2) }\end{array}$ & 28,30 & 34,7 & 35,20 & 35,87 & 25,96 \\
\hline $\begin{array}{l}\text { Rejeito da depuração primária } \\
\text { (linha 2) }\end{array}$ & 17,50 & 21,40 & 22,09 & 21,91 & 14,67 \\
\hline $\begin{array}{c}\text { Diluição de rejeito na } \\
\text { depuração primária (linha 2) }\end{array}$ & 4066 ppm & 5091 ppm & 5144 ppm & 3289 ppm & 4455 ppm \\
\hline $\begin{array}{l}\text { Entrada polpa na depuração } \\
\text { secundária (linha 2) }\end{array}$ & 17,10 & 21,01 & 21,69 & 21,44 & 14,25 \\
\hline $\begin{array}{l}\text { Aceite da depuração } \\
\text { secundária (linha 2) }\end{array}$ & 10,20 & 12,56 & 12,73 & 12,92 & 9,40 \\
\hline $\begin{array}{l}\text { Rejeito da depuração } \\
\text { secundária (linha 2) }\end{array}$ & 6,87 & 8,46 & 8,97 & 8,53 & 4,88 \\
\hline
\end{tabular}




\begin{tabular}{|c|c|c|c|c|c|}
\hline Descrição & [SD] & $\begin{array}{c}\text { Pinch } \\
\text { Máquina } \\
\text { de Papel }\end{array}$ & $\begin{array}{c}\text { LP } \\
\text { Máquina de } \\
\text { Papel }\end{array}$ & $\begin{array}{l}\text { Pinch } \\
\text { Processo } \\
\text { integrado }\end{array}$ & $\begin{array}{c}\text { LP } \\
\text { Processo } \\
\text { Integrado }\end{array}$ \\
\hline Corrente & Original & Caso 1 & Caso 2 & Caso 3 & Caso 4 \\
\hline $\begin{array}{l}\text { Diluição rejeito da depuração } \\
\text { secundária (linha 2) }\end{array}$ & 4066 ppm & $5091 \mathrm{ppm}$ & 5144 ppm & 3289 ppm & $4455 \mathrm{ppm}$ \\
\hline $\begin{array}{l}\text { Entrada de polpa no } \\
\text { refinador primário (linha 1) }\end{array}$ & 0,00 & 0,00 & 0,00 & 0,00 & 0,00 \\
\hline $\begin{array}{c}\text { Água de diluição no refinador } \\
\text { primário (linha 1) }\end{array}$ & 4747 ppm & 5816 ppm & 5890 ppm & 5308 ppm & 0 ppm \\
\hline $\begin{array}{l}\text { Saída de polpa do refinador } \\
\text { primário (linha 1) }\end{array}$ & 1,19 & 1,30 & 1,30 & 1,25 & 0,744 \\
\hline $\begin{array}{l}\text { Entrada de polpa no } \\
\text { refinador secundário (linha 1) }\end{array}$ & 1,77 & 2,00 & 2,05 & 1,89 & 1,16 \\
\hline $\begin{array}{l}\text { Água de diluição no refinador } \\
\text { secundário (linha 1) }\end{array}$ & $4747 \mathrm{ppm}$ & $5816 \mathrm{ppm}$ & 5890 ppm & 5308 ppm & $4455 \mathrm{ppm}$ \\
\hline $\begin{array}{l}\text { Saída de polpa do refinador } \\
\text { secundário (linha 1) }\end{array}$ & 3,45 & 3,77 & 3,83 & 3,63 & 2,65 \\
\hline $\begin{array}{l}\text { Entrada de polpa no } \\
\text { refinador de rejeitos }\end{array}$ & 0,47 & 0,58 & 0,59 & 0,53 & 0,42 \\
\hline $\begin{array}{c}\text { Água de diluição no refinador } \\
\text { de rejeitos }\end{array}$ & 4747 ppm & 5816 ppm & 5890 ppm & 3985 ppm & 4455 ppm \\
\hline $\begin{array}{l}\text { Saída de polpa do refinador } \\
\text { de rejeitos }\end{array}$ & 1,25 & 1,40 & 1,41 & 1,33 & 1,18 \\
\hline $\begin{array}{c}\text { Água de diluição do tanque } \\
\text { de latência }\end{array}$ & 4066 ppm & 5091 ppm & 5144 ppm & 3826 ppm & 3486 ppm \\
\hline $\begin{array}{c}\text { Entrada de polpa na } \\
\text { depuração primária (linha 1) }\end{array}$ & 25,20 & 30,76 & 31,10 & 23,72 & 21,29 \\
\hline $\begin{array}{l}\text { Aceite da depuração } \\
\text { primária (linha 1) }\end{array}$ & 19,80 & 24,17 & 24,44 & 18,59 & 16,75 \\
\hline $\begin{array}{l}\text { Rejeito da depuração primária } \\
\text { (linha 1) }\end{array}$ & 5,39 & 6,58 & 6,66 & 5,13 & 4,53 \\
\hline Entrada de polpa na prensa 2 & 4,51 & 5,53 & 5,60 & 5,05 & 3,98 \\
\hline Saída da Polpa da Prensa 2 & 0,47 & 0,58 & 0,59 & 0,53 & 0,42 \\
\hline Filtrado da Prensa 2 & 4747 ppm & $5816 \mathrm{ppm}$ & 5890 ppm & 5308 ppm & $4189 \mathrm{ppm}$ \\
\hline Entrada de polpa na prensa 1 & 5,39 & 6,67 & 6,97 & 6,04 & 3,99 \\
\hline Saída da Polpa da Prensa 1 & 0,57 & 0,71 & 0,74 & 0,64 & 0,42 \\
\hline $\begin{array}{l}\text { Aceite da peneira inclinada } \\
\text { (após depuração) }\end{array}$ & 4747 ppm & 5816 ppm & 5890 ppm & 5308 ppm & 4189 ppm \\
\hline $\begin{array}{l}\text { Rejeito da peneira inclinada } \\
\text { (após depuração) }\end{array}$ & 9,54 & 11,76 & 12,12 & 10,69 & 7,68 \\
\hline $\begin{array}{l}\text { Entrada na peneira inclinada } \\
\text { (após prensa) }\end{array}$ & 8,86 & 10,91 & 11,24 & 9,92 & 7,13 \\
\hline $\begin{array}{l}\text { Aceite da peneira inclinada } \\
\text { (após prensa) }\end{array}$ & 4747 ppm & 5816 ppm & 5890 ppm & 5308 ppm & 4189 ppm \\
\hline
\end{tabular}




\begin{tabular}{|c|c|c|c|c|c|}
\hline Descrição & [SD] & $\begin{array}{c}\text { Pinch } \\
\text { Máquina } \\
\text { de Papel }\end{array}$ & $\begin{array}{c}\text { LP } \\
\text { Máquina de } \\
\text { Papel }\end{array}$ & $\begin{array}{c}\text { Pinch } \\
\text { Processo } \\
\text { integrado }\end{array}$ & $\begin{array}{c}\text { LP } \\
\text { Processo } \\
\text { Integrado }\end{array}$ \\
\hline Corrente & Original & Caso 1 & Caso 2 & Caso 3 & Caso 4 \\
\hline $\begin{array}{l}\text { Rejeito da peneira inclinada } \\
\text { (após prensa) }\end{array}$ & 0,36 & 0,44 & 0,46 & 0,40 & 0,29 \\
\hline $\begin{array}{l}\text { Entrada de polpa no } \\
\text { filtro a disco }\end{array}$ & 19,80 & 24,17 & 24,44 & 18,59 & 16,75 \\
\hline Saída da polpa do filtro disco & 8,41 & 10,30 & 10,62 & 7,59 & 6,55 \\
\hline Filtrado claro do filtro disco & 4662 ppm & 5695 ppm & 5755 ppm & 4212 ppm & 3807 ppm \\
\hline Filtrado turvo do filtro disco & 4662 ppm & 5695 ppm & 5755 ppm & 4212 ppm & 3807 ppm \\
\hline $\begin{array}{l}\text { Água do chuveiro } \\
\text { do filtro disco }\end{array}$ & 4662 ppm & 5695 ppm & 5755 ppm & 3422 ppm & 3378 ppm \\
\hline $\begin{array}{l}\text { Entrada de polpa no conjunto } \\
\text { filtro tambor } 1\end{array}$ & 29,03 & 35,68 & 36,16 & 36,81 & 26,66 \\
\hline $\begin{array}{l}\text { Saída da polpa do conjunto } \\
\text { filtro tambor } 1\end{array}$ & 10,05 & 12,34 & 12,50 & 12,25 & 8,88 \\
\hline $\begin{array}{l}\text { Filtrado do conjunto filtro } \\
\text { tambor } 1\end{array}$ & 4849 ppm & $5951 \mathrm{ppm}$ & $6031 \mathrm{ppm}$ & 6138 ppm & $4455 \mathrm{ppm}$ \\
\hline $\begin{array}{l}\text { Água do chuveiro do conjunto } \\
\text { filtro tambor } 1\end{array}$ & 4662 ppm & 5695 ppm & 5754 ppm & 3422 ppm & 3378 ppm \\
\hline $\begin{array}{l}\text { Entrada de polpa no conjunto } \\
\text { filtro tambor } 2\end{array}$ & 9,47 & 11,62 & 11,77 & 11,98 & 8,69 \\
\hline $\begin{array}{l}\text { Saída da polpa do conjunto } \\
\text { filtro tambor } 2\end{array}$ & 3,26 & 3,98 & 4,04 & 3,72 & 2,85 \\
\hline $\begin{array}{l}\text { Filtrado do filtro conjunto filtro } \\
\text { tambor } 2\end{array}$ & 4849 ppm & 5951 ppm & 6031 ppm & 6138 ppm & 4455 ppm \\
\hline $\begin{array}{l}\text { Água do chuveiro do conjunto } \\
\text { filtro tambor } 2\end{array}$ & 4662 ppm & 5695 ppm & 5754 ppm & 3422 ppm & 3378 ppm \\
\hline $\begin{array}{c}\text { Entrada de polpa no filtro } \\
\text { save-all } 2\end{array}$ & 34,00 & 47,56 & 48,60 & 45,83 & 46,47 \\
\hline $\begin{array}{l}\text { Saída da polpa do filtro } \\
\text { save-all } 2\end{array}$ & 8,73 & 12,45 & 12,37 & 11,78 & 12,15 \\
\hline $\begin{array}{l}\text { Filtrado claro do filtro } \\
\text { save-all } 2\end{array}$ & 2487 ppm & 3477 ppm & 3559 ppm & 3352 ppm & 3399 ppm \\
\hline $\begin{array}{c}\text { Filtrado superclaro do filtro } \\
\text { save-all } 2\end{array}$ & 2487 ppm & 3477 ppm & 3559 ppm & 3352 ppm & 3399 ppm \\
\hline $\begin{array}{l}\text { Filtrado turvo do filtro } \\
\text { save-all } 2\end{array}$ & $2487 \mathrm{ppm}$ & 3477 ppm & 3559 ppm & 3352 ppm & 3399 ppm \\
\hline $\begin{array}{c}\text { Água do chuveiro do filtro } \\
\text { save-all } 2\end{array}$ & 2487 ppm & 3477 ppm & 3559 ppm & 3289 ppm & 3289 ppm \\
\hline $\begin{array}{l}\text { Entrada de polpa no filtro } \\
\text { save-all } 1\end{array}$ & 40,40 & 56,49 & 57,84 & 55,06 & 55,07 \\
\hline $\begin{array}{l}\text { Saída da polpa do filtro } \\
\text { save-all } 1\end{array}$ & 10,10 & 14,43 & 14,35 & 13,80 & 14,05 \\
\hline $\begin{array}{l}\text { Filtrado claro do filtro } \\
\text { save-all } 1\end{array}$ & 2487 ppm & 3477 ppm & 3558 ppm & 3352 ppm & 3398 ppm \\
\hline
\end{tabular}




\begin{tabular}{|c|c|c|c|c|c|}
\hline Descrição & [SD] & $\begin{array}{c}\text { Pinch } \\
\text { Máquina } \\
\text { de Papel }\end{array}$ & $\begin{array}{c}\text { LP } \\
\text { Máquina de } \\
\text { Papel }\end{array}$ & $\begin{array}{l}\text { Pinch } \\
\text { Processo } \\
\text { integrado }\end{array}$ & $\begin{array}{c}\text { LP } \\
\text { Processo } \\
\text { Integrado }\end{array}$ \\
\hline Corrente & Original & Caso 1 & Caso 2 & Caso 3 & Caso 4 \\
\hline $\begin{array}{c}\text { Filtrado superclaro do filtro } \\
\text { save-all } 1\end{array}$ & 2487 ppm & 3477 ppm & 3558 ppm & 3352 ppm & 3398 ppm \\
\hline $\begin{array}{c}\text { Filtrado turvo do filtro } \\
\text { save-all } 1\end{array}$ & $2487 \mathrm{ppm}$ & 3477 ppm & 3558 ppm & 3352 ppm & 3398 ppm \\
\hline $\begin{array}{l}\text { Água do chuveiro do filtro } \\
\text { save-all } 1\end{array}$ & 2487 ppm & 3477 ppm & 3558 ppm & 3289 ppm & 3398 ppm \\
\hline $\begin{array}{l}\text { Saída de polpa do } \\
\text { tanque } 3 \text { de TMP }\end{array}$ & 21,70 & 26,62 & 27,16 & 23,55 & 18,27 \\
\hline $\begin{array}{l}\text { Saída de polpa do } \\
\text { tanque } 2 \text { de TMP }\end{array}$ & 13,90 & 17,34 & 17,66 & 15,54 & 12,84 \\
\hline $\begin{array}{l}\text { Saída de polpa do } \\
\text { tanque } 1 \text { de TMP }\end{array}$ & 14,50 & 18,48 & 19,42 & 17,67 & 12,88 \\
\hline $\begin{array}{l}\text { Água de diluição para } \\
\text { Tanque } 1 \text { de TMP }\end{array}$ & $2451 \mathrm{ppm}$ & 3348 ppm & 3502 ppm & 3282 ppm & 3378 ppm \\
\hline $\begin{array}{l}\text { Água de diluição para } \\
\text { tanque de branqueado }\end{array}$ & $2451 \mathrm{ppm}$ & 3348 ppm & 3524 ppm & 3285 ppm & 3238 ppm \\
\hline $\begin{array}{l}\text { Saída de polpa do } \\
\text { tanque de celulose }\end{array}$ & 0,01 & 0,01 & 0,01 & 0,01 & 0,01 \\
\hline $\begin{array}{l}\text { Saída de polpa do } \\
\text { tanque de mistura }\end{array}$ & 31,70 & 43,76 & 44,08 & 42,32 & 37,34 \\
\hline $\begin{array}{l}\text { Saída do tanque de } \\
\text { massa recuperada }\end{array}$ & 18,80 & 26,89 & 26,72 & 25,59 & 26,20 \\
\hline $\begin{array}{l}\text { Saída do tanque de } \\
\text { água da tela }\end{array}$ & 90,72 & 92,00 & 93,60 & 89,13 & 89,80 \\
\hline $\begin{array}{c}\text { Entrada no cleaner } 4^{0} \text { estágio } \\
(4 \text { cleaners })\end{array}$ & 3,70 & 5,29 & 5,25 & 5,17 & 5,01 \\
\hline $\begin{array}{l}\text { Aceite do cleaner } \\
4^{\circ} \text { estágio }\end{array}$ & 1,47 & 2,12 & 2,10 & 2,07 & 2,00 \\
\hline $\begin{array}{c}\text { Entrada no cleaner } 3^{\circ} \text { estágio } \\
\text { ( } 31 \text { cleaners })\end{array}$ & 8,17 & 11,76 & 11,68 & 11,49 & 11,14 \\
\hline $\begin{array}{l}\text { Aceite do cleaner } \\
3^{\circ} \text { estágio }\end{array}$ & 4,50 & 6,47 & 6,43 & 6,32 & 6,13 \\
\hline $\begin{array}{c}\text { Rejeito do cleaner } \\
3^{\circ} \text { estágio }\end{array}$ & 3,67 & 5,28 & 5,25 & 5,17 & 5,01 \\
\hline $\begin{array}{c}\text { Entrada no cleaner } 2^{0} \text { estágio } \\
\text { (49 cleaners) }\end{array}$ & 26,70 & 38,45 & 38,18 & 37,58 & 36,42 \\
\hline $\begin{array}{l}\text { Aceite do cleaner } \\
2^{\circ} \text { estágio }\end{array}$ & 20,00 & 28,80 & 28,61 & 28,16 & 27,29 \\
\hline $\begin{array}{c}\text { Rejeito do cleaner } \\
2^{\circ} \text { estágio }\end{array}$ & 6,69 & 9,64 & 9,57 & 9,42 & 9,13 \\
\hline $\begin{array}{l}\text { Entrada no cleaner } 1^{\circ} \text { estágio } \\
\text { (157 cleaners) }\end{array}$ & 133,10 & 191,6 & 190,22 & 187,23 & 141,46 \\
\hline $\begin{array}{l}\text { Aceite do cleaner } \\
\text { 1o estágio }\end{array}$ & 106,40 & 153,10 & 152,04 & 149,65 & 145,04 \\
\hline $\begin{array}{c}\text { Rejeito do cleaner } \\
1^{\circ} \text { estágio }\end{array}$ & 26,70 & 38,45 & 38,18 & 37,58 & 36,42 \\
\hline $\begin{array}{l}\text { Água branca na seção de } \\
\text { formação } 1\end{array}$ & 2273 ppm & 3322 ppm & 3400 ppm & 3209 ppm & 3226 ppm \\
\hline
\end{tabular}




\begin{tabular}{|c|c|c|c|c|c|}
\hline Descrição & [SD] & $\begin{array}{c}\text { Pinch } \\
\text { Máquina } \\
\text { de Papel }\end{array}$ & $\begin{array}{c}\text { LP } \\
\text { Máquina de } \\
\text { Papel }\end{array}$ & $\begin{array}{c}\text { Pinch } \\
\text { Processo } \\
\text { integrado }\end{array}$ & $\begin{array}{c}\text { LP } \\
\text { Processo } \\
\text { Integrado }\end{array}$ \\
\hline Corrente & Original & Caso 1 & Caso 2 & Caso 3 & Caso 4 \\
\hline $\begin{array}{l}\text { Água branca na seção de } \\
\text { formação } 2\end{array}$ & 2273 ppm & 3322 ppm & 3400 ppm & 3209 ppm & 3226 ppm \\
\hline $\begin{array}{l}\text { Polpa após seção de } \\
\text { formação }\end{array}$ & 5,20 & 7,64 & 7,68 & 7,40 & 7,29 \\
\hline Saída do couch Pit & 4,20 & 6,80 & 6,15 & 5,76 & 5,08 \\
\hline $\begin{array}{l}\text { Água branca na } \\
\text { seção de prensa }\end{array}$ & 2273 ppm & 3321 ppm & 3400 ppm & 3209 ppm & 3226 ppm \\
\hline Polpa após seção de prensa & 0,90 & 1,42 & 1,41 & 1,38 & 1,34 \\
\hline Polpa após secador & 0,97 & 1,42 & 1,41 & 1,38 & 1,33 \\
\hline $\begin{array}{l}\text { Após silo: mistura para } \\
\text { consistência } 1 \%\end{array}$ & 2417 ppm & 3457 ppm & 3500 ppm & 3375 ppm & 3309 ppm \\
\hline Saída do tanque de refugo & 1,83 & 2,94 & 2,63 & 3,38 & 2,42 \\
\hline Entrada filtro de refugo & 4,44 & 7,13 & 6,49 & 6,15 & 5,39 \\
\hline $\begin{array}{l}\text { Saída da polpa do } \\
\text { filtro de refugo }\end{array}$ & 1,83 & 2,94 & 2,63 & 3,38 & 2,42 \\
\hline Filtrado do filtro de refugo & 2380 ppm & 3338 ppm & 3494 ppm & 3299 ppm & $3222 \mathrm{ppm}$ \\
\hline $\begin{array}{l}\text { Água do chuveiro do } \\
\text { filtro de refugo }\end{array}$ & 2487 ppm & 2487 ppm & 3494 ppm & 5308 ppm & $3116 \mathrm{ppm}$ \\
\hline $\begin{array}{c}\text { Entrada na depuração antes } \\
\text { da caixa de entrada }\end{array}$ & 130,90 & 188,40 & 180,07 & 184,13 & 178,45 \\
\hline Aceite da depuração & 130,70 & 188,17 & 186,86 & 183,92 & 178,26 \\
\hline $\begin{array}{l}\text { Água fresca para } \\
\text { Máquina de Papel }\end{array}$ & 0,00 & 0,00 & 0,00 & 0,00 & 0,00 \\
\hline
\end{tabular}




\section{APÊNDICE B}

B1. Programa em Matlab para exemplo ilustrativo 4, "Aplicação de programação matemática para otimização de rede de água para lavagem de polpa celulósica" descrito no capítulo 4.

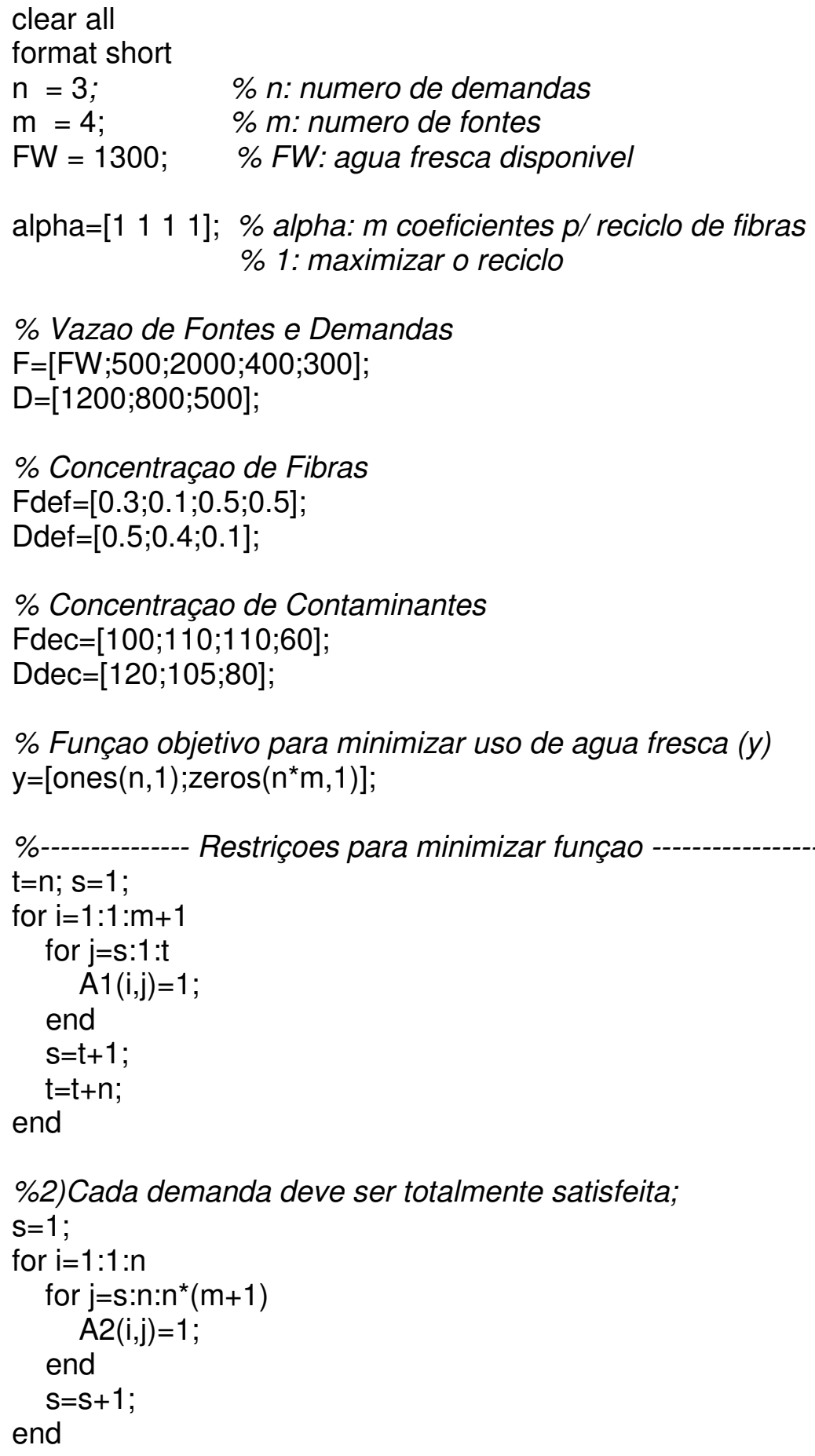


\%3)A quantidade de contaminante fornecida para as demandas nao $\%$ deve ser superior ao valor maximo admitido para tais demandas; $\mathrm{s}=\mathrm{n}+1$

$\mathrm{k}=1$;

for $i=1: 1: n$

for $\mathrm{j}=\mathrm{s}: \mathrm{n}: \mathrm{n}^{*}(\mathrm{~m}+1)$

$A 3(i, j)=F d e c(k)$;

$\mathrm{k}=\mathrm{k}+1$;

end

$\mathrm{S}=\mathrm{S}+1$

$\mathrm{k}=1$;

end

\%4)A quantidade de fibras fornecida para as demandas nao deve

$\%$ ser superior ao valor maximo admitido para tais demandas;

$\mathrm{s}=\mathrm{n}+1$

$\mathrm{k}=1$;

for $i=1: 1: n$

for $\mathrm{j}=\mathrm{s}: \mathrm{n}: \mathrm{n}^{\star}(\mathrm{m}+1)$

$\mathrm{A} 4(\mathrm{i}, \mathrm{j})=\mathrm{Fdef}(\mathrm{k})$;

$\mathrm{k}=\mathrm{k}+1$;

end

$\mathrm{S}=\mathrm{S}+1$

$\mathrm{k}=1$;

end

\%5)Todas as variaveis devem ser positivas

$\mathrm{lb}=\operatorname{zeros}\left(\mathrm{n}^{\star}(\mathrm{m}+1), 1\right)$;

$\%$

$\%$ Englobando a Matriz de inequaçoes A1, A3 e A4, constroi-se a matriz $A$ $A=[A 1 ; A 3 ; A 4] ;$

for $\mathrm{i}=1: 1: \mathrm{n}$

$\mathrm{DC}(\mathrm{i})=\mathrm{D}(\mathrm{i})^{*} \operatorname{Ddec}(\mathrm{i})$;

$\mathrm{DF}(\mathrm{i})=\mathrm{D}(\mathrm{i})^{\star} \operatorname{Ddef}(\mathrm{i})$;

end

$\mathrm{b}=\left[\mathrm{F} ; \mathrm{DC} \mathrm{C}^{\prime} ; \mathrm{DF}{ }^{\prime}\right]$

$\%$ Matriz de igualdade Aeq e vetor beq

Aeq $=[$ A2];

$\mathrm{beq}=[\mathrm{D}]$;

\%Aplicando otimizaçao por LP da funçao objetivo x1

$\mathrm{x} 1$ = linprog(y,A,b,Aeq,beq,lb);

$\%$ Construindo a Matriz Pij da funçao x1

$\mathrm{S}=0$;

for $i=1: 1: m+1$

for $j=1: 1: n$

$\mathrm{P} 1(\mathrm{i}, \mathrm{j})=\mathrm{x} 1(\mathrm{j}+\mathrm{s})$;

end 


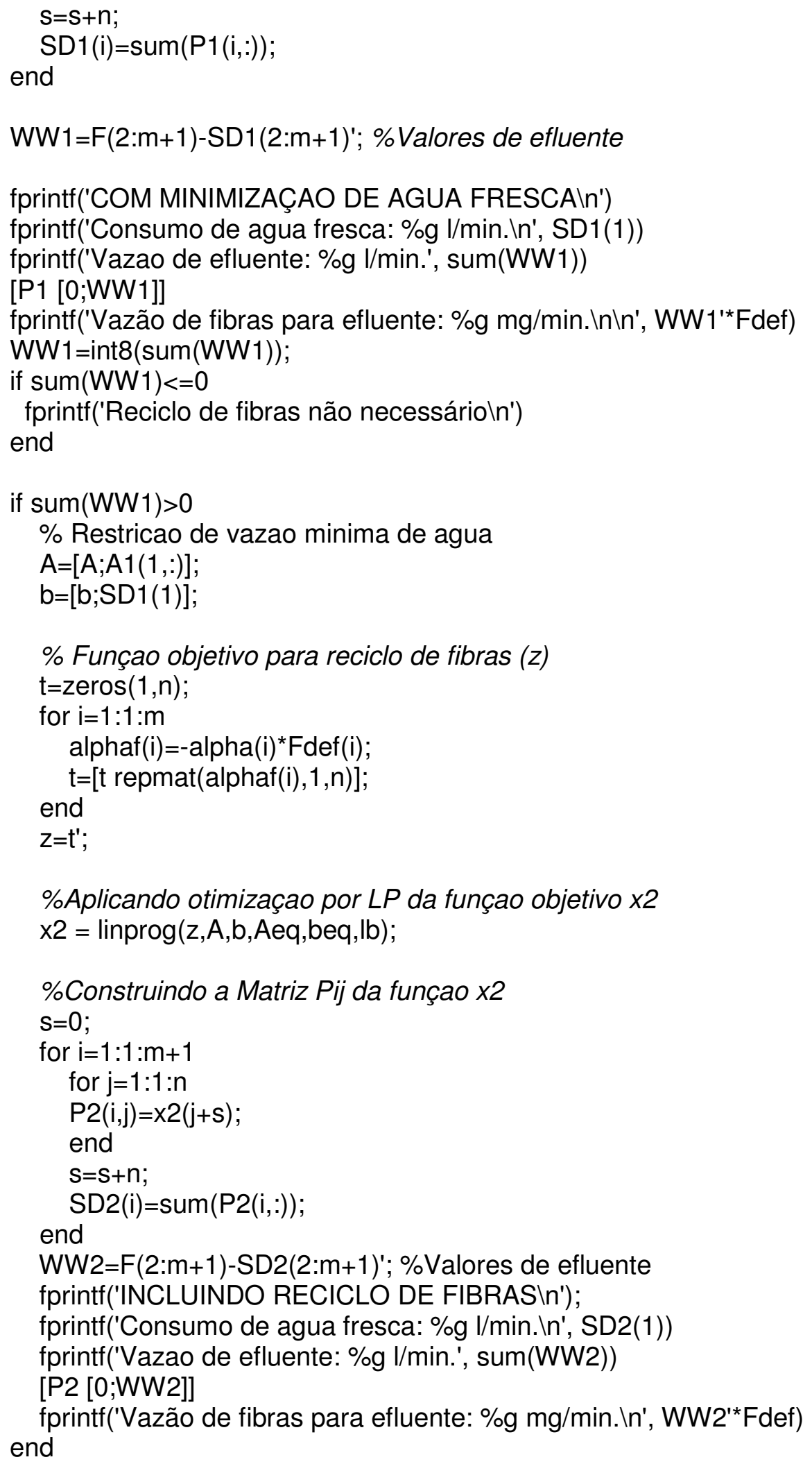




\section{B2. Programa desenvolvido em Matlab para minimizar o consumo de água por programação matemática linear, utilizado no capítulo 5.}

clear all

format short

$\mathrm{n}=9$;

$\%$ : numero de demandas

$\mathrm{m}=4$

$\%$ m: numero de fontes

FWtmp $=0$;

$\mathrm{FWmp}=3420$;

$\%$ agua fresca consumida na TMP em L/min

$F W=F W t m p+F W m p ;$

$\%$ agua fresca consumida na MP em L/min

alpha $=\left[\begin{array}{llll}0 & 0 & 0 & 0\end{array}\right]$;

$\%$ FW: agua fresca disponivel em $\mathrm{L} / \mathrm{min}$

$\%$ alpha: $m$ coeficientes $p /$ reciclo de fibras

\% Vazao de Fontes e Demandas

$\mathrm{D}=[1484 ; 4292 ; 1255 ; 997.4 ; 996.7 ; 20966 ; 299 ; 3420 ; 43823]$;

$\mathrm{F}=[\mathrm{FW} ; 2316 ; 17451 ; 1407 ; 54323]$;

\% Concentraçao de Fibras (valores limites para demandas)

Fdef $=[0.025 ; 0.05 ; 0.01 ; 0.351]$;

$\%$ Ddef $=[0.5 ; 0.1 ; 0.5 ; 0.5 ; 0.5 ; 0.3 ; 0.5 ; 0.018 ; 0.3]$

Ddef=[0.8;0.1;0.8;0.8;0.8;0.3;0.8;0.018;0.3008];

\%Ddefs=[0.082;0.047;0.082;0.05;0.082;0.3;0.05;10e-10;0.3];

\% Concentraçao de Contaminantes (valores limites para demandas)

Fdec=[2487;2487;2380;2273];

Ddec=[5000;5000;5000;5000;5000;5000;5000;5000;5000;2500];

\% Funçao objetivo para minimizar uso de agua fresca (y)

$\mathrm{y}=\left[\mathrm{ones}(\mathrm{n}, 1) ; z \cos \left(\mathrm{n}^{*} \mathrm{~m}, 1\right)\right]$;

\%------------- Restriçoes para minimizar funçao

\%1)A vazao total da demanda satisfeita por uma fonte nao

$\%$ deve ser superior a vazao disponivel dessa fonte;

$\mathrm{t}=\mathrm{n} ; \mathrm{s}=1$;

for $i=1: 1: m+1$

for $j=s: 1: t$

$\mathrm{A} 1(\mathrm{i}, \mathrm{j})=1$;

end

$\mathrm{s}=\mathrm{t}+1$;

$t=t+n$;

end

\%2)Cada demanda deve ser totalmente satisfeita;

$\mathrm{S}=1$;

for $\mathrm{i}=1: 1: \mathrm{n}$

for $\mathrm{j}=\mathrm{s}: \mathrm{n}: \mathrm{n}^{*}(\mathrm{~m}+1)$

$A 2(i, j)=1$;

end

$\mathrm{S}=\mathrm{S}+1$;

end

\%3)A quantidade de contaminante fornecida para as demandas nao 
$\%$ deve ser superior ao valor maximo admitido para tais demandas;

$\mathrm{s}=\mathrm{n}+1$;

$\mathrm{k}=1$;

for $\mathrm{i}=1: 1: \mathrm{n}$

for $\mathrm{j}=\mathrm{s}: \mathrm{n}: \mathrm{n}^{*}(\mathrm{~m}+1)$

$A 3(i, j)=F d e c(k)$;

$\mathrm{k}=\mathrm{k}+1$;

end

$\mathrm{S}=\mathrm{S}+1$

$\mathrm{k}=1$;

end

\%4)A quantidade de fibras fornecida para as demandas nao deve

$\%$ ser superior ao valor maximo admitido para tais demandas;

$\mathrm{s}=\mathrm{n}+1$

$\mathrm{k}=1$;

for $i=1: 1: n$

for $\mathrm{j}=\mathrm{s}: \mathrm{n}: \mathrm{n}^{*}(\mathrm{~m}+1)$

$\mathrm{A} 4(\mathrm{i}, \mathrm{j})=\mathrm{Fdef}(\mathrm{k})$;

$\mathrm{k}=\mathrm{k}+1$;

end

$\mathrm{S}=\mathrm{S}+1$

$\mathrm{k}=1$;

end

\%5)Todas as variaveis devem ser positivas

$\mathrm{lb}=\operatorname{zeros}\left(\mathrm{n}^{*}(\mathrm{~m}+1), 1\right)$;

$\%$

$\%$ Englobando a Matriz de inequaçoes A1, A3 e A4, constroi-se a matriz A $A=[A 1 ; A 3 ; A 4]$;

for $\mathrm{i}=1: 1: \mathrm{n}$

$\mathrm{DC}(\mathrm{i})=\mathrm{D}(\mathrm{i})^{*} \operatorname{Ddec}(\mathrm{i})$;

$\mathrm{DF}(\mathrm{i})=\mathrm{D}(\mathrm{i})^{\star} \operatorname{Ddef}(\mathrm{i})$;

end

$\mathrm{b}=\left[\mathrm{F} ; \mathrm{DC} C^{\prime} ; \mathrm{DF}\right]$;

$\%$ Matriz de igualdade Aeq e vetor beq

Aeq $=[\mathrm{A} 2] ; \% ; \mathrm{A} 4]$;

beq $=[\mathrm{D}] ; \%$ DFsim'];

\%Aplicando otimizaçao por LP da funçao objetivo x1

$\mathrm{x} 1$ = linprog(y,A,b,Aeq,beq,lb);

$\%$ Construindo a Matriz Pij da funçao x1

$\mathrm{S}=0$;

for $\mathrm{i}=1: 1: \mathrm{m}+1$

for $\mathrm{j}=1: 1: \mathrm{n}$

$P 1(i, j)=x 1(j+s)$

end

$\mathrm{s}=\mathrm{s}+\mathrm{n}$; 


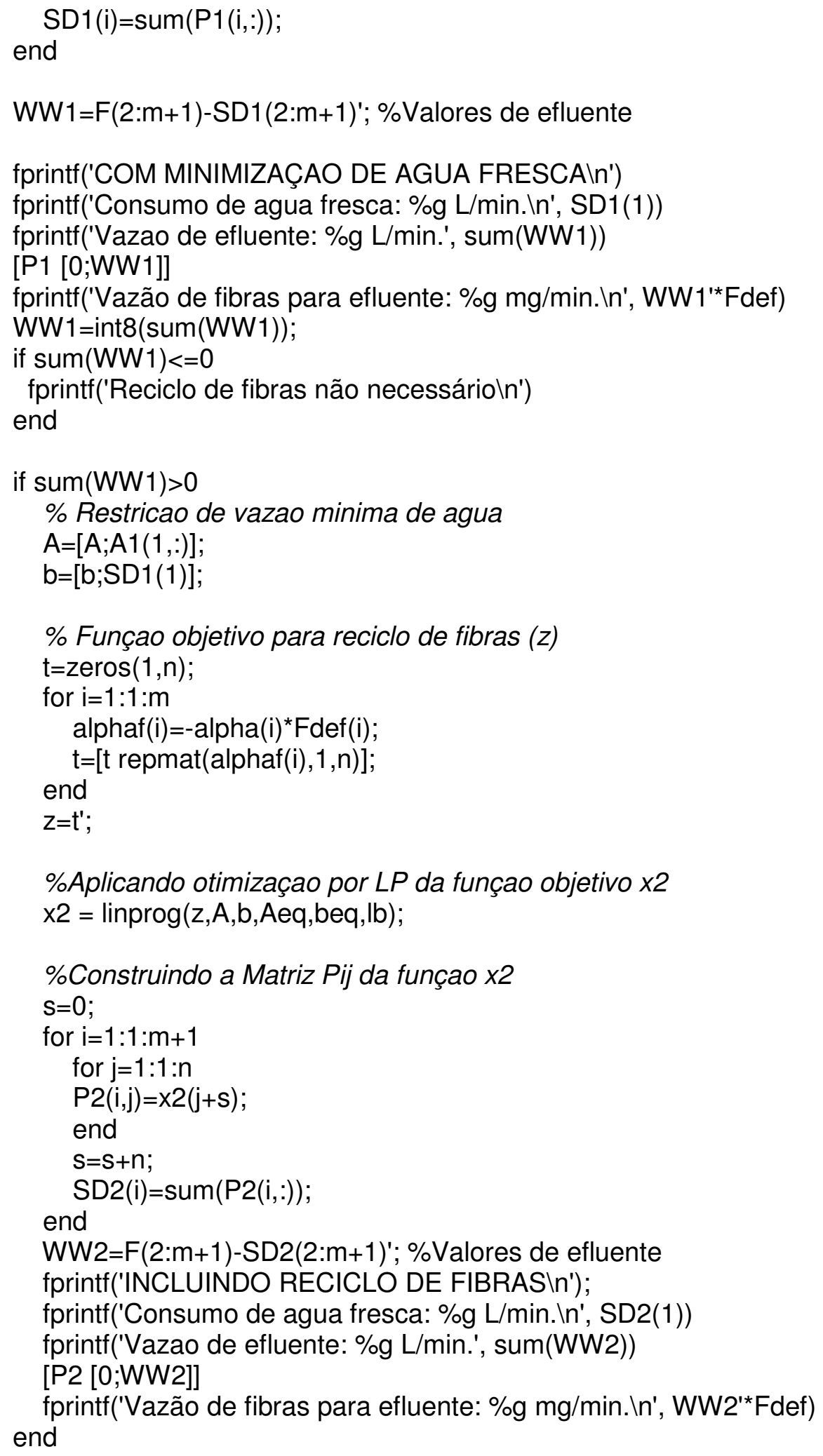


Para o processo integrado, as entradas do programa são:

clear all

format short

$\mathrm{n}=18$;

$\%$ n: numero de demandas

$\mathrm{m}=9$;

$\mathrm{FW}=4207$

$\%$ m: numero de fontes

alpha $=\left[\begin{array}{lllllllll}0 & 0 & 0 & 0 & 0 & 0 & 0 & 0 & 0\end{array}\right]$

$\%$ FW: agua fresca disponivel em L/min

$\%$ alpha: $m$ coeficientes $p /$ reciclo de fibras

$\%$ Vazao de Fontes e Demandas

$\mathrm{F}=[\mathrm{FW} ; 606 ; 1087 ; 2537 ; 5544 ; 1781 ; 2116 ; 17451 ; 1407 ; 54323]$;

$\mathrm{D}=[356 ; 384 ; 8279 ; 40 ; 55 ; 94 ; 109 ; 4946 ; 1585 ; 1484 ; 1255 ; 997.4 ; 996.7 ; 20966 ; 299 ; 3420 ; 7$ $87 ; 43823]$

\% Concentraçao de Fibras (valores limites para demandas)

Fdef $=[0.4 ; 0.05 ; 0.03 ; 0.05 ; 0.3 ; 0.025 ; 0.05 ; 0.01 ; 0.351]$;

Ddef $=[0.8 ; 0.8 ; 0.8 ; 0.8 ; 0.8 ; 0.8 ; 0.8 ; 0.8 ; 0.8 ; 0.8 ; 0.8 ; 0.8 ; 0.8 ; 0.8 ; 0.8 ; 0.018 ; 0.018 ; 0.8]$;

\% Concentraçao de Contaminantes (valores limites para demandas)

Fdec=[4747;4662;4662;4849;4747;2487;2487;2380;2273];

Ddec $=[5000 ; 5000 ; 5000 ; 5000 ; 5000 ; 5000 ; 5000 ; 5000 ; 5000 ; 5000 ; 5000 ; 5000 ; 5000$; 5000;5000;5000;5000;3500]; 


\section{APÊNDICE C}

Esse apêndice mostra a simulação detalhada do caso 3 após modificações. 0 sistema foi modificado em pontos estratégicos para respeitar os limites estabelecidos para contaminantes.

Tabela C1 - Resultado da simulação do caso 3 após modificações

\begin{tabular}{|c|c|c|c|c|}
\hline $\begin{array}{c}\text { Corrente Pinch integrado } \\
\text { Caso 3 corrigido }\end{array}$ & $\begin{array}{c}\text { Vazão } \\
\text { mássica de } \\
\text { água }\end{array}$ & $\begin{array}{c}\text { Vazão mássica } \\
\text { de Sólidos } \\
\text { dissolvidos }\end{array}$ & $\begin{array}{c}\text { Vazão } \\
\text { mássica } \\
\text { de fibras }\end{array}$ & Consist. \\
\hline Descrição & kg/min & kg/min ou ppm & kg/min & $\%$ \\
\hline $\begin{array}{c}\text { Saída de cavaco do } \\
\text { silo (linha 1) }\end{array}$ & 260,0 & 0,00 & 260,00 & 50,000 \\
\hline $\begin{array}{c}\text { Entrada de polpa no refinador } \\
\text { primário (linha 2) }\end{array}$ & 260,0 & 0,00 & 260,00 & 50,000 \\
\hline $\begin{array}{c}\text { Água de diluição no refinador } \\
\text { primário (linha 2) }\end{array}$ & 356,0 & 2812 ppm & 1,07 & 0,299 \\
\hline $\begin{array}{c}\text { Saída de polpa do refinador } \\
\text { primário (linha 2) }\end{array}$ & 317,6 & 3,88 & 258,20 & 44,543 \\
\hline $\begin{array}{c}\text { Entrada polpa no refinador } \\
\text { secundário (linha 2) }\end{array}$ & 317,6 & 3,88 & 258,20 & 44,543 \\
\hline $\begin{array}{c}\text { Água de diluição no refinador } \\
\text { secundário (linha 2) }\end{array}$ & 373,8 & 2812 ppm & 1,12 & 0,299 \\
\hline $\begin{array}{c}\text { Saída de polpa do refinador } \\
\text { secundário (linha 2) }\end{array}$ & 331,3 & 7,80 & 266,47 & 44,000 \\
\hline $\begin{array}{c}\text { Água de diluição do tanque } \\
\text { de latência (linha 1) }\end{array}$ & 8279,0 & 4457 ppm & 4,06 & 0,049 \\
\hline $\begin{array}{c}\text { Água fresca } \\
\text { para TMP }\end{array}$ & 99,3 & 0,00 & 0,00 & 0,000 \\
\hline $\begin{array}{c}\text { Saída de polpa do } \\
\text { tanque de latência }\end{array}$ & 9346,3 & 46,71 & 270,59 & 2,800 \\
\hline $\begin{array}{c}\text { Entrada de polpa no refinador } \\
\text { baixa consistência }\end{array}$ & 4510,8 & 22,54 & 130,59 & 2,800 \\
\hline $\begin{array}{c}\text { Saída da polpa do refinador } \\
\text { baixa consistência }\end{array}$ & 4510,8 & 24,11 & 129,02 & 2,766 \\
\hline $\begin{array}{c}\text { Entrada de polpa no refinador } \\
\text { baixa consistência }\end{array}$ & 4835,8 & 24,17 & 140,00 & 2,800 \\
\hline $\begin{array}{c}\text { Saída de polpa do refinador } \\
\text { baixa consistência }\end{array}$ & 4835,8 & 25,85 & 138,32 & 2,766 \\
\hline $\begin{array}{c}\text { Saída de polpa do tanque de } \\
\text { latência (linha 2) }\end{array}$ & 9346,3 & 49,96 & 267,34 & 2,766 \\
\hline $\begin{array}{c}\text { Entrada de polpa depa na depuração (linha 2) } \\
\text { primária (linha 2) }\end{array}$ & 9346,3 & 49,96 & 267,34 & 2,766 \\
\hline $\begin{array}{c}\text { Aceite da depuração } \\
\text { primana (linha 2) }\end{array}$ & 5800,0 & 3546,6 & 130,00 & 2,181 \\
\hline
\end{tabular}




\begin{tabular}{|c|c|c|c|c|}
\hline $\begin{array}{l}\text { Corrente Pinch integrado } \\
\text { Caso } 3 \text { corrigido }\end{array}$ & $\begin{array}{c}\text { Vazão } \\
\text { mássica de } \\
\text { água }\end{array}$ & $\begin{array}{c}\text { Vazão mássica } \\
\text { de Sólidos } \\
\text { dissolvidos }\end{array}$ & $\begin{array}{c}\text { Vazão } \\
\text { mássica } \\
\text { de fibras }\end{array}$ & Consist \\
\hline Descrição & $\mathrm{kg} / \mathrm{min}$ & kg/min ou ppm & $\mathrm{kg} / \mathrm{min}$ & $\%$ \\
\hline $\begin{array}{l}\text { Diluição de rejeito } \\
\text { primária (linha 2) }\end{array}$ & 40,0 & 2988 ppm & 0,12 & 0,299 \\
\hline $\begin{array}{c}\text { Entrada de polpa na } \\
\text { depuração secundária (linha 2) }\end{array}$ & 3473,8 & 18,47 & 133,14 & 3,672 \\
\hline $\begin{array}{l}\text { Aceite da depuração } \\
\text { secundária (linha 2) }\end{array}$ & 2100,0 & 11,16 & 64,50 & 2,965 \\
\hline $\begin{array}{l}\text { Rejeito da depuração } \\
\text { secundária (linha 2) }\end{array}$ & 1373,8 & 7,30 & 68,64 & 4,735 \\
\hline $\begin{array}{l}\text { Diluição rejeito da depuração } \\
\text { secundária (linha 2) }\end{array}$ & 55,0 & 2812 ppm & 0,165 & 0,299 \\
\hline $\begin{array}{l}\text { Entrada de polpa no refinador } \\
\text { primário (linha 1) }\end{array}$ & 62,0 & 0,00 & 62,00 & 50,000 \\
\hline $\begin{array}{l}\text { Água de diluição no refinador } \\
\text { primário (linha 1) }\end{array}$ & 94,0 & 4603 ppm & 0,38 & 0,400 \\
\hline $\begin{array}{l}\text { Saída de polpa do refinador } \\
\text { primário (linha 1) }\end{array}$ & 113,4 & 1,18 & 61,63 & 34,980 \\
\hline $\begin{array}{c}\text { Entrada de polpa no refinador } \\
\text { secundário (linha 1) }\end{array}$ & 242,3 & 1,73 & 114,52 & 31,937 \\
\hline $\begin{array}{l}\text { Água de diluição no refinador } \\
\text { secundário (linha 1) }\end{array}$ & 61,9 & 4603 ppm & 0,25 & 0,400 \\
\hline $\begin{array}{l}\text { Saída de polpa do refinador } \\
\text { secundário (linha 1) }\end{array}$ & 279,5 & 3,41 & 113,40 & 28,610 \\
\hline $\begin{array}{l}\text { Entrada de polpa no } \\
\text { refinador de rejeitos }\end{array}$ & 109,1 & 0,46 & 44,76 & 29,000 \\
\hline $\begin{array}{l}\text { Água de diluição no } \\
\text { refinador de rejeitos }\end{array}$ & 47,1 & 4603 ppm & 0,19 & 0,400 \\
\hline $\begin{array}{l}\text { Saída de polpa do } \\
\text { refinador de rejeitos }\end{array}$ & 154,2 & 1,23 & 44,41 & 22,219 \\
\hline $\begin{array}{l}\text { Água de diluição do } \\
\text { tanque de latência }\end{array}$ & 5076,6 & 3298 ppm & 1,39 & 0,027 \\
\hline $\begin{array}{c}\text { Entrada de polpa na depuração } \\
\text { primária (linha 1) }\end{array}$ & 5510,4 & 21,43 & 159,84 & 2,797 \\
\hline $\begin{array}{l}\text { Aceite da depuraccão } \\
\text { primária (linha 1) }\end{array}$ & 4360,4 & 16,96 & 122,20 & 2,716 \\
\hline $\begin{array}{l}\text { Rejeito da depuração } \\
\text { primária (linha 1) }\end{array}$ & 1150,0 & 4,47 & 37,00 & 3,105 \\
\hline Entrada de polpa na prensa 2 & 946,6 & 4,38 & 49,04 & 4,904 \\
\hline Saída da Polpa da Prensa 2 & 109,1 & 0,46 & 44,76 & 29,000 \\
\hline Filtrado da Prensa 2 & 847,5 & 4603 ppm & 4,28 & 0,500 \\
\hline Entrada de polpa na prensa 1 & 1118,5 & 5,17 & 57,94 & 4,904 \\
\hline Saída da Polpa da Prensa 1 & 128,9 & 0,55 & 52,89 & 29,000 \\
\hline
\end{tabular}




\begin{tabular}{|c|c|c|c|c|}
\hline $\begin{array}{c}\text { Corrente Pinch integrado } \\
\text { Caso } 3 \text { corrigido }\end{array}$ & $\begin{array}{c}\text { Vazão } \\
\text { mássica de } \\
\text { água }\end{array}$ & $\begin{array}{c}\text { Vazão mássica } \\
\text { de Sólidos } \\
\text { dissolvidos }\end{array}$ & $\begin{array}{c}\text { Vazão } \\
\text { mássica } \\
\text { de fibras }\end{array}$ & Consist. \\
\hline Descrição & $\mathrm{kg} / \mathrm{min}$ & kg/min ou ppm & $\mathrm{kg} / \mathrm{min}$ & $\%$ \\
\hline $\begin{array}{l}\text { Aceite da peneira inclinada } \\
\text { (após depuração) }\end{array}$ & 579,3 & 4603 ppm & 2,34 & 0,400 \\
\hline $\begin{array}{l}\text { Rejeito da peneira inclinada } \\
\text { (após depuração) }\end{array}$ & 1990,0 & 9,20 & 103,01 & 4,900 \\
\hline $\begin{array}{l}\text { Entrada na peneira inclinada } \\
\text { (após prensa) }\end{array}$ & 1847,0 & 8,54 & 9,33 & 0,500 \\
\hline $\begin{array}{l}\text { Aceite da peneira inclinada } \\
\text { (após prensa) }\end{array}$ & 1771,9 & 4603 ppm & 5,36 & 0,300 \\
\hline $\begin{array}{l}\text { Rejeito da peneira inclinada } \\
\text { (após prensa) }\end{array}$ & 75,0 & 0,35 & 3,97 & 5,000 \\
\hline $\begin{array}{l}\text { Entrada de polpa no } \\
\quad \text { filtro a disco }\end{array}$ & 4360,4 & 16,96 & 122,20 & 2,716 \\
\hline Saída da polpa do filtro disco & 1784,4 & 6,58 & 124,50 & 6,500 \\
\hline Filtrado claro do filtro disco & 2638,4 & 3671 ppm & 0,79 & 0,030 \\
\hline Filtrado turvo do filtro disco & 1130,5 & 3671 ppm & 0,57 & 0,050 \\
\hline $\begin{array}{l}\text { Água do chuveiro } \\
\text { do filtro disco }\end{array}$ & 1192,8 & 2930 ppm & 3,67 & 0,306 \\
\hline $\begin{array}{l}\text { Entrada de polpa no conjunto } \\
\text { filtro tambor } 1\end{array}$ & 5958,2 & 31,80 & 146,69 & 2,390 \\
\hline $\begin{array}{l}\text { Saída da polpa do conjunto } \\
\text { filtro tambor } 1\end{array}$ & 2079,3 & 10,58 & 145,29 & 6,500 \\
\hline Filtrado do conjunto filtro tambor 1 & 4092,1 & 5309 ppm & 2,06 & 0,050 \\
\hline $\begin{array}{l}\text { Água do chuveiro do conjunto } \\
\text { filtro tambor } 1\end{array}$ & 213,2 & 2930 ppm & 0,66 & 0,305 \\
\hline $\begin{array}{l}\text { Entrada de polpa no conjunto } \\
\text { filtro tambor } 2\end{array}$ & 1941,8 & 10,36 & 47,81 & 2,390 \\
\hline $\begin{array}{l}\text { Saída da polpa do conjunto filtro } \\
\text { tambor } 2\end{array}$ & 682,0 & 3,21 & 47,63 & 6,500 \\
\hline $\begin{array}{l}\text { Filtrado do filtro conjunto } \\
\text { filtro tambor } 2\end{array}$ & 1438,8 & 5309 ppm & 0,72 & 0,050 \\
\hline $\begin{array}{l}\text { Água do chuveiro do conjunto } \\
\text { filtro tambor } 2\end{array}$ & 178,9 & 2930 ppm & 0,55 & 0,305 \\
\hline Entrada de polpa no filtro save-all 2 & 13621,7 & 39,27 & 138,98 & 1,007 \\
\hline Saída da polpa do filtro save-all 2 & 3506,6 & 10,10 & 131,33 & 3,600 \\
\hline Filtrado claro do filtro save-all 2 & 7929,0 & 2873 ppm & 3,98 & 0,050 \\
\hline Filtrado superclaro do filtro save-all 2 & 1057,5 & 2873 ppm & 0,27 & 0,025 \\
\hline Filtrado turvo do filtro save-all 2 & 1581,8 & 2873 ppm & 4,77 & 0,300 \\
\hline
\end{tabular}




\begin{tabular}{|c|c|c|c|c|}
\hline $\begin{array}{l}\text { Corrente Pinch integrado } \\
\text { Caso } 3 \text { corrigido }\end{array}$ & $\begin{array}{c}\text { Vazão } \\
\text { mássica de } \\
\text { água }\end{array}$ & $\begin{array}{c}\text { Vazão mássica } \\
\text { de Sólidos } \\
\text { dissolvidos }\end{array}$ & $\begin{array}{l}\text { Vazão } \\
\text { mássica } \\
\text { de fibras }\end{array}$ & Consist. \\
\hline Descrição & $\mathrm{kg} / \mathrm{min}$ & kg/min ou ppm & $\mathrm{kg} / \mathrm{min}$ & $\%$ \\
\hline Água do chuveiro do filtro save all 2 & 453,2 & 2812 ppm & 1,36 & 0,299 \\
\hline Entrada de polpa no filtro save all 1 & 16346,6 & 47,13 & 166,78 & 1,007 \\
\hline Saída da polpa do filtro save all 1 & 4102,8 & 11,82 & 153,66 & 3,600 \\
\hline Filtrado claro do filtro save all 1 & 9599,2 & 2873 ppm & 4,82 & 0,050 \\
\hline Filtrado superclaro do filtro save all 1 & 1280,2 & 2873 ppm & 0,32 & 0,025 \\
\hline Filtrado turvo do filtro save all 1 & 1911,2 & 2873 ppm & 9,63 & 0,500 \\
\hline Água do chuveiro do filtro save all 1 & 546,8 & 2812 ppm & 1,64 & 0,299 \\
\hline Saída de polpa do tanque 3 de TMP & 4545,7 & 20,37 & 317,42 & 6,500 \\
\hline Saída de polpa do tanque 2 de TMP & 3311,6 & 13,44 & 175,00 & 5,000 \\
\hline Saída de polpa do tanque 1 de TMP & 4156,5 & 15,16 & 151,30 & 3,500 \\
\hline $\begin{array}{l}\text { Água de diluição para tanque } 1 \mathrm{de} \\
\text { TMP }\end{array}$ & 1372,5 & 2806 ppm & 4,18 & 0,303 \\
\hline Água de diluição para tanque $B Q$ & 1549,8 & 2809 ppm & 4,69 & 0,301 \\
\hline $\begin{array}{l}\text { Saída de polpa do tanque de } \\
\text { celulose }\end{array}$ & 980,0 & 0,01 & 36,00 & 3,540 \\
\hline Saída de polpa do tanque de mistura & 11445,7 & 35,87 & 442,98 & 3,715 \\
\hline $\begin{array}{c}\text { Saída do tanque de massa } \\
\text { recuperada }\end{array}$ & 7609,4 & 21,92 & 284,99 & 3,600 \\
\hline Saída do tanque de água da tela & 26475,3 & 76,34 & 291,36 & 1,109 \\
\hline $\begin{array}{l}\text { Entrada no cleaner } 4^{\circ} \text { estágio } \\
\text { (4 cleaners) }\end{array}$ & 1525,9 & 4,41 & 6,03 & 0,392 \\
\hline Aceite do cleaner $4^{\circ}$ estágio & 611,0 & 1,77 & 1,81 & 0,294 \\
\hline $\begin{array}{c}\text { Entrada no cleaner } 3^{\circ} \text { estágio } \\
\text { (31 cleaners) }\end{array}$ & 3392,3 & 9,81 & 12,06 & 0,353 \\
\hline Aceite do cleaner $3^{\circ}$ estágio & 1866,4 & 5,9 & 6,03 & 0,321 \\
\hline Rejeito do cleaner $3^{\circ}$ estágio & 1525,9 & 4,41 & 6,03 & 0,392 \\
\hline $\begin{array}{c}\text { Entrada no cleaner } 2^{0} \text { estágio } \\
\text { (49 cleaners) }\end{array}$ & 11093,2 & 32,06 & 73,19 & 0,654 \\
\hline Aceite do cleaner $2^{0}$ estágio & 8311,9 & 24,03 & 62,95 & 0,749 \\
\hline
\end{tabular}




\begin{tabular}{|c|c|c|c|c|}
\hline $\begin{array}{l}\text { Corrente Pinch integrado } \\
\text { Caso } 3 \text { corrigido }\end{array}$ & $\begin{array}{c}\text { Vazão } \\
\text { mássica de } \\
\text { água }\end{array}$ & $\begin{array}{c}\text { Vazão mássica } \\
\text { de Sólidos } \\
\text { dissolvidos }\end{array}$ & $\begin{array}{l}\text { Vazão } \\
\text { mássica } \\
\text { de fibras }\end{array}$ & Consist. \\
\hline Descrição & $\mathrm{kg} / \mathrm{min}$ & kg/min ou ppm & $\mathrm{kg} / \mathrm{min}$ & $\%$ \\
\hline Rejeito do cleaner $2^{\circ}$ estágio & 2781,3 & 8,04 & 10,25 & 0,366 \\
\hline $\begin{array}{c}\text { Entrada no cleaner } 1^{\circ} \text { estágio } \\
\text { (157 cleaners) }\end{array}$ & 55269,7 & 159,76 & 563,03 & 1,006 \\
\hline Aceite do cleaner $1^{0}$ estágio & 44117,4 & 127,69 & 489,83 & 1,094 \\
\hline Rejeito do cleaner $1^{\circ}$ estágio & 11093,2 & 32,06 & 73,19 & 0,654 \\
\hline Água branca na seção de formação 1 & 41554,6 & 2742 ppm & 160,62 & 0,384 \\
\hline Água branca na seção de formação 2 & 13089,7 & 2742 ppm & 31,46 & 0,239 \\
\hline Polpa após seção de formação & 2297,4 & 6,32 & 343,84 & 12,987 \\
\hline Saída do couch Pit & 1874,4 & 5,44 & 23,04 & 1,211 \\
\hline Água branca na seção de prensa & 1870,1 & 2742 ppm & 8,59 & 0,456 \\
\hline Polpa após seção de prensa & 427,3 & 1,17 & 335,25 & 43,895 \\
\hline Polpa após secador & 31,0 & 1,17 & 333,57 & 91,200 \\
\hline $\begin{array}{l}\text { Após o silo: mistura para } \\
1 \% \text { de consistência }\end{array}$ & 55269,7 & 2882 ppm & 563,03 & 1,006 \\
\hline Saída do tanque de refugo & 856,3 & 2,44 & 26,56 & 3,000 \\
\hline Entrada filtro de refugo & 1971,1 & 5,71 & 26,04 & 1,300 \\
\hline Saída da polpa do filtro de refugo & 856,3 & 2,44 & 26,56 & 3,000 \\
\hline Filtrado do filtro de refugo & 1387,1 & 2889 ppm & 0,14 & 0,010 \\
\hline $\begin{array}{l}\text { Água do chuveiro do } \\
\text { filtro de refugo }\end{array}$ & 272,3 & 2749 ppm & 0,65 & 0,239 \\
\hline $\begin{array}{l}\text { Entrada na depuração antes } \\
\text { da caixa de entrada }\end{array}$ & 54354,7 & 157,11 & 558,81 & 1,015 \\
\hline Aceite da depuração & 54294,7 & 156,94 & 553,80 & 1,007 \\
\hline Água fresca para Máquina de Papel & 2824,0 & 0,00 & 0,00 & 0,000 \\
\hline
\end{tabular}

